\title{
Characterization and Modeling of the Ratcheting Behavior of the Ferritic-Martensitic Steel P91
}

\author{
Zur Erlangung des akademischen Grades \\ Doktor der Ingenieurwissenschaften \\ der Fakultät für Maschinenbau \\ Karlsruher Institut für Technologie (KIT)
}

genehmigte

Dissertation

von

Dipl.-Ing. Kuo Zhang

aus Nanjing 


\section{Abstract}

The ratcheting behavior of $9 \% \mathrm{Cr}-1 \%$ Mo ferritic-martensitic (FM) steel P91 is investigated by uniaxial cyclic loading tests at room temperature and $550{ }^{\circ} \mathrm{C}$. Accumulation rates of strains (ratcheting rates) under multiple loading conditions are recorded to build a database for P91 for further application in Generation IV fission reactors.

Strain-controlled low cycle fatigue (LCF) tests are performed before stress-controlled tests to evaluate the cyclic softening of the material. Afterwards stress-controlled tests are performed both at room temperature and $550{ }^{\circ} \mathrm{C}$, with various peak tensile stresses, mean stresses, stress rates and hold times. The unconventional asymmetry of stress under strain-controlled LCF tests at room temperature predicted the non-zero ratcheting with zero mean stress, which is equally verified by the subsequent symmetric stress-controlled tests.

A unified visco-plastic deformation model taking into account the complex nonsaturating cyclic softening of Reduced Activation Ferritic Martensitic (RAFM) steels is further modified to adapt the ratcheting behavior of P91. It is hereby informed that the current model for RAFM steel fits cyclic softening behavior in strain-controlled LCF tests very well. However, this model strongly overestimates the uniaxial ratcheting rates in stress-controlled tests, because the term for dynamic recovery of kinematic hardening in the current model follows the Armstrong-Frederick dynamic recovery rule. Based upon further analysis of back stresses, a new constitutive model is proposed. A new dynamic recovery rule is designed to fit the ratcheting rates under multiple loading conditions, including those with smaller stress ratios $(R<-0.8)$, larger stress ratios $(R>-0.8)$, zero mean stress, various stress rates, and various hold times. Parameter values for various new proposed models are fitted to find the best dynamic recovery rule for kinematic hardening. 


\section{Zusammenfassung}

Das Ratcheting-Verhalten des 9\% Cr-1\% Mo ferritisch-martensitischen (FM) Stahls P91 wird durch einachsige zyklische Belastungen bei Raumtemperatur und bei $550^{\circ} \mathrm{C}$ untersucht. Hierbei werden die Akkumulationsraten der Dehnung (Ratchetingraten) unter verschiedenen Belastungsbedingungen aufgezeichnet, um die Datenbank für P91 in Bezug auf die Anwendung in der Generation IV Spaltungsreaktoren zu erweitern.

$\mathrm{Zu}$ Beginn werden dehnungsgesteuerte LCF-Versuche und anschließend spannungsgesteuerte Versuche durchgeführt, um die zyklische Entfestigung des Materials zu bewerten. Die spannungsgesteuerten Versuche werden sowohl bei Raumtemperatur als auch bei $550^{\circ} \mathrm{C}$ unter Variation der Spannungsspitzen, der Mittelspannungen, der Spannungsraten und der Haltezeiten durchgeführt. Die untypische Asymmetrie der Spannung bei den dehnungsgesteuerten LCF-Versuchen bei Raumtemperatur ist die Ursache für das Auftreten von Ratcheting ohne Mittelspannung. Außerdem wird dies durch die folgenden symmetrischen spannungsgesteuerten Versuchen bestätigt.

Um das Ratcheting-Verhalten von P91 zu beschreiben, wird ein viskoplastisches Verformungsmodell unter Berücksichtigung der komplexen nicht sättigenden zyklischen Entfestigung der Reduced Activation Ferritic Martensitic (RAFM) Stähle weiter modifiziert. Es wird gezeigt, dass das aktuelle Modell für RAFM Stähle in der Lage ist, das zyklische Entfestigungsverhalten bei spannungsgesteuerten LCF-Versuchen sehr gut zu beschreiben. Allerdings überschätzt dieses Modell offensichtlich die einachsigen Ratchetingraten in spannungsgesteuerten Versuchen. Verantwortlich ist die dynamische Erholung der kinematischen Verfestigung im aktuellen Modell, die auf das Modell von Armstrong-Frederick zurückzuführen ist. Es wurde ein neues konstitutives Modell, welches auf Untersuchungen der Rückspannung basiert, entwickelt. Zur besseren Beschreibung des Ratchetings wurde ein neuer dynamischer Erholungsterm verwendet, der die unterschiedlichen Belastungsbedingungen berücksichtigt. Typische Belastungsbedingungen sind beispielsweise kleine $(R<-0,8)$, und große $(R>-0,8)$ Spannungsverhältnisse, keine Mittelspannung, Variation der Spannungsraten und unterschiedliche Haltezeiten. Es wurden Parametersätze für die verschiedenen vorgeschlagenen neuen Modelle bestimmt, mit denen die dynamische Erholung der kinematischen Verfestigung gut beschrieben werden

kann. 


\section{Contents}

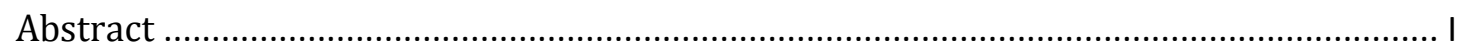

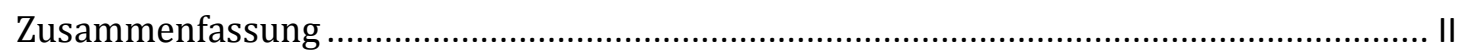

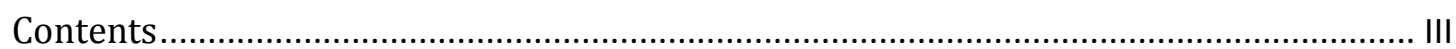

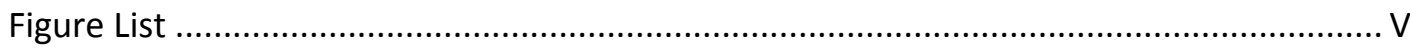

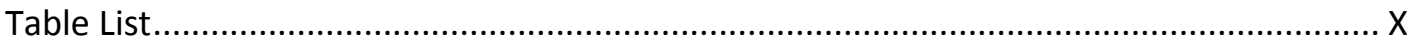

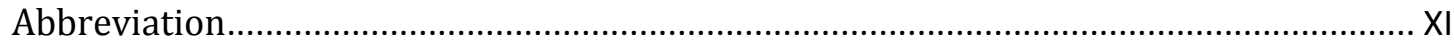

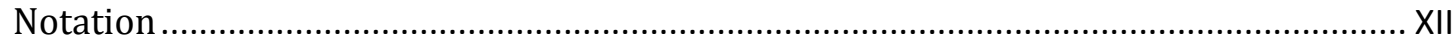

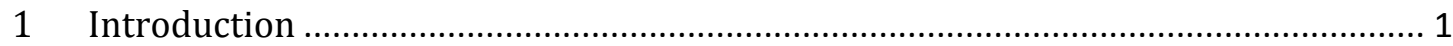

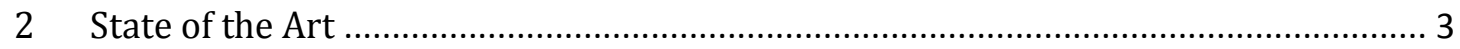

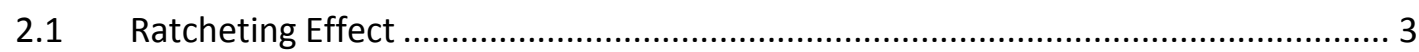

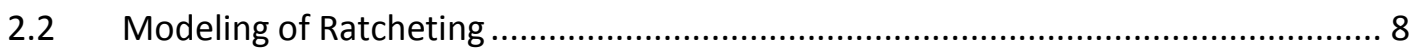

2.3 Advantage of Ferritic-Martensitic (FM) Steel ....................................................... 15

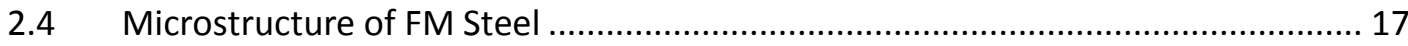

2.5 Cyclic Softening of FM Steel and Corresponding Modeling ................................... 19

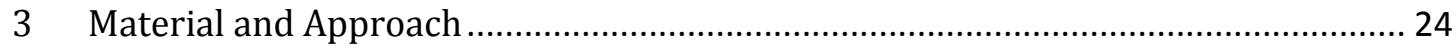

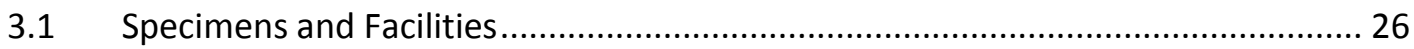

3.2 Experimental Planning for Testing at Room Temperature...................................... 27

3.2.1 Strain-controlled Tests at RT ................................................................ 27

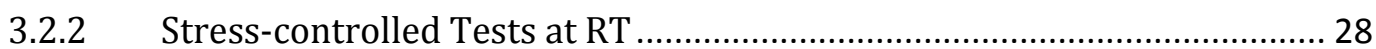

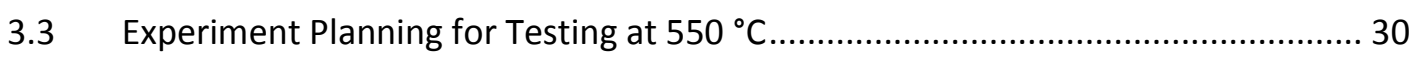

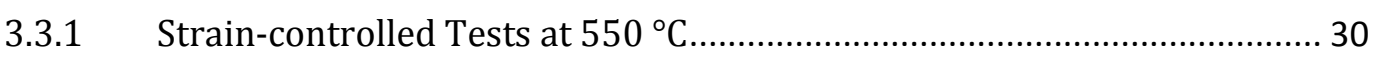

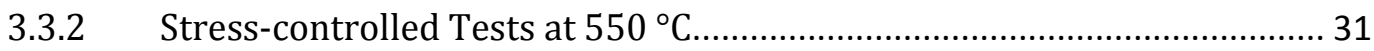

4 Experiments at Room Temperature ............................................................................ 34

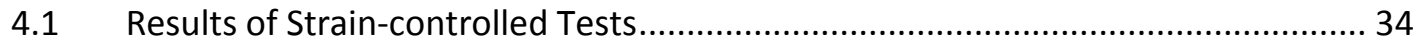

4.2 Results of Stress-controlled Ratcheting Tests .................................................... 40

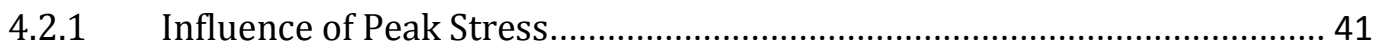

4.2.2 Influence of mean stress/stress ratio.......................................................... 44

4.2.3 Ratcheting with zero mean stress ............................................................ 48 


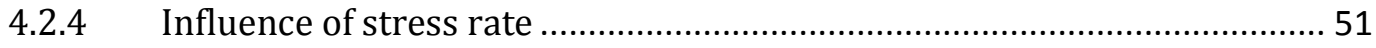

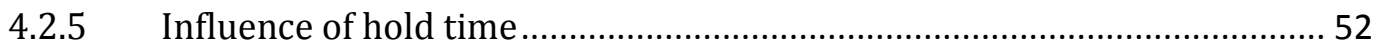

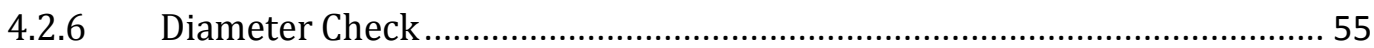

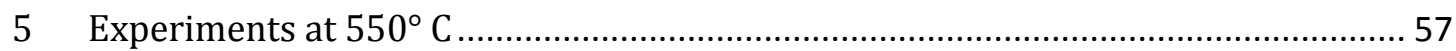

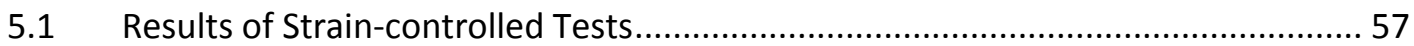

5.2 Results of Stress-controlled Ratcheting Tests ...................................................... 64

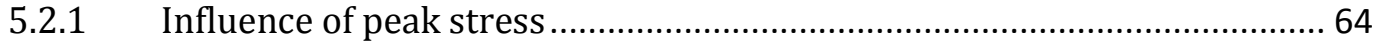

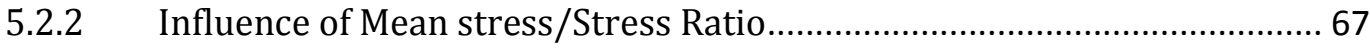

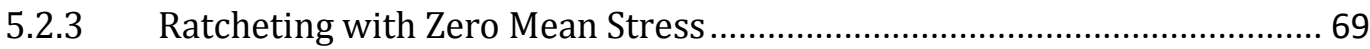

5.2.4 Influence of stress rate ……………...................................................... 70

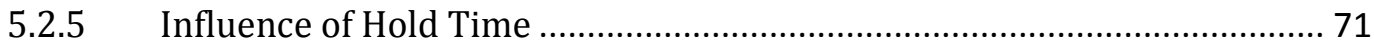

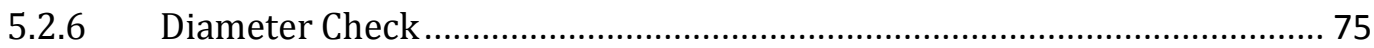

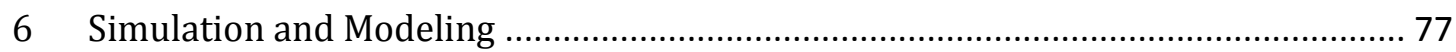

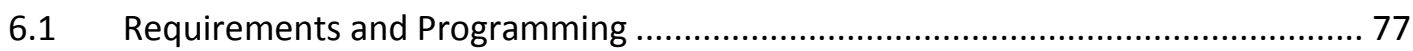

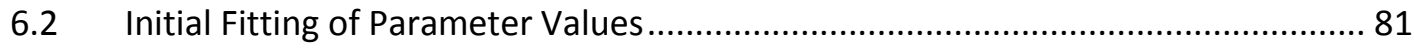

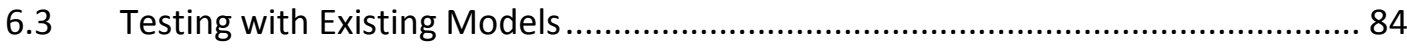

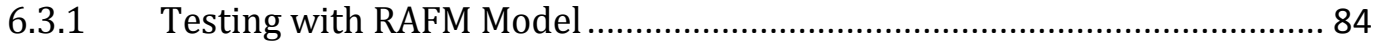

6.3.2 Testing with Ohno-Wang Model I (OW I) ................................................ 87

6.3.3 Testing with Ohno-Wang Model II (OW II) ................................................ 88

6.4 Development of New Model for Room Temperature ............................................ 91

6.4.1 Formulation for Room Temperature ....................................................... 92

6.4.2 Simulation Results for Room Temperature .................................................... 98

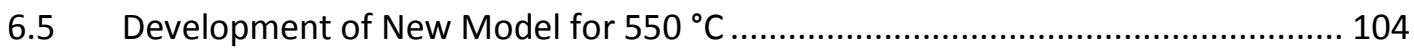

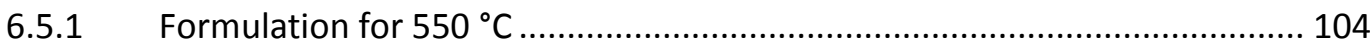

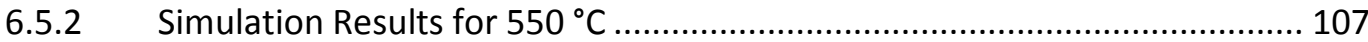

6.6 Multiaxial Formulation of the New Developed Model......................................... 112

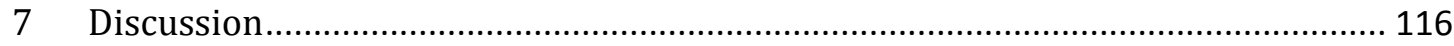

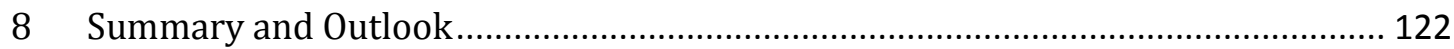

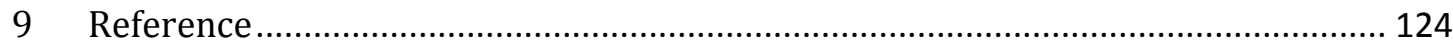




\section{Figure List}

Fig. 2.1 Generic strain path for a cyclic tension test where the total strain path is a superposition of mean and alternate strain [10].

Fig. 2.2 Shapes of some loading paths used in the multiaxial stress-controlled cycling tests. [11, 15, 17, 31, 35, 49, 50]...

Fig. 2.3 Effects of the applied stress amplitude on progressive deformation instability owing to the cyclic softening of the mod. $9 \mathrm{Cr}-1 \mathrm{Mo}$ steel [24].....7

Fig. 2.4 Effects of the mean stress on progressive deformation instability owing to the cyclic softening of the mod. 9Cr-1Mo steel [24]..............................7

Fig. 2.5 Stress-strain hysteresis loops under stress ratio of -1.025 [26]............. 8

Fig. 2.6 Evolution of $\boldsymbol{\Omega}_{i}$ on the surface of $f_{i}=0 \quad$ [3] ........................................11

Fig. 2.7 Change of $\Omega i$ under uniaxial tensile loading [3] .................................12

Fig. 2.8 Change of BS and its sub-components under uniaxial tensile loading in the case of $\mu_{i}=0,(M=3)$ [6].

Fig. 2.9 Simulations of uniaxial ratcheting under stress ratio conditions between -0.75 and 0 by proposed constitutive model, with $\sigma_{\max }=400 \mathrm{MPa}$, stress rate $\pm 50 \mathrm{MPa} / \mathrm{s}[7]$

Fig. 2.10 Test results of the cyclic softening characteristics of mod. $9 \mathrm{Cr}-1 \mathrm{Mo}$ steel at $600{ }^{\circ} \mathrm{C}$ (strain-controlled) [24].

Fig. 2.11 Peak stress vs. number of cycles in Yaguchi-Takahashi model description for strain-controlled LCF tests performed with various strain amplitudes

Fig. 2.12 The results of $P 91$ strain-controlled tests at $600^{\circ} \mathrm{C}[101] \ldots \ldots \ldots \ldots \ldots . . .22$

Fig. 3.1 Process of research on ratcheting behavior of P91. .............................25

Fig. 3.2 Technical drawing of P91 specimen together with a real photo.............27

Fig. 3.3 Schema of true stress controlling .......................................................2. 29

Fig. 4.1 Symmetric strain-controlled LCF tests at $R T, \Delta \varepsilon=1.5 \%$.....................35

Fig. 4.2 Strain-controlled LCF tests at RT performed with strain ranges $0.6 \%$ $1.5 \%$.

Fig. 4.3 Engineering peak compressive stresses (abs.) compared with engineering peak tensile stresses, at $R T$.

Fig. 4.4 True peak compressive stresses (abs.) compared with true peak tensile stresses, at RT.

Fig. 4.5 a) Simulation for a strain-controlled LCF test at RT performed with $\Delta \varepsilon=1.0 \%$, the $100^{\text {th }}$ cycle. b) Simulation for a stress-controlled ratcheting test with $\sigma_{\text {mean }}=0 \mathrm{MPa}$ and $\sigma_{a}=500 \mathrm{MPa}$. c) Zoom of the peak tensile stresses of the sub-figure.

Fig. 4.6 Ratcheting tests at RT performed with $\sigma_{\text {peak }}=500 \mathrm{MPa}, \sigma_{\text {mean }}=25 \mathrm{MPa}$, stress rate $\pm 50 \mathrm{MPa} / \mathrm{s}$.

Fig. 4.7 Ratcheting tests at RT performed with $\sigma_{\text {mean }}=25 \mathrm{MPa}$, stress rate $\pm 50 \mathrm{MPa} / \mathrm{s}$, various $\sigma_{\text {peak }}, \varepsilon_{r} v \mathrm{~s}$. number of cycles.

Fig. 4.8 Ratcheting tests at $R T$ performed with $\sigma_{\text {mean }}=25 \mathrm{MPa}$, stress rate $\pm 50 \mathrm{MPa} / \mathrm{s}$, various $\sigma_{\text {peak }}, \Delta \varepsilon^{\text {in }} v$ s. number of cycles.

Fig. 4.9 Ratcheting tests at $R T$ performed with $\sigma_{\text {mean }}=25 \mathrm{MPa}$, stress rate $\pm 50 \mathrm{MPa} / \mathrm{s}$, average ratcheting rates $v$ s. $\sigma_{\text {peak }}$ in log-linear diagram

Fig. 4.10 Two groups of ratcheting tests at RT performed with symmetric $\sigma_{\text {mean }}$, $\varepsilon_{r}$ vs. number of cycles. 
Fig. 4.11 Ratcheting tests at RT performed with $\sigma_{\text {peak }}=500 \mathrm{MPa}$, stress rate $\pm 50 \mathrm{MPa} / \mathrm{s}$, various $\sigma_{\text {mean }}, \varepsilon_{r} v \mathrm{~s}$. number of cycles.

Fig. 4.12 Ratcheting tests at RT performed with $\sigma_{\text {peak }}=500 \mathrm{MPa}$, stress rate $\pm 50 \mathrm{MPa} / \mathrm{s}$, various $\sigma_{\text {mean }}, \Delta \varepsilon^{\text {in }}$ vs. number of cycles.

Fig. 4.13 Ratcheting tests at RT performed with $\sigma_{\text {peak }}=500 \mathrm{MPa}$, stress rate $\pm 50 \mathrm{MPa} / \mathrm{s}$, various $\sigma_{\text {mean }}$, average ratcheting rates (until $1250^{\text {th }}$ cycle) vs. stress ratios.

Fig. 4.14 Ratcheting test at $R T$ performed with $\sigma_{\text {peak }}=500 \mathrm{MPa}$, $\sigma_{\text {mean }}=250 \mathrm{MPa}$, stress rate $\pm 50 \mathrm{MPa} / \mathrm{s}$.

Fig. 4.15 Ratcheting tests at $R T$ performed with zero $\sigma_{\text {mean }}$ stress rate $\pm 50 \mathrm{MPa} / \mathrm{s}$, various $\sigma_{a}, \varepsilon_{r}$ vs. number of cycles.

Fig. 4.16 Ratcheting tests at $R T$ performed with zero $\sigma_{\text {mean }}$, stress rate $\pm 50 \mathrm{MPa} / \mathrm{s}$, various $\sigma_{a}$, and $\Delta \varepsilon^{\text {in }}$ vs. number of cycles.

Fig. 4.17 Ratcheting tests at $R T$ performed with zero $\sigma_{\text {mean }}$ stress rate \pm 50 $M P a / s$, various $\sigma_{a}$, average ratcheting rates vs. $\sigma_{a}$ in log-linear diagram. 50

Fig. 4.18 Ratcheting tests at RT performed with $\sigma_{\text {peak }}=500 \mathrm{MPa}$, $\sigma_{\text {mean }}=25 \mathrm{MPa}$, various stress rates, $\varepsilon_{r} v$ s. number of cycles

Fig. 4.19 Ratcheting tests at RT performed with $\sigma_{\text {peak }}=500 \mathrm{MPa}$, $\sigma_{\text {mean }}=25 \mathrm{MPa}$, various stress rates, $\Delta \varepsilon^{\text {in }}$ vs. number of cycles.

Fig. 4.20 Ratcheting tests at RT performed with $\sigma_{\text {peak }}=500 \mathrm{MPa}$, $\sigma_{\text {mean }}=25 \mathrm{MPa}$, stress rate $\pm 50 \mathrm{MPa} / \mathrm{s}$, various hold time types, $\varepsilon_{r} v s$. number of cycles.

Fig. 4.21 Ratcheting tests at RT performed with $\sigma_{\text {peak }}=500 \mathrm{MPa}$,

$\sigma_{\text {mean }}=25 \mathrm{MPa}$, stress rate $\pm 50 \mathrm{MPa} / \mathrm{s}$, inelastic strain during hold times at tensile \& compressive peaks vs. number of cycles.

Fig. 4.22 Test at RT performed with $\sigma=500 M P a$, inelastic strain vs. time. .........53

Fig. 4.23 Ratcheting tests at RT performed with $\sigma_{\text {peak }}=500 \mathrm{MPa}$,

$\sigma_{\text {mean }}=25 \mathrm{MPa}$, stress rate $\pm 50 \mathrm{MPa} / \mathrm{s}$, stress $v$ s. inelastic strain (normalized) at $500^{\text {th }}$ cycle.

Fig. 4.24 Ratcheting test at $R T$ performed with $\sigma_{\text {peak }}=500 \mathrm{MPa}, \sigma_{\text {mean }}=25 \mathrm{MPa}$, stress rate $\pm 50 \mathrm{MPa} / \mathrm{s}$, no hold time, ratcheting rate vs. number of cycles. 55

Fig. 4.25 Diameter check of several specimens in RT ratcheting tests. ..............56

Fig. 5.1 Symmetric strain-controlled LCF tests at $550^{\circ} \mathrm{C}, \Delta \varepsilon=1.5 \%$................58

Fig. 5.2 Definition of lifetime in LCF tests at $550^{\circ} \mathrm{C}$. Strain-controlled LCF test with strain range $1.5 \%$.

Fig. 5.3 Strain-controlled LCF tests at $550{ }^{\circ} \mathrm{C}$ performed with strain ranges $0.6 \% \sim 1.5 \%$.

Fig. 5.4 Engineering peak compressive stresses (abs.) compared with engineering peak tensile stresses at $550{ }^{\circ} \mathrm{C}$.

Fig. 5.5 True peak compressive stresses (abs.) compared with true peak tensile stresses at $550{ }^{\circ} \mathrm{C}$.

Fig. 5.6 Strain-controlled LCF tests at $550{ }^{\circ} \mathrm{C}$ performed with strain range $1.0 \%$ and various hold times.

Fig. 5.7 Ratcheting tests at $550^{\circ} \mathrm{C}$ performed with $\sigma_{\text {peak }}=325 \mathrm{MPa}, \sigma_{\text {mean }}=10 \mathrm{MPa}$, stress rate $\pm 50 \mathrm{MPa} / \mathrm{s}$, hysteresis loops of the $1^{\text {st }} 100^{\text {th }} 200^{\text {th }} 300^{\text {th }} 400^{\text {th }}$ $500^{\text {th }}$ cycles.

Fig. 5.8 Ratcheting tests at $550^{\circ} \mathrm{C}$ performed with $\sigma_{\text {mean }}=25 \mathrm{MPa}$, stress rate $\pm 50 \mathrm{MPa} / \mathrm{s}$, various $\sigma_{\text {peak }}, \varepsilon_{r}$ vs. number of cycles. 
Fig. 5.9 Ratcheting tests at $550^{\circ} \mathrm{C}$ performed with $\sigma_{\text {mean }}=25 \mathrm{MPa}$, stress rate $\pm 50 \mathrm{MPa} / \mathrm{s}$, various $\sigma_{\text {peak }}, \Delta \varepsilon^{\text {in }} v \mathrm{~s}$. number of cycles.

Fig. 5.10 Ratcheting tests at $550^{\circ} \mathrm{C}$ performed with $\sigma_{\text {mean }}=25 \mathrm{MPa}$, stress rate $\pm 50 \mathrm{MPa} / \mathrm{s}$, average ratcheting rates $v$ s. $\sigma_{\text {peak }}$ in log-linear diagram.

Fig. 5.11 A group of ratcheting tests at $550{ }^{\circ} \mathrm{C}$ performed with symmetric $\sigma_{\text {mean }}$ $( \pm 7.5 \mathrm{MPa}), \varepsilon_{r} v \mathrm{~s}$. number of cycles.

Fig. 5.12 Ratcheting tests at $550{ }^{\circ} \mathrm{C}$ performed with $\sigma_{\text {peak }}=325 \mathrm{MPa}$, stress rate $\pm 50 \mathrm{MPa} / \mathrm{s}$, various $\sigma_{\text {mean }}, \varepsilon_{r} v \mathrm{~s}$. number of cycles.

Fig. 5.13 Ratcheting tests at $550{ }^{\circ} \mathrm{C}$ performed with $\sigma_{\text {peak }}=325 \mathrm{MPa}$, stress rate $\pm 50 \mathrm{MPa} / \mathrm{s}$, various $\sigma_{\text {mean }}, \Delta \varepsilon^{\text {in }} v$ s. number of cycles.

Fig. 5.14 Ratcheting tests at $550^{\circ} \mathrm{C}$ performed with $\sigma_{\text {peak }}=325 \mathrm{MPa}$, stress rate $\pm 50 \mathrm{MPa} / \mathrm{s}$, average ratcheting rates vs. stress ratios.

Fig. 5.15 Ratcheting tests at $550^{\circ} \mathrm{C}$ performed with zero $\sigma_{\text {mean }}$, stress rate $\pm 50 \mathrm{MPa} / \mathrm{s}$, various $\sigma_{a}, \varepsilon_{r} v \mathrm{~s}$. number of cycles.

Fig. 5.16 Ratcheting tests at $550{ }^{\circ} \mathrm{C}$ performed with zero $\sigma_{\text {mean }}$, stress rate $\pm 50 \mathrm{MPa} / \mathrm{s}$, various $\sigma_{a}, \Delta \varepsilon^{i n} v$ s. number of cycles.

Fig. 5.17 Ratcheting tests at $550{ }^{\circ} \mathrm{C}$ performed with $\sigma_{\text {peak }}=325 \mathrm{MPa}$, $\sigma_{\text {mean }}=7.5 \mathrm{MPa}$, various stress rates, $\varepsilon_{r}$ vs. number of cycles.

Fig. 5.18 Ratcheting tests at $550{ }^{\circ} \mathrm{C}$ performed with $\sigma_{\text {peak }}=325 \mathrm{MPa}$, $\sigma_{\text {mean }}=7.5 \mathrm{MPa}$, various stress rates, $\Delta \varepsilon^{\text {in }} v$ s. number of cycles.

Fig. 5.19 Comparison between ratcheting tests with hold times and creep tests at $550^{\circ} \mathrm{C}$, strain vs. time.

Fig. 5.20 Ratcheting tests at $550{ }^{\circ} \mathrm{C}$ performed with $\sigma_{\text {peak }}=325 \mathrm{MPa}$, $\sigma_{\text {mean }}=7.5 \mathrm{MPa}$, stress rate $\pm 50 \mathrm{MPa}$, hold 0.5 min at peak tension, creep strains during hold times vs. number of cycles.

Fig. 5.21 Minimum creep rates vs. $\sigma_{\text {peak }}$ for mod. $9 \mathrm{Cr}-1 \mathrm{Mo}$ steel at $550^{\circ} \mathrm{C}$......74

Fig. 5.22 Necking check on specimens in $550{ }^{\circ} \mathrm{C}$ ratcheting tests. .76

Fig. 6.1 Comparison between material response (markers) and model description (curves): Strain-controlled LCF tests on EUROFER97 at $550{ }^{\circ} \mathrm{C}$. Left: hysteresis loops of the first cycles. Right: peak tensile stresses vs. normalized number of cycles.

Fig. 6.2 Comparison between material response (markers) and RAFM model description (curves): Strain-controlled LCF tests on P91 at RT performed with various strain ranges.

Fig. 6.3 Comparison between material response (markers) and RAFM model description (curves): Stress-controlled test at RT performed with $\sigma_{\text {peak }}=500 \mathrm{MPa}, \sigma_{\text {mean }}=25 \mathrm{MPa}$, stress rate $\pm 50 \mathrm{MPa} / \mathrm{s}$. Left: loop of the first cycle. Right: accumulation of strain vs number of cycles.

Fig. 6.4 Comparison between material response (markers) and RAFM model description (curves) with various parameter values for dynamic recovery: Stress-controlled tests at RT performed with $\sigma_{\text {peak }}=500 \mathrm{MPa}$, $\sigma_{\text {mean }}=25 \mathrm{MPa}$, stress rate $\pm 50 \mathrm{MPa} / \mathrm{s}$. Left: loop of the first cycle. Right: accumulation of strain vs number of cycles.

Fig. 6.5 Comparison between material response (markers) and RAFM model description (curves): Stress-controlled tests with $C 1=1979$ and $C 2=5$. Left: loop of the first cycle. Right: accumulation of strain vs. number of cycles.

Fig. 6.6 Comparison between material response (markers) and OW I description (curves): Stress-controlled tests at RT performed with $\sigma_{\text {peak }}=500 \mathrm{MPa}$, 
$\sigma_{\text {mean }}=25 \mathrm{MPa}$, stress rate $50 \mathrm{MPa} / \mathrm{s} . C_{1}=1979, C_{2}=256.7$, Left: loop of

the first cycle. Right: accumulation of strain vs. number of cycles.

Fig. 6.7 Comparison between material response (markers) and OW II

description (curves): Stress-controlled tests at RT performed with $\sigma_{\text {peak }}=$

$500 \mathrm{MPa}, \sigma_{\text {mean }}=25 \mathrm{MPa}$, stress rate $50 \mathrm{MPa} / \mathrm{s} . C_{1}=1979, C_{2}=256.7$.

Left: loop of the first cycle. Right: accumulation of strain vs. number of cycles.

Fig. 6.8 Comparison between material response (markers) and OW II description (curves): Stress-controlled tests at RT performed with $\sigma_{\text {peak }}=500 \mathrm{MPa}, \sigma_{\text {mean }}=250 \mathrm{MPa}$, stress rate $\pm 50 \mathrm{MPa} / \mathrm{s}$. $C_{1}=1979, C_{2}=256.7, m_{1}=8, m_{2}=7$, Left: loop of the first cycle. Right: accumulation of strain vs. number of cycles.

Fig. 6.9 Comparison between material response (markers) and OW II description (curves): Stress-controlled tests at RT performed with $\sigma_{\text {peak }}=500 \mathrm{MPa}, \sigma_{\text {mean }}=25 \mathrm{MPa}$, stress rate $\pm 50 \mathrm{MPa} / \mathrm{s}$, and hold 10 min at tensile peak. $C_{1}=1979, C_{2}=256.7, m_{1}=8$, and $m_{2}=7$. Left: loop of the first cycle. Right: accumulation of strain vs. number of cycles.

Fig. 6.10 Back stress components in the new developed model for the test simulated at $R T$ with $\sigma_{\text {peak }}=500 \mathrm{MPa}, \sigma_{\text {mean }}=25 \mathrm{MPa}$, stress rate $\pm 50 \mathrm{MPa} / \mathrm{s}$

Fig. 6.11 Comparison between material response(markers) and model description(curves): Stress-controlled tests at RT with $\sigma_{\max }=500 \mathrm{MPa}$, $\sigma_{\min }=-550 \mathrm{MPa}$, stress rate $\pm 50 \mathrm{MPa} / \mathrm{s}$

Fig. 6.12 Comparison between material response (markers) and model description (curves): Stress-controlled tests at RT performed with $\sigma_{\text {peak }}=500 \mathrm{MPa}, \sigma_{\text {mean }}=0 \mathrm{MPa}$, stress rate $\pm 50 \mathrm{MPa} / \mathrm{s}$, with various values of $\mu 2$.

Fig. 6.13 Comparison between material response (markers) and model description (curves): Stress-controlled tests at RT performed with $\sigma_{\text {peak }}=500 \mathrm{MPa}, \sigma_{\text {mean }}=25 \mathrm{MPa}$, stress rate $\pm 50 \mathrm{MPa} / \mathrm{s}$, with or without term of softening in simulation.

Fig. 6.14 Comparison between material response (markers) and model description (curves): Strain-controlled LCF tests performed with various strain ranges on $P 91$ at $R T$.

Fig. 6.15 Comparison between material response (markers) and model description (curves): Ratcheting tests at RT performed with $\sigma_{\text {mean }}=25 \mathrm{MPa}$, stress rate $\pm 50 \mathrm{MPa} / \mathrm{s}$, various $\sigma_{\text {peak }}, \varepsilon_{r} v \mathrm{~s}$. number of cycles.

Fig. 6.16 Comparison between material response (markers) and model description (curves): Ratcheting tests at $R T$ performed with $\sigma_{\text {mean }}=25 \mathrm{MPa}$, stress rate $\pm 50 \mathrm{MPa} / \mathrm{s}$, various $\sigma_{\text {peak }}$, average ratcheting rates $v s . \sigma_{\text {peak }} .100$

Fig. 6.17 Comparison between material response (markers) and model description (curves): Ratcheting tests at RT performed with $\sigma_{\text {peak }}=500 \mathrm{MPa}$, stress rate $\pm 50 \mathrm{MPa} / \mathrm{s}$, various stress ratios, and average ratcheting rates vs. stress ratios.

Fig. 6.18 Comparison between material response (markers) and model description (curves): Ratcheting tests at $R T$ performed with zero $\sigma_{\text {mean }}$, stress rate $\pm 50 \mathrm{MPa} / \mathrm{s}$, various $\sigma_{a}$, and $\varepsilon_{r}$ vs. number of cycles.

Fig. 6.19 Comparison between material response (markers) and model description (curves): Ratcheting tests at RT performed with zero $\sigma_{\text {mean }}$, stress rate $\pm 50 \mathrm{MPa} / \mathrm{s}$, various $\sigma_{a}$, and average ratcheting rates $v s . \sigma_{a} .102$ 
Fig. 6.20 Comparison between material response (markers) and model description (curves): Ratcheting tests at RT performed with

$\sigma_{\text {peak }}=500 \mathrm{MPa}, \sigma_{\text {mean }}=25 \mathrm{MPa}$, various stress rates, and $\varepsilon_{r} v$ s. number of cycles.

Fig. 6.21 Comparison between material response (markers) and model description (curves): Ratcheting tests at RT performed with $\sigma_{\text {peak }}=500 \mathrm{MPa}, \sigma_{\text {mean }}=25 \mathrm{MPa}$, various hold time types, and $\varepsilon_{r} v s$. number of cycles.

Fig. 6.22 Comparison between material response (markers) and model description (curves): Stress-controlled tests at $550^{\circ} \mathrm{C}$ performed with $\sigma_{\max }=310 \mathrm{MPa}, \sigma_{\min }=-325 \mathrm{MPa}$, and stress rate $\pm 50 \mathrm{MPa} / \mathrm{s}$.

Fig. 6.23 Comparison between material response (markers) and model description (curves): Strain-controlled LCF tests performed with various strain ranges on $P 91$ at $550{ }^{\circ} \mathrm{C}$.

Fig. 6.24 Comparison between material response (markers) and model description (curves): Ratcheting tests at $550{ }^{\circ} \mathrm{C}$ performed with $\sigma_{\text {mean }}=25 \mathrm{MPa}$, stress rate $\pm 50 \mathrm{MPa} / \mathrm{s}$, various $\sigma_{\text {peak }}$, and $\varepsilon_{r} v \mathrm{~s}$. number of cycles.

Fig. 6.25 Comparison between material response (markers) and model description (curves): Ratcheting tests at $550{ }^{\circ} \mathrm{C}$ performed with $\sigma_{\text {mean }}=25 \mathrm{MPa}$, stress rate $\pm 50 \mathrm{MPa} / \mathrm{s}$, various $\sigma_{\text {peak }}$, average ratcheting rates $v s . \sigma_{\text {peak }}$.

Fig. 6.26 Comparison between material response (markers) and model description (curves): Ratcheting tests at $550{ }^{\circ} \mathrm{C}$ performed with $\sigma_{\text {peak }}=325 \mathrm{MPa}$, stress rate $\pm 50 \mathrm{MPa} / \mathrm{s}$, various stress ratios, and average ratcheting rates $v$ s. stress ratios.

Fig. 6.27 Comparison between material response (markers) and model description (curves): Ratcheting test at $550{ }^{\circ} \mathrm{C}$ performed with $\sigma_{\text {peak }}=325 \mathrm{MPa}, \sigma_{\text {mean }}=7.5 \mathrm{MPa}$, various stress rates, and $\varepsilon_{r} v \mathrm{~s}$. number of cycles.

Fig. 6.28 Comparison between material response (markers) and model description (curves): Ratcheting test at $550{ }^{\circ} \mathrm{C}$ performed with $\sigma_{\text {peak }}=325 \mathrm{MPa}, \sigma_{\text {mean }}=7.5 \mathrm{MPa}$, stress rate $\pm 50 \mathrm{MPa} / \mathrm{s}$, hold $0.5 \mathrm{~min}$ at tensile peak and without hold time, and $\varepsilon_{r} v s$. number of cycles.

Fig. 6.29 Comparison between material response (markers) and model description (curves): Ratcheting test at $550{ }^{\circ} \mathrm{C}$ performed with $\sigma_{\text {peak }}=325 \mathrm{MPa}, \sigma_{\text {mean }}=7.5 \mathrm{MPa}$, stress rate $\pm 50 \mathrm{MPa} / \mathrm{s}$, hold $5 \mathrm{~min}$ at tensile peak, and strain vs. time.

Fig. 7.1 Simulated stress-strain hysteresis loop of $200^{\text {th }}$ cycle in the straincontrolled LCF test performed with $\Delta \varepsilon=1.5 \%$ at $550{ }^{\circ} \mathrm{C}$

Fig. 7.2 Comparison between using Macaulay bracket and absolute value, simulated result: $200^{\text {th }}$ cycle of the strain-controlled LCF test performed with $\Delta \varepsilon=1.5 \%$ at $550^{\circ} \mathrm{C}$, increasing rate of BS 2 vs. inelastic strain..... 121 


\section{Table List}

Table 2.1 Comparison of notations in different reports.

9

Table 2.2 Nominal compositions of commercial and experimental FM steels [67-

$70]$

Table 3.1 Chemical compositions of P91

Table 3.2 Symmetric alternating strain-controlled LCF tests at RT .................28

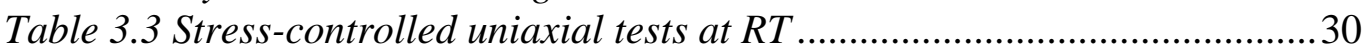

Table 3.4 Symmetric alternating strain-controlled LCF tests at $550{ }^{\circ} \mathrm{C}$............... 31

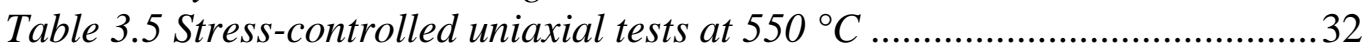

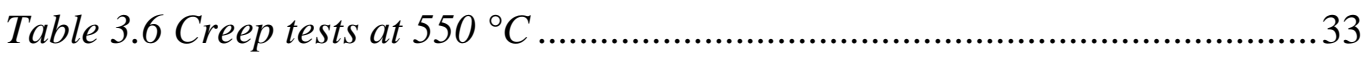

Table 6.1 Constitutive equations in RAFM model ............................................ 78

Table 6.2 Test results with various time steps in Runge-Kutta fourth order iteration method.

Table 6.3 Parameter values determined for P91 at RT based on strain-controlled LCF tests.

Table 6.4 Constitutive equations of new developed model for P91 at RT.

Table 6.5 Candidates of equations for dynamic recovery of back stress 2 in new developed model for P91 at RT.

Table 6.6 Parameters of the new developed model determined for P91 at RT. ..98

Table 6.7 Constitutive equations of new developed model for P91 at $550{ }^{\circ} \mathrm{C} . .105$

Table 6.8 Candidates of equations for dynamic recovery of back stress 2 in new developed model for $\mathrm{P91}$ at $550{ }^{\circ} \mathrm{C}$

Table 6.9 Parameters of the new developed model determined for P91 at $550{ }^{\circ} \mathrm{C}$

Table 6.10 Constitutive equations of new developed model for P91 in its multiaxial formulation. 


\section{Abbreviation}

\begin{tabular}{l|l}
\hline AF & $\begin{array}{l}\text { Armstrong-Frederick } \\
\text { AS }\end{array}$ \\
BS & $\begin{array}{l}\text { Aktaa-Schmitt } \\
\text { Back Stress } \\
\text { French Alternative Energies and Atomic Energy } \\
\text { Commission } \\
\text { European Organization for Nuclear Research } \\
\text { CERN }\end{array}$ \\
FM & $\begin{array}{l}\text { Ferritic-Martensitic } \\
\text { Low Cycle Fatigue } \\
\text { LCF }\end{array}$ \\
MATTER & $\begin{array}{l}\text { Ohno-Wang } \\
\text { OW }\end{array}$ \\
OAK & Ohno-Abdel-Karim \\
PAGB & Prior Austenite Grain Boundaries \\
Room Temperature \\
RA
\end{tabular}




\section{Notation}

\begin{tabular}{l|l}
\hline$\varepsilon$ & Strain \\
$\Delta \varepsilon$ & Strain range \\
$\varepsilon_{\text {peak }}$ & Peak tensile strain /maximum strain \\
$\varepsilon_{\text {min }}$ & Minimum strain \\
$\varepsilon^{\text {in }}$ & Inelastic strain \\
$\Delta \varepsilon^{\text {in }}$ & Inelastic strain range \\
$\varepsilon_{r} / \varepsilon_{\text {mean }}{ }^{\mathrm{i}}$ & Ratcheting strain/mean strain \\
$\varepsilon_{r}{ }^{\mathrm{ii}}$ & Ratcheting rate \\
$\sigma$ & Stress \\
$\sigma_{\text {peak }} / \sigma_{\text {max }}{ }^{\mathrm{iii}}$ & Peak stress/peak tensile stress/maximum stress \\
$\sigma_{\text {min }}$ & Minimum stress \\
$\sigma_{\text {mean }}$ & Mean stress \\
$\sigma_{a}$ & Stress amplitude \\
$\sigma_{\text {eng }}$ & Engineering stress \\
$\sigma_{\text {true }}$ & True stress \\
$\dot{\sigma}$ & Stress rate \\
$R$ & Stress ratio \\
$\Omega$ & Back stress/ Kinematic hardening \\
\hline & \\
\hline
\end{tabular}

\footnotetext{
${ }^{\mathrm{i}}$ Ratcheting strain is mean value of maximum and minimum strain in one cycle, hence the term "mean strain" and "ratcheting strain" is identical in the topic of ratcheting.

${ }^{\text {ii }}$ Ratcheting rate is the increase/decrease of mean strain of one cycle to the one in the previous cycle, namely $\varepsilon_{r}^{\prime}=\frac{\Delta \varepsilon_{r}}{\Delta N}$.

iii In case of confusion, the default meaning of peak stress is peak tensile stress. Since in all experiments mentioned in literature and performed in the current $\mathrm{PhD}$ program, the maximum stresses are tensile stresses, therefore, the term "maximum stress", "peak stress" and "peak tensile stress" are synonyms in this paper. On the other hand, in spite of a few cases where minimum stresses are zero or tensile stresses, minimum stresses are generally compressive stresses. Therefore, the term "peak compressive stress" is the same as "minimum stress" if without extra explanation.
} 


\section{Introduction}

The task of the current PhD program is a part of the MATerial Testing and Rules (MATTER) project, which is a material research program for the construction of a European Generation IV reactor. Currently available tests and evaluation standards are not sufficient to predict the structural material behavior under the operational conditions of the LFR ETPP (Lead Fast Reactor European Technology Pilot Plant) MYRRHA and SFT Prototype ASTRID, which are two prototype European Gen. IV reactors.

The scope of the MATTER project is to contribute to covering the existing gaps by pointing out methodologies, recovering existing experiences and performing experiments. One of the goals of the MATTER project is to provide the design rules for $9 \mathrm{Cr}-1 \mathrm{Mo}$ ferritic-martensitic (FM) steel.

For the application of $9 \mathrm{Cr}-1 \mathrm{Mo}$ FM steel in the construction of a nuclear power plant, not only a wide database of its mechanical characteristics is required, but also new rules need to be set, with which reliable construction planning can be done according to the characteristics of the steel. Although FM steels are preferable to austenitic steels in reactor construction owing to their lower swelling under radiation, they still have a negative side that they show cyclic softening. Cyclic softening plays a major role in ratcheting, in the sense that the strain ranges of hysteresis loops can increase cycle by cycle owing to softening and it accelerates the ratcheting. The current criteria regarding the influence of cyclic loading on ratcheting are limited since they are mainly developed for materials showing cyclic hardening. These criteria, if used without further improvement, cannot be applied to the constructions with $9 \mathrm{Cr}-1 \mathrm{Mo}$ FM steels.

Although many investigations have been carried out on $9 \mathrm{Cr}-1 \mathrm{Mo} \mathrm{FM}$ steels, the ratcheting behavior has not been extensively studied. This is because, firstly, a variety of unique material characteristics were not reported in every study on this type of steel, such as cyclic softening and asymmetry of material strength under tension and compression; secondly, a thorough study on the influence of cyclic softening on the ratcheting is lacking; thirdly, the material responses under a variety of loading conditions have not been extensively evaluated. On the other hand, although various models have been proposed to simulate the ratcheting behavior of the material, a simple, robust and convincing model is still missing, owing to excessive parameters in the previously developed models and the lack of tests under various loading conditions to verify the simulation ability of these models.

In this $\mathrm{PhD}$ program, uniaxial material behavior of $9 \mathrm{Cr}-1 \mathrm{Mo}$ steel $\mathrm{P} 91$ at room temperature (RT) and at $550{ }^{\circ} \mathrm{C}$ is studied. The experimental data from both straincontrolled low cycle fatigue (LCF) tests and stress-controlled ratcheting tests are collected to build a database for P91. Cyclic softening is evaluated according to the data collected from strain-controlled tests and the factors influencing ratcheting, 
including peak stress $\left(\sigma_{\text {peak }}\right)$, mean stress $\left(\sigma_{\text {mean }}\right)$, stress rate $(\dot{\sigma})$ and hold time are evaluated according to the data collected from the stress-controlled tests.

The constitutive model proposed by Aktaa and Schmitt [1] describes typical cyclic softening for Reduced Activation Ferritic Martensitic (RAFM) steels. Hence, this model was also named the RAFM model, which has been proved to have good simulation ability for strain-controlled LCF tests on EUROFER 97 and F82H mod.

Based on the developed database built in this work, the simulation ability of RAFM model for P91 is tested. Especially the ability to simulate the ratcheting strain $\left(\varepsilon_{r}\right)$ under a variety of stress-controlled loading conditions is tested. A new constitutive model is proposed based on the RAFM model to simulate the uniaxial isothermal behavior of P91 at both RT and $550{ }^{\circ} \mathrm{C}$.

In Chapter 2, a variety of previous studies are reviewed, including those focusing on ratcheting of various materials, modeling approaches for ratcheting, and characteristics such as cyclic softening of FM steel.

In Chapter 3, the specimens and experimental facility are presented. The experiment planning at $\mathrm{RT}$ and $550{ }^{\circ} \mathrm{C}$ is presented, including both strain- and stress-controlled tests.

In Chapter 4, experiments at RT are illustrated with diagrams and initial analysis. The effects of various influencing factors on ratcheting are presented in separate sections.

Following the same structure, Chapter 5 presents the experiments at $550{ }^{\circ} \mathrm{C}$.

Chapter 6 presents the detailed process of the development of the new constitutive model, starting from the modeling criteria. The simulation ability of the RAFM model and some other proposed models are tested for P91. A final designed model is chosen and its simulation ability is verified by comparing the model and material responses under multiple loading conditions.

In Chapter 7, the experiment and simulation results are further discussed.

Chapter 8 summarizes the current work and proposes several suggestions for future research on ratcheting of FM steel. 


\section{State of the Art}

\subsection{Ratcheting Effect}

The word "ratchet" is the name of a mechanical device that allows continuous linear or rotary motion in only one direction. In material science, the term "metaphorical ratcheting effect" is used synonymously with "progressive deformation" [2], which means that the mean strain $\left(\varepsilon_{\text {mean }}\right)$ (arithmetic mean of maximum and minimum strain during one loading cycle) accumulates only in one direction when the structure is subjected to asymmetric cyclic loading. Ratcheting is known as "cyclic creep", owing to the similar feature of "monotonic increase of strain" as "creep". However, creep deformations generally only become obvious at a temperature above approximately $30 \%$ of the melting point, while "cyclic creep" or ratcheting is already observable at much lower temperatures. Further, creep is a result of long-term stress. Therefore, creep is a "time-dependent" deformation, while ratcheting can be either time-dependent or time-independent. Note that the term "mean strain $\left(\varepsilon_{\text {mean }}\right)$ " and "ratcheting strain $\left(\varepsilon_{r}\right)$ " is identical in the topic of ratcheting.

The ratcheting behavior can be distinguished into material ratcheting and structural ratcheting. Material ratcheting occurs without structural effects, assuming the stress is distributed homogeneously in a structure. It is a purely material-related effect, which can be analytically modeled with constitutive equations. Structural ratcheting, on the other hand, can occur even if there is no material ratcheting. It happens due to inhomogeneity of the state of stress in a structure [2]. In the current work, only material ratcheting is taken into account, so in this report, the word "ratcheting" means only material ratcheting.

Ratcheting test is performed under stress-controlled cyclic loading during which the hysteresis loops do not close. As a result of non-closed hysteresis loops, the $\varepsilon_{\text {mean }}$ during each loading cycle is different from that in the previous cycle. In most cases, $\varepsilon_{\text {mean }}$ accumulates in the direction of $\sigma_{\text {mean }}$ (arithmetic mean of maximum and minimum stress during one loading cycle).

Note that there is a distinction between the term "strain accumulation" $\varepsilon^{a c c}{ }_{i j}=$ $\int \dot{\varepsilon}^{p l}{ }_{i j} d t$ and "accumulated plastic strain" $p=\int\left(\frac{2}{3} \dot{\varepsilon}^{p l}{ }_{i j} \dot{\varepsilon}^{p l}{ }_{i j}\right)^{1 / 2} d t$ [2]. Strain accumulation $\varepsilon^{a c c}{ }_{i j}$ is zero in a closed hysteresis loop while accumulated plastic strain $p$ can only increase monotonically. Accumulated plastic strain $p$ is used in various constitutive theories [3-7].

One of the earliest observations of ratcheting was reported for 1100 aluminum, which showed shifting of hysteresis loops in the presence of mean stress [8]. Researchers have found ratcheting effect on a wide range of materials, including: 
- Austenitic steels such as 316L [9-11], 316LN [12], 304 [13-20], 304L [21], 304LN [22] (304L means "low carbon", 304LN means "low carbon and high nitrogen" [23]);

- Ferritic steels [24-28];

- Carbon steels (CS) 40Cr [29], 42CrMo [18, 30, 31], 16MnR[32], X42 and X56 [33], 20 CS [34, 35], 45 CS [36];

- Other steels such as SA333C-Mn steels [37], Interstitial-Free Steel [38];

- Other metallic materials, such as zirconium alloys [39], pure titanium [40], titanium alloys [41], NiTi shape memory alloy [42, 43];

- Ceramic matrix composites [44]; and

- Polymers such as polytetrafluoroethylenes (PTFE) [45], polypropylene [46], polyacetal/polyoxymethylene[47], epoxy resin[48] etc.

Some of the research on ratcheting of a variety of steels is reviewed in the following.

Although ratcheting tests are supposed to be performed under stress-controlled cyclic loading, strain-controlled ratcheting tests were also performed $[9,10]$, which are known as "cyclic tension tests". The imposed strain was a combination of an alternate strain and a mean strain, as shown in Fig. 2.1).

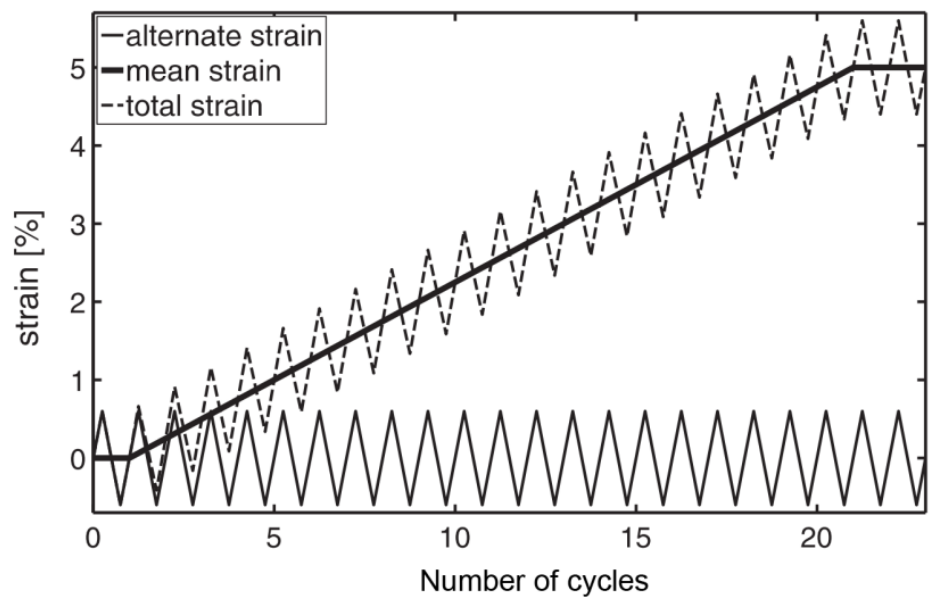

Fig. 2.1 Generic strain path for a cyclic tension test where the total strain path is a superposition of mean and alternate strain [10].

Such strain-controlled ratcheting tests were performed on AISI 316L austenitic stainless steel at RT and $200{ }^{\circ} \mathrm{C}$ [10]. It was found that the material response was characterized by an additional hardening and a non-zero $\sigma_{\text {mean }}$, and the authors suggested that the response was a superposition of two mechanisms: a cyclic one (hardening corresponding to LCF behavior) and a monotonic one (hardening owing to drifting of the $\varepsilon_{\text {mean }}$ ). So-called "fatigue/creep-fatigue tests with superimposed strain" were carried out on mod. $9 \mathrm{Cr}-1 \mathrm{Mo}$ steel at 550 and $450{ }^{\circ} \mathrm{C}$ [28], which were essentially the same as the "strain-controlled ratcheting tests". However, stress-controlling still plays a large part in ratcheting research. The other ratcheting research discussed in this chapter is all stress-controlled if without extra explanation.

Ratcheting tests can be distinguished into uniaxial and multiaxial tests. Although uniaxial tests require a relatively simple experimental facility, multiaxial tests are 
closer to real working conditions in the sense that real components are generally under multiaxial loading. Specimens for multiaxial ratcheting tests are tubular with typical outer/inner diameters of 13/10mm [26], 15/12mm [15, 17, 19], 16/13mm [11, $31,35]$, or $22 / 18 \mathrm{~mm}[49]$. To verify the multiaxial constitutive models, not only axial stresses but also shear stresses were placed on tubular specimens. Various steels have been tested under multiaxial loading, such as mod. 9Cr-1Mo steel [26], 304 [15, 17, 19], 304L[50], 316L [11] , carbon steel 42CrMo [31], carbon steel 20 [35], U71Mn rail steel [51] and $1 \mathrm{Cr} 18 \mathrm{Ni}$ Ti stainless steel [49]. A variety of loading paths used in multiaxial tests are illustrated in Fig. 2.2.

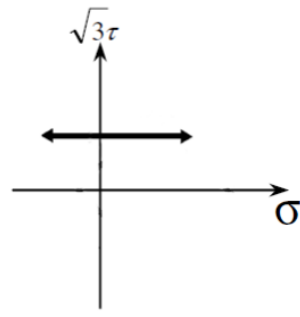

(a) $0^{\circ}$ linear

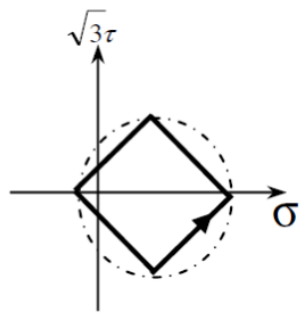

(e) rhombic

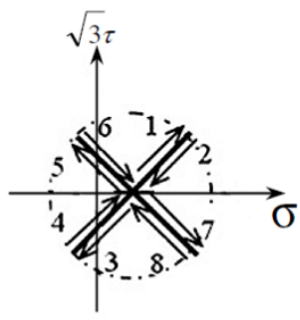

(i) X-typed

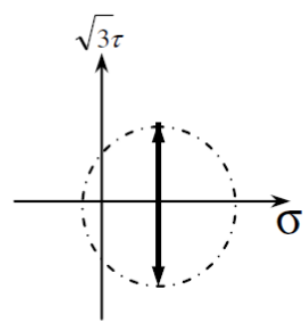

(b) $90^{\circ}$ linear

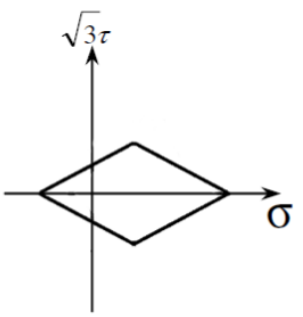

(f) $1 / 2$ rhombic

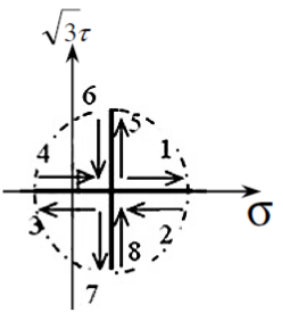

(j) cross

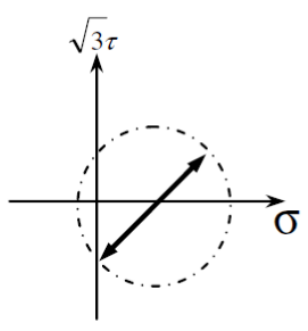

(c) $45^{\circ}$ linear

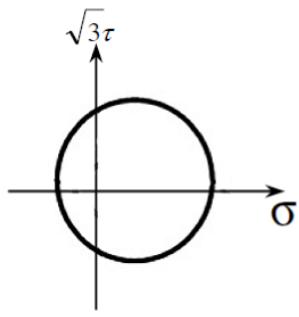

(g) circular

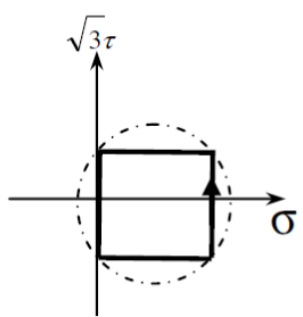

(k) square

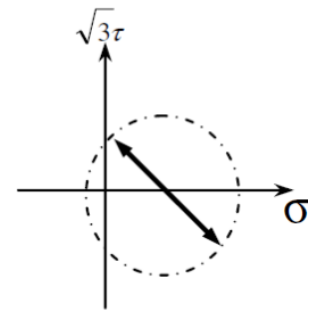

(d) $135^{\circ}$ linear

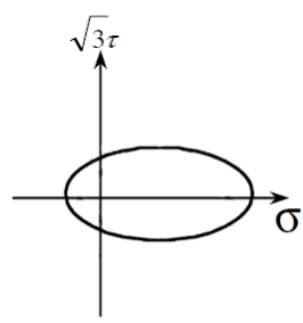

(h) Elliptical

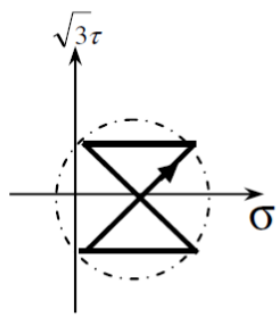

(1) butterfly-typed

Fig. 2.2 Shapes of some loading paths used in the multiaxial stress-controlled cycling tests. [11, 15, 17, 31, 35, 49, 50]

However, for reasons of simplicity and restriction of testing facility, uniaxial ratcheting tests still play a large role in ratcheting research.

Specimens in uniaxial ratcheting tests are mostly in the shape of a solid cylinder; however, cylindrical shell of stainless steel 304L has been also subjected to uniaxial loading [21], since the shell form has a wide range of applications in industry owing to its lightweight and high strength. The ratcheting behavior of cylindrical shell was noted at RT. Although the shells mentioned in [21] and the tubular specimens for multiaxial ratcheting tests $[11,15,17,19,26,31,35,49]$ had similar shape, the shells in [21] had an outer diameter of $42 \mathrm{~mm}$ and shell thickness $1.5 \mathrm{~mm}$, with the diameter-to-thickness ratio of 28 , while in e.g. [11], this ratio of the tubular specimen 
was only 10. With larger diameter-to-thickness ratio, the structure was more susceptible to buckling. Note that the uniaxial ratcheting was studied together with buckling behavior of the shells [21].

The failure modes under uniaxial cyclic loading were investigated with carbon steel 45 at RT [36]. Strain-controlled tests were firstly performed to fit the parameters in the Coffin-Manson formula [52-54] with cycle number to the failure of the material $\left(N_{f}\right)$. Then ratcheting behavior was studied in stress-controlled tests. It was found that, in strain-controlled tests, and in stress-controlled tests performed with high $\sigma_{a}$ and small $\sigma_{\text {mean }}$, the failure mode was fracture, while in stress-controlled tests performed with relatively small $\sigma_{a}$ and large $\sigma_{\text {mean }}$, the failure mode was ductile localized necking. Therefore, the fatigue damage $D_{f}$ was relatively larger with larger $\sigma_{a}$ and smaller $\sigma_{\text {mean }}$, while $D_{f}$ was relatively smaller with relatively smaller $\sigma_{a}$ and larger $\sigma_{\text {mean }}[36]$.

The uniaxial and non-proportionally multiaxial ratcheting behavior of austenitic steel 304 was researched under asymmetrical stress-controlled cyclic loading with variable $\sigma_{a}$ and $\sigma_{\text {mean }}$, loading paths, and loading histories. A phenomenon named "dynamic strain aging" was found in the temperature range of $400-600{ }^{\circ} \mathrm{C}$, in which much greater cyclic hardening and less ratcheting were observed than at RT [15]. The explanation for this phenomenon was that the interactions of dislocation and point defect were significantly active, which resulted in a remarkable enhancement of deformation resistance, hence the cyclic hardening was greater. This phenomenon was not reported for the other steels.

In most ratcheting research $[3-5,9,14,16,24,26,30,36]$, minimum stress in each hysteresis loop was compressive. On the contrary, uniaxial ratcheting tests with tensile minimum stresses were carried out on ferritic steel X12CrMoWVNbN10-1-1 with various hold times and stress ratios at a temperature of $600{ }^{\circ} \mathrm{C}[25,27]$. Because the minimum stress in each cycle was tensile, the hysteresis loops were always within the tensile range. The total accumulated strain was decomposed into accumulated ratcheting strain (partial inelastic strain formed during stress-changing process) and accumulated creep strain (strain increase during hold time). The so-called shakedown behavior of ratcheting was observed on specimens subjected to a relatively long hold time (i.e. 5 and 20min), which meant the partial inelastic strain formed during the stress-changing process of each cycle continuously decreased until no ratcheting was observed [25, 27].

On the other hand, when the hold time was less than 5min, the total accumulated strain was mainly composed of the increased ratcheting strain owing to the inelastic creep recovery. For longer hold times $(10,20$ or 30min) however, the accumulated creep strains were the controlling mechanism of deformation [25, 27].

Generally speaking, ratcheting happens with a non-zero $\sigma_{\text {mean }}$, or in other words, asymmetric stress-controlled loading, while positive ratcheting (strain accumulation in the direction of tensile stress) with zero $\sigma_{\text {mean }}$ on mod. $9 \mathrm{Cr}-1 \mathrm{Mo}$ steel at $550{ }^{\circ} \mathrm{C}$ was also observed [7, 26]. This behavior was named "unconventional ratcheting". It was suggested that the reason for this unconventional behavior had something to do with hydrostatic pressure and this suggestion was used in the construction of the 
constitutive model $[7,26]$. The corresponding modeling approach is discussed in detail in Section 2.2.

In another study on ratcheting of mod. $9 \mathrm{Cr}-1 \mathrm{Mo}$ steel, a phenomenon named "progressive deformation instability" was observed at $600{ }^{\circ} \mathrm{C}$ [24]. Fig. 2.3 and Fig. 2.4 show diagrams of $\varepsilon_{r}$ versus number of cycles. Fig. 2.3 shows the results with the same $\sigma_{\text {mean }}$ and different $\sigma_{a}$, while Fig. 2.4 shows the results with the same $\sigma_{a}$ and different $\sigma_{\text {mean }}$. It was clear that ratcheting rate $\varepsilon_{r}^{\prime}$ (change of mean strain/ratcheting strain per cycle) increased with increasing $\sigma_{a}$ (with the same $\sigma_{\text {mean }}$ ) and increased with increasing $\sigma_{\text {mean }}$ (with the same $\sigma_{a}$ ). The sudden changes of $\varepsilon_{r}^{\prime}$ were the so-called "progressive deformation instability", which was explained as being due to severe cyclic softening characteristic of the tested material [24]. A detailed discussion of cyclic softening is provided in Section 2.5.

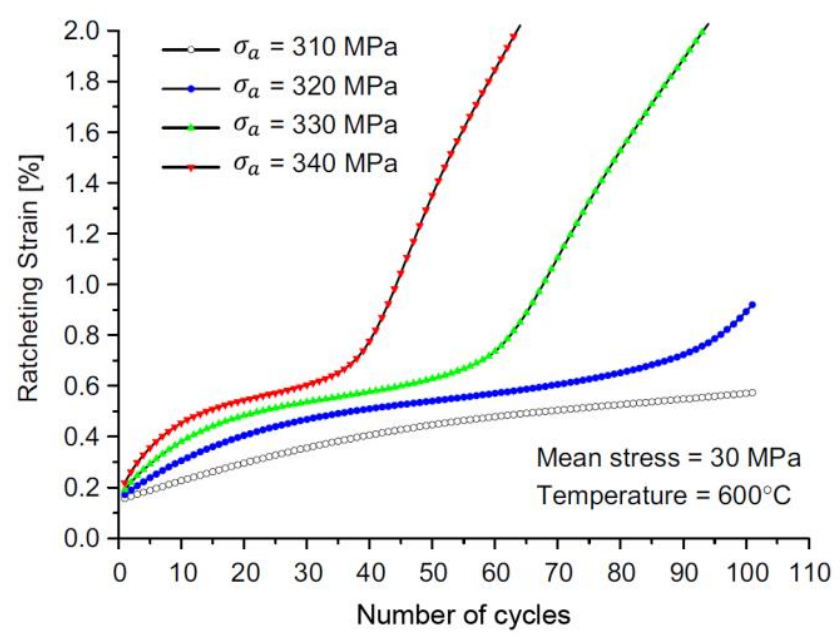

Fig. 2.3 Effects of the applied stress amplitude on progressive deformation instability owing to the cyclic softening of the mod. 9Cr-1Mo steel [24].

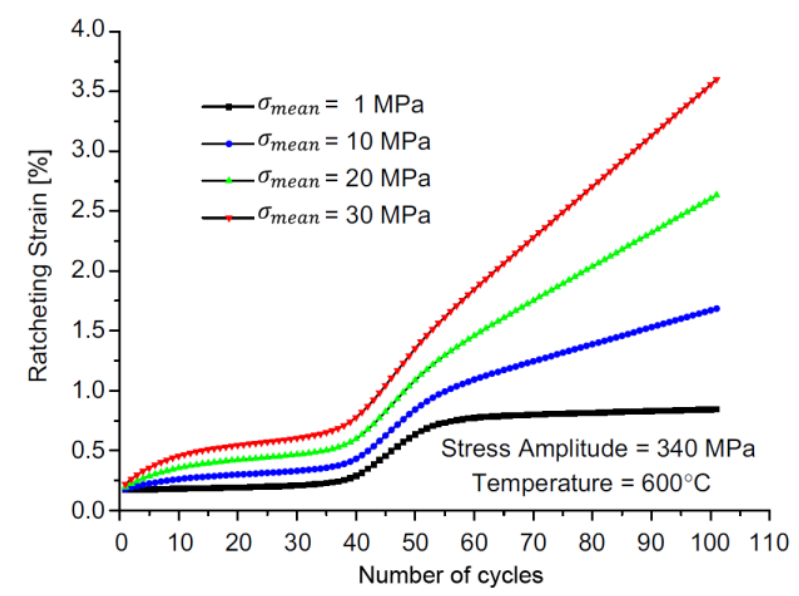

Fig. 2.4 Effects of the mean stress on progressive deformation instability owing to the cyclic softening of the mod. 9Cr-1Mo steel [24].

However, such "progressive deformation instability" was not mentioned for mod. $9 \mathrm{Cr}-1 \mathrm{Mo}$ steel at $550{ }^{\circ} \mathrm{C}[7,26]$ while only an increase of strain range was observed in tests at $550{ }^{\circ} \mathrm{C}$, as shown in Fig. 2.5. 


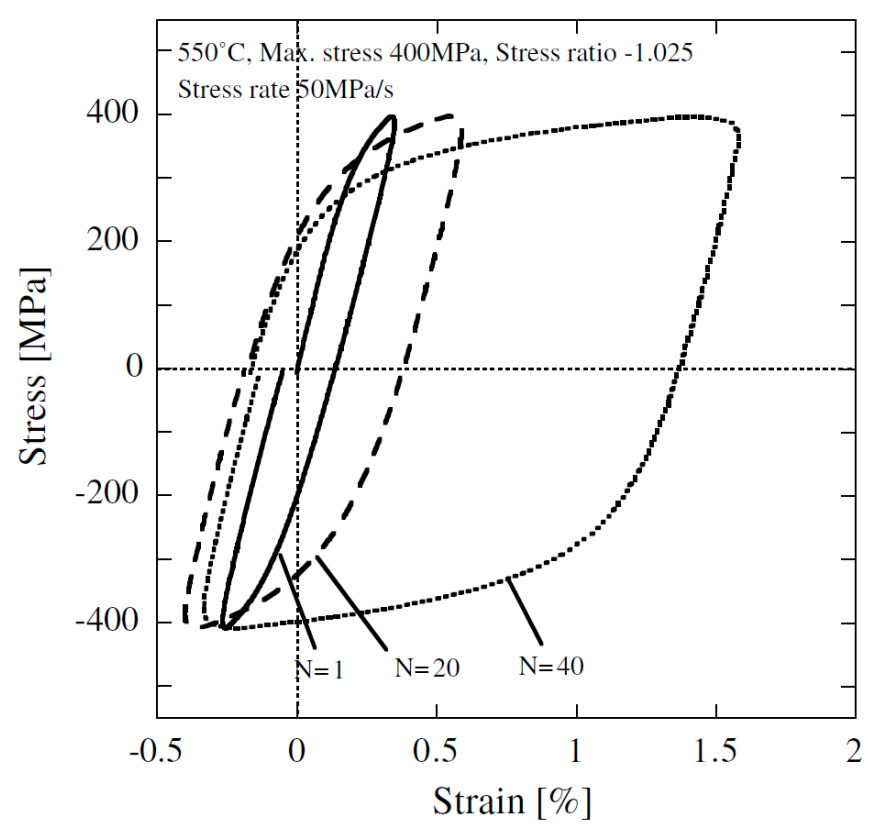

Fig. 2.5 Stress-strain hysteresis loops under stress ratio of -1.025 [26].

Compared to austenitic steels, ratcheting research on ferritic steels, especially on mod. 9Cr-1Mo steel is relatively sparse. Currently, no reports about ratcheting behavior of this material at RT can be found in the literature, and some research at $550{ }^{\circ} \mathrm{C}$ is still doubtful. For instance, the ultimate tensile strength measured in $\mathrm{SCK} \cdot \mathrm{CEN}$ [55] at $550{ }^{\circ} \mathrm{C}$ was $374 \mathrm{MPa}$, however according to [26], a group of ratcheting tests were performed with $\varepsilon_{\text {peak }}=400 \mathrm{MPa}$ at $550{ }^{\circ} \mathrm{C}$ which would be impossible if they were testing on the same material, since both materials mentioned in [26] and [55] were mod. 9Cr-1Mo FM steels. On the other hand, the positive ratcheting in the vicinity of zero $\sigma_{\text {mean }}$ reported in [26] also requires further verification. Further, the progressive deformation instability induced by cyclic softening at $600{ }^{\circ} \mathrm{C}$ [24] should be checked at $550{ }^{\circ} \mathrm{C}$.

\subsection{Modeling of Ratcheting}

One of the main aims in research on ratcheting is to give a better model of the visco-plasticity characteristic of materials with better prediction of the ratcheting effect. Most work in recent decades [3, 4, 6, 7, 14, 30, 56, 57] is based on the Chaboche model [5, 58-61], the Armstrong-Frederick (AF) rule of dynamic recovery of kinematic hardening [62], and the Ohno-Wang (OW) model [3, 4].

The Chaboche model was a so-called unified deformation model that described visco-plasticity without the separation in time-dependent creep and time-independent plasticity $[1,63]$. "Standard" constitutive models, which were usually used in finite-element codes, decomposed the total strain into elastic, plastic, creep and anelastic contributions, while the "unified" model considered creep and plasticity as arising from the same dislocation source [62]. 
The basic visco-plastic equations in the Chaboche model are as follows:

$$
\begin{aligned}
& \dot{\boldsymbol{\varepsilon}}^{i n}=\frac{3}{2}\left\langle\frac{\Sigma_{e q}-K}{Z}\right\rangle^{n} \frac{\boldsymbol{\Sigma}}{\Sigma_{e q}} \\
& \boldsymbol{\Sigma}=\boldsymbol{s}-\boldsymbol{\Omega}, \\
& \Sigma_{e q}=\sqrt{\frac{3}{2} \boldsymbol{\Sigma}: \boldsymbol{\Sigma}} \\
& \boldsymbol{s}=\boldsymbol{\sigma}-\frac{1}{3} \operatorname{trace}(\boldsymbol{\sigma}) \mathbf{1} \\
& \boldsymbol{\Omega}=\sum_{i=1}^{M} \boldsymbol{\Omega}_{i}
\end{aligned}
$$

\langle\rangle indicated the Macaulay bracket, which operated as $\langle x\rangle=0$ when $x<0$ and $\langle x\rangle=x$ when $x \geq 0 . \Omega$ represented the back stress (BS). $M$ meant that the BS was composed of $M$ sub-components. $K, Z$, and $n$ were material and temperaturedependent parameters.

To avoid confusion, all notation in this work follows the form as in Aktaa and Schmitt [1]. A comparison between notations in Aktaa and Schmitt [1] and notations in other reports can be found in Table 2.1

\begin{tabular}{c|c|c}
\hline$[1]$ & {$[5,58]$} & {$[3,4,6]$} \\
\hline $\boldsymbol{s}$ & $\boldsymbol{\sigma}^{\prime}$ & $\boldsymbol{s}$ \\
$\Sigma_{e q}$ & $\boldsymbol{X}$ & $\boldsymbol{a}$ \\
$\boldsymbol{\varepsilon}^{\boldsymbol{i n}}$ & $J(\boldsymbol{\sigma}-\boldsymbol{X})$ & $\sigma_{e f f}$ \\
$H_{i}$ & $\boldsymbol{\varepsilon}_{\boldsymbol{p}}$ & $\boldsymbol{\varepsilon}^{\boldsymbol{p}}$ \\
$C_{i}$ & $C_{i}$ & $h_{i}=\zeta_{i} \cdot r_{i}$ \\
\hline
\end{tabular}

Table 2.1 Comparison of notations in different reports.

From the microstructural point of view, the term "back stress" is defined as follows: The acting stress on the leading dislocation in a pile-up is the acting stress on the glide plane multiplied by the number of dislocations in the pile-up. A similar stress, but with opposite sign, opposes the operation of the generator, in the form of a "back stress"[64]. In the theory of solid mechanics concerning flow laws, BS is referred to as "kinematic hardening variable". It is also known as the "microstress component" [62].

Armstrong and Frederick [62] provided a type of equation of BS which can be simplified as follows: 


$$
\dot{\boldsymbol{\Omega}}_{i}=\frac{2}{3} H_{i} \dot{\boldsymbol{\varepsilon}}^{i n}-C_{i} \boldsymbol{\Omega}_{i} \dot{p}-R_{i}\left|\boldsymbol{\Omega}_{i}\right|^{m_{i}-1} \boldsymbol{\Omega}_{i}
$$

with

$$
\dot{p}=\sqrt{\frac{2}{3} \dot{\varepsilon}^{i n}: \dot{\varepsilon}^{i n}}
$$

The second and the last term in eq. (2-6) represent the dynamic recovery and static recovery of the back stress component $\boldsymbol{\Omega}_{i}$, respectively. $H_{i}, C_{i}, R_{i}$ and $m_{i}$ are the material and temperature dependent parameters. This is commonly referred to as the Armstrong-Frederick rule of kinematic hardening (AF rule).

Note that the static recovery term was already introduced in the original ArmstrongFrederick report [62], but with a linear dependency of BS. This term was not included in many modeling approaches $[3,4,6,51,58]$.

A well-known disadvantage of the AF rule is that, it predicts too much accumulated strain under non-symmetric loading conditions [6, 62]; in other words, constitutive models with the AF rule predict too much ratcheting.

Improved rules were developed to avoid the defect of the AF rule on ratcheting prediction by, for example, introducing a power function of the BS in the dynamic recovery term as follows:

$$
\dot{\boldsymbol{\Omega}}_{i}=\frac{2}{3} H_{i} \dot{\boldsymbol{\varepsilon}}^{i n}-\frac{C_{i}{ }^{2}}{H_{i}}\left[J\left(\boldsymbol{\Omega}_{i}\right)\right]^{m-1} \boldsymbol{\Omega}_{i} \dot{p}
$$

where $J(x)$ represents the von Mises invariant $\left(\frac{3}{2} x^{\prime}: x^{\prime}\right)^{1 / 2} . x^{\prime}$ is the deviator of $x$, as in eq.(2-4). Note that there was no static recovery term in eq.(2-8) [58].

The Ohno-Wang model includes Ohno-Wang model I (OW I) and model II (OW II). It was assumed that the dynamic recovery of BS is activated fully only when its magnitude $\overline{\boldsymbol{\Omega}}_{i}$ attains a critical value, resulting from the energy required for cross slip $[3,4]$. In OW I, the critical state of dynamic recovery is represented by a surface $f_{i}=0$ :

$$
f_{i}=\overline{\boldsymbol{\Omega}}_{i}{ }^{2}-r_{i}{ }^{2}
$$

with parameter $r_{i}=\frac{H_{i}}{C_{i}}$ and

$$
\overline{\boldsymbol{\Omega}}_{i}=\sqrt{\frac{3}{2} \Omega_{i}: \Omega_{i}}
$$

The equation for BS in OW I is as follows:

with

$$
\dot{\boldsymbol{\Omega}}_{i}=\frac{2}{3} H_{i} \dot{\boldsymbol{\varepsilon}}^{i n}-H s\left(f_{i}\right) C_{i} \boldsymbol{\Omega}_{i} \dot{\lambda}_{i}
$$




$$
\dot{\lambda}_{i}=\left\langle\dot{\varepsilon}^{i n}: \boldsymbol{k}_{i}\right\rangle
$$

where $\boldsymbol{k}_{i}$ denotes the direction of $\boldsymbol{\Omega}_{i}$.

$$
\boldsymbol{k}_{i}=\frac{\boldsymbol{\Omega}_{i}}{\overline{\boldsymbol{\Omega}}_{i}}
$$

Fig. 2.6 illustrates the evolution of BS component $\boldsymbol{\Omega}_{\boldsymbol{i}}$. $\dot{\lambda}_{\boldsymbol{i}}$ takes the form of eq. (2-12) to keep $\boldsymbol{\Omega}_{\boldsymbol{i}}$ in the critical state $f_{i}=0$.

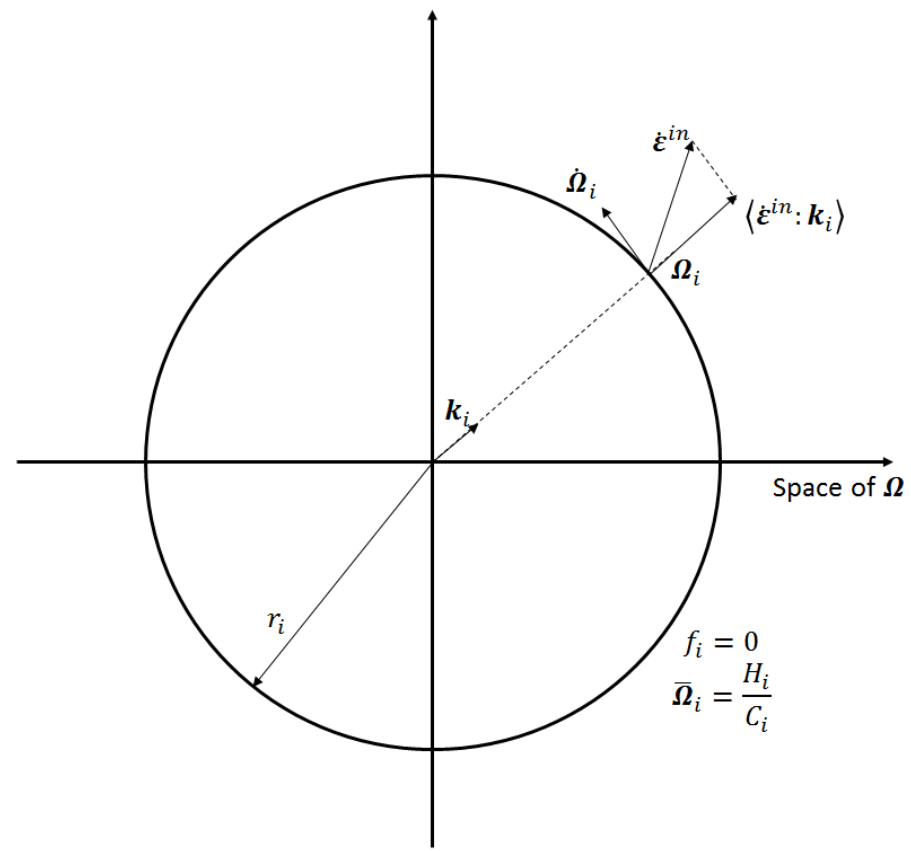

Fig. 2.6 Evolution of $\boldsymbol{\Omega}_{i}$ on the surface of $f_{i}=0 \quad$ [3]

$H s$ denotes the Heaviside step function, which operates as $H s(x)=0$ when $x<0$ and $H s(x)=1$ when $x \geq 0$.

However, the simulated hysteresis loops with OW I are piecewise linear, without everywhere-differentiability and expressed no uniaxial $\varepsilon_{r}[3,4]$.

In OW II, the Heaviside step function in OW I is replaced with an everywheredifferentiable term $\left(\frac{\bar{\Omega}_{i}}{r_{i}}\right)^{m_{i}}$. Equation for BS in OW II is as follows:

$$
\dot{\boldsymbol{\Omega}}_{i}=\frac{2}{3} H_{i} \dot{\boldsymbol{\varepsilon}}^{i n}-\left(\frac{\overline{\boldsymbol{\Omega}}_{i}}{r_{i}}\right)^{m_{i}} C_{i} \boldsymbol{\Omega}_{i} \dot{p}
$$

in which $m_{i}$ is the material- and temperature-dependent parameter. When $m_{i} \rightarrow \infty$, eq. (2-14) reduced into eq. (2-11). 
Fig. 2.6 in [3] shows the comparison between the OW I, II and AF model. In both OW I and II, the magnitudes of the dynamic recovery terms were minimized, while OW II avoided the non-differentiable corner when $\overline{\boldsymbol{\Omega}}_{i} \rightarrow{ }^{H_{i}} / C_{i}$.

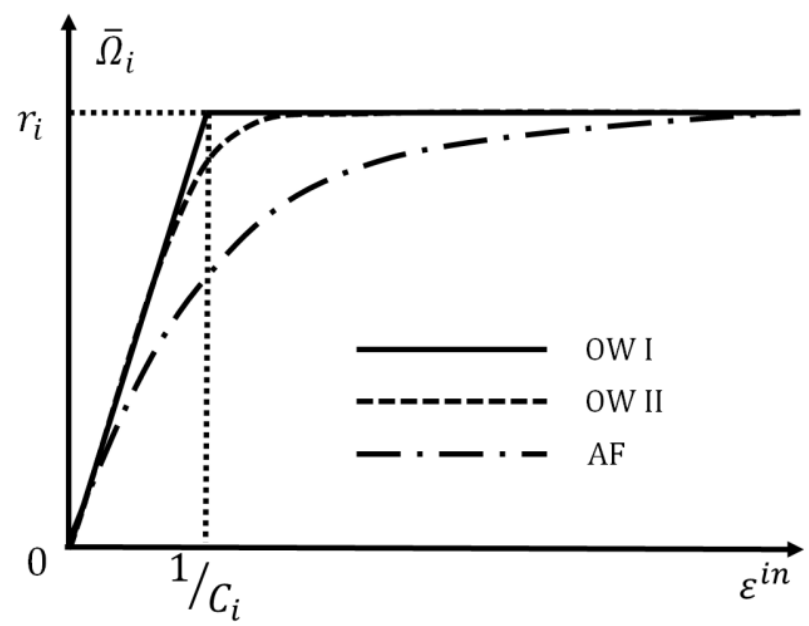

Fig. 2.7 Change of $\bar{\Omega}_{i}$ under uniaxial tensile loading [3]

Both OW I and II should have four or eight BS components to fit the experimental loop shapes and $\varepsilon_{r}$, which required too much effort in fitting the parameters. On the other hand, the two examples in [4] to verify the simulation ability of OW model were with $\sigma_{\text {peak }}=400 \mathrm{MPa} \& \sigma_{\text {mean }}=100 \mathrm{MPa}$ and with $\sigma_{\text {peak }}=400 \mathrm{MPa} \&$ $\sigma_{\text {mean }}=150 \mathrm{MPa}$, respectively, in which $\varepsilon_{r}$ in the material responses were too small (no more than $0.5 \%$ ). Hence, these two verifications were not persuasive.

Another modeling approach was to combine the AF rule into the OW model in the evolution equation for dynamic recovery, which can be referred to as Ohno-AbdelKarim (OAK) model [6]:

$$
\dot{\boldsymbol{\Omega}}_{i}=\frac{2}{3} H_{i} \dot{\boldsymbol{\varepsilon}}^{i n}-\mu_{i} C_{i} \boldsymbol{\Omega}_{i} \dot{p}-H s\left(f_{i}\right) C_{i}\left\langle\dot{\lambda}_{i}\right\rangle \boldsymbol{\Omega}_{i}
$$

with

$$
\dot{\lambda}_{i}=\dot{\varepsilon}^{i n}: \frac{\Omega_{i}}{r_{i}}-\mu_{i} \dot{p}
$$

The parameter $\mu_{i}$ combines the AF rule into the OW model in eq. (2-15): When $\mu_{i}=0$, eq. (2-15) was the same in OW I as eq. (2-11). If $\mu_{i}=1$, it was the same in the AF rule as eq. (2-6), in spite of the term for static recovery.

To determine the parameters $H_{i}$ and $C_{i}$, the relation of BS $\boldsymbol{\Omega}$ and inelastic strain $\boldsymbol{\varepsilon}^{\text {in }}$ was linearized and eq. (2-15) was correspondingly reduced to OW I $\left(\mu_{i}=0\right)$, which was perfectly linear. As illustrated in Fig. 2.8, multiaxial case was simplified into the uniaxial case and the curve of $\Omega-\varepsilon^{\text {in }}$ was linearized into 3 linear sections with corners $(M=3)[6]$.

As $\mu_{i} \rightarrow 0$, 


$$
\begin{aligned}
& C_{i}=\frac{1}{\varepsilon_{(i)}^{i n}} \\
& H_{i}=C_{i}\left[\frac{\Omega_{(i)}-\Omega_{(i-1)}}{\varepsilon_{(i)}^{i n}-\varepsilon_{(i-1)}^{i n}}-\frac{\Omega_{(i+1)}-\Omega_{(i)}}{\varepsilon_{(i+1)}^{i n}-\varepsilon_{(i)}^{i n}}\right] \varepsilon_{(i)}^{i n}
\end{aligned}
$$

where $\varepsilon_{(0)}^{\text {in }}$ and $\Omega_{(0)}=0$.

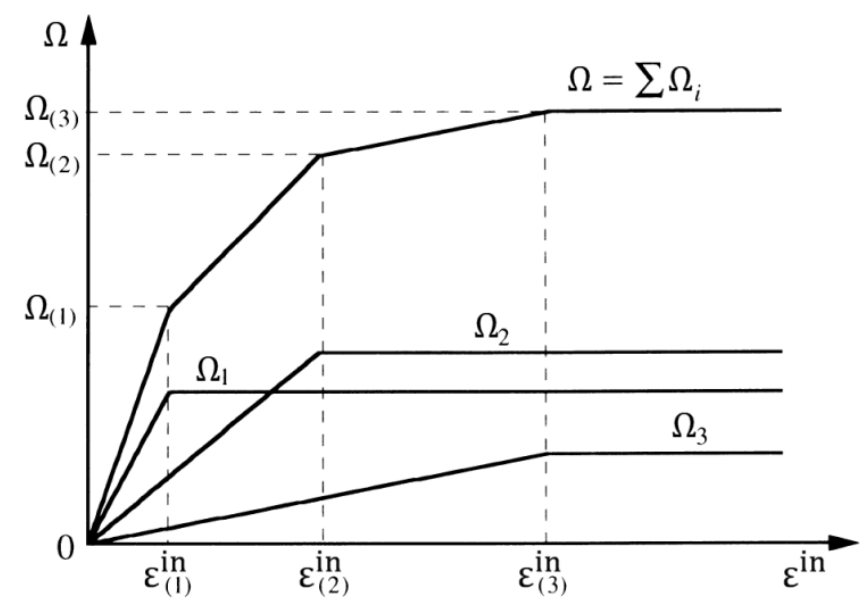

Fig. 2.8 Change of BS and its sub-components under uniaxial tensile loading in the case of $\mu_{i}=0,(M=3)[6]$.

The BS was decomposed into eight components in [6] to simulate the material responses of mod. 9Cr-1Mo steel, which meant eight groups $(M=8)$ of $H_{i}$ and $C_{i}$ should be determined. This OAK model developed in [6] was employed in [17, 20] to simulate uniaxial and multiaxial ratcheting of stainless steel 304.

The equation of BS was further modified into eq. (2-19) in another modeling approach [51].

$$
\dot{\boldsymbol{\Omega}}_{i}=\frac{2}{3} H_{i} \dot{\boldsymbol{\varepsilon}}^{i n}-\mu_{i} C_{i} \boldsymbol{\Omega}_{i} \dot{p}-H s\left(f_{i}\right) C_{i}\left(1-\mu_{i}\right) \dot{p} \boldsymbol{\Omega}_{i}
$$

The term $\left\langle\dot{\varepsilon}^{i n}: \frac{\Omega_{i}}{r_{i}}-\mu_{i} \dot{p}\right\rangle$ in eq. (2-15) was changed into(1- $\left.\mu_{i}\right) \dot{p}$ in eq. (2-19). This model proposed in [51] can be referred to as the Kang model, which was employed in [30] to simulate uniaxial ratcheting of $42 \mathrm{CrMo}$ steel and in [65] to study uniaxial ratcheting and to predict multiaxial ratcheting of $\mathrm{SiC}_{\mathrm{p}} / 6061 \mathrm{Al}$ composites.

Note that the static recovery term in AF rule (see eq. (2-6)) was not included in the OW I and II models, the OAK model or the Kang model.

In another modeling approach, the cyclic softening was taken into account in the simulation of the ratcheting behavior of mod. $9 \mathrm{Cr}-1 \mathrm{Mo}$ steel at $550{ }^{\circ} \mathrm{C}$ [7]. The simulation of cyclic softening in [7] is discussed in detail in Section 2.5. 
The model proposed in [7] can be referred to as the Yaguchi-Takahashi (YT) model. OW I model was applied in the YT model with the addition of the static recovery term of BS. The equation for BS in the YT model is as follows:

$$
\begin{aligned}
& \dot{\boldsymbol{\Omega}}_{i}=\frac{2}{3} H_{i} \dot{\boldsymbol{\varepsilon}}^{i n}-H s\left(f_{i}\right) C_{i}\left\langle\dot{\boldsymbol{\varepsilon}}^{i n}: \frac{\boldsymbol{\Omega}_{i}}{\overline{\boldsymbol{\Omega}}_{i}}\right\rangle \boldsymbol{\Omega}_{i}-R_{i}\left|\boldsymbol{\Omega}_{i}\right|^{m_{i}-1} \boldsymbol{\Omega}_{i} \\
& f_{i}=\overline{\boldsymbol{\Omega}}_{i}{ }^{2}-r_{i}{ }^{2}
\end{aligned}
$$

Although the original OW I expressed no $\varepsilon_{r}$, the term of static recovery in eq. (2-20) yielded a non-zero $\varepsilon_{r}$, which was confusing because the ratcheting was supposed to be only owing to the static recovery of BS in YT model. Moreover, this model overestimated the ratcheting particularly with larger $\sigma_{\text {mean }}$, as shown in Fig. 2.9.

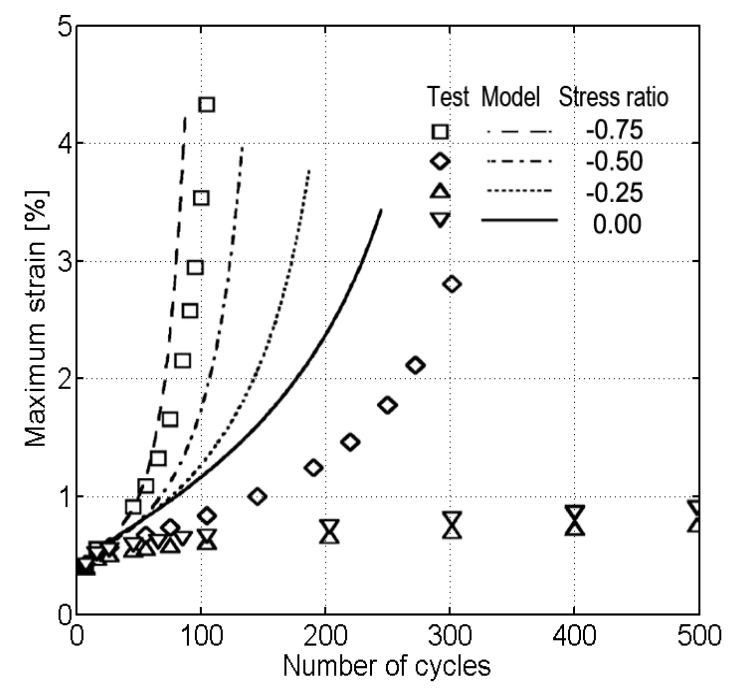

Fig. 2.9 Simulations of uniaxial ratcheting under stress ratio conditions between -0.75 and 0 by proposed constitutive model, with $\sigma_{\max }=400 \mathrm{MPa}$, stress rate $\pm 50 \mathrm{MPa} / \mathrm{s}[7]$.

As mentioned in Section 2.1, positive ratcheting with zero $\sigma_{\text {mean }}$ was reported in [26]. Hydrostatic pressure was suggested to be the reason for this unconventional ratcheting behavior. Accordingly, the Chaboche model was modified with the addition of $J_{m}(\sigma)$ [7].

$$
J_{m}(\boldsymbol{\sigma})=\eta|\operatorname{tr}(\boldsymbol{\sigma})|^{l} \operatorname{sgn}(\operatorname{trace}(\boldsymbol{\sigma}))
$$

with $\operatorname{sgn}(x)$ works as

$$
\operatorname{sgn}(x)=\left\{\begin{array}{c}
1 \text { if } x>0 \\
0 \text { if } x=0 \\
-1 \text { if } x<0
\end{array}\right.
$$

Eq. (2-1) in the Chaboche model was modified to the following equation:

$$
\dot{\boldsymbol{\varepsilon}}^{i n}=\frac{3}{2}\left\langle\frac{\Sigma_{e q}-K+J_{m}(\boldsymbol{\sigma})}{Z}\right\rangle^{n} \frac{\boldsymbol{\Sigma}}{\Sigma_{e q}}
$$


Consequently, the value of $\dot{\boldsymbol{\varepsilon}}^{\text {in }}$ was larger under tensile stress than compressive stress, since $J_{m}(\boldsymbol{\sigma})>0$ when $\operatorname{tr}(\boldsymbol{\sigma})>0$. As a result, under symmetric cyclic loading, the rate of inelastic strain $\varepsilon^{i n}$ was larger in the tensile part of each hysteresis loop than in the compressive part, hence the loops were not closed and the $\varepsilon_{\text {mean }}$ during each loading cycle was larger than that of the earlier cycle, even when the peak tensile stresses were equal to the peak compressive stresses. In other word, the model yielded positive ratcheting with zero $\sigma_{\text {mean }}$.

Instead of four, eight or even 12 BS components as in $[4,6,7,51]$, a further modeling approach reduced the number, leaving merely three BS components, which reduced the complexity of the model [24]. It was found that one of the components should have a very large value of $H_{1}$ to match the plastic modulus at the yielding. Another one had a smaller value of $H_{2}$ to satisfy the following $\sigma \sim \varepsilon$ relationship at or near the plastic strain limit, and the third component should have a very small value of $C_{3}$ to fit $\varepsilon_{r}$. This concept was basically the same as the concepts in the OW and OAK models, since by checking the determined parameters for the BS components in previously reviewed modeling approaches, it was found that some groups of $H_{i}$ and $C_{i}$ had very large values, which had a larger influence on simulated loop shapes, while some others had very small values, which controlled the simulated $\varepsilon_{r}^{\prime}$. Therefore, it is possible to eliminate some BS components, leaving only three components as in [24] to simulate ratcheting behavior.

The above reviewed modeling approaches lead to the conclusion that the dynamic recovery terms play a vital role in the simulation of ratcheting of various materials. Abdel-Karim [66] reviewed a variety of modeling approaches and proposed several more equations of BSs, in which the only differences were found in the terms of dynamic recovery. In the current work, the simulation ability of several approaches is checked. If the already existing models are not suitable for simulating material responses of $\mathrm{P} 91$ at room temperature and $550{ }^{\circ} \mathrm{C}$ under multiple loading conditions, they should be further modified.

\subsection{Advantage of Ferritic-Martensitic (FM) Steel}

Ferritic-Martensitic steels include those ferritic steels with a martensite microstructure. The nominal compositions of a group of commercial and experimental FM steels are listed in Table 2.2. 


\begin{tabular}{|c|c|c|c|c|c|c|c|c|c|c|c|c|}
\hline Steel & $\mathrm{C}$ & $\bar{S}$ & $\mathrm{Mn}$ & $\mathrm{Cr}$ & $\overline{\mathrm{Ni}}$ & Mo & $\mathrm{W}$ & $\bar{V}$ & $\mathrm{Nb}$ & $\mathrm{B}$ & $\mathrm{N}$ & Other \\
\hline 9Cr-1Mo (T9) & 0.12 & 0.6 & 0.45 & 9 & 0.2 & 1 & & & & & & \\
\hline Mod 9Cr-1Mo (T/P 91) & 0.1 & 0.4 & 0.4 & 9 & 0.1 & 1 & & 0.2 & 0.08 & & 0.05 & \\
\hline E911 & 0.11 & 0.4 & 0.4 & 9 & 0.2 & 1 & 1 & 0.2 & 0.08 & & 0.07 & \\
\hline NF616 (T/P 92) & 0.07 & 0.06 & 0.45 & 9 & 0.25 & 0.5 & 1.8 & 0.2 & 0.05 & 0.004 & 0.06 & \\
\hline $\mathrm{F} 82 \mathrm{H}$ & 0.1 & 0.2 & 0.5 & 8 & & & 2 & 0.2 & & 0.003 & & $0.04 \mathrm{Ta}$ \\
\hline EUROFER & 0.11 & 0.05 & 0.5 & 8.5 & & & 1 & 0.25 & & 0.005 & & $0.08 \mathrm{Ta}$ \\
\hline ORNL 9Cr-2WVTa & 0.1 & 0.3 & 0.4 & 9 & & & 2 & 0.25 & & & 0.025 & $0.07 \mathrm{Ta}$ \\
\hline 12Cr-1MoWV (HT9) & 0.2 & 0.4 & 0.6 & 12 & 0.5 & 1 & 0.5 & 0.25 & & & & \\
\hline HCM12A (T122) & 0.11 & 0.1 & 0.6 & 12 & 0.3 & 0.4 & 2 & 0.25 & 0.05 & 0.003 & 0.06 & $1.0 \mathrm{Cu}$ \\
\hline CLAM & 0.10 & $<0.002$ & 0.45 & 9.0 & & & 1.5 & 0.2 & & & $<0.02$ & $0.15 \mathrm{Ta}$ \\
\hline INRAFM & $0.09-0.12$ & $<0.002$ & $0.4-0.6$ & $8.8-9.2$ & $<0.005$ & $<0.002$ & $1.3-1.5$ & $0.2-0.24$ & $<0.001$ & $<0.001$ & $0.02-0.04$ & $0.06-0.08 \mathrm{Ta}$ \\
\hline
\end{tabular}

Table 2.2 Nominal compositions of commercial and experimental FM steels [67-70]

Among the FM steels listed in Table 2.2, two of them belong to a more specific group, namely Grade 91 FM steels, including T9 and T/P91, where "9" indicates 9\% Cr and " 1 " indicate $1 \%$ Mo. T9 is standard $9 \mathrm{Cr}-1 \mathrm{Mo}$ steel and T/P91 is modified $9 \mathrm{Cr}-1 \mathrm{Mo}$ steel. EUROFER belongs to the so-called reduced activation ferritic-martensitic (RAFM) steel because the $1 \%$ Mo is replaced by $1 \% \mathrm{~W}$, which has a shorter half decay period. The other typical alloying elements, $\mathrm{Nb}, \mathrm{Ni}, \mathrm{Cu}$, and $\mathrm{N}$, also need to be eliminated or minimized in RAFM [67, 71, 72].

HT9 and T122 lie on the boundary between ferritic-martensitic steel and ferritic steel. The other FM steels in Table 2.2 have 8 9\% Cr but the percentages of Mo and $\mathrm{W}$ are different from those of Grade $91 \mathrm{FM}$ steel. CLAM is China Low Activation Martensitic steel [69] and INRAFM is Indian Reduced Activation Ferritic Martensitic steel $[68,70]$.

The material under investigation in the current work is P91, which belongs to mod. 9Cr-1Mo FM steel and further belongs to Grade $91 \mathrm{FM}$ steel. Hence, more attention is paid to research on these types of steel.

Comparing to austenitic steels, such as types 316 and 304 stainless steel, FM steel has a lower thermal expansion coefficient and excellent irradiation resistance to void swelling [67, 73], owing to the non-compact crystal structure of ferrite. Void swelling limits the use of austenitic steels for fuel cladding and other in-core applications [67].

In high-temperature applications, Grade 91 FM steel can result in substantial reductions in component thickness compared to weaker alloys, such as Grade 22. The frequent startups, shutdowns, and load changes imposed by cycling duty lead to thermal fatigue, with the biggest challenges to the heat-recovery steam generator. By using higher-strength materials, such as Grade 91 FM steel, pressure-containing components can be made in thinner sections, which have smaller temperature gradient across the wall thickness and require less time to reach thermal equilibrium. This is an effective way to fight thermal fatigue [74].

The development of Grade 91 FM steel began in 1978 at Oak Ridge National Laboratories for the breeder reactor and was further developed by other researchers [75]. P/T-91 steels ("P91" for piping and "T91" for tubing) are modified Grade 91 
steels with small additions of niobium $(\mathrm{Nb})$, vanadium $(\mathrm{V})$ and nitrogen $(\mathrm{N})$ to give improved long-term creep properties [76].

An upgrade from the traditional P22 alloy to P91 can [74]:

- Reduce wall thickness by nearly two-thirds and component weight by $60 \%$.

- Raise allowable strength in the $510 \sim 593{ }^{\circ} \mathrm{C}$ range by up to $150 \%$.

- Raise the oxidation limit by $55^{\circ} \mathrm{C}$, enabling a lower corrosion allowance.

- Increase thermal-fatigue life by a factor of 10 to 12 .

Modified Grade 91 FM steels are specifically intended for high-integrity structural service at elevated temperature, usually $500{ }^{\circ} \mathrm{C}$ or higher. These steels are now widely used for components such as headers, main steam piping, and turbine casings in fossil fueled power generating plants [76].

\subsection{Microstructure of FM Steel}

The superior properties of FM steel mentioned in the previous section have been attributed to a tempered martensitic microstructure consisting of dispersed carbide particles and a tangled dislocation substructure [77, 78]. As reported in [79] and [80] about mod. $9 \mathrm{Cr}-1 \mathrm{Mo}$ steel, the precipitates on prior austenite grain boundaries (PAGB) and lath boundaries were identified as $\mathrm{M}_{23} \mathrm{C}_{6}$ type carbides ( $\mathrm{M}$ is $\mathrm{Cr}, \mathrm{Fe}, \mathrm{Mo}$ ) whereas the precipitates inside the laths were identified as MX type carbides ( $\mathrm{M}$ was $\mathrm{V}, \mathrm{Nb}$ and $\mathrm{X}$ was carbon and nitrogen).

The excellent properties of FM steel depend entirely on the creation of a precise microstructure by heat treatment, and on the preservation of this microstructure throughout its service life. Failure to obtain this precise microstructure in production can seriously degrade the alloy's high-temperature properties. This is different from traditional carbon and low-alloy steels such as Grade 11 and 22 (operating at the low stresses typical of power applications), which are less sensitive to microstructure change [74].

Heat treatment of the Cr-Mo and Cr-W FM steels is crucial to induce the required microstructure [74]. These steels are firstly normalized, then air-cooled, and tempered afterwards [67]. Detailed heat treatment of, for example, mod. $9 \mathrm{Cr}-1 \mathrm{Mo}$ steel is as follows: the alloy is firstly heated above its upper critical transformation temperature $\left(\mathrm{AC}_{3}\right.$ line) for $0.5 \sim 1$ hour until it is fully austenitic. Then, the steel is cooled in air below $200{ }^{\circ} \mathrm{C}$ for the full transformation of austenite into untempered martensite, which is very strong but brittle [74, 77]. The material is then tempered at around $760{ }^{\circ} \mathrm{C}$ to improve ductility and toughness and to induce the formation of critical carbide and carbo-nitride precipitates [79]. However, over-tempered mod. $9 \mathrm{Cr}-1 \mathrm{Mo}$ steel can have a substantially higher creep rate at temperature of $560{ }^{\circ} \mathrm{C}$ and a much lower hardness value ( $<180$ on the Vickers Hardness scale or HV, instead of the expected 200+ HV). In addition to incorrect heat treatment, any action that alters the precise microstructure of the steel, such as hot bending, forging, and welding which regularly occurs during component fabrication and plant construction, can lead to failure to achieve superior high-temperature properties [74]. 
On the other hand, microstructure stability during the whole service life has the same importance as the precise microstructure achievement during production. The fracture toughness of many power plant steels deteriorates during service at elevated temperatures owing to evolution of carbides and intermetallic phases and segregation of tramp elements (e.g. P, As, Sn) to PAGB [80]. It was also reported in [81] that standard $9 \mathrm{Cr}-1 \mathrm{Mo}$ steel was susceptible to temper embrittlement.

The differences between microstructures of standard and modified $9 \mathrm{Cr}-1 \mathrm{Mo}$ steel are discussed next: The sequence of carbide precipitation processes in mod. $9 \mathrm{Cr}-1 \mathrm{Mo}$ steel is consistent with those for the standard composition. However, the replacement of $\mathrm{Cr}_{2} \mathrm{C}$ in the modified alloy during tempering by arrays of fine vanadium carbide particles along the lath interfaces leads to a significant improvement in microstructural stability at temperature up to $650{ }^{\circ} \mathrm{C}$, even under static tensile and creep conditions. As a result, the lath morphology in the modified alloy remains intact for long periods at temperatures up to $650{ }^{\circ} \mathrm{C}$ owing to the interfacial pinning by vanadium carbide precipitates, which coarsen very slowly [77]. The average prior austenite grain size (PAGS) of modified alloy is $20 \mu \mathrm{m}$, which is smaller than that of standard alloy $(\sim 40 \mu \mathrm{m})$. This is attributed to the presence of un-dissolved carbides along the austenite grain boundaries during normalization treatment, which inhibits the growth of austenite grains [80].

It was reported that the lath structure was retained, at least in certain regions, even after $10000 \mathrm{~h}$ of aging at elevated temperatures. Although carbides in mod. $9 \mathrm{Cr}-1 \mathrm{Mo}$ steel grew with aging time and temperature, the coarsening of $\mathrm{V}(\mathrm{Nb})$ carbides was negligible compared to $\mathrm{M}_{23} \mathrm{C}_{6}$ carbides [80]. In the current work, all experiments were done either at room temperature or supposedly for no more than 100 hours at $550{ }^{\circ} \mathrm{C}$, which is a much shorter time than that of aging tests (e.g., >5000 hours reported in [80]). Hence, the change of microstructure owing to aging is negligible for experiments in the current work.

Another concern with FM steel is the oxidation during experiments at elevated temperatures. However, according to [82-84], oxidation occurs only at the surface. It was reported that the oxide layer would assist crack initiation and propagation for specimens tested under compressive hold [82]. A detailed investigation was carried out on the oxidation of mod. $9 \mathrm{Cr}-1 \mathrm{Mo}$ steel at $550{ }^{\circ} \mathrm{C}$ : The thickest oxide layer on the surface was found to be $20 \mu \mathrm{m}$ for a high strain range creep-fatigue experiment with a fatigue strain range of $0.7 \%$ and a creep range $0.5 \%$. In other experiments, such as pure fatigue and low strain range creep-fatigue tests, the oxide layers were only 2-3 $\mu \mathrm{m}$ thick. In static oxidation tests, an extreme case was that the oxide thickness was merely $2.80 \mu \mathrm{m}$ after 36 days of oxidation at $550{ }^{\circ} \mathrm{C}$ [84]. Since the specimens in the current work are $8.8 \mathrm{~mm}$ in diameter, which is much larger than the possible thickness of oxide layer, the oxidation is not taken into account.

The microstructural evolution of FM steel during ratcheting is rarely reported in the literature. The only report was about the microstructure of steel $\mathrm{X} 12 \mathrm{CrMoWVNbN10-1-1}$ after stress-controlled creep-fatigue loadings at $600{ }^{\circ} \mathrm{C}$. The collapse of martensitic laths after the ratcheting tests was observed. It was found that such collapse of laths gradually disappeared with decreasing grade of unloading [27, 85]. 
Such collapse of laths was not reported for FM steel in creep tests or without loading [77, 80, 86-88]. However, in strain-controlled LCF tests, a similar disappearance of martensitic laths was observed in high-chromium martensitic GX12CrMoVNbN9-1 (GP91) cast steel at RT, $550{ }^{\circ} \mathrm{C}$, and $600{ }^{\circ} \mathrm{C}$. Such disappearance was suggested to be the dominant factor in the acceleration of fatigue softening of the material [89]. Another observation was on mod. 9Cr-1Mo steel in LCF tests, which mentioned the conversion of the initial heavily dislocated lath structure to equiaxed cells with low dislocation density and coarse carbides. This conversion was suggested to cause cyclic softening $[82,83,90]$. A detailed review of work on cyclic softening is given in the next section.

Therefore, according to these reports ([27, 82, 83, 85, 89, 90]) the collapse/disappearance/conversion of the martensitic lath structure is common under cyclic loading, either stress- or strain-controlled.

\subsection{Cyclic Softening of FM Steel and Corresponding}

\section{Modeling}

As mentioned in the previous sections, one of the main disadvantages of FM steel is cyclic softening, which was reported for various FM steels, such as $9 \mathrm{Cr}-1 \mathrm{Mo}$ steel [24, 73, 91-95], EUROFER [1, 96], F82H [97, 98], P92 [93], and HT-9 [99]. The reported causes of cyclic softening are decrease of dislocation density by cell structure formation [73], conversion of lath structure to equiaxed cells [82, 83, 90, 92, 99], disappearance of lath [89], annihilation of low angle boundary [91], coarsening of laths and subgrains [73, 94], and coarsening of precipitate [99].

In one of the earliest reports on cyclic softening of FM steel, the cause of cyclic softening was cited as rearrangement of dislocations previously introduced by the quenching. LCF tests were carried out on ferrite-pearlite steel AISI 420, FM steel MANET II, and RAFM steel F82H mod. No cyclic softening occurred on AISI 420 $\left(\mathrm{RT}-550{ }^{\circ} \mathrm{C}\right)$, but obvious cyclic softening occurred on MANET II $\left(150-550{ }^{\circ} \mathrm{C}\right)$ and F82H mod. (550 and $\left.650{ }^{\circ} \mathrm{C}\right)$ [100].

After comparing the LCF behaviors of P91 and P92 steels, it was found that the softening rate of $\mathrm{P9} 2$ steel increased with increase in strain amplitude whereas the softening rate of P91 remained constant with strain amplitude [93]. This indicates the modeling of cyclic softening for P91 can be suitable for a large range of strain amplitudes $\left(\varepsilon_{a}=0.25-0.60 \%\right.$ in [93]).

A typical LCF test on mod. 9Cr-1Mo FM steel is illustrated in a stress-strain diagram in [24], as shown in Fig. 2.10: The strain range kept constant but both peak tensile stress and peak compressive stress decreased as the number of cycles increased. It was suggested that the cyclic softening was the reason for the so-called "progressive 
deformation instability" in ratcheting tests [24], as shown in Fig. 2.3 and Fig. 2.4 in Section 2.1.

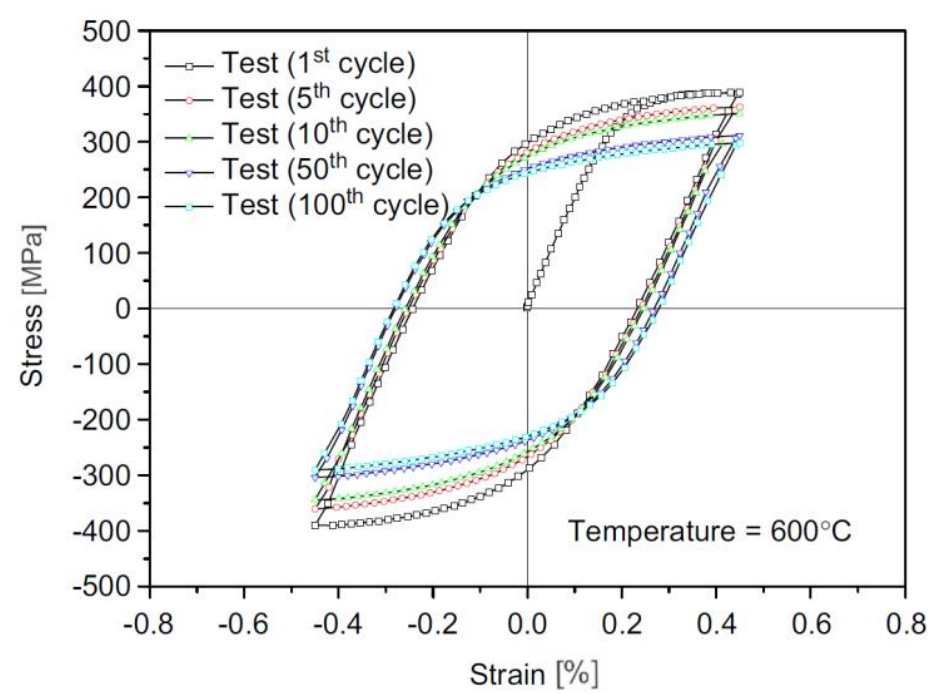

Fig. 2.10 Test results of the cyclic softening characteristics of mod. $9 \mathrm{Cr}-1 \mathrm{Mo}$ steel at $600{ }^{\circ} \mathrm{C}$ (strain-controlled) [24].

As mentioned in Section 2.2, the cyclic softening was taken into account in the simulation of the ratcheting behavior of the mod. $9 \mathrm{Cr}-1 \mathrm{Mo}$ steel at $550{ }^{\circ} \mathrm{C}$ in the YT model [7]. The cyclic softening behavior was expressed through variation of the asymptotic values of parameter $r_{i}$, which was given as:

$$
\begin{aligned}
& r_{i}=r_{i}^{0}-r_{i}^{s} \\
& \dot{r}_{i}^{s}=d\left(\bar{r}_{i}^{s}-r_{i}^{s}\right)^{q} \dot{p} \\
& \dot{\bar{r}}_{i}^{s}=\left\langle r_{0}-\bar{r}_{i}^{s}\right\rangle
\end{aligned}
$$

where $r_{i}^{0}, d, q$ and $h_{i}$ are material and temperature-dependent parameters. The value of $H_{i}$ decreased from the initial value of $r_{i}^{0}$ by subtracting $r_{i}^{S}$ which expressed the progress of the cyclic softening.

By recalculation using the YT model, the result is shown in Fig. 2.11: 


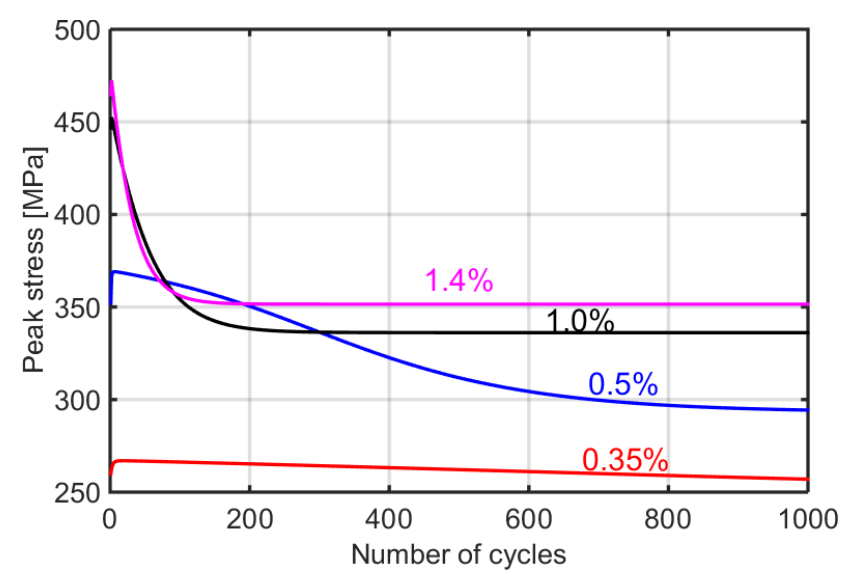

Fig. 2.11 Peak stress vs. number of cycles in Yaguchi-Takahashi model description for strain-controlled LCF tests performed with various strain amplitudes

It is clear that the simulated $\sigma_{\text {peak }}$ decreases with increasing cycle number and it reaches a saturation stage with negligible decrease. This is, however, different from the experimental results, such as those reported in [1], in which a saturation stage (stage 2) was reached after the initial fast decrease of $\sigma_{\text {peak }}$ (stage 1) but $\sigma_{\text {peak }}$ still decreased linearly with a constant slope until a macro crack appeared.

Another approach is to introduce an isotropic hardening factor $R$ into eq. (2-1) of the Chaboche model, as in eq. (2-26) [101]:

$$
\dot{\boldsymbol{\varepsilon}}^{i n}=\frac{3}{2}\left\langle\frac{\Sigma_{e q}-K-R}{Z}\right\rangle^{n} \frac{\Sigma}{\Sigma_{e q}}
$$

in which $R$ is the key to expressing the cyclic softening. The equation for $R$ is as follows:

$$
R=h p+Q\left(1-e^{-b p}\right)
$$

in which $h, Q$, and $b$ are material- and temperature-dependent parameters. The term $h p$ is the linear part of eq. (2-27), which simulates stage 2 of the cyclic softening. As shown in Fig. 2.12, $h$ indicates the slope of stage 2. The second term in eq. (2-27) represents stage 1 of the cyclic softening. $Q$ was estimated as the difference between point $\mathrm{X}$ and $\sigma_{\text {peak }}$ in the first cycle in Fig. 2.12 while parameter $b$ was the speed to reach $\sigma_{\text {peak }}$ at the end of stage 1 [101]. 


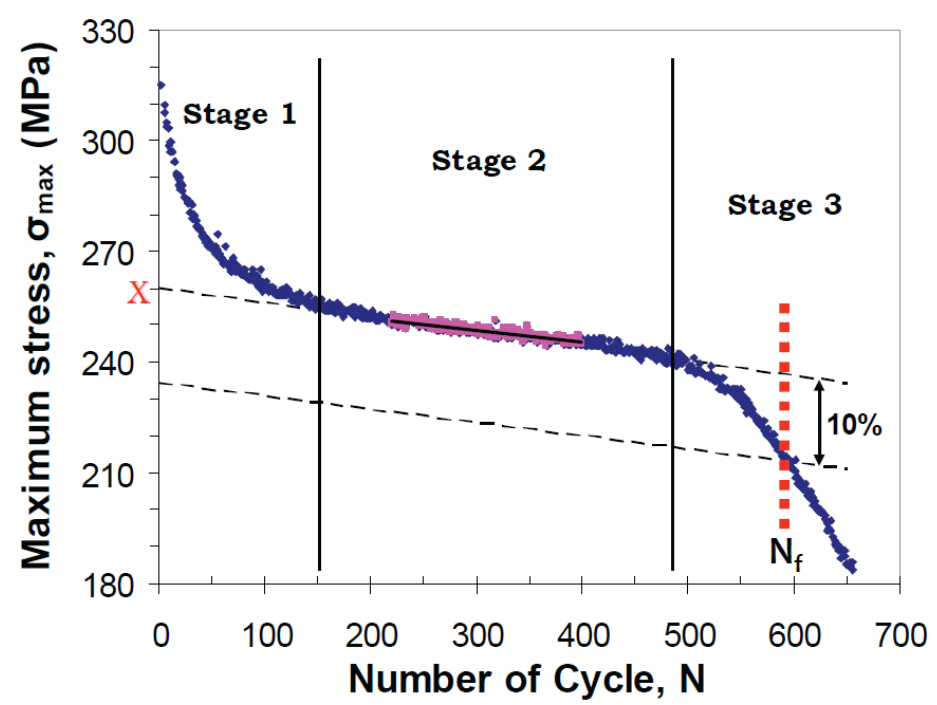

Fig. 2.12 The results of $P 91$ strain-controlled tests at $600^{\circ} \mathrm{C}$ [101].

Note that Fig. 2.12 illustrates how to define the number of cycle to failure, namely $N_{f}$. It is defined according to BS7270:2006 standard as the cycle during which $\sigma_{\text {peak }}$ has decreased by $10 \%$ from that predicted by extrapolation of the saturation curve (stage 2 ) [101].

The cyclic softening of RAFM steel, including F82H mod and EUROFER97, was evaluated with LCF tests and a constitutive model was built correspondingly [1]. This model proposed in [1] is referred to as the Aktaa-Schmitt (AS) model. In the current work, the influence of cyclic softening on ratcheting behavior is evaluated and the AS model is applied for the cyclic softening, since both EUROFER97 and P91 are Grade 91 FM steels.

The AS model follows the way of the Chaboche model with the AF rule as in eqs. (2-1)-(2-6). Eq. (2-2) was modified with a softening factor $\psi$ to describe cyclic softening (see eq. (2-28)). In eq. (2-31), the last term represents the static recovery of cyclic softening. Further, the AF rule (see eq. (2-6)) was applied with static recovery of kinematic hardening in the Aktaa-Schmitt model:

$$
\begin{aligned}
& \boldsymbol{\Sigma}=\frac{\boldsymbol{S}}{\psi}-\boldsymbol{\Omega}_{i} \\
& \psi=\psi_{1}+\psi_{2} \\
& \text { with } \psi_{1}(t=0)=0 \text { and } \psi_{2}(t=0)=1 \\
& \dot{\psi}_{1}=-h \dot{p} \\
& \dot{\psi}_{2}=c\left(\psi_{s}-\psi_{2}\right) \dot{p}-r_{\psi}\left|\psi_{2}-\psi_{r}\right|^{m_{\psi^{-1}}}\left(\psi_{2}-\psi_{r}\right) \\
& \psi_{s}=1-\psi_{s, \infty}\left(1-\exp \left(-c_{s-\infty<\tau<t} \max _{e q}^{i n}(\tau) \mid\right)\right)
\end{aligned}
$$




$$
\varepsilon_{e q}^{i n}(\tau)=\sqrt{\frac{2}{3} \varepsilon^{i n}(\tau): \varepsilon^{i n}(\tau)}
$$

The AS model was used to successfully simulate strain-controlled LCF tests on EUROFER97 at 450 and $550{ }^{\circ} \mathrm{C}$, as well as tests on $\mathrm{F} 82 \mathrm{H}$ mod at 450, 550 and $650{ }^{\circ} \mathrm{C}$ [1]. Note that the AS model assumes only one BS, instead of four, eight, or even 12 BS components used in other modeling approaches [3, 4, 6, 30]. Therefore, one BS is enough for modeling of material responses under strain-controlled loadings. 


\section{Material and Approach}

The current work is organized according to previous research reviewed in Chapter 2, especially on mod. $9 \mathrm{Cr}-1 \mathrm{Mo} \mathrm{FM}$ steels. The task is to investigate the ratcheting behavior of mod. $9 \mathrm{Cr}-1 \mathrm{Mo}$ steel (P91) at RT and $550{ }^{\circ} \mathrm{C}$.

Since no study on the ratcheting of mod. $9 \mathrm{Cr}-1 \mathrm{Mo}$ FM steel at RT has been reported, this shall be carried out in the current work. On the other hand, although there have been reports such as [7, 24-28] about the ratcheting of FM steel at high temperatures, only Yaguchi and Takahashi $[7,26]$ have reported about the ratcheting at $550{ }^{\circ} \mathrm{C}$. As mentioned in Section 2.1, some tests reported in [26] were still doubtful, since ratcheting tests performed with $\varepsilon_{\text {peak }}=400 \mathrm{MPa}$ contradict the ultimate tensile strength of $374 \mathrm{MPa}$ of $\mathrm{T} 91$ reported in SCK $\cdot \mathrm{CEN}$ [55], since both materials mentioned in [26] and [55] are mod. 9Cr-1Mo FM steel.

The tension-compression asymmetry reported in [7, 26] should also be double checked, since no other reports $[1,3,4,6,24-28,74,82,102]$ mentioned such an asymmetry of FM steel at high temperature. Furthermore, in the modeling approach in [7], the tension-compression asymmetry was expressed by a term of hydrostatic pressure to modify the yield stress, which is also in question, because steel is supposed to be a solid material hence no influence of hydrostatic stress exists, although there were debates about the influence of hydrostatic pressure, such as in Jung [103], Casey and Sullivan [104], and Drucker [105].

Before stress-controlled ratcheting tests, strain-controlled LCF tests are performed to evaluate the cyclic softening of the material because softening can accelerate ratcheting.

The process of the work in the current research is illustrated in Fig. 3.1. 


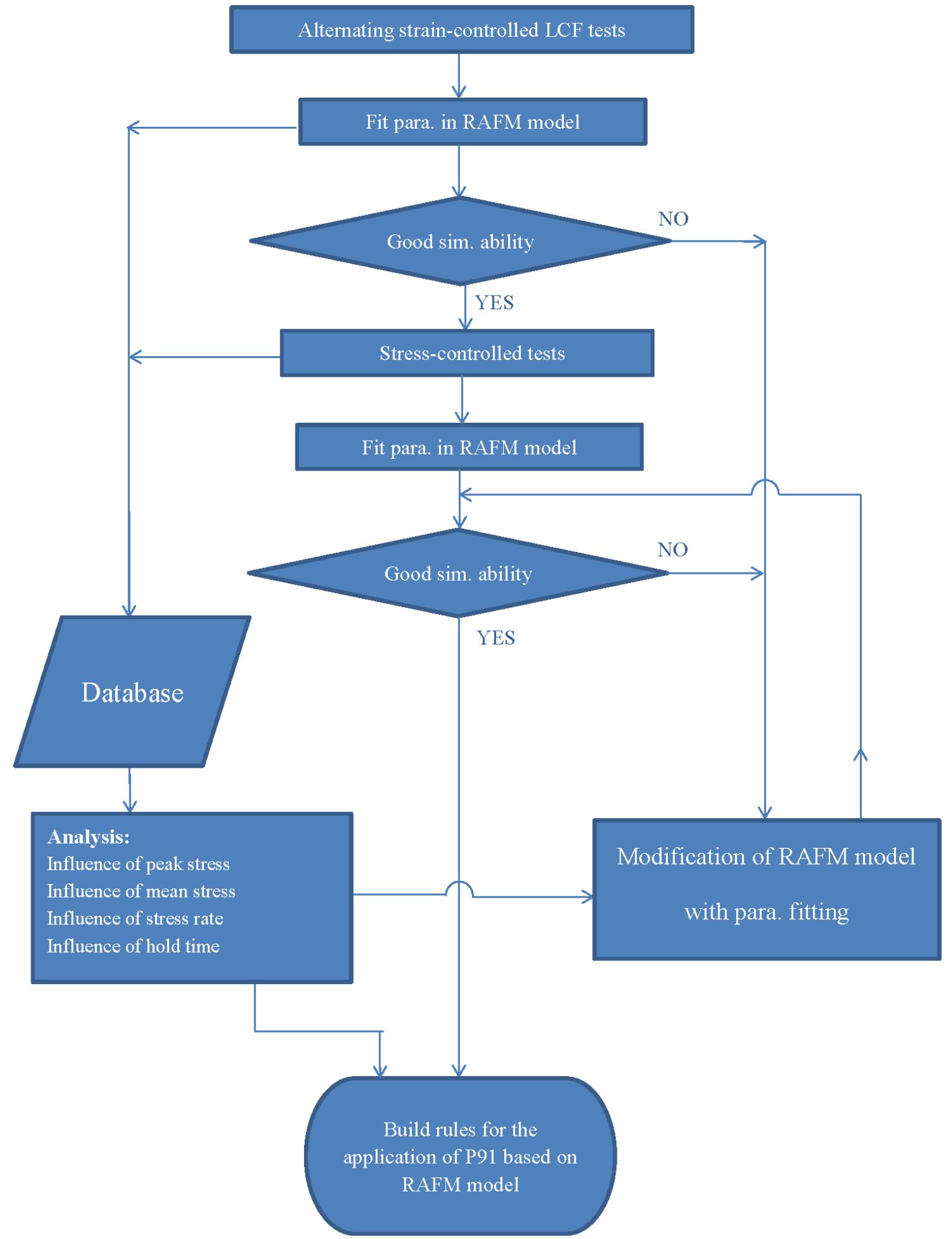

Fig. 3.1 Process of research on ratcheting behavior of $P 91$. 


\subsection{Specimens and Facilities}

The steel plate of P91 was provided by French Alternative Energies and Atomic Energy Commission (CEA) with the specification RM2432 of the RCC-MR code (1993 edition). The plate was austenitized at $1050{ }^{\circ} \mathrm{C}$ for $30 \mathrm{~min}$, quenched, and then tempered at $780{ }^{\circ} \mathrm{C}$ for $1 \mathrm{~h}$. Both austenitizing and tempering temperatures are 10 20 ${ }^{\circ} \mathrm{C}$ higher than those reported in [74] and [77].

The chemical compositions are listed in Table 3.1

\begin{tabular}{|c|c|c|c|c|c|c|c|c|c|c|}
\hline Elements & $\mathrm{C}$ & $\mathrm{Cr}$ & $\mathrm{Mo}$ & $\mathrm{Mn}$ & $\mathrm{Si}$ & $\mathrm{V}$ & $\mathrm{Ni}$ & $\mathrm{Nb}$ & $\mathrm{Cu}$ & $\mathrm{N}_{2}$ \\
\hline \% Mass & 0.086 & 8.910 & 0.917 & 0.363 & 0.324 & 0.198 & 0.149 & 0.08 & 0.068 & 0.041 \\
\hline
\end{tabular}

\begin{tabular}{|c|c|c|c|c|c|c|c|c|c|c|}
\hline Elements & $\mathrm{Al}$ & $\mathrm{P}$ & $\mathrm{As}$ & $\mathrm{W}$ & $\mathrm{Sn}$ & $\mathrm{Ti}$ & $\mathrm{O}_{2}$ & $\mathrm{~S}$ & $\mathrm{~B}$ & $\mathrm{Zr}$ \\
\hline \% Mass & 0.018 & 0.017 & 0.012 & 0.01 & 0.005 & 0.002 & 0.002 & 0.001 & 0.001 & 0.001 \\
\hline
\end{tabular}

Table 3.1 Chemical compositions of P91

The specimens were fabricated from a steel plate with a thickness of $30 \mathrm{~mm}$. The fabrication was carried out in three steps. First, raw samples with diameter of $16 \mathrm{~mm}$ and length of $80 \mathrm{~mm}$ were cut from one plate by wire EDM (electrical discharge machining) technique. Afterwards, the specimens were produced by turning to an entire length of $77 \mathrm{~mm}$ (gauge length is $23 \mathrm{~mm}$ ) with a nominal diameter of 8.8 $\mathrm{mm}$. Finally, the surface was radially polished to remove the turning grooves. Fig. 3.2 shows a technical drawing of the P91 specimens with a photo of a real one.

The experiments were performed on a SCHENCK hydraulic testing machine controlled by Instron 8800 . The controlling programs were written in DASYLab with graphic programming language. Strain/stress ranges and rates were used as input test parameters for the DASYLab program. 

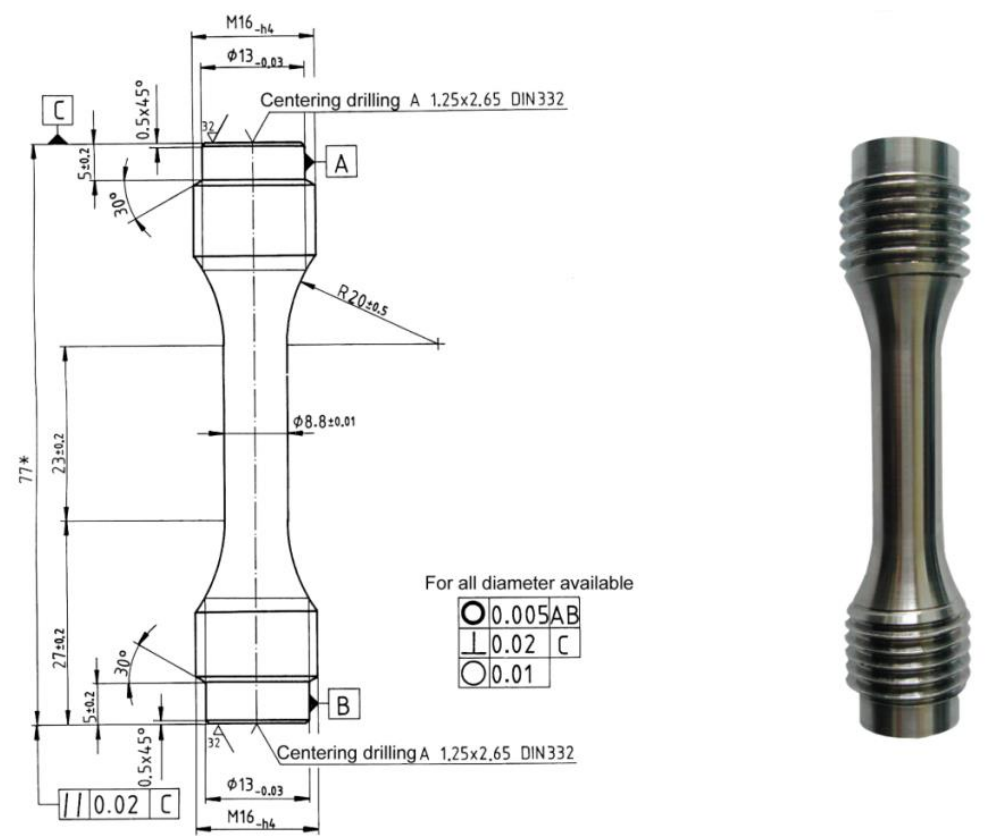

Fig. 3.2 Technical drawing of P91 specimen together with a real photo.

\subsection{Experimental Planning for Testing at Room}

\section{Temperature}

\subsubsection{Strain-controlled Tests at RT}

A tensile test with strain rate $1 \times 10^{-4} / \mathrm{s}$ was performed at the very beginning. The material at RT has an ultimate tensile strength $666.8 \mathrm{MPa}$ with a uniform elongation of $9.7 \%$. Yield strength with an offset of $0.2 \%$ was found to be $481.8 \mathrm{MPa}$.

There are two stages of experiments at the same temperature. The first stage includes alternating strain-controlled LCF tests to evaluate the cyclic softening of P91. As listed in Table 3.2, the strain range is $0.6-1.5 \%$ with a strain rate of $\pm 3 \times 10^{-4} / \mathrm{s}$. Data points are recorded every 0.02 second, hence at least 2000 data points are sampled in one cycle, which is quite enough to represent the material responses. The results of the strain-controlled tests at RT are presented in Section 4.1. 


\begin{tabular}{|c|c|}
\hline Strain range $\Delta \varepsilon(\%)$ & Strain rate \\
\hline 0.6 & \\
\hline 0.8 & \\
\hline 1.0 & $\pm 3 \times 10^{-4} / \mathrm{s}$ \\
\hline 1.2 & \\
\hline 1.5 & \\
\hline
\end{tabular}

Table 3.2 Symmetric alternating strain-controlled LCF tests at RT

\subsubsection{Stress-controlled Tests at RT}

After the strain-controlled LCF tests, the Young's modulus and yield strength were determined, with which the stress ranges in the following stress-controlled tests were roughly determined. The chosen stress should at least induce a measurable inelastic strain since no ratcheting exists with only elastic deformation. On the other hand, the imposed stress should be not too high. At RT, the peak tensile stress applied on the specimen was limited to $550 \mathrm{MPa}$ where the corresponding total strain is around $1 \%$.

Owing to a large difference between $\sigma_{\text {eng }}$ and $\sigma_{\text {true }}$ with high deformation, the recorded data mix both material response and influence of structure. For instance, when engineering stress $\sigma_{\text {eng }}=550 \mathrm{MPa}$ and $\varepsilon=5 \%$, the corresponding true stress $\sigma_{\text {true }}=577.5 \mathrm{MPa}$. Therefore, the real time deformation is taken to modify the signal, which controls the loading on specimen, to adapt the reduced cross section of specimen with high strain. In the following analytical modeling process, pure material responses are required to compare with model description. Hence, all stress-controlled tests listed in Table 3.3 are true-stress-controlled, instead of engineering-stresscontrolled.

The schema for true-stress controlling is illustrated in Fig. 3.3. In the controlling software DASYLab, there is a module called "signal generator" that can generate a signal in triangle wave. The real-time deformation is measured by the extensometer and transformed to the real-time total strain through the module of the data processor. When the signal generator is supposed to generate a loading of, for example, $500 \mathrm{MPa}$ and the real time total strain is $\varepsilon=1 \%$, the output of the signal generator is $500 / 1.01$ $=495 \mathrm{MPa}$. Consequently, the current engineering stress is $\sigma_{e n g}=495 \mathrm{MPa}$, but $\sigma_{\text {true }}=500 \mathrm{MPa}$, according to eq. (3-1):

$$
\sigma_{\text {true }}=\sigma_{\text {eng }}(\varepsilon+1)
$$

The true-stress controlling is based on the von Mises criterion with no volumetric plastic strain. 


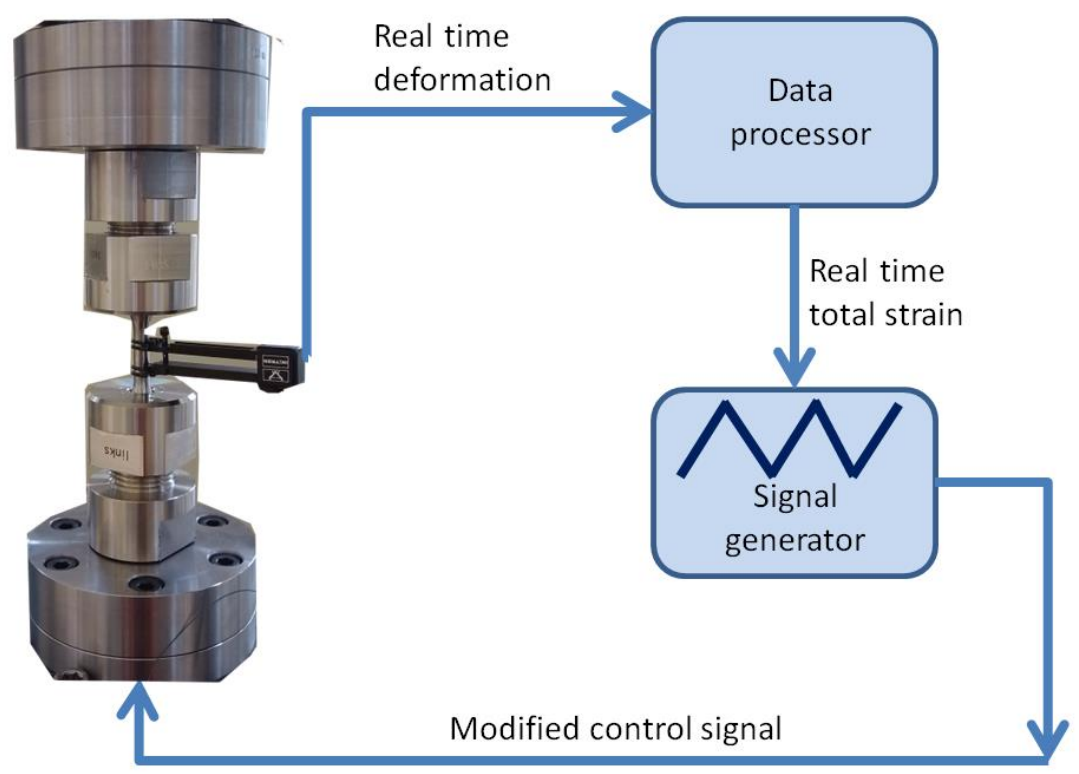

Fig. 3.3 Schema of true stress controlling

Several groups of experiments are planned to explore the influences of main factors to ratcheting, as listed in Table 3.3. The results of the stress-controlled tests at RT are presented in Section 4.2. 
a) Influence of peak stress

\begin{tabular}{|c|c|c|c|c|c|c|c|c|}
\hline$\sigma_{\max }[\mathrm{MPa}]$ & 550 & 520 & 500 & 480 & 460 & 450 & 430 & 400 \\
\hline$\sigma_{\min }[\mathrm{MPa}]$ & -500 & -470 & -450 & -430 & -410 & -400 & -380 & -350 \\
\hline Stress ratio & -0.909 & -0.904 & -0.9 & -0.896 & -0.891 & -0.889 & -0.884 & -0.875 \\
\hline$\sigma_{\text {mean }}[\mathrm{MPa}]$ & \multicolumn{8}{|c|}{25} \\
\hline$\dot{\sigma}[\mathrm{MPa} / \mathrm{s}]$ & \multicolumn{8}{|c|}{ \pm 50} \\
\hline
\end{tabular}

b) Influence of mean stress/stress ratio

\begin{tabular}{|c|c|c|c|c|c|c|c|c|c|c|c|}
\hline$\sigma_{\max }[\mathrm{MPa}]$ & \multicolumn{10}{|c|}{500} \\
\hline$\sigma_{\text {min }}[\mathrm{MPa}]$ & 0 & -300 & -400 & -430 & -440 & -450 & -460 & -480 & -500 & -510 & -550 \\
\hline Stress ratio & 0.00 & -0.6 & -0.8 & -0.86 & -0.88 & -0.9 & -0.92 & -0.96 & -1.0 & -1.02 & -1.1 \\
\hline$\sigma_{\text {mean }}[\mathrm{MPa}]$ & 250 & 100 & 50 & 35 & 30 & 25 & 20 & 10 & 0 & -5 & -25 \\
\hline$\dot{\sigma}[\mathrm{MPa} / \mathrm{s}]$ & \multicolumn{10}{|c|}{ \pm 50} \\
\hline
\end{tabular}

c) Ratcheting with zero mean stress

\begin{tabular}{|c|c|c|c|c|c|}
\hline$\sigma_{\max }[\mathrm{MPa}]$ & 550 & 520 & 500 & 480 & 450 \\
\hline$\sigma_{\min }[\mathrm{MPa}]$ & -550 & -520 & -500 & -480 & -450 \\
\hline Stress ratio & \multicolumn{5}{|c|}{0} \\
\hline$\sigma_{\text {mean }}[\mathrm{MPa}]$ & \multicolumn{5}{|c|}{ \pm 50} \\
\hline$\dot{\sigma}[\mathrm{MPa} / \mathrm{s}]$ & \multicolumn{5}{|c}{} \\
\hline
\end{tabular}

d) Influence of stress rate

\begin{tabular}{|c|c|c|c|}
\hline$\sigma_{\max }[\mathrm{MPa}]$ & \multicolumn{3}{|c|}{500} \\
\hline$\sigma_{\min }[\mathrm{MPa}]$ & & -450 & \\
\hline$\dot{\sigma}[\mathrm{MPa} / \mathrm{s}]$ & \pm 10 & \pm 50 & \pm 250 \\
\hline
\end{tabular}

e) Influence of hold time

\begin{tabular}{|c|c|}
\hline$\sigma_{\max }[\mathrm{MPa}]$ & 500 \\
\hline$\sigma_{\min }[\mathrm{MPa}]$ & -450 \\
\hline$\dot{\sigma}[\mathrm{MPa} / \mathrm{s}]$ & \pm 50 \\
\hline Hold $10 \mathrm{~min}$ at peak & Compression \\
\hline
\end{tabular}

Table 3.3 Stress-controlled uniaxial tests at RT

\subsection{Experiment Planning for Testing at $550{ }^{\circ} \mathrm{C}$}

\subsubsection{Strain-controlled Tests at $550{ }^{\circ} \mathrm{C}$}

A tensile test with strain rate $1 \times 10^{-4} / \mathrm{s}$ was performed at the very beginning. The material at $550{ }^{\circ} \mathrm{C}$ was found to have an ultimate tensile strength $386.1 \mathrm{MPa}$ with uniform elongation of $1.6 \%$. Yield strength with an offset of $0.2 \%$ is $353.7 \mathrm{MPa}$.

At $550{ }^{\circ} \mathrm{C}$, similar uniaxial symmetric strain-controlled LCF tests are carried out on P91. The five tests with total strain ranging $\Delta \varepsilon=0.6-1.5 \%$ are listed in Table 3.4. 
The strain rates are $\pm 3 \times 10^{-4} / \mathrm{s}$ and the sampling interval is 0.02 seconds. The results of the strain-controlled tests at $550{ }^{\circ} \mathrm{C}$ are presented in Section 5.1.

\begin{tabular}{|c|c|}
\hline Strain range $\Delta \varepsilon(\%)$ & Strain rate \\
\hline 0.6 & \\
\hline 0.8 & \\
\hline 1.0 & \\
\hline 1.2 & \\
\hline 1.5 & \\
\hline
\end{tabular}

Table 3.4 Symmetric alternating strain-controlled LCF tests at $550{ }^{\circ} \mathrm{C}$

\subsubsection{Stress-controlled Tests at $550{ }^{\circ} \mathrm{C}$}

The high-temperature stress-controlled tests on P91 are essentially the same as those at RT; the only difference is the lower imposed stresses owing to reduced strength at high temperature. The maximum stress in the following cyclic tests is limited to 350 $\mathrm{MPa}$, which is approximately equal the yield strength at $0.2 \%$ offset at $550{ }^{\circ} \mathrm{C}$.

The planned ratcheting tests at $550{ }^{\circ} \mathrm{C}$ are listed in Table 3.5. Creep tests are performed (see Table 3.6) to compare with the ratcheting tests with hold times (see Table 3.5e). The results of stress-controlled tests at $550{ }^{\circ} \mathrm{C}$ are presented in Section 5.2.

Note that the high-temperature stress-controlled tests are also true-stress-controlled, as with the RT tests, by modifying the output signal with real-time deformation, as discussed in Section 3.2.2. 
a) Influence of peak stress

\begin{tabular}{|c|c|c|c|c|c|c|}
\hline$\sigma_{\text {max }}[\mathrm{MPa}]$ & 350 & 335 & 325 & 315 & 300 & 275 \\
\hline$\sigma_{\min }[\mathrm{MPa}]$ & -300 & -285 & -275 & -265 & -250 & -225 \\
\hline Stress ratio & -0.86 & -0.85 & -0.85 & -0.84 & -0.83 & -0.82 \\
\hline$\sigma_{\text {mean }}[\mathrm{MPa}]$ & \multicolumn{6}{|c|}{25} \\
\hline$\dot{\sigma}[\mathrm{MPa} / \mathrm{s}]$ & \multicolumn{6}{|c|}{ \pm 50} \\
\hline
\end{tabular}

b) Influence of mean stress/stress ratio

\begin{tabular}{|c|c|c|c|c|c|c|c|c|}
\hline$\sigma_{\text {max }}[\mathrm{MPa}]$ & 325 & 325 & 325 & 325 & 325 & 325 & 325 & 325 \\
\hline$\sigma_{\text {min }}[\mathrm{MPa}]$ & 0 & -125 & -175 & -225 & -250 & -260 & -275 & -285 \\
\hline Stress ratio & 0 & -0.39 & -0.54 & -0.69 & -0.77 & -0.80 & -0.85 & -0.88 \\
\hline$\sigma_{\text {mean }}[\mathrm{MPa}]$ & 162.5 & 100 & 75 & 50 & 37.5 & 32.5 & 25 & 15 \\
\hline$\dot{\sigma}[\mathrm{MPa} / \mathrm{s}]$ & \multicolumn{8}{|c|}{ \pm 50} \\
\hline
\end{tabular}

\begin{tabular}{|c|c|c|c|c|c|c|c|c|}
\hline$\sigma_{\max }[\mathrm{MPa}]$ & 325 & 325 & 325 & 325 & 325 & 325 & 325 & 325 \\
\hline$\sigma_{\min }[\mathrm{MPa}]$ & -295 & -300 & -305 & -310 & -315 & -320 & -330 & -335 \\
\hline Stress ratio & -0.91 & -0.92 & -0.94 & -0.95 & -0.97 & -0.98 & -1.02 & -1.03 \\
\hline$\sigma_{\text {mean }}[\mathrm{MPa}]$ & 15 & 12.5 & 10 & 7.5 & 5 & 2.5 & -2.5 & -5 \\
\hline$\dot{\sigma}[\mathrm{MPa} / \mathrm{s}]$ & \multicolumn{7}{|c|}{ \pm 50} \\
\hline
\end{tabular}

c) Ratcheting with zero mean stress

\begin{tabular}{|c|c|c|c|c|}
\hline$\sigma_{\text {max }}[\mathrm{MPa}]$ & 350 & 340 & 325 & 315 \\
\hline$\sigma_{\min }[\mathrm{MPa}]$ & -350 & -340 & -325 & -315 \\
\hline Stress ratio & -1 & -1 & -1 & -1 \\
\hline$\sigma_{\text {mean }}[\mathrm{MPa}]$ & \multicolumn{5}{|c|}{0} \\
\hline$\dot{\sigma}[\mathrm{MPa} / \mathrm{s}]$ & \multicolumn{5}{|c|}{ \pm 50} \\
\hline
\end{tabular}

d) Influence of stress rate

\begin{tabular}{|c|c|c|c|}
\hline$\sigma_{\max }[\mathrm{MPa}]$ & \multicolumn{3}{|c|}{325} \\
\hline$\sigma_{\min }[\mathrm{MPa}]$ & \multicolumn{3}{|c|}{-310} \\
\hline Stress ratio & \multicolumn{3}{|c|}{-0.95} \\
\hline$\sigma_{\text {mean }}[\mathrm{MPa}]$ & \multicolumn{3}{|c|}{7.5} \\
\hline$\dot{\sigma}[\mathrm{MPa} / \mathrm{s}]$ & \pm 10 & \pm 50 & \pm 250 \\
\hline
\end{tabular}

e) Influence of hold time

\begin{tabular}{|c|c|c|c|}
\hline$\sigma_{\max }[\mathrm{MPa}]$ & \multicolumn{3}{|c|}{325} \\
\hline$\sigma_{\min }[\mathrm{MPa}]$ & \multicolumn{3}{|c|}{-310} \\
\hline Stress ratio & \multicolumn{3}{|c|}{-0.95} \\
\hline$\sigma_{\text {mean }}[\mathrm{MPa}]$ & \multicolumn{3}{|c|}{7.5} \\
\hline$\dot{\sigma}[\mathrm{MPa} / \mathrm{s}]$ & \multicolumn{3}{|c|}{ \pm 50} \\
\hline Hold time at ten. peak[min] & 5 & 0.5 & 0 \\
\hline Hold time at comp. peak[min] & 0 & 0 & 5 \\
\hline
\end{tabular}

Table 3.5 Stress-controlled uniaxial tests at $550{ }^{\circ} \mathrm{C}$ 


\begin{tabular}{|c|c|c|c|c|c|}
\hline Stress (MPa) & 325 & 325 & -310 & 275 & 200 \\
\hline Control type & $\begin{array}{c}\text { Engineering } \\
\text {-stress } \\
\text { controlled }\end{array}$ & $\begin{array}{c}\text { True-stress } \\
\text { controlled }\end{array}$ & $\begin{array}{c}\text { True-stress } \\
\text { controlled }\end{array}$ & $\begin{array}{c}\text { True-stress } \\
\text { controlled }\end{array}$ & $\begin{array}{c}\text { True-stress } \\
\text { controlled }\end{array}$ \\
\hline
\end{tabular}

Table 3.6 Creep tests at $550{ }^{\circ} \mathrm{C}$ 


\section{Experiments at Room Temperature}

In this chapter, the results of the experiments performed at room temperature are reported. In Section 4.1, the experimental results from the strain-controlled LCF tests are illustrated. In Section 4.2, the results of the stress-controlled tests are presented in sub-sections according to various influencing factors.

\subsection{Results of Strain-controlled Tests}

In the first stage of experiments, alternating strain-controlled LCF tests were carried out. Fig. 4.1 illustrates one of the tests performed with a strain range of $\Delta \varepsilon=1.5 \%$. Since the strain is in a triangle wave, the magnitude of the strain rate is constant, as shown in Fig. 4.1a. The stress is yielded as a consequence (see Fig. 4.1b). The strain rate is chosen to be $\pm 3 \times 10^{-4} / \mathrm{s}$, hence the yielded stress has a stress rate of around $\pm 50 \mathrm{MPa} / \mathrm{s}$ in the elastic region, compared to $\pm 50 \mathrm{MPa} / \mathrm{s}$ as the chosen $\dot{\sigma}$ in the following stress-controlled tests in the second stage of the RT experiments.

The experiment was ended after a macro crack was observed with which a kink on the compressive half of hysteresis loop appears, as shown in Fig. 4.1c. The appearance of this kink is owing to closing of a macro crack: During one cycle of alternating stress, the crack is opened gradually under tension and joins together rapidly under compression, and consequently a kink appears on the hysteresis loop. In straincontrolled LCF tests at RT, the measured peak stresses do not smoothly decrease in every test, instead, they behave in a random way. The reason is that the specimen section with homogenous radius has a length of $23 \mathrm{~mm}$, but the gage length of the extensometer is only $10 \mathrm{~mm}$. Therefore, the crack does not always appear within the gage length of the extensometer. Hence, the reliable data in the LCF test at RT is only taken until a roughly defined cycle $N_{0}$ within the stage where the peak stress is linearly decreasing (saturation stage of cyclic softening) and near the cycle where the deviation of peak stress from the linear decrease appears due to the macro crack. Further, the lifetime is roughly determined as the total cycle number, $N_{0}$.

Fig. 4.1d shows the hysteresis loops in three cycles. The peak stresses for the first and $300^{\text {th }}$ cycles are obviously different while the difference between the $300^{\text {th }}$ and $800^{\text {th }}$ cycles is relatively small. The change of $\sigma_{\text {peak }}$ versus number of cycles is illustrated in Fig. 4.1e and $\mathrm{f}$.

It was found that $\sigma_{\text {peak }}$ increases in the initial 5-10 cycles owing to cyclic hardening. As shown in Fig. 4.1e, the $\sigma_{\text {peak }}$ reaches its maximum in the sixth cycle in this test performed with $\Delta \varepsilon=1.5 \%$. After this initial increase, $\sigma_{\text {peak }}$ decreases (see Fig. 4.1f) which shows the obvious cyclic softening of P91. In the saturation stage of cyclic softening, the peak stress is still decreasing, although it is not obvious in the view of 
Fig. 4.1f. The $\sigma_{\text {peak }}$ after around the $1000^{\text {th }}$ cycle has an accelerated decrease owing to macroscopic crack propagation.

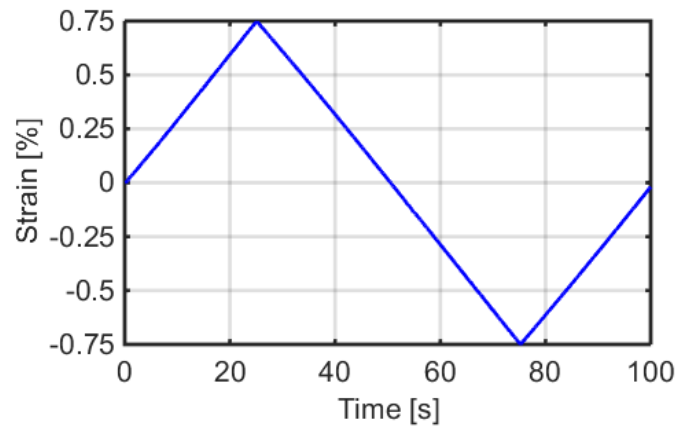

a) $1^{\text {st }}$ cycle, strain vs. time.

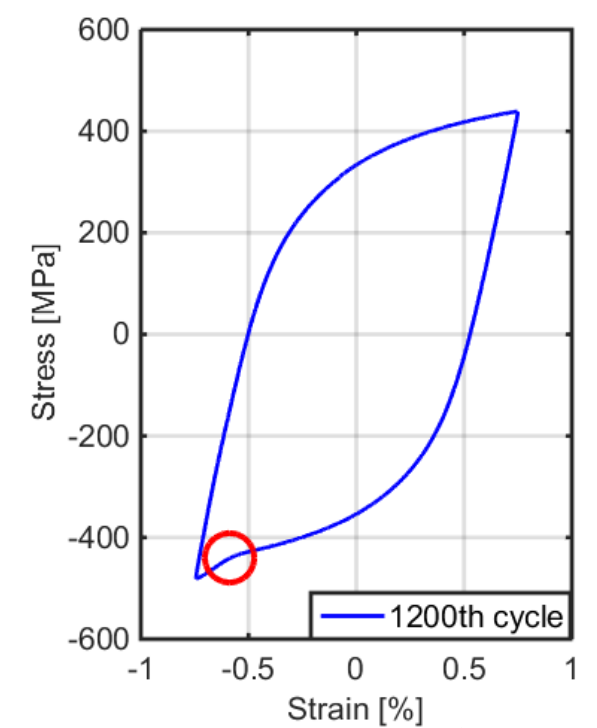

c) Hysteresis loops of $1200^{\text {th }}$ cycle

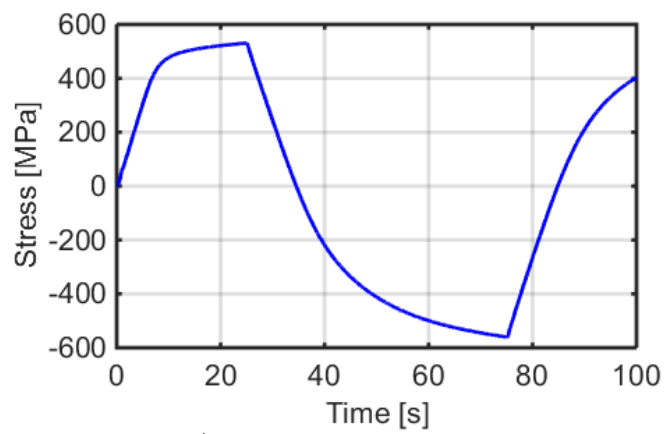

b) $1^{\text {st }}$ cycle, stress vs. time.

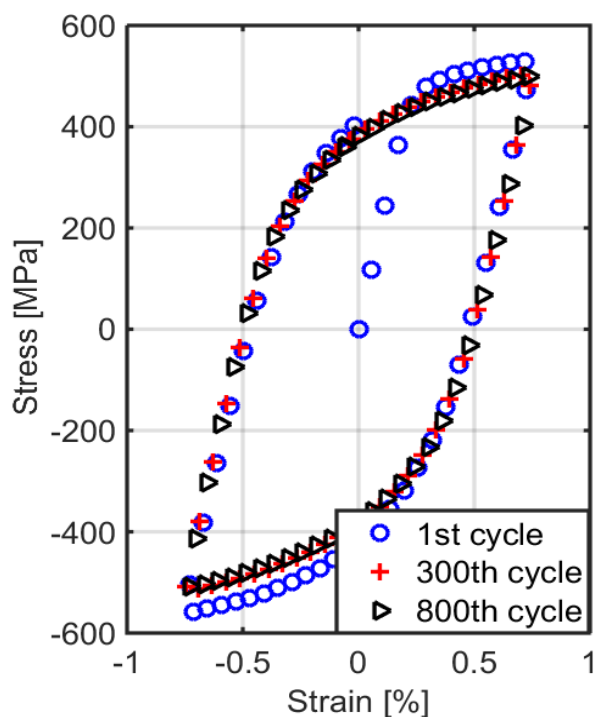

d) Hysteresis loops of $1^{\text {st }}, 300^{\text {th }}, 800^{\text {th }}$ cycle.

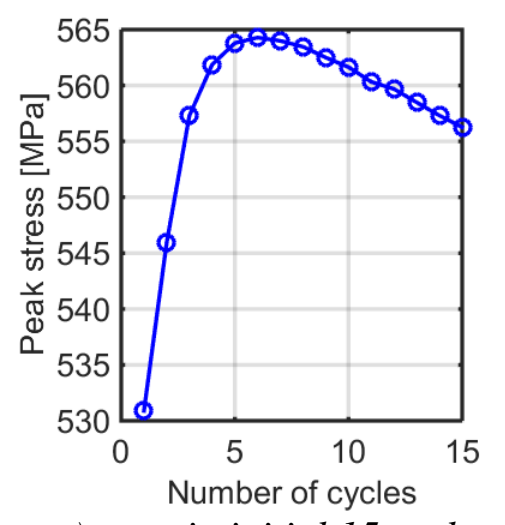

e) $\sigma_{\text {peak }}$ in initial 15 cycles.

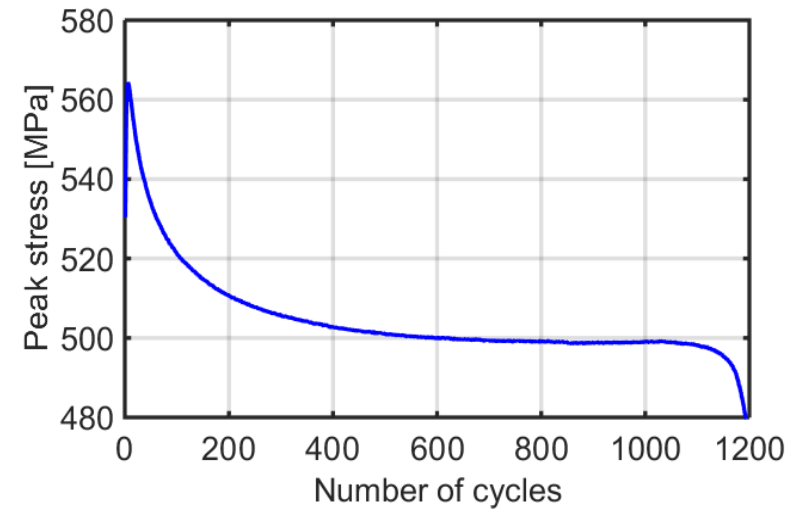

f) $\sigma_{\text {peak }}$ in cycles till fracture

Fig. 4.1 Symmetric strain-controlled LCF tests at RT, $\Delta \varepsilon=1.5 \%$.

Cyclic softening was also found in the other tests with $\Delta \varepsilon=0.6 \%, 0.8 \%, 1.0 \%$, and $1.2 \%$, as illustrated in Fig. 4.2c. According to the curves of peak tensile stresses versus number of cycles, the cyclic softening is more rapid in the initial stage. After the initial fast softening, $\sigma_{\text {peak }}$ has a linear and slower decrease. The second stage is 
also called the saturation stage, as reviewed in Section 2.5. This stage lasts until the appearance of a macro crack.

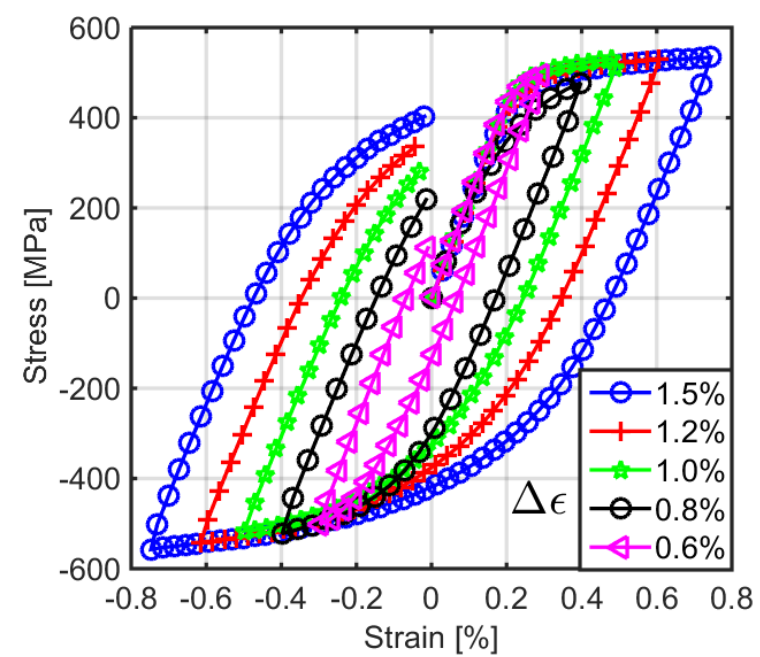

a) Hysteresis loops of the first cycle.

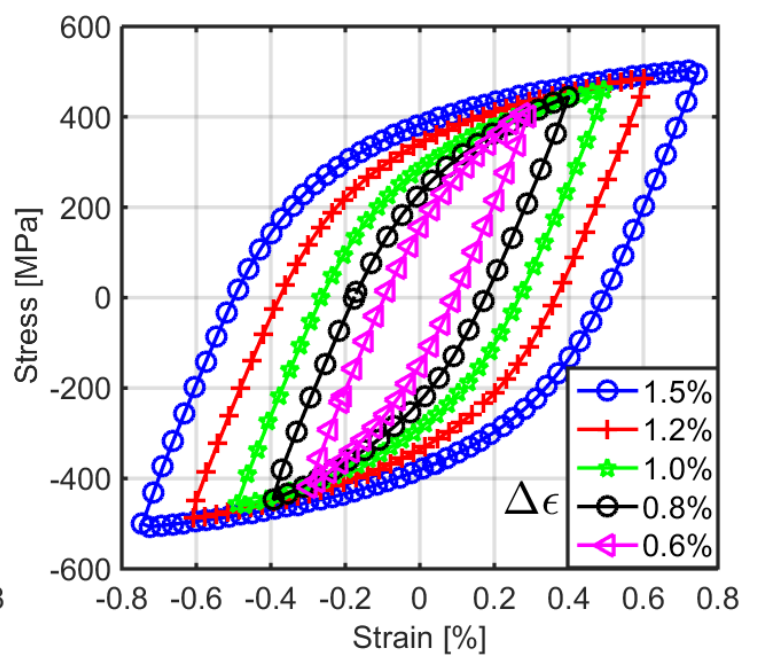

b) Hysteresis loops of the cycle at $N_{0} / 2$

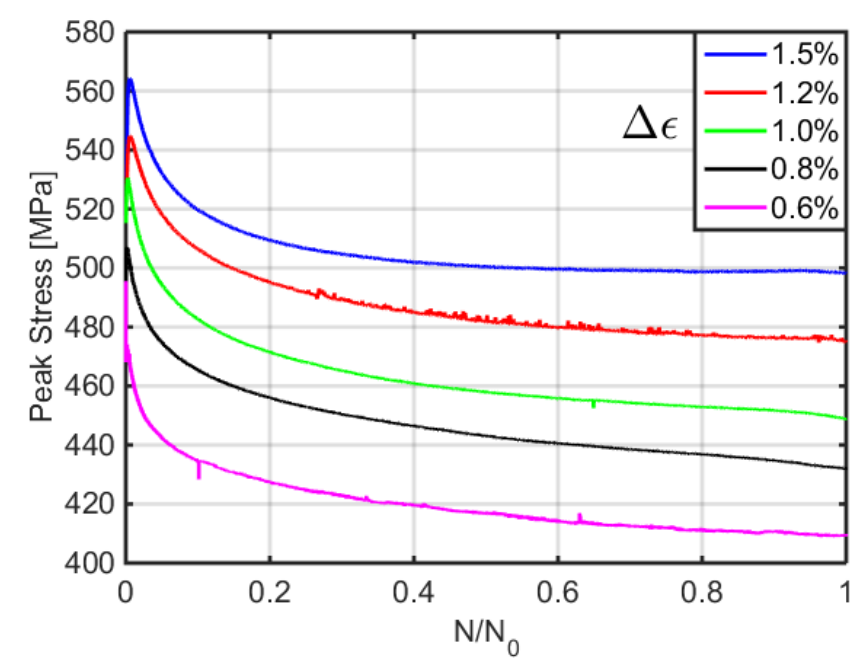

c) Peak tensile stresses vs. normalized number of cycles

Fig. 4.2 Strain-controlled LCF tests at RT performed with strain ranges $0.6 \% \sim 1.5 \%$.

As with the peak tensile stresses, the magnitudes of the peak compressive stresses decrease during the LCF test. However, an interesting phenomenon was found in these strain-controlled tests: The magnitude of peak compressive stress is larger than the corresponding peak tensile stress in every cycle, as shown in Fig. 4.3. In these diagrams, red curves indicate the absolute value of the peak compressive stresses and the blue curves indicate the peak tensile stresses. The larger strain range leads to a larger difference between the magnitudes of the peak tensile and compressive stresses. In the test performed with $\Delta \varepsilon=0.6 \%$, this difference in the saturation stage was around $6 \mathrm{MPa}$ while with $\Delta \varepsilon=1.5 \%$, this difference was around $12 \mathrm{MPa}$.

One reason for this difference is the difference between $\sigma_{\text {eng }}$ and $\sigma_{\text {true }}$. It is well known that $\sigma_{\text {true }}$ is larger than $\sigma_{\text {eng }}$ under tension owing to reduction of cross section area (the other way around under compression). $\sigma_{\text {eng }}$ shown in Fig. 4.3 is transferred into $\sigma_{\text {true }}$ shown in Fig. 4.4. Although the differences between tensile and 
compressive peaks are smaller in true-stress cases, they still cannot be ignored: for example, around $3.5 \mathrm{MPa}$ for $\Delta \varepsilon=0.6 \%$ and around $4 \mathrm{MPa}$ for $\Delta \varepsilon=1.5 \%$.
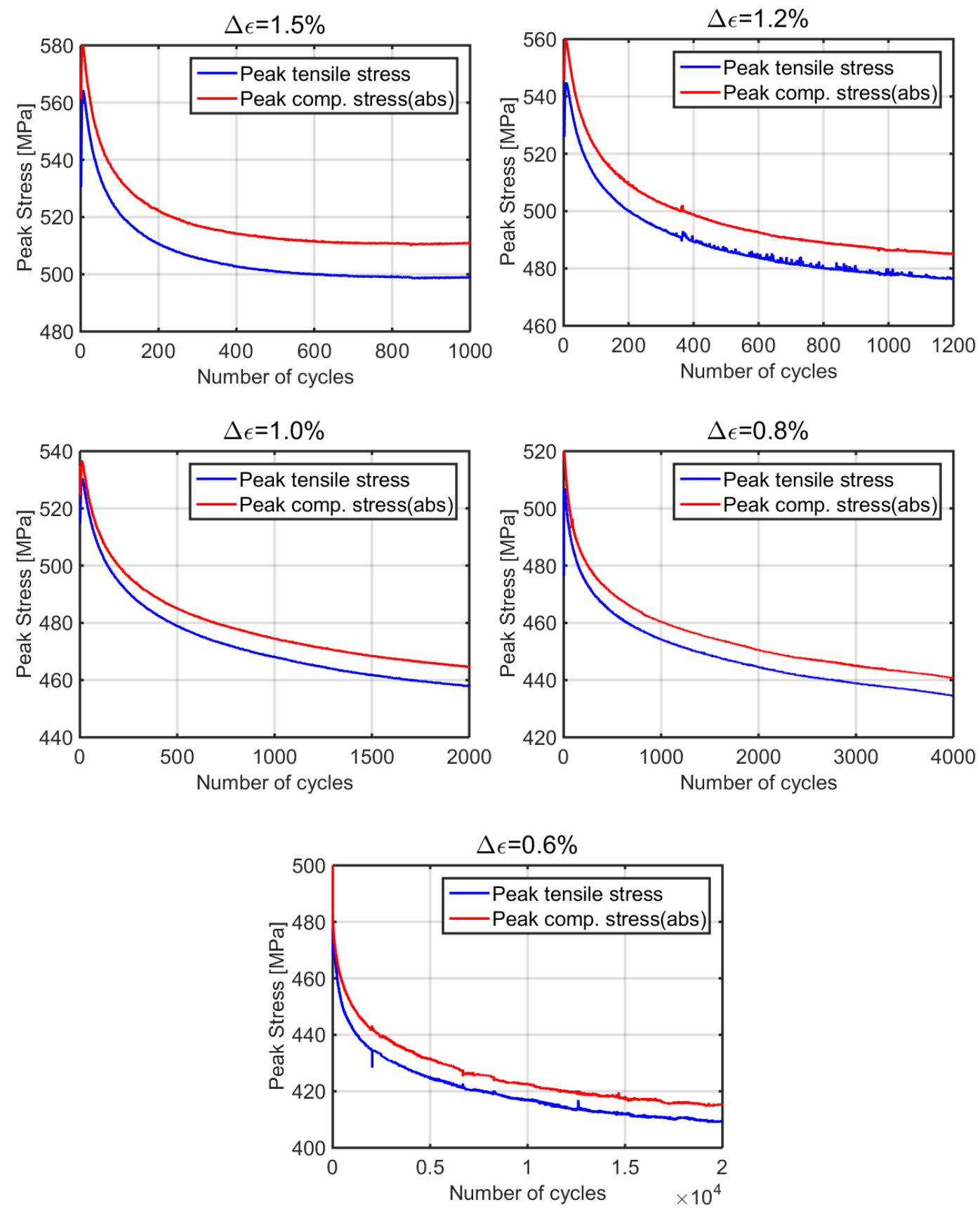

Fig. 4.3 Engineering peak compressive stresses (abs.) compared with engineering peak tensile stresses, at RT. 

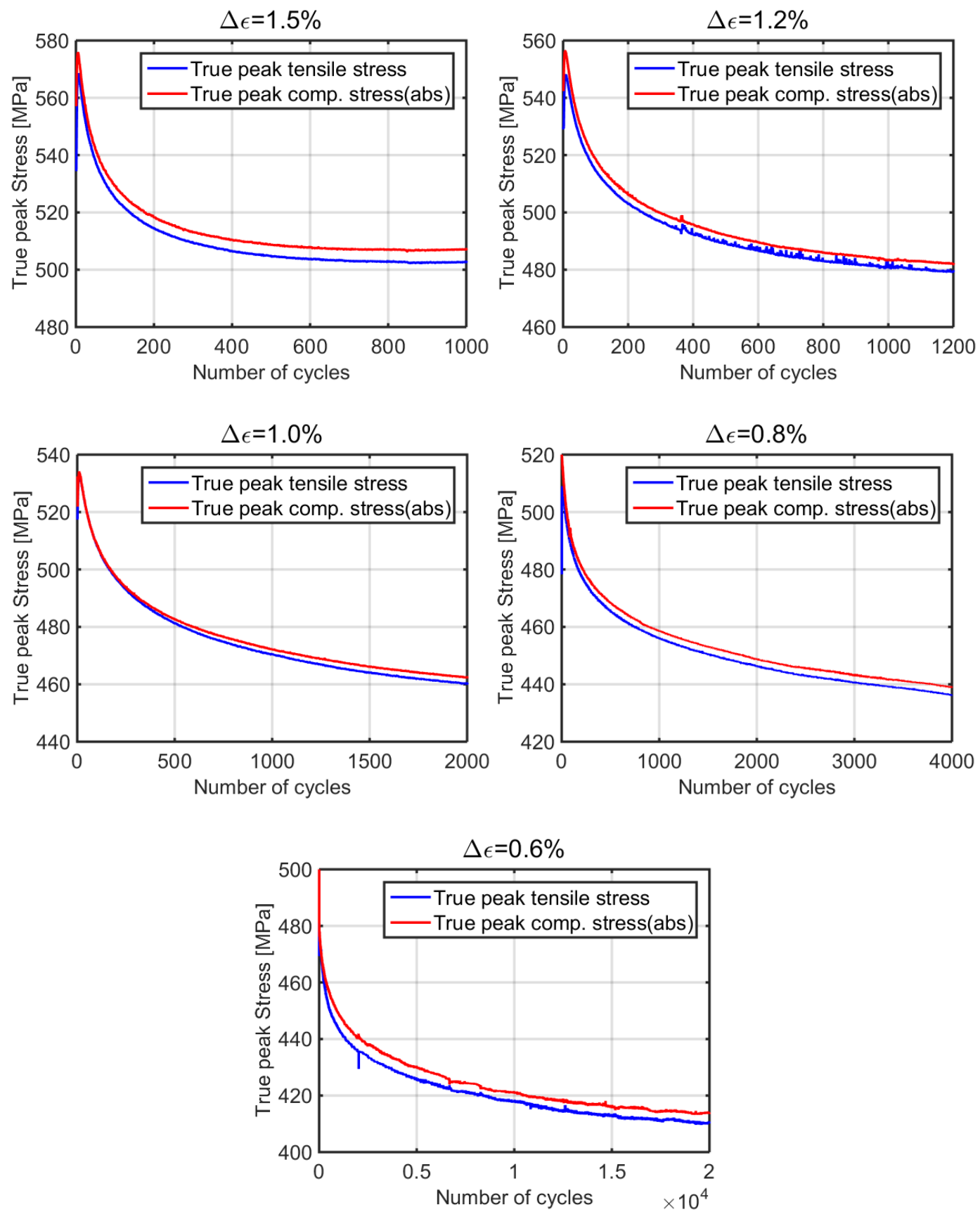

Fig. 4.4 True peak compressive stresses (abs.) compared with true peak tensile stresses, at RT.

According to the analysis above, such asymmetry of peak tensile and compressive stresses is obviously material behavior, which indicates that the material strength under tension and compression is not the same at RT. This asymmetry can yield positive ratcheting in stress-controlled tests with zero $\sigma_{\text {mean }}$ in the second stage of RT experiments. The reason is that the symmetry of the strain leads to the asymmetry of the stress, hence in the other way around, the symmetry of the stress should lead to the asymmetry of the strain. Since peak compressive stresses are larger than peak tensile stresses in symmetric strain-controlled LCF tests, when the stress become symmetric, the change of strain during stress-increasing process should be larger than that during the stress-decreasing process in the symmetric stress-controlled tests. As a result, positive ratcheting appears with zero $\sigma_{\text {mean }}$. As reviewed in Section 2.1, the non-zero 
$\varepsilon_{r}$ with zero $\sigma_{\text {mean }}$ was also reported in $[7,26]$ for mod. $9 \mathrm{Cr}-1 \mathrm{Mo}$ FM steel at $550{ }^{\circ} \mathrm{C}$. It is possible to simulate such a material behavior with a constitutive model.

By modifying a constitutive model with such asymmetric properties (this is discussed in detail in Chapter 6), it is possible to simulate asymmetry of stress in symmetric strain-controlled LCF tests. Fig. 4.5a shows the simulated result: The peak tensile stress in the $100^{\text {th }}$ cycle is $491.8 \mathrm{MPa}$ while the peak compressive stress here is -509.3 $\mathrm{MPa}$. The peak tensile and compressive strains are $\pm 0.5 \%$. With the same model and the same parameter values, another simulation is performed with stress controlling, as shown in Fig. $4.5 \mathrm{~b}$ and c. The stress amplitude is $500 \mathrm{MPa}$ and $\sigma_{\text {mean }}$ is zero. Owing to asymmetry, the stress-increasing half of the loop (blue curve in Fig. 4.5b and c) yields a larger change of strain than that in the stress-decreasing half of the loop (red curve in Fig. $4.5 \mathrm{~b}$ and c). Consequently, the material has accumulated strain even with zero $\sigma_{\text {mean }}$. This is verified in the second stage of experiments at RT.

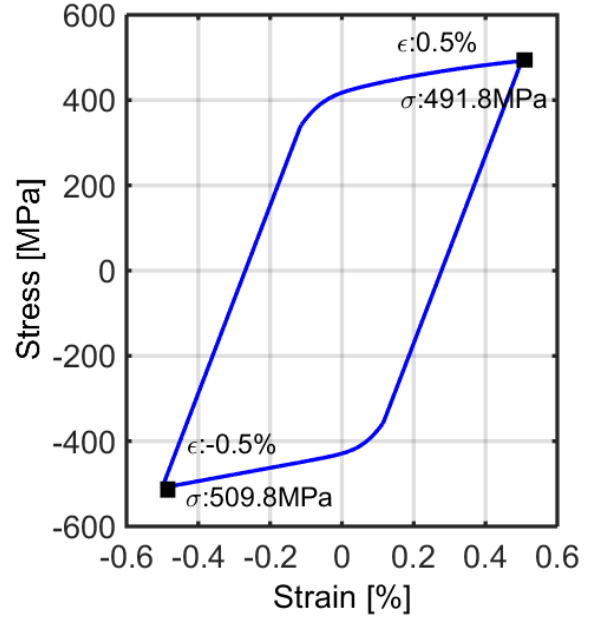

a)

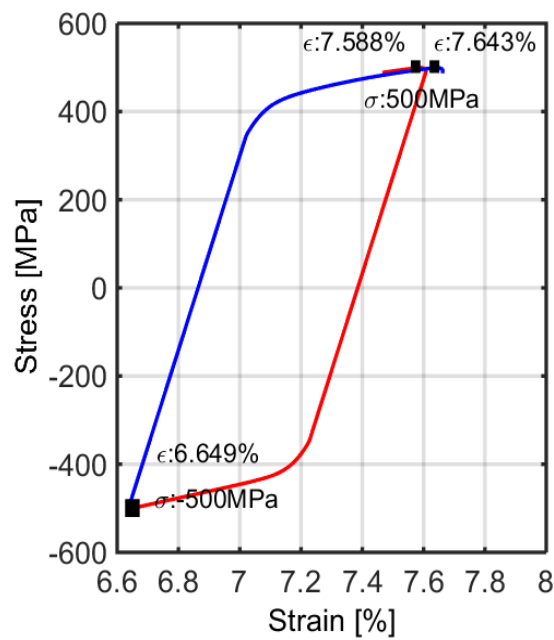

b)

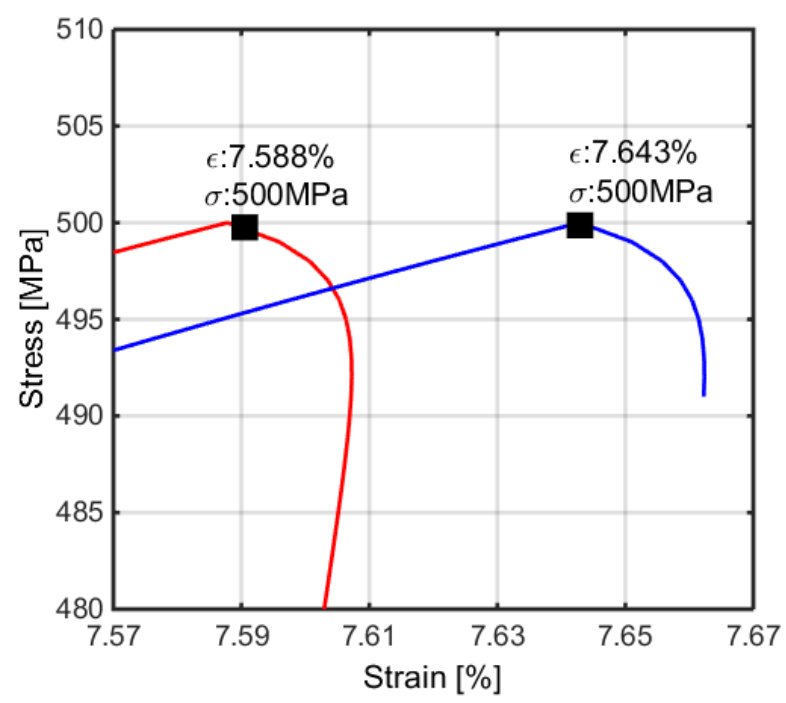

c)

Fig. 4.5 a) Simulation for a strain-controlled LCF test at RT performed with $\Delta \varepsilon=1.0 \%$, the $100^{\text {th }}$ cycle. b) Simulation for a stress-controlled ratcheting test with $\sigma_{\text {mean }}=0 \mathrm{MPa}$ and $\sigma_{a}=500 \mathrm{MPa}$. c) Zoom of the peak tensile stresses of the subfigure. 


\subsection{Results of Stress-controlled Ratcheting Tests}

In the second stage of experiments at RT, uniaxial stress-controlled tests were carried out. Fig. 4.6 shows one of the tests performed with $\sigma_{\text {peak }}=500 \mathrm{MPa}, \sigma_{\text {mean }}=25$ $\mathrm{MPa}$, and $\dot{\sigma}= \pm 50 \mathrm{MPa} / \mathrm{s}$. The tests were performed with a triangle wave of stress. Hence, the magnitude of the stress rate was constant, as shown in Fig. 4.6a. The strain was yielded as a consequence. Fig. 4.6b illustrates the yielded strain in the first cycle.

Fig. 4.6c shows several hysteresis loops $\left(1^{\text {st }}, 250^{\text {th }}, 500^{\text {th }}, 750^{\text {th }}, 1000^{\text {th }}\right.$, and $1400^{\text {th }}$ cycle) in this test. Although in the first cycle, the maximum strain reached only less than $0.5 \%$, the strain reached more than $4.5 \%$ after the $1400^{\text {th }}$ cycle. Therefore, ratcheting behavior exists at RT on P91.

Ratcheting is evaluated by plotting the mean strain $\left(\varepsilon_{\text {mean }}\right)$ of each cycle together with its corresponding cycle number to show the rate of ratcheting. In other words, the speed of strain accumulation. Fig. $4.6 \mathrm{~d}$ shows $\varepsilon_{\text {mean }}$ versus number of cycles of this test.

Owing to cyclic softening, the strain range of hysteresis loop $(\Delta \varepsilon)$ increases, as shown in Fig. 4.6e. The reduction of $\Delta \varepsilon$ in the initial cycles is owing to initial cyclic hardening, which corresponds to cyclic hardening in the initial 5-10 cycles of the strain-controlled LCF tests.

From an engineering point of view, the deformation of a component is not allowed to be larger than 5\%. Concerning this reason, ratcheting tests can be ended after the strain reaches $5 \%$. Since the measurement range of the extensometer is $\pm 10 \%$, some ratcheting tests with fast $\varepsilon_{r}^{\prime}$ were ended at strains larger than 5\%. Owing to limited experimental time, some ratcheting tests with very low $\varepsilon_{r}^{\prime}$ were ended at strains smaller than $5 \%$.

In the following Sections 4.2.1-4.2.4, diagrams show results of various groups of ratcheting tests according to Table 3.3. 


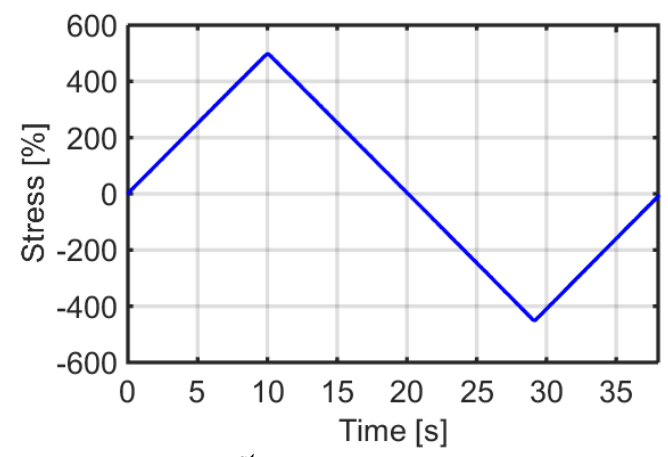

a) $1^{\text {st }}$ cycle, stress v.s. time.

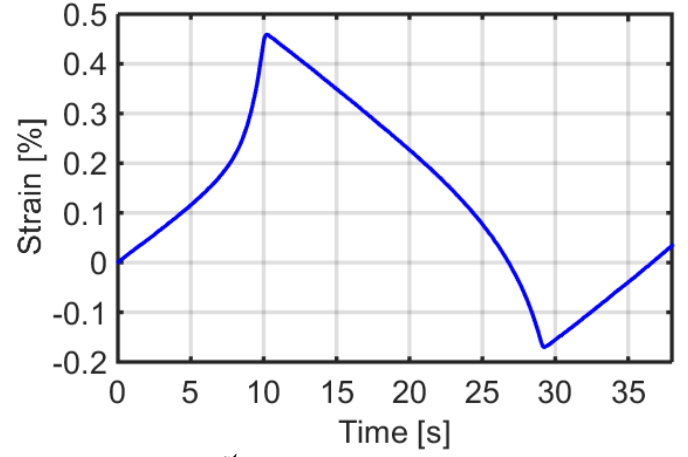

b) $1^{\text {st }}$ cycle, strain v.s. time.

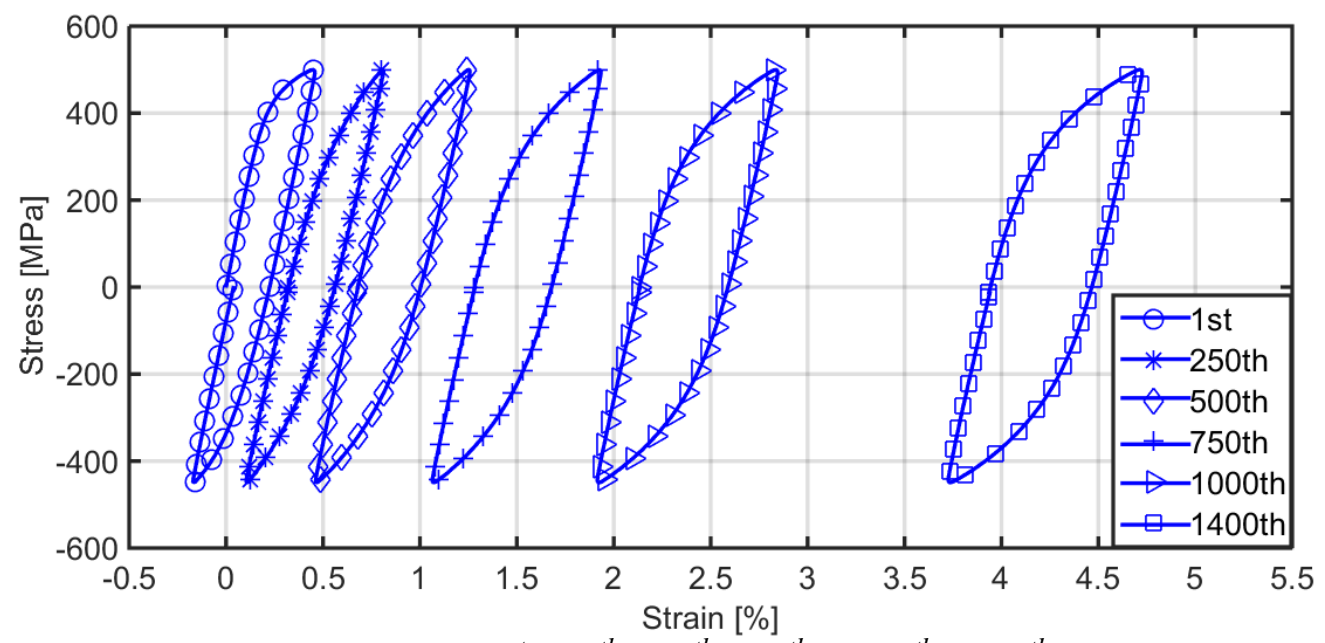

c) Hysteresis loops of $1^{\text {st }}, 250^{\text {th }}, 500^{\text {th }}, 750^{\text {th }}, 1000^{\text {th }}, 1400^{\text {th }}$ cycle.

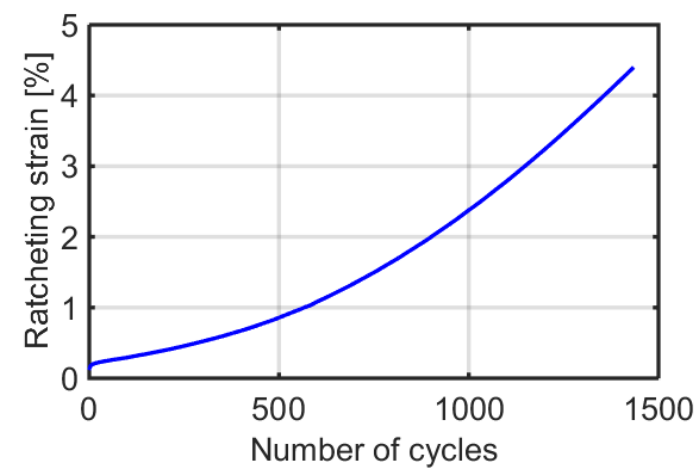

d) $\varepsilon_{r} v s$. number of cycles

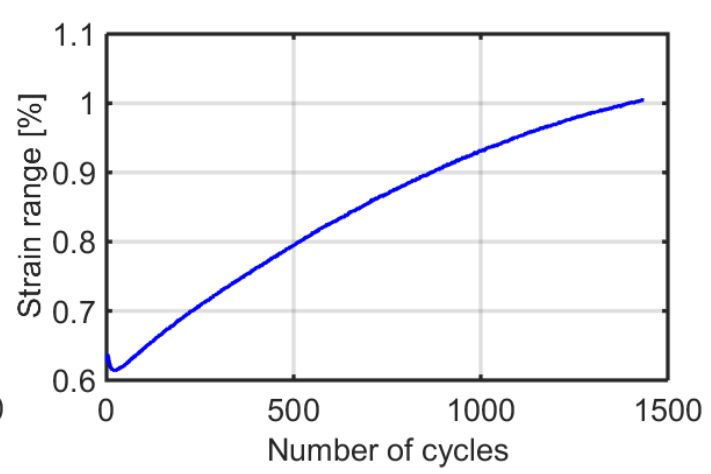

e) Strain ranges of hysteresis loops

Fig. 4.6 Ratcheting tests at RT performed with $\sigma_{\text {peak }}=500 \mathrm{MPa}, \sigma_{\text {mean }}=25 \mathrm{MPa}$, stress rate $\pm 50 \mathrm{MPa} / \mathrm{s}$.

\subsubsection{Influence of Peak Stress}

According to Table 3.3a, eight experiments were carried out to explore the influence of peak stress on ratcheting. The $\sigma_{\text {mean }}$ are all the same as $25 \mathrm{MPa}$ and $\sigma_{\text {peak }}$ range from 550 to $400 \mathrm{MPa}$. The ratcheting strains (mean strain in each cycle) are plotted together with the number of cycles in Fig. 4.7. 


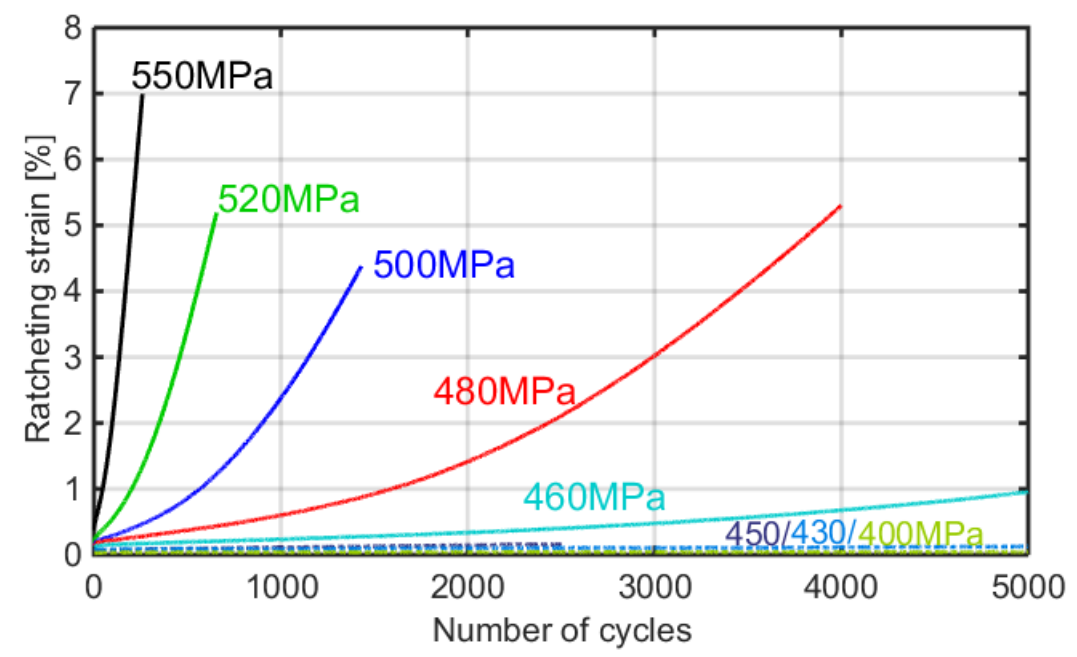

a)

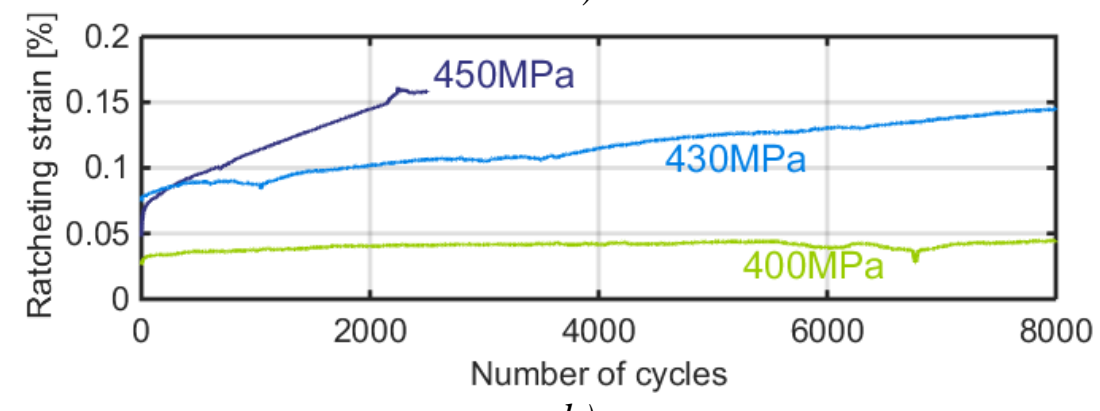

b)

Fig. 4.7 Ratcheting tests at $R T$ performed with $\sigma_{\text {mean }}=25 \mathrm{MPa}$, stress rate $\pm 50 \mathrm{MPa} / \mathrm{s}$, various $\sigma_{\text {peak }}, \varepsilon_{r} v$ s. number of cycles

In Fig. $4.7 \mathrm{a}$, the ratcheting with $\sigma_{\text {peak }} \leq 450 \mathrm{MPa}$ is negligible compared to those tests performed with larger $\sigma_{\text {peak }}$. These results with $\sigma_{\text {peak }}=450,430$, and $400 \mathrm{MPa}$ are plotted separately in Fig. $4.7 \mathrm{~b}$. With $\sigma_{\text {peak }}=550 \mathrm{MPa}$, the accumulated strain reaches $7 \%$ in the $238^{\text {th }}$ cycle, while with $\sigma_{\text {peak }}=400 \mathrm{MPa}$, the maximum strain reaches only $0.2235 \%$ after 8000 loading cycles. Obviously the larger $\sigma_{\text {peak }}$ leads to faster ratcheting, and the ratcheting behavior is negligible with $\sigma_{\text {peak }}<400 \mathrm{MPa}$.

The inelastic strain range $\Delta \varepsilon^{\text {in }}$ of each cycle is illustrated in Fig. 4.8. It is clear that $\Delta \varepsilon^{i n}$ increases with increasing cycle number, which is due to cyclic softening. However, the cyclic softening in these stress-controlled tests does not show two stages as in the strain-controlled LCF tests (see Fig. 4.2c); instead, $\Delta \varepsilon^{\text {in }}$ decreases in the initial five cycles owing to initial hardening and then increases until the end of the test. Note that all eight tests shown in Fig. 4.7 and Fig. 4.8 ended without a macro crack. 


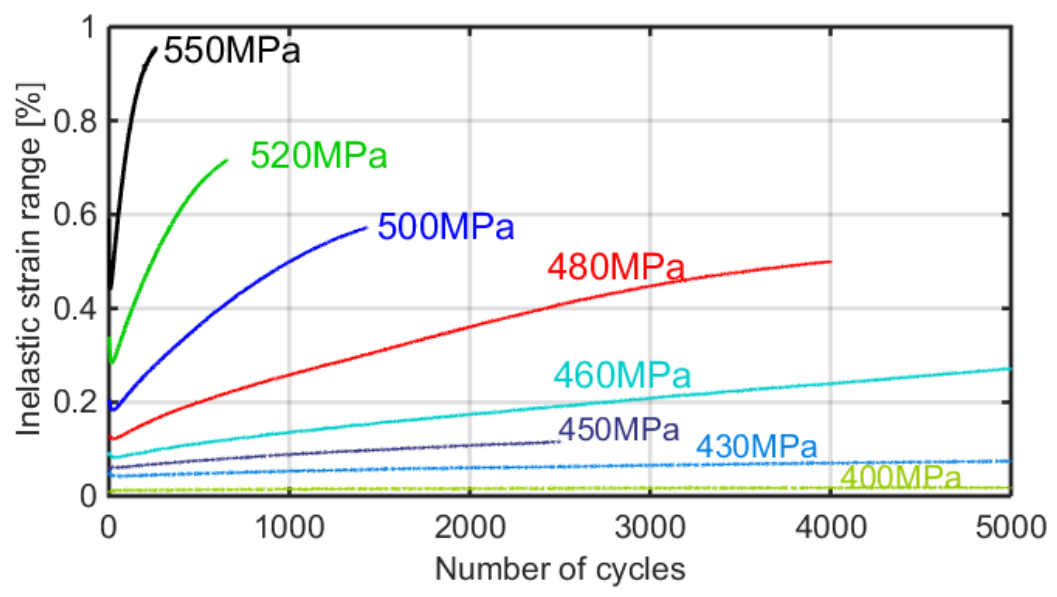

Fig. 4.8 Ratcheting tests at $R T$ performed with $\sigma_{\text {mean }}=25 \mathrm{MPa}$, stress rate $\pm 50 \mathrm{MPa} / \mathrm{s}$, various $\sigma_{\text {peak }}, \Delta \varepsilon^{\text {in }}$ vs. number of cycles

The average ratcheting rate $\varepsilon_{r}^{\prime}$ are put together with their $\sigma_{\text {peak }}$ in a log-linear plot (see Fig. 4.9) and a quasi-linear relationship can be seen. The $\varepsilon_{r}^{\prime}$ shown in Fig. 4.9 are calculated as the average rates until the cycle in which the maximum strain reaches $4 \%$ or the cycle number achieves 2500 , whichever comes first.

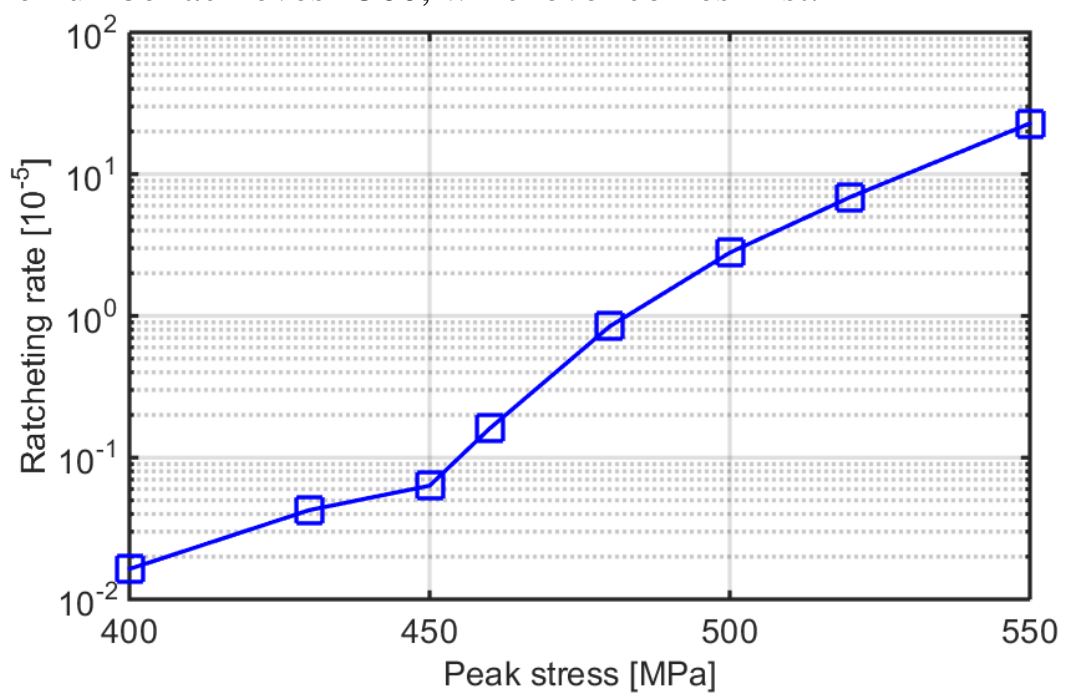

Fig. 4.9 Ratcheting tests at $R T$ performed with $\sigma_{\text {mean }}=25 \mathrm{MPa}$, stress rate $\pm 50 \mathrm{MPa} / \mathrm{s}$, average ratcheting rates $v$ s. $\sigma_{\text {peak }}$ in log-linear diagram

In the above-mentioned experiments, the focus is on the influence of peak tensile stress. Two additional verification tests were performed to check whether the influence of peak compressive stress is the same as that of peak tensile stress. One of these verification tests was performed with $\sigma_{\max }=450 \mathrm{MPa}$ and $\sigma_{\min }=-500 \mathrm{MPa}, \dot{\sigma}$ $= \pm 50 \mathrm{MPa} / \mathrm{s}$. Comparing to the test performed with a stress range of $500 \sim-450 \mathrm{MPa}$, $\sigma_{a}$ is the same, only $\sigma_{\text {mean }}$ is changed from $+25 \mathrm{MPa}$ to $-25 \mathrm{MPa}$. Another verification test was performed with a stress range of 500 -550 MPa, in comparison to the test performed with a stress range of 550 -500 MPa.

The results are illustrated in Fig. 4.10. The two loading cases with stress ranges of 550 -500 MPa and 500 -550 MPa have similar magnitudes of $\varepsilon_{r}^{\prime}$; the loading cases with stress ranges of 500 -450 MPa and 450 -500 MPa also have similar magnitudes 
of $\varepsilon_{r}$. However, the case with 450 -500 MPa has a lower $\varepsilon_{r}^{\prime}$ (absolute value) than that in the loading case of 500 -450 MPa.

A similar difference can be found between the two tests performed with stress ranges of 550 -500 MPa and 500 -550 MPa. These small differences between the absolute values of $\varepsilon_{r}^{\prime}$ show that more accumulated strain is induced with tensile $\sigma_{\text {mean }}$ than with the same magnitude of compressive $\sigma_{\text {mean }}$. Together with the asymmetry of the $\sigma_{\text {peak }}$ in the symmetric strain-controlled LCF test reported in Section 4.1, they support the assumption of asymmetry of material strength under tension and compression.

One confusion can be eliminated after these two verification tests shown in Fig. 4.10: The so-called "influence of peak stress", as the title of the current section, is specifically the "influence of maximum absolute value of stress". In other words, if peak compressive stress has a larger absolute value than that of peak tensile stress, then the $\varepsilon_{r}^{\prime}$ is mainly decided by the peak compressive stress. However, since most ratcheting tests performed in the current work have larger absolute values of peak tensile stresses than the absolute values of peak compressive stresses, the term "peak stress" or "maximum stress" means "peak tensile stress" $\left(\sigma_{\text {peak }}=\sigma_{\text {max }}\right)$ if given without a specific explanation.

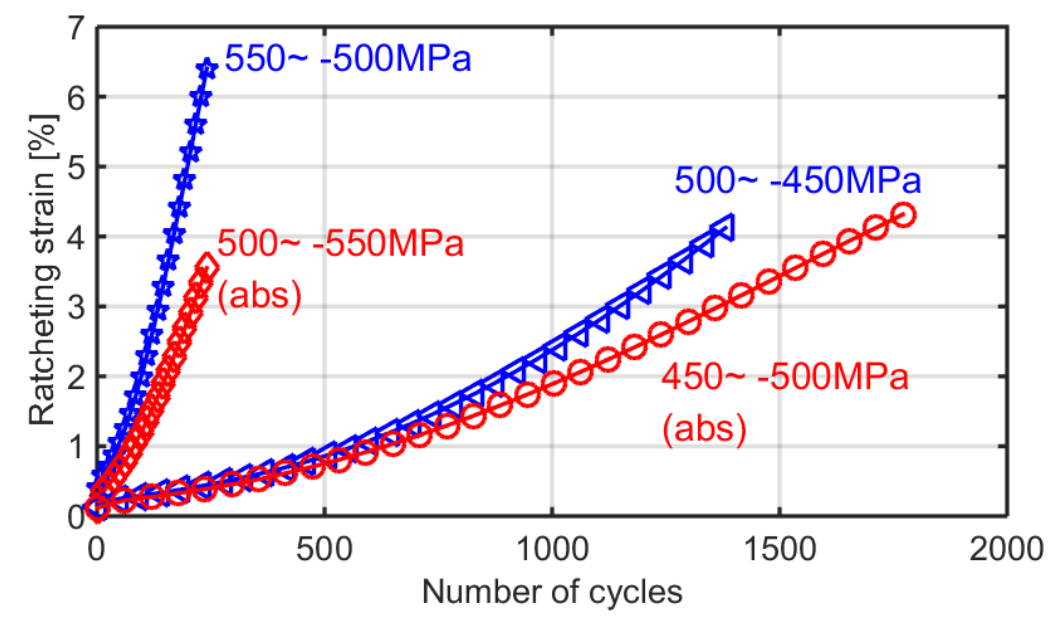

Fig. 4.10 Two groups of ratcheting tests at RT performed with symmetric $\sigma_{\text {mean }}$, $\varepsilon_{r} v s$. number of cycles.

\subsubsection{Influence of mean stress/stress ratio.}

In stress-controlled tests, if the $\sigma_{\text {peak }}$ are the same, one stress ratio $(R)$ corresponds to one mean stress $\sigma_{\text {mean }}$

$$
\begin{gathered}
\sigma_{\text {mean }}=\frac{\sigma_{\text {peak }}+\sigma_{\text {min }}}{2} \\
R=\frac{\sigma_{\text {min }}}{\sigma_{\text {peak }}}
\end{gathered}
$$

With (4-1) and (4-2), we have 


$$
R=\frac{2 \sigma_{\text {mean }}-\sigma_{\text {peak }}}{\sigma_{\text {peak }}}
$$

Hence "the influence of mean stress" and "the influence of stress ratio" are identical with the same $\sigma_{\text {peak }}$.

The experiments were performed according to Table $3.3 \mathrm{~b}$ ). $\varepsilon_{r}$ versus number of cycles is plotted in Fig. 4.11. They have the same peak tensile stress of $500 \mathrm{MPa}$ and the same stress rate of $\pm 50 \mathrm{MPa} / \mathrm{s}$. The tests with $\sigma_{\text {mean }}=100$ and $250 \mathrm{MPa}$ are plotted separately in Fig. 4.11 b) for their relatively low $\varepsilon_{r}^{\prime}$.

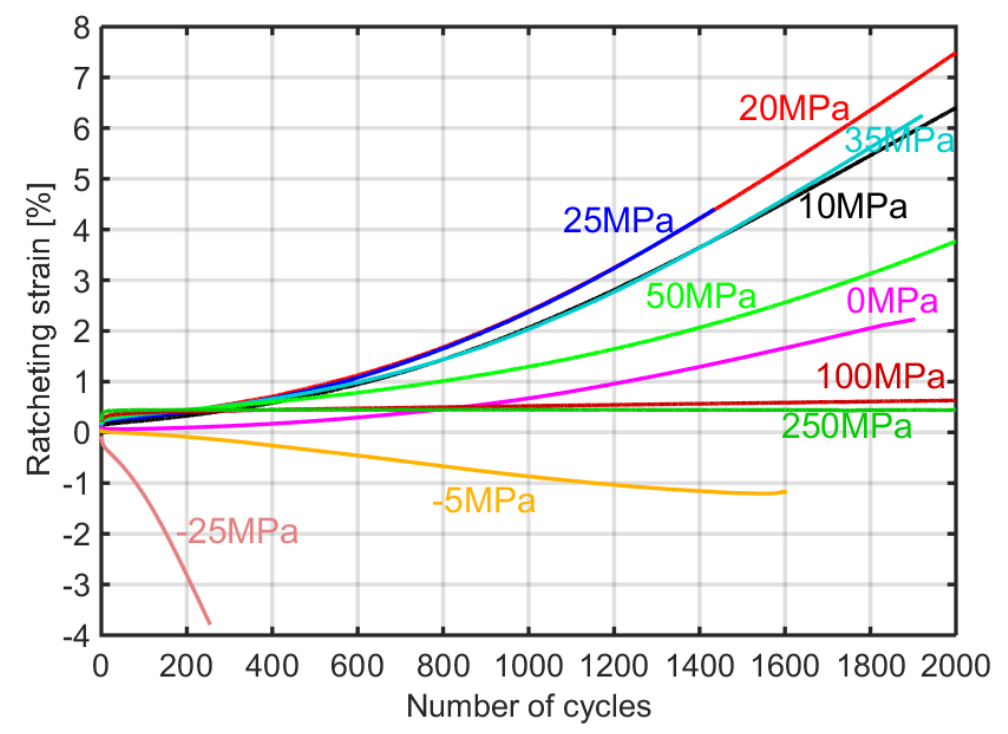

a)

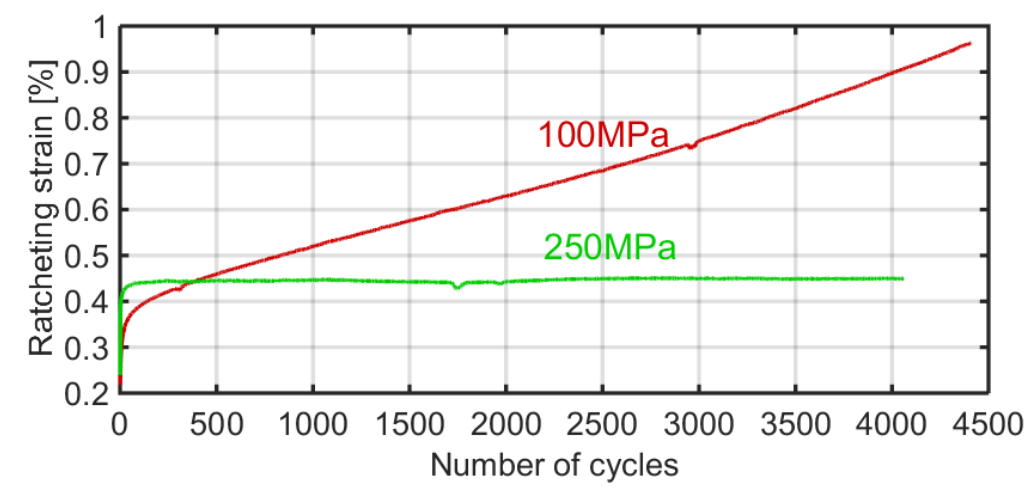

b)

Fig. 4.11 Ratcheting tests at RT performed with $\sigma_{\text {peak }}=500 \mathrm{MPa}$, stress rate $\pm 50 \mathrm{MPa} / \mathrm{s}$, various $\sigma_{\text {mean }}, \varepsilon_{r}$ vs. number of cycles.

$\Delta \varepsilon^{\text {in }}$ versus number of cycles is plotted in Fig. 4.12. The evolution of $\Delta \varepsilon^{\text {in }}$ is similar to that shown in Fig. 4.8, with an initial decrease followed by an even and smooth increase until the end of the test. As shown in Fig. 4.12, a larger stress range leads to a higher increase in the rate of $\Delta \varepsilon^{i n}$. For instance, the largest stress range is with $\sigma_{\text {mean }}=-25 \mathrm{MPa}\left(\sigma_{\max }=500 \mathrm{MPa}, \sigma_{\min }=-550 \mathrm{MPa}\right)$, which has the highest increase in rate of $\Delta \varepsilon^{i n}$. No macro crack was observed on the specimens for these 10 ratcheting tests shown in Fig. 4.11 and Fig. 4.12. 


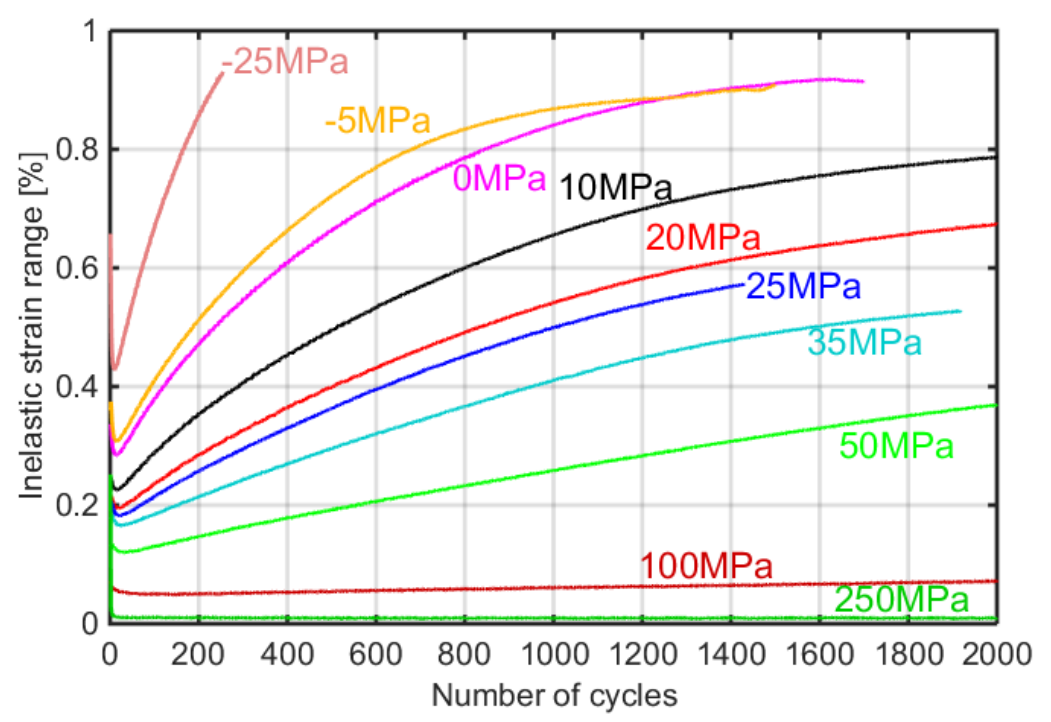

Fig. 4.12 Ratcheting tests at RT performed with $\sigma_{\text {peak }}=500 \mathrm{MPa}$, stress rate $\pm 50 \mathrm{MPa} / \mathrm{s}$, various $\sigma_{\text {mean }}, \Delta \varepsilon^{\text {in }} v \mathrm{vs}$. number of cycles.

Fig. 4.13 shows the relation between average $\varepsilon_{r}^{\prime}$ and stress ratio. The average $\varepsilon_{r}^{\prime}$ before the $1250^{\text {th }}$ cycle of the experiments together with their corresponding stress ratios are plotted in this diagram. The case with stress range 500--550 $\mathrm{MPa}$ is not shown in Fig. 4.13 because it did not reach $1250^{\text {th }}$ cycle before buckling.

Unlike the influence of peak stress, the ratcheting is not accelerated by an increase of mean stress. As shown in Fig. $4.11 \mathrm{a}, \varepsilon_{r}^{\prime}$ reaches its maximum with $\sigma_{\text {mean }}=20 \mathrm{MPa}$. The largest mean stress of $250 \mathrm{MPa}$, on the contrary, leads to the minimum magnitude of $\varepsilon_{r}^{\prime}$. As shown in Fig. 4.13, $\varepsilon_{r}^{\prime}$ reaches the maximum with the stress ratio at around -0.9 .

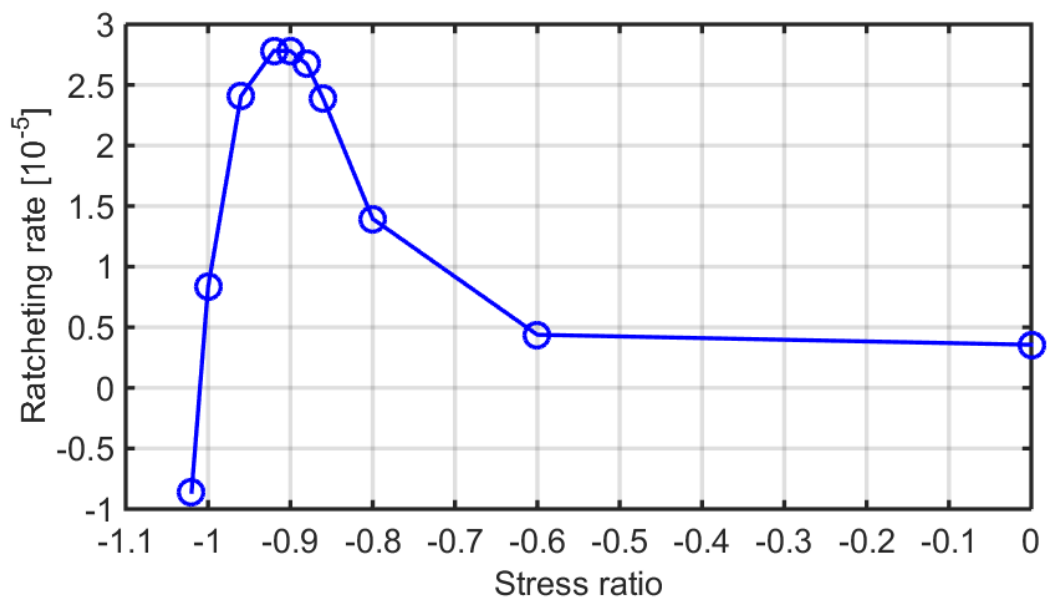

Fig. 4.13 Ratcheting tests at $R T$ performed with $\sigma_{\text {peak }}=500 \mathrm{MPa}$, stress rate $\pm 50 \mathrm{MPa} / \mathrm{s}$, various $\sigma_{\text {mean }}$, average ratcheting rates (until $1250^{\text {th }}$ cycle) vs. stress ratios.

This phenomenon can be explained by Fig. 4.14: The hysteresis loops include mostly elastic regions if $\sigma_{\text {mean }}=250 \mathrm{MPa}$, which means the inelastic strain is too small to induce ratcheting. Consequently, ratcheting with the same $\sigma_{\text {peak }}$ and larger $\sigma_{\text {mean }}$ has 
less inelastic strain, which leads to a lower $\varepsilon_{r}^{\prime}$. An intuitive explanation can be stated as follows: $\varepsilon_{r}^{\prime}$ is controlled by the difference between the change of inelastic strain $\left(\left|\Delta \varepsilon^{i n}\right|\right)$ during the stress-increasing and stress-decreasing half in each cycle. With stress ratio $-1<R<-0.9$, both $\left|\Delta \varepsilon^{i n}\right|$ during the stress-increasing and -decreasing half are large and $\left|\Delta \varepsilon^{i n}\right|$ during stress-increasing half is even larger than that during the stress-decreasing half. At $R \cong-0.9$, this difference between the two $\left|\Delta \varepsilon^{i n}\right|$ reaches the maximum. When $R>-0.9$ and approaches zero, both $\left|\Delta \varepsilon^{i n}\right|$ during stress-increasing and -decreasing half decrease and the difference decreases correspondingly until zero, which leads to a decrease of $\varepsilon_{r}$.

However, $\varepsilon_{r}^{\prime}$ in the test performed with $\sigma_{\text {peak }}=500 \mathrm{MPa}$ and $\sigma_{\text {mean }}=250 \mathrm{MPa}$ is still not exactly zero since the material response is not completely elastic. As shown in Fig. 4.14a, the difference between the loops of the $1^{\text {st }}$ and $500^{\text {th }}$ cycles is obvious, but the loops of the $500^{\text {th }}$ and $4000^{\text {th }}$ cycles are almost the same and are both composed only of an elastic region. Fig. $4.14 \mathrm{~b}$ shows the inelastic strain ranges $\Delta \varepsilon^{\text {in }}$ in each cycle and Fig. 4.14c illustrates those in the initial 30 cycles. It is clear that $\Delta \varepsilon^{i n}$ decreased rapidly in the initial cycles and stayed constant afterwards, with a value of only $0.01 \%$. Therefore, the elastic shake down happens in this case. 


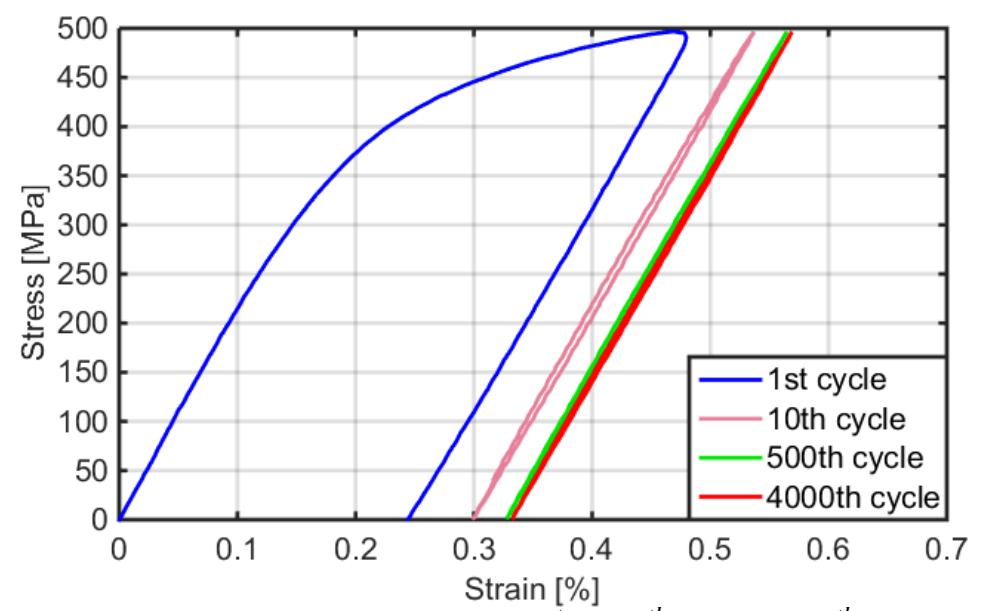

a) Hysteresis loops of the $1^{\text {st }}, 500^{\text {th }}$ and $4000^{\text {th }}$ cycle

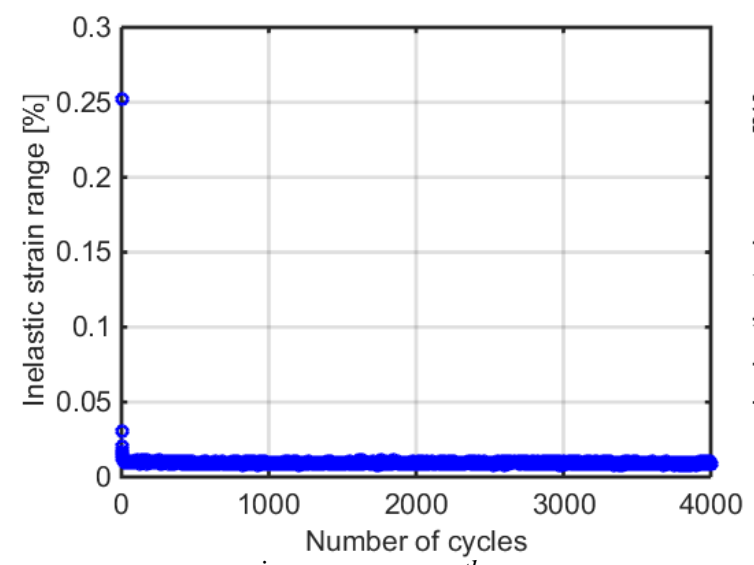

b) $\Delta \varepsilon^{\text {in }}$ until $4000^{\text {th }}$ cycle

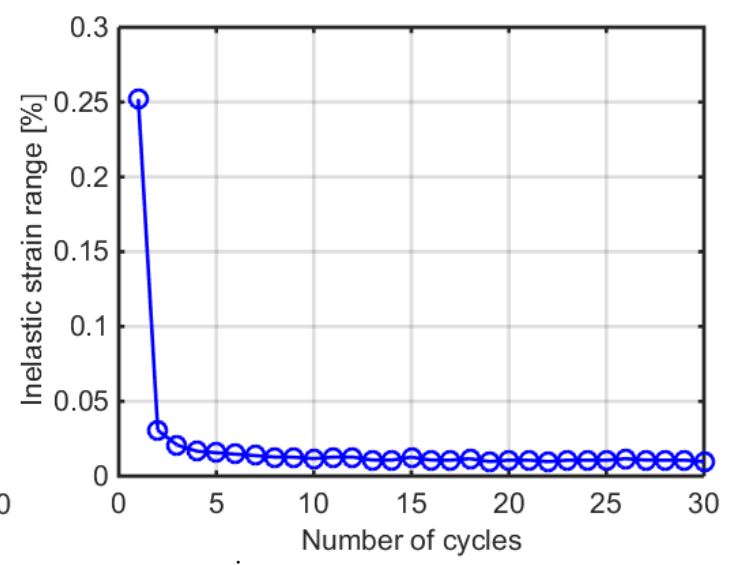

c) $\Delta \varepsilon^{\text {in }}$ in the initial 30 cycles

Fig. 4.14 Ratcheting test at $R T$ performed with $\sigma_{\text {peak }}=500 \mathrm{MPa}, \sigma_{\text {mean }}=250 \mathrm{MPa}$, stress rate $\pm 50 \mathrm{MPa} / \mathrm{s}$.

\subsubsection{Ratcheting with zero mean stress}

In symmetric strain-controlled LCF tests, asymmetry of peak tensile and compressive stress is observed. This can yield positive ratcheting, as discussed in Section 4.1. Based on this assumption, a group of tests was carried out according to Table 3.3c, the results of which are shown in Fig. 4.15. In the test performed with $\sigma_{a}=450 \mathrm{MPa}, \dot{\varepsilon}_{r}^{\prime}$ is relatively negligible, hence it is separately shown in Fig. 4.15b. 


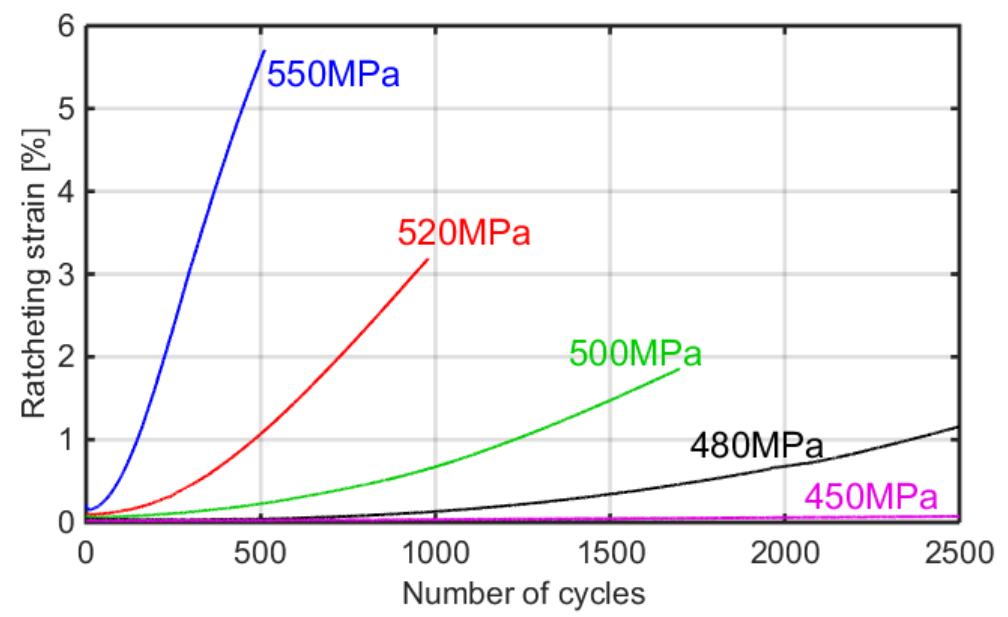

a)

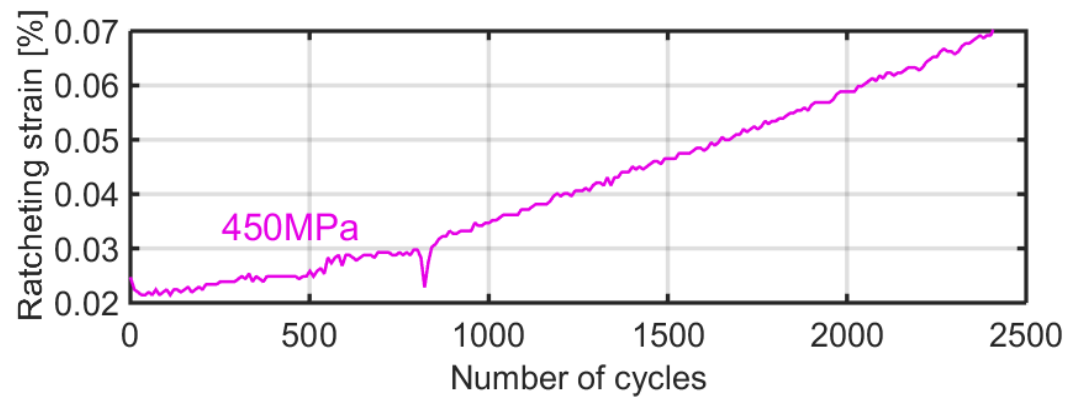

b)

Fig. 4.15 Ratcheting tests at RT performed with zero $\sigma_{\text {mean, }}$ stress rate $\pm 50 \mathrm{MPa} / \mathrm{s}$, various $\sigma_{a}, \varepsilon_{r}$ vs. number of cycles.

$\Delta \varepsilon^{i n}$ versus number of cycles is plotted in Fig. 4.16. Only the tests performed with $\sigma_{a}=520 \mathrm{MPa}$ were ended with macro cracks, and the corresponding $\Delta \varepsilon^{i n}$ increases in the last stage of this test. The other four tests were ended without macro cracks. $\Delta \varepsilon^{\text {in }}$ in the test performed with $\sigma_{a}=550 \mathrm{MPa}$ showed an obvious decrease of the rate and $\Delta \varepsilon^{i n}$ even decreased in the last stage of the test. This indicates that the cyclic softening of the material under stress-controlled loading can be progressively saturated and followed by further hardening.

Another possible reason for the decrease of $\Delta \varepsilon^{i n}$ in the last stage of the test performed with $\sigma_{a}=550 \mathrm{MPa}$ is that, at very large deformation $(\varepsilon>5 \%)$, the effect of asymmetry of tensile and compressive strength is less. However, this phenomenon only appeared once and was not observed in other RT ratcheting tests. 


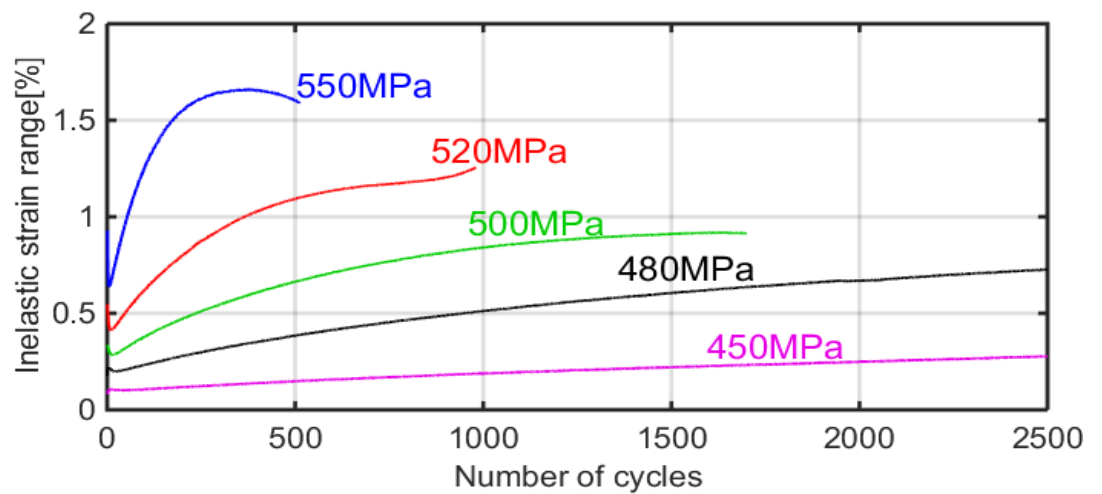

Fig. 4.16 Ratcheting tests at RT performed with zero $\sigma_{\text {mean }}$, stress rate $\pm 50 \mathrm{MPa} / \mathrm{s}$, various $\sigma_{a}$, and $\Delta \varepsilon^{\text {in }}$ vs. number of cycles.

It is clear that $\varepsilon_{r}^{\prime}$ under symmetric stress-controlled loading is higher with larger peak tensile stress, which is also stress amplitude $\sigma_{a}$ since $\sigma_{\text {mean }}$ is zero. As shown in Fig. 4.17, in the log-linear plot of $\varepsilon_{r}^{\prime}$ versus $\sigma_{a}$, a quasi-linear line can be found. The $\varepsilon_{r}^{\prime}$ shown in Fig. 4.17 are calculated as the average rates until the cycle in which the maximum strain reaches $2 \%$ or the cycle number achieves 1500 , which ever comes first.

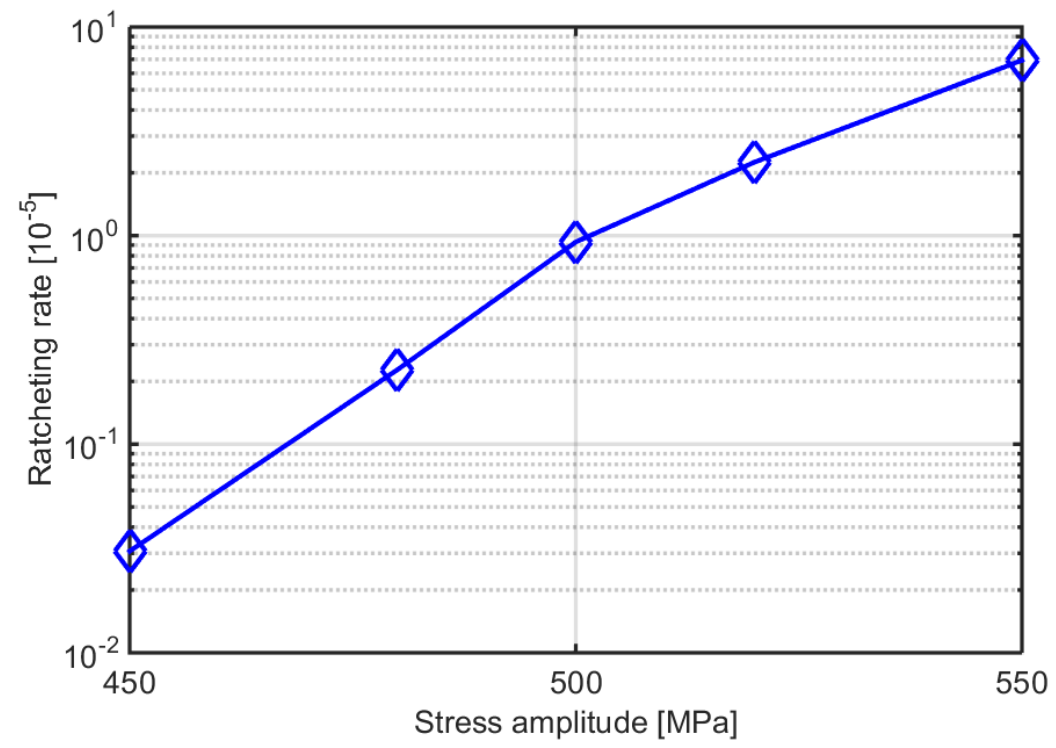

Fig. 4.17 Ratcheting tests at RT performed with zero $\sigma_{\text {mean, }}$ stress rate $\pm 50 \mathrm{MPa} / \mathrm{s}$, various $\sigma_{a}$, average ratcheting rates vs. $\sigma_{a}$ in log-linear diagram.

There are now three phenomena for P91 at RT:

1. The asymmetry of peak tensile and compressive stress in strain-controlled LCF tests (see Fig. 4.4).

2. Lower magnitude of $\varepsilon_{r}$ with compressive $\sigma_{\text {mean }}$ (see Fig. 4.10).

3. Positive $\varepsilon_{r}^{\prime}$ with zero $\sigma_{\text {mean }}$ (see Fig. 4.17).

These three phenomena together lead to the conclusion that at room temperature the strength of $\mathrm{P} 91$ is higher under compression than under tension. 


\subsubsection{Influence of stress rate}

Owing to the possible visco-plasticity of P91 steel at RT, the influence of time on ratcheting behavior was tested in experiments, including tests performed with different $\dot{\sigma}$ (stated in this section) and tests performed with different hold times (stated in Section 4.2.4). Two tests with $\dot{\sigma}= \pm 10$ and $\pm 250 \mathrm{MPa} / \mathrm{s}$ were performed. Together with the test performed with $\dot{\sigma}= \pm 50 \mathrm{MPa} / \mathrm{s}$ in the previous group, these results are shown in Fig. 4.18. The $\sigma_{\text {peak }}$ and $\sigma_{\text {mean }}$ are the same in these three tests, as listed in Table 3.3d.

It is clear that visco-plasticity plays a role at RT, as shown in Fig. 4.18, since lower $\dot{\sigma}$ leads to higher $\varepsilon_{r}^{\prime}$. According to the average $\varepsilon_{r}^{\prime}$ before the cycle in which the maximum strain reaches $4 \%$, the test performed with $\pm 10 \mathrm{MPa} / \mathrm{s}$ has an $18.3 \%$ higher $\varepsilon_{r}$ than the test performed with $\pm 50 \mathrm{MPa} / \mathrm{s}$, and the test performed with $\pm 250 \mathrm{MPa} / \mathrm{s}$ has a $22.3 \%$ lower $\varepsilon_{r}^{\prime}$ than the test performed with $\pm 50 \mathrm{MPa} / \mathrm{s}$. Hence, a five times higher $\dot{\sigma}$ leads to an approximately $20 \%$ lower $\dot{\varepsilon}_{r}$.

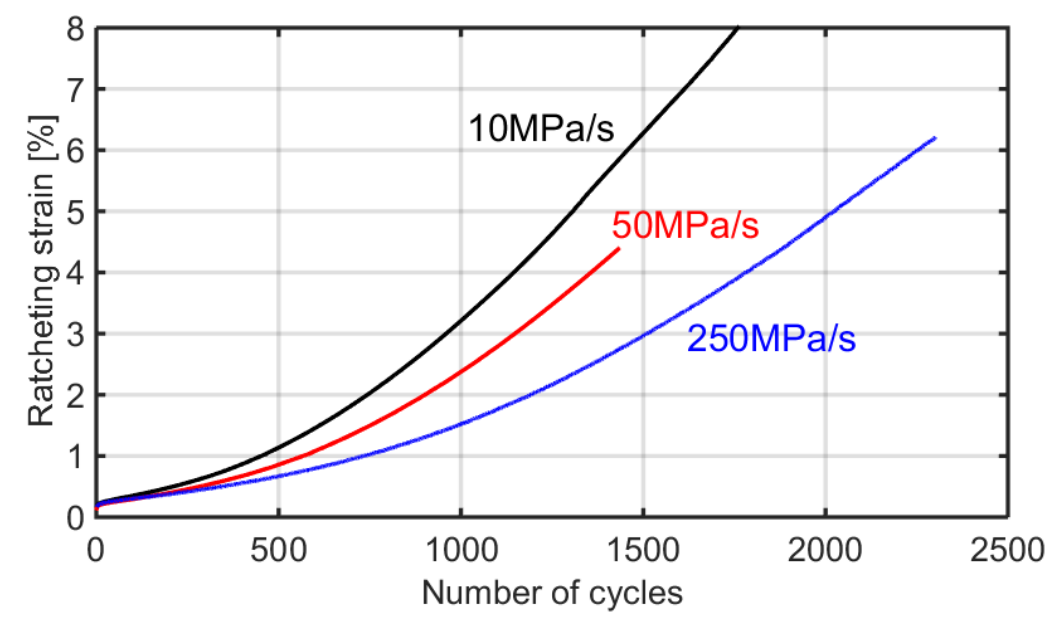

Fig. 4.18 Ratcheting tests at RT performed with $\sigma_{\text {peak }}=500 \mathrm{MPa}, \sigma_{\text {mean }}=25 \mathrm{MPa}$, various stress rates, $\varepsilon_{r} v s$. number of cycles.

The inelastic strain range of each cycle is plotted with corresponding cycle number in Fig. 4.19. It is clear that the higher stress rate leads to lower $\Delta \varepsilon^{\text {in }}$ owing to visco-plasticity. The evolution of $\Delta \varepsilon^{\text {in }}$ with each stress rate is similar to that in the other ratcheting test at RT (see Fig. 4.8, Fig. 4.12, and Fig. 4.16 ): After a short initial decrease, $\Delta \varepsilon^{\text {in }}$ increases evenly and smoothly but with a decreasing increase rate until the end of the test. 


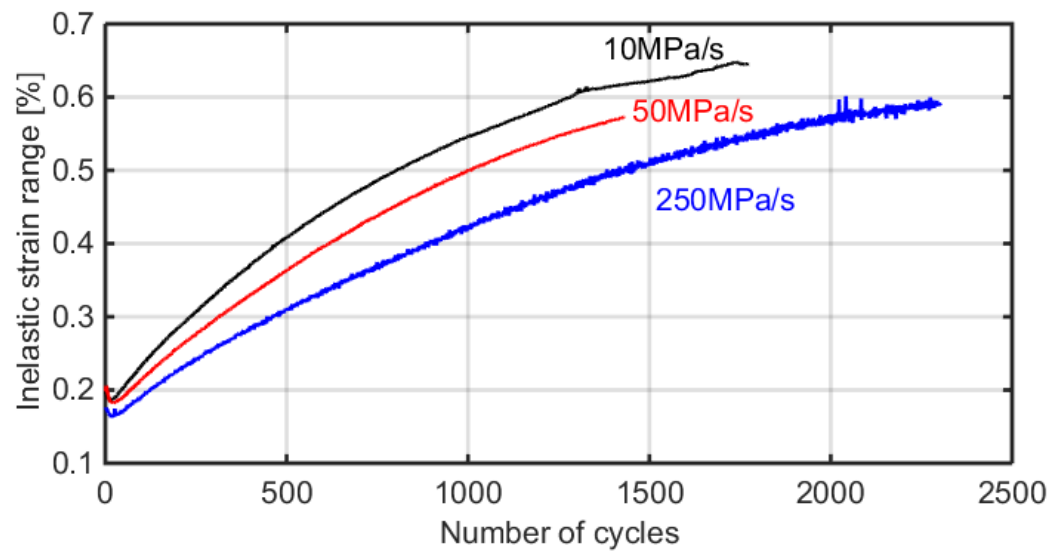

Fig. 4.19 Ratcheting tests at RT performed with $\sigma_{\text {peak }}=500 \mathrm{MPa}, \sigma_{\text {mean }}=25 \mathrm{MPa}$, various stress rates, $\Delta \varepsilon^{\text {in }}$ vs. number of cycles.

\subsubsection{Influence of hold time}

As planned in Table 3.3e, two tests with 10 min hold times at peak tensile and compressive stresses were performed to discover the role of time/visco-plasticity at RT. Together with the test performed with no hold time in the previous group, the results are shown in Fig. 4.20. The $\sigma_{\text {peak }}, \sigma_{\text {mean }}$ and $\dot{\sigma}$ were the same in these three tests.

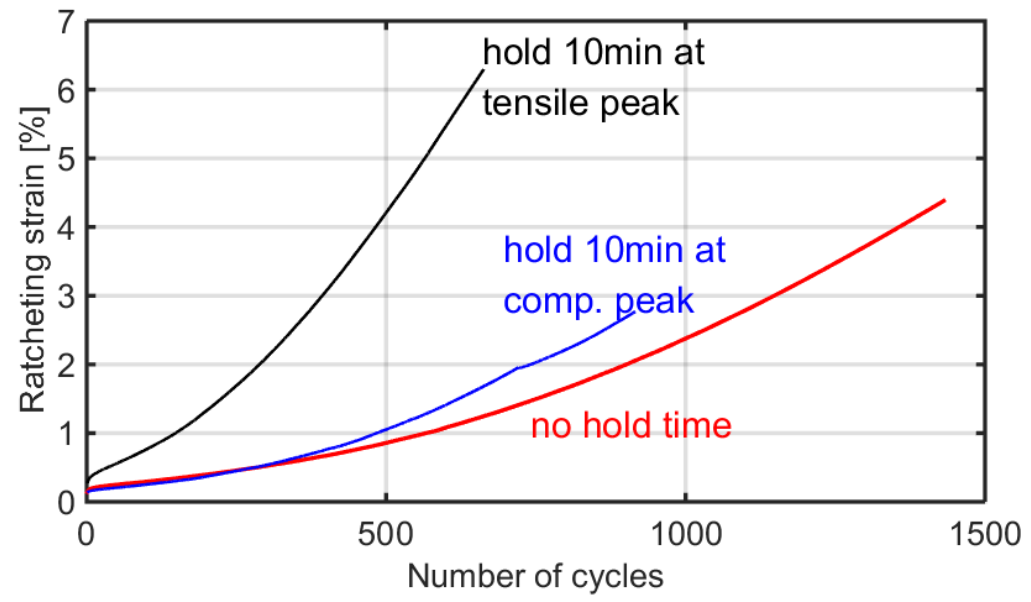

Fig. 4.20 Ratcheting tests at RT performed with $\sigma_{\text {peak }}=500 \mathrm{MPa}, \sigma_{\text {mean }}=25 \mathrm{MPa}$, stress rate $\pm 50 \mathrm{MPa} / \mathrm{s}$, various hold time types, $\varepsilon_{r}$ vs. number of cycles.

The $10 \mathrm{~min}$ hold times at tensile peaks (500 MPa) dramatically accelerated the ratcheting while hold times at compressive peaks (-450 MPa) scarely accelerated the ratcheting.

After analysis of the two tests with hold times at the tensile and compressive peaks, the inelastic strains during the hold time in each cycle can be found, as illustrated in Fig. 4.21. As can be seen, the inelastic strains at tensile and compressive peaks agree with each other. The inelastic strain during the first cycle of the test with 10 min hold time at tensile peak is around $0.115 \%$. The inelastic strains in the initial approximately 30 cycles decrease rapidly and then slightly increase again until the 
end of the test owing to cyclic softening. Because of the limit of accuracy, only conservative calculations of the accumulated inelastic strains can be acquired, which are $16.70 \%$ and $-15.63 \%$ at tensile and compressive hold times, respectively. Concerning the total accumulated inelastic strain, the accumulated partial inelastic strain formed during the stress-changing process was $-12.49 \%$ in the test performed with 10 min hold times at tensile peaks, while this accumulated strain of the test performed with 10 min hold times at compressive peaks was $16.68 \%$.

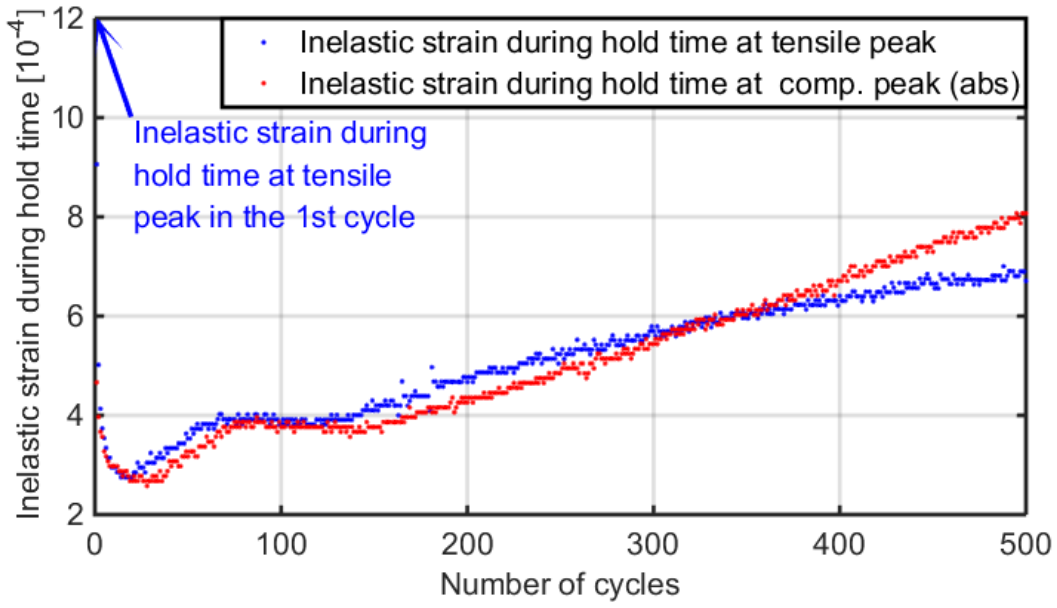

Fig. 4.21 Ratcheting tests at RT performed with $\sigma_{\text {peak }}=500 \mathrm{MPa}, \sigma_{\text {mean }}=25 \mathrm{MPa}$, stress rate $\pm 50 \mathrm{MPa} / \mathrm{s}$, inelastic strain during hold times at tensile \& compressive peaks vs. number of cycles.

An additional test was performed with the same equipment as the ratcheting tests, with stress of $500 \mathrm{MPa}$. The result is illustrated in Fig. 4.22. In spite of the initial stage of fast increase of inelastic strain, the strain increase after the first hour until the $24^{\text {th }}$ hour is negligible. Therefore, the accumulated inelastic strain during hold times in the ratcheting test is much higher than that in the test with static stress of $500 \mathrm{MPa}$, because the mechanical behavior during hold times is similar to the initial stage in the test with static stress. The inelastic strain in the first $10 \mathrm{~min}$ in the test with static stress is $0.18 \%$, which is comparable with $0.12 \%$ during the 10 min hold time at tensile peak in the first cycle of the ratcheting test.

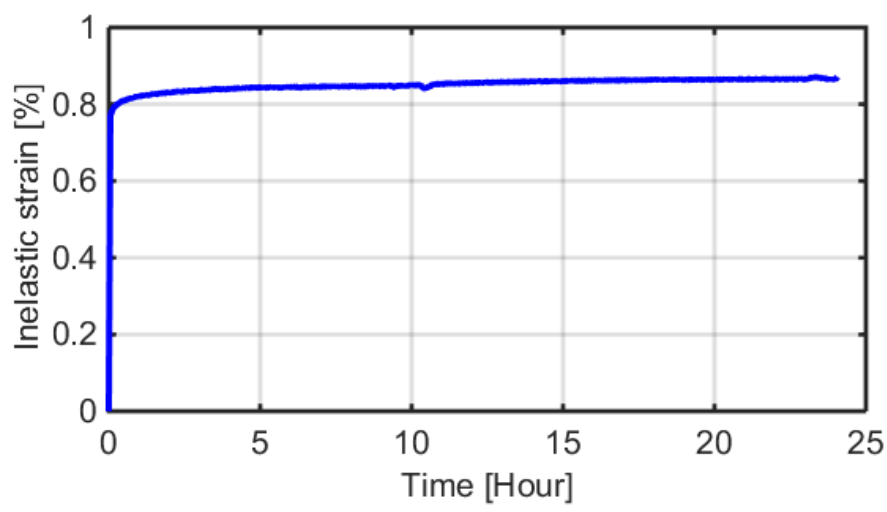

Fig. 4.22 Test at RT performed with $\sigma=500 M P a$, inelastic strain vs. time.

To understand why the accumulated inelastic strain during the stress-changing process is negative $(-12.49 \%)$ in the test performed with hold times at tensile peaks, the hysteresis loops of three tests are plotted in Fig. 4.23. The three loops are aligned by 
setting the center as zero. As can be seen, in spite of a slight total inelastic strain increment (ratcheting), the material response to the cyclic stress-controlled loading has a tendency to close the hysteresis loop. This tendency is much clearer in the case with hold time at the compressive peak: As shown in Fig. 4.23, the change of inelastic strain during the hold time is $-0.080 \%$, while the total inelastic strain increment during this cycle (ratcheting) is only $0.003 \%$. This means the partial inelastic strain formed during the stress-changing process compensates most of the partial inelastic strain increment during the hold time. Owing to this tendency, $\varepsilon_{r}^{\prime}$ of the test performed with hold time at tensile peak is only around five times higher than that without hold time, and the test performed with hold times at compressive peaks still has positive ratcheting.

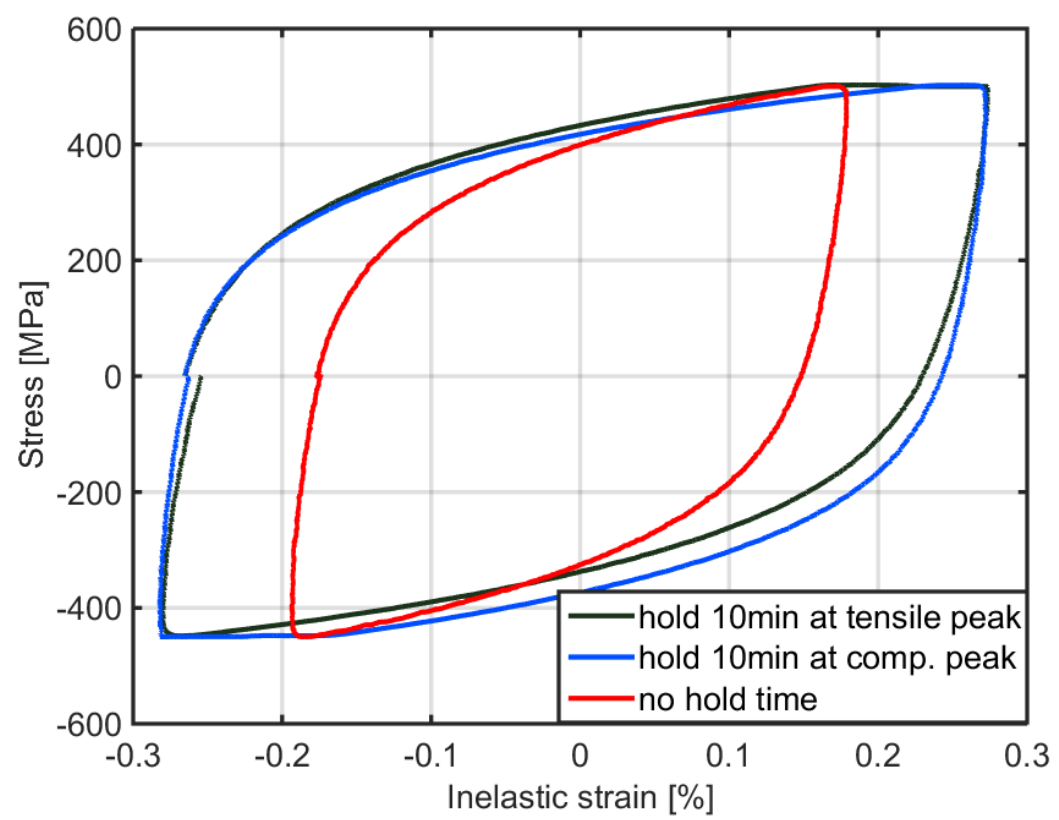

Fig. 4.23 Ratcheting tests at RT performed with $\sigma_{\text {peak }}=500 \mathrm{MPa}, \sigma_{\text {mean }}=25 \mathrm{MPa}$, stress rate $\pm 50 \mathrm{MPa} / \mathrm{s}$, stress vs. inelastic strain (normalized) at $500^{\text {th }}$ cycle.

This tendency to close the loop can also be approved by the decrease of $\varepsilon_{r}$ in the initial cycles in the ratcheting tests, when cyclic softening has not played a key role: $\varepsilon_{r}^{\prime}$ in each cycle versus cycle number is plotted in Fig. 4.24. Those $\varepsilon_{r}^{\prime}$ in the initial cycles are marked with larger markers. As can be seen, $\varepsilon_{r}^{\prime}$ decreases rapidly in the initial cycles, which means the hysteresis loop tends to close in the initial stage of the ratcheting tests. $\varepsilon_{r}^{\prime}$ increases slightly in the following cycles until the end of the test, owing to cyclic softening. This phenomenon also exists in the other ratcheting tests. 


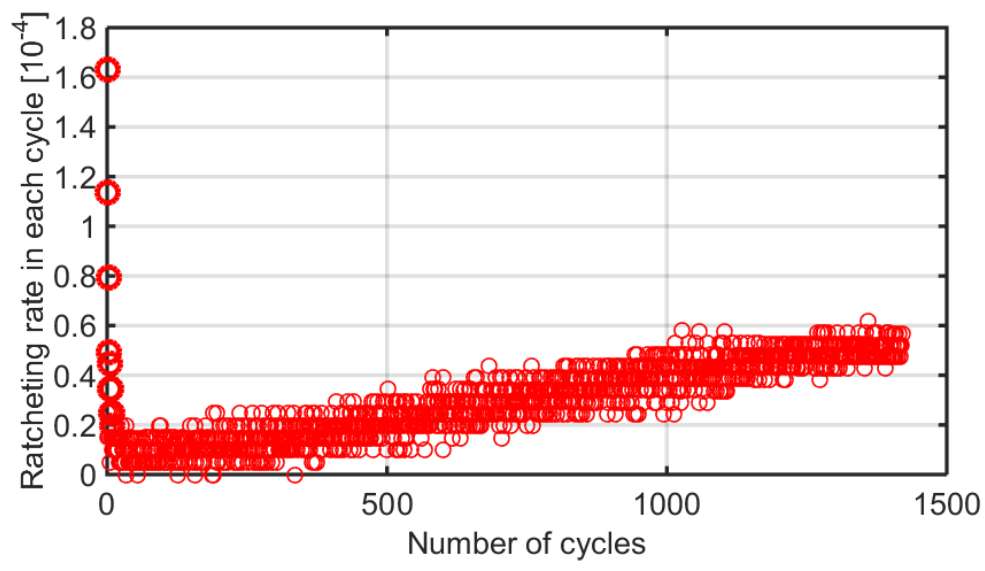

Fig. 4.24 Ratcheting test at $R T$ performed with $\sigma_{\text {peak }}=500 \mathrm{MPa}, \sigma_{\text {mean }}=25 \mathrm{MPa}$, stress rate $\pm 50 \mathrm{MPa} / \mathrm{s}$, no hold time, ratcheting rate vs. number of cycles.

\subsubsection{Diameter Check}

After the experiments at room temperature, the diameters of the specimens in different axial positions were checked. Fig. 4.25 shows some examples of the tested specimens. The three marked diameters on each specimen include two near the end of gage length and one in the middle.

As shown in Fig. 4.25, the three measured diameters on each specimen are similar, hence no necking occurs. Further, in the test of stress range 550 -500 MPa, the average of the three measured diameters was $8.50 \mathrm{~mm}$ while the initial diameter of the received specimen was $8.80 \mathrm{~mm}$. The shrinkage of the cross section is $1 / 1.072$, which approximately corresponds to the $7.4 \%$ of strain. In the other tests, the shrinkage of the specimen also corresponds to each final strain. Therefore the prerequisite to apply the so called "true-stress-controlled ratcheting test" is verified, which is that the shrinkage of cross section corresponds to the real time strain, based on the assumption of no volumetric plastic strain during tests. 


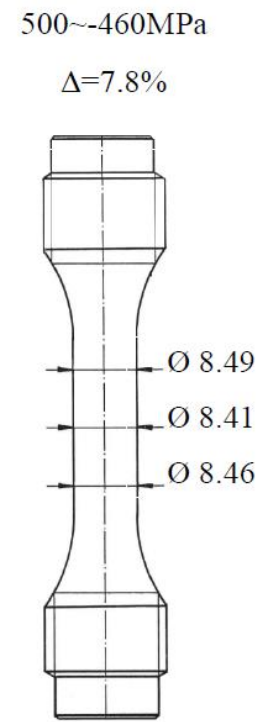

$$
\begin{gathered}
550 \sim-500 \mathrm{MPa} \\
\Delta=7.4 \%
\end{gathered}
$$

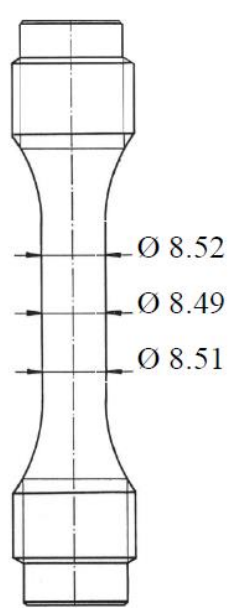

$500 \sim-480 \mathrm{MPa}$

$\Delta=7.0 \%$

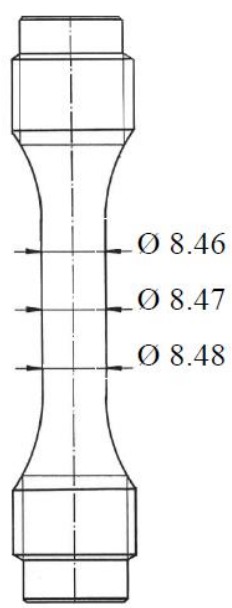

$500 \sim-450 \mathrm{MPa}$

$\Delta=4.1 \%$

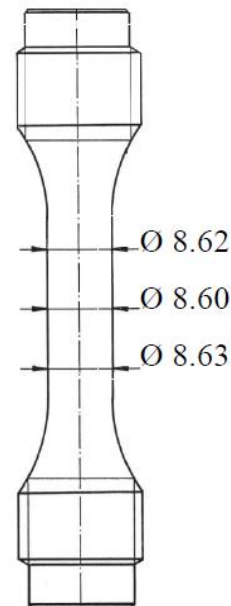

Fig. 4.25 Diameter check of several specimens in RT ratcheting tests. 


\section{Experiments at $550^{\circ} \mathrm{C}$}

The previous chapter reported the material responses under symmetric uniaxial strain-controlled cyclic loading and under asymmetric/symmetric uniaxial stress-controlled cyclic loading at room temperature. Various unique phenomena were found on P91 at room temperature, such as cyclic softening and asymmetry of material strength under tension and compression. It is interesting to investigate the material responses at high temperature $\left(550{ }^{\circ} \mathrm{C}\right)$ to check whether these phenomena still exist.

In this chapter, the results of experiments at $550{ }^{\circ} \mathrm{C}$ are presented. The hydraulic machine, measure and control equipment, and software are the same as at those used at RT, as presented in Section 3.1. The difference is an additional oven to heat the specimens together with the specimen-holder for the oven. As reviewed in Chapter 2, oxidation effect on cyclic softening and ratcheting can be ignored [82-84], and crack initiation and propagation is not taken into account. The planned experiments are listed in Section 3.3, including strain-controlled LCF tests in Section 3.3.1 and stress-controlled tests in Section 3.3.2. The results of the strain-controlled tests are presented in Section 5.1, and Section 5.2 reports the results of stress-controlled tests, including the influences of various factors on ratcheting, such as $\sigma_{\text {peak }}, \sigma_{\text {mean }}, \dot{\sigma}$, and hold time. The ratcheting results with zero $\sigma_{\text {mean }}$ at $550{ }^{\circ} \mathrm{C}$ are shown in Section 5.2.3, in comparison to those at RT reported in Section 4.2.3.

\subsection{Results of Strain-controlled Tests}

According to Table 3.4, five symmetric strain-controlled LCF tests were performed. The results are essentially the same as those shown in Fig. 4.1a-c.

The main difference between results at RT and $550{ }^{\circ} \mathrm{C}$ is obviously lower induced stresses at $550{ }^{\circ} \mathrm{C}$. Fig. 5.1a shows the hysteresis loops of the $1^{\text {st }}, 200^{\text {th }}$, and $400^{\text {th }}$ cycles of the LCF test performed with $\Delta \varepsilon=1.5 \%$. Compared with Fig. $4.1 \mathrm{~d}$, it was found that both the initial $\sigma_{\text {peak }}$ and those during saturation stage were much lower at $550{ }^{\circ} \mathrm{C}$ than that at RT, as the material strength is much lower at $550{ }^{\circ} \mathrm{C}$ than at RT.

Another difference is that the initial cyclic hardening is negligible at $550{ }^{\circ} \mathrm{C}$; the peak tensile stress monotonically decreases either after the $1^{\text {st }}$ cycle $(\Delta \varepsilon=1.5$ and $1.2 \%)$ or after the $2^{\text {nd }}$ cycle $(\Delta \varepsilon=1.0$ and 0.8 and $0.6 \%)$. Fig. $5.1 \mathrm{~b}$ shows the peak tensile stresses in the initial 15 cycles in the LCF test performed with $\Delta \varepsilon=1.5 \%$, compared with Fig. 4.1e for the case at RT. 
One more difference is the obviously shorter lifetime. Comparing Fig. 5.1c and Fig. 4.1f, the cycle number until macro cracks appear at $550{ }^{\circ} \mathrm{C}$ is around 400 at $550{ }^{\circ} \mathrm{C}$, compared with around 1100 cycles at RT.

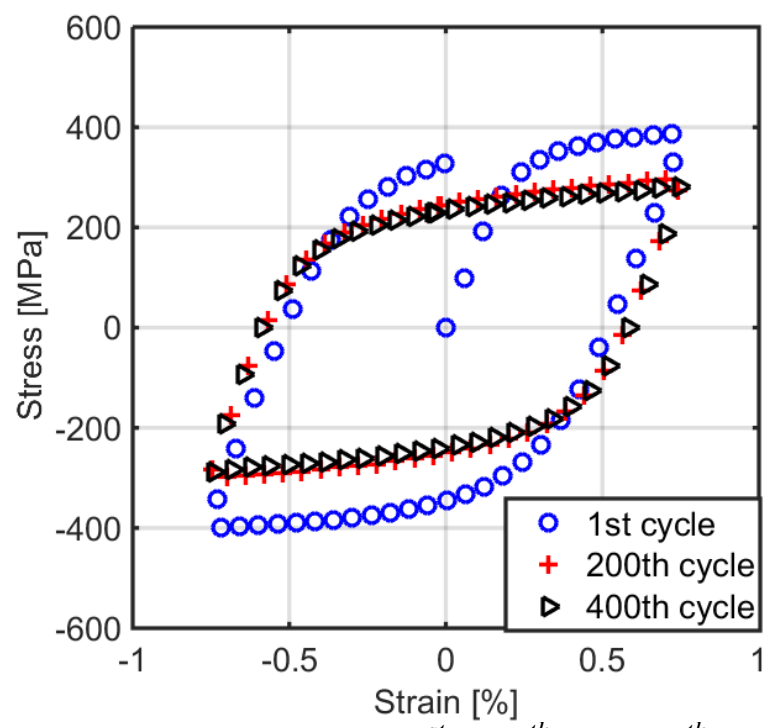

a) Hysteresis loops of $1^{\text {st }}, 200^{\text {th }}$ and $400^{\text {th }}$ cycle.
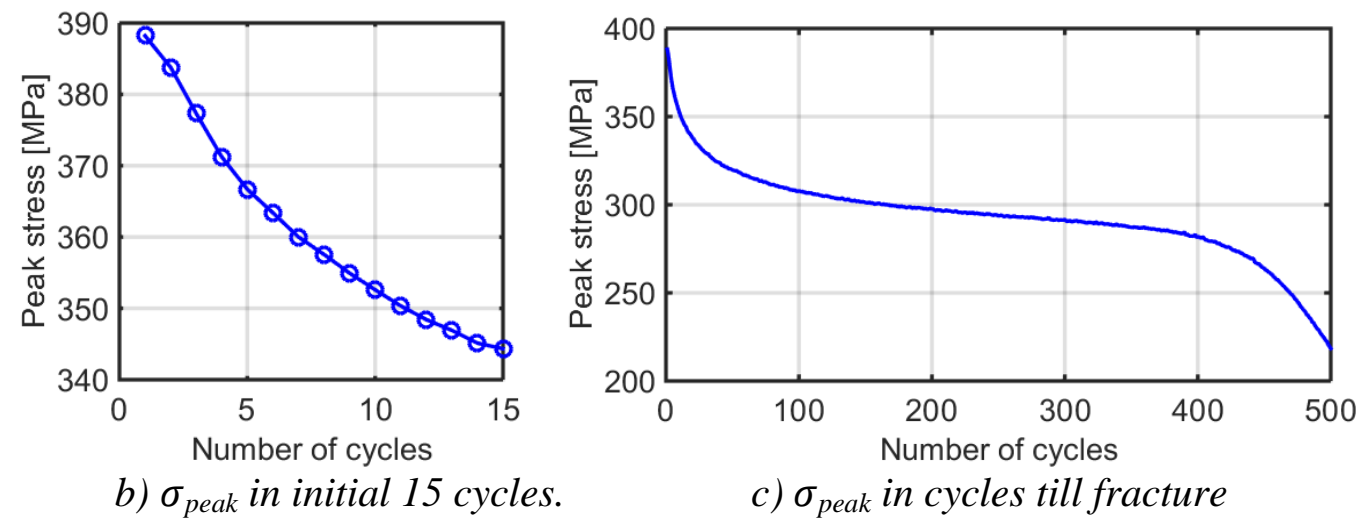

Fig. 5.1 Symmetric strain-controlled LCF tests at $550^{\circ} \mathrm{C}, \Delta \varepsilon=1.5 \%$.

The lifetime in LCF test at $550{ }^{\circ} \mathrm{C}$ is clearly defined, which is different from that for RT cases, because the peak tensile stresses in all five LCF tests decrease smoothly cycle by cycle after the macro cracks appear, since the gage length of the extensometer is $20 \mathrm{~mm}$ and the macro crack always appears within this gage length. As illustrated in Fig. 5.2, the cycle number of lifetime, or cycle number to failure, is defined as the cycle during which $\sigma_{\text {peak }}$ has decreased by $10 \%$ from that predicted by extrapolation of the saturation curve, as in Saad et al. [101].

Hysteresis loops of initial cycles and cycles at the half lifetime of the five LCF tests are illustrated in Fig. 5.3a and b, respectively, and the peak tensile stresses are illustrated in Fig. 5.3c. As same as at RT, the peak tensile stress decreases rapidly in the initial 1/4 lifetime and the saturation stage follows afterwards until macro cracks appear. 


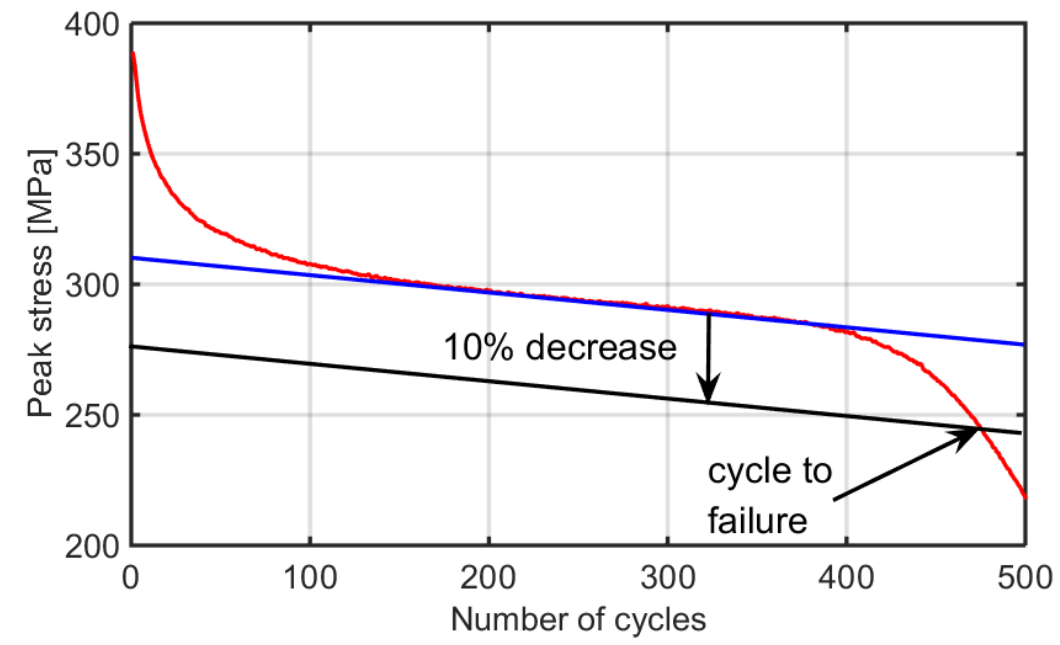

Fig. 5.2 Definition of lifetime in LCF tests at $550{ }^{\circ} \mathrm{C}$. Strain-controlled LCF test with strain range $1.5 \%$.

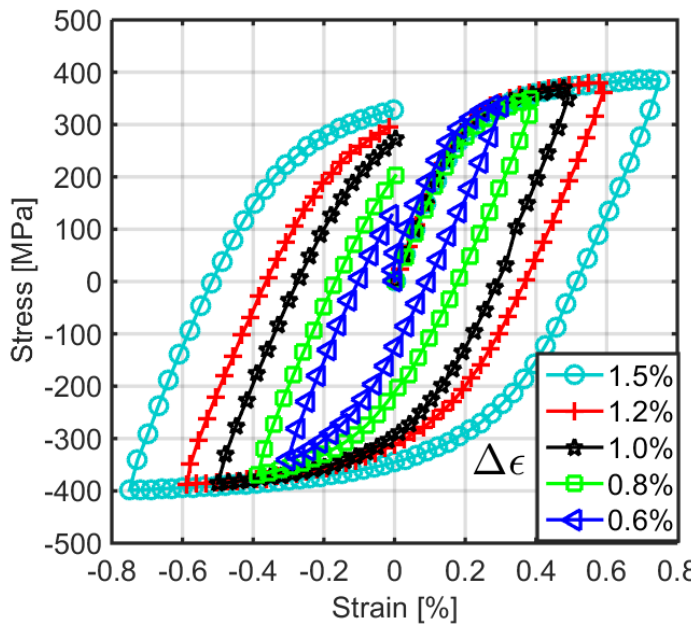

a) Hysteresis loops of the first cycle

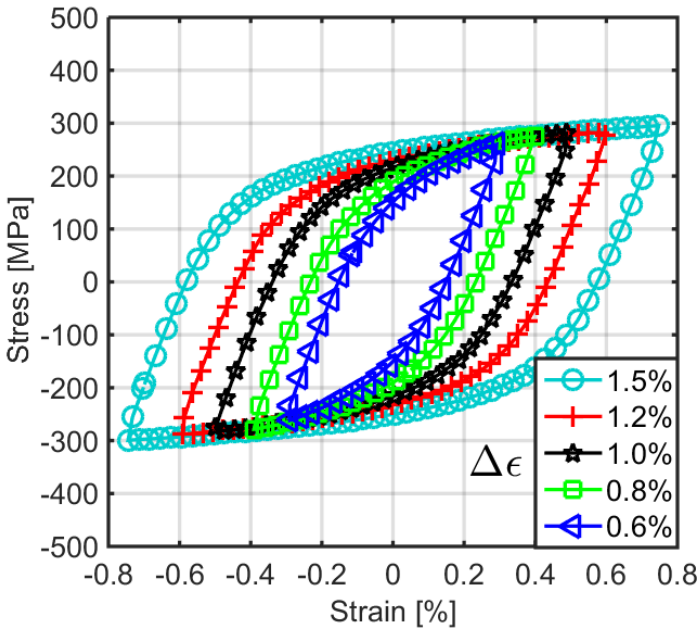

b) Hysteresis loops of the cycle at $N_{f} / 2$

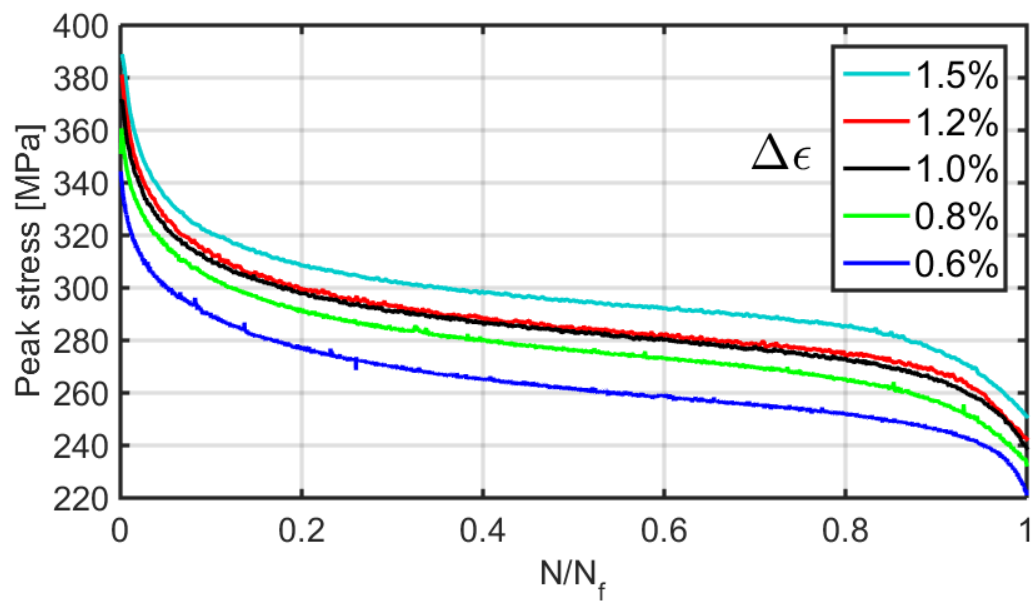

c) Peak tensile stresses vs. normalized number of cycles.

Fig. 5.3 Strain-controlled LCF tests at $550{ }^{\circ} \mathrm{C}$ performed with strain ranges $0.6 \% \sim 1.5 \%$. 
The grades of cyclic softening at two temperatures are also compared. By calculating the ratio between the engineering peak tensile stress in the middle of the saturation stage and the maximum engineering peak tensile stress during whole lifetime, it was found that the grade of cyclic softening is larger at $550{ }^{\circ} \mathrm{C}$ : The ratio is $0.88 \pm 0.01$ at RT and $0.76 \pm 0.01$ at $550{ }^{\circ} \mathrm{C}$.

The magnitudes of peak compressive stresses also decrease as peak tensile stresses. There were also differences of 2 5 MPa between peak tensile and compressive stresses in all cycles. As shown in Fig. 5.4, the red curves indicate the absolute value of peak compressive stresses and the blue curves indicate peak tensile stresses.

By converting the $\sigma_{\text {eng }}$ in Fig. 5.4 into $\sigma_{\text {true }}$ in Fig. 5.5, pure material responses are clear: The absolute values of true peak compressive stresses are not larger than the true peak tensile stresses, both in the initial rapid decreasing stages of peak stresses and in the saturation stage. The differences appear only after the appearance of macro cracks.

It is clear that the asymmetry of $\sigma_{\text {peak }}$ in the symmetric strain-controlled LCF at $550{ }^{\circ} \mathrm{C}$ is negligible, comparing to the asymmetry at RT. It is assumed that the material strength under tension and compression is the same at $550{ }^{\circ} \mathrm{C}$. Therefore, it is interesting to predict what can happen in the following stress-controlled tests: is there still positive ratcheting under symmetric loading as at RT? 

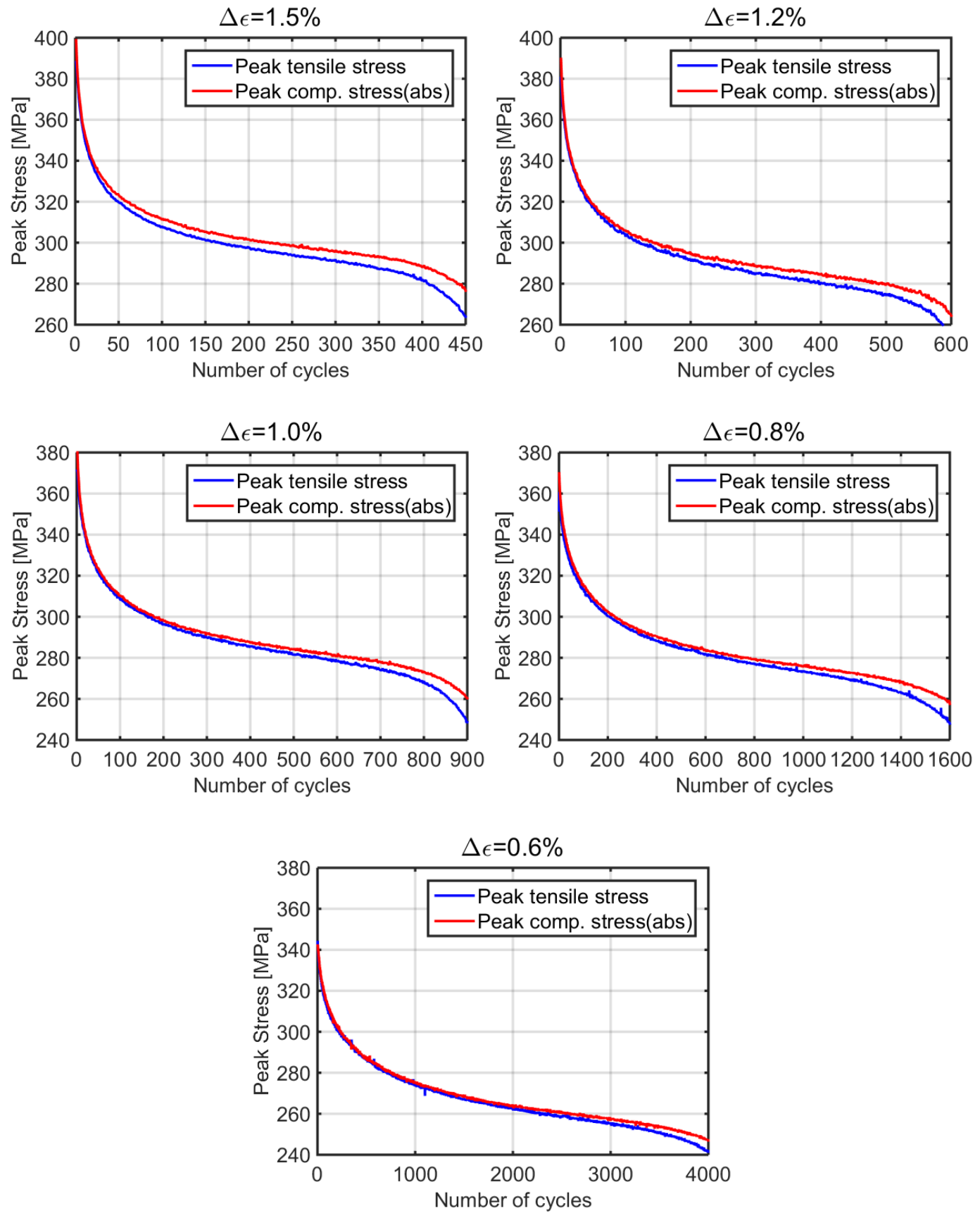

Fig. 5.4 Engineering peak compressive stresses (abs.) compared with engineering peak tensile stresses at $550{ }^{\circ} \mathrm{C}$. 

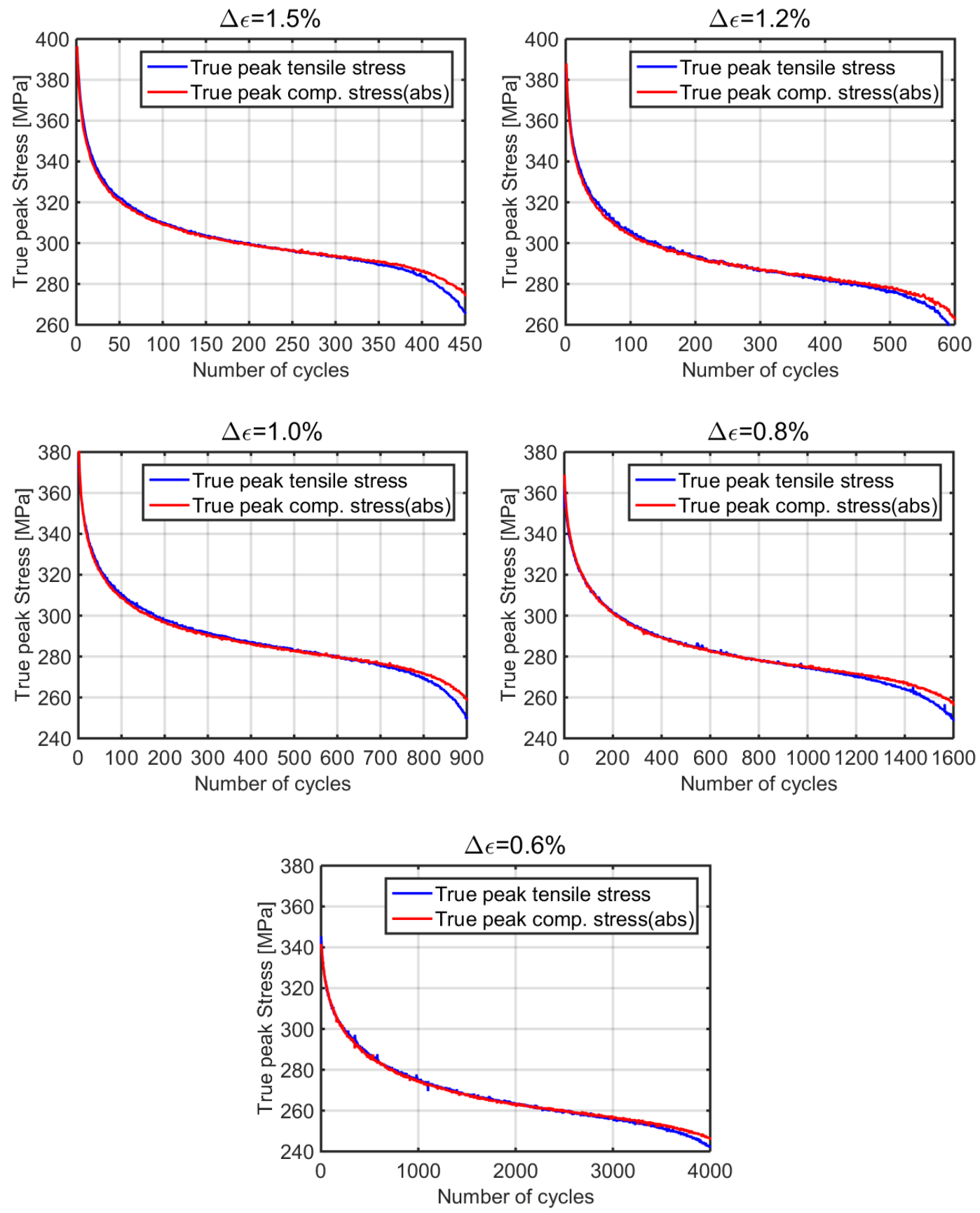

Fig. 5.5 True peak compressive stresses (abs.) compared with true peak tensile stresses at $550{ }^{\circ} \mathrm{C}$.

In addition, due to the non-negligible stress relaxation in strain-controlled tests at high temperature, another two LCF tests were performed with hold time at peak strain under tension and under compression. The results are presented in Fig. 5.6. 


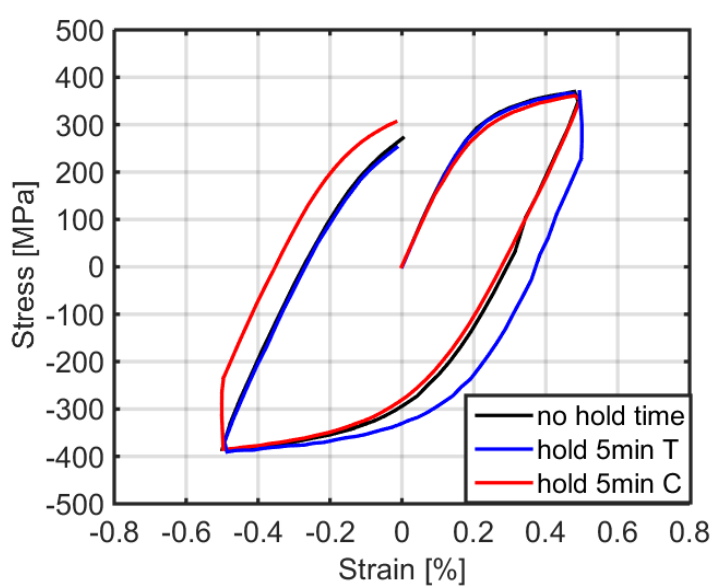

a) Hysteresis loops of the first cycle.

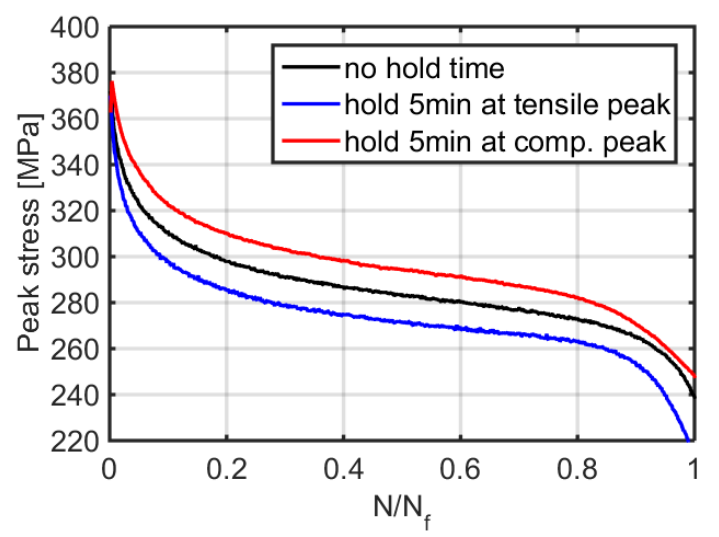

c) $\sigma_{\text {peak }} v$ s. normalized number of cycles

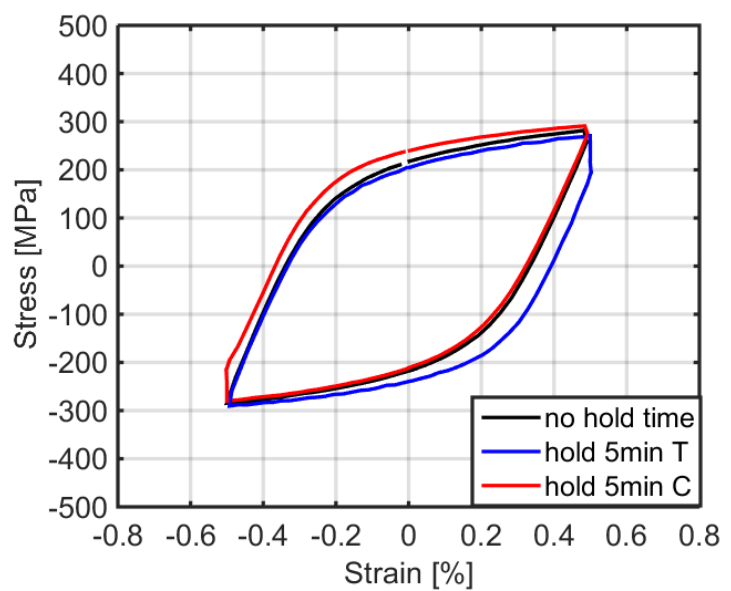

b) Hysteresis loops of the cycle at the half lifetime.

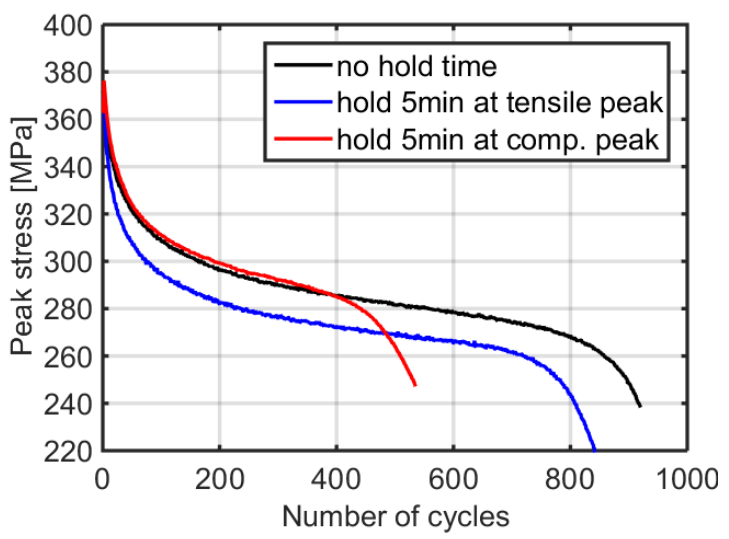

d) $\sigma_{\text {peak }} v s$. real number of cycles

Fig. 5.6 Strain-controlled LCF tests at $550{ }^{\circ} \mathrm{C}$ performed with strain range $1.0 \%$ and various hold times.

As shown in Fig. 5.6, the peak tensile stress in the test performed with 5 min hold time at compressive peak was around $10 \mathrm{MPa}$ larger than that without hold time, while the test performed with 5 min hold time at tensile peak was around $10 \mathrm{MPa}$ smaller than that without hold time. This phenomenon explains why the lifetime with compressive hold is shorter than those without and with tensile hold, as shown in Fig. 5.6d. The lifetime with tensile hold is shorter than that without hold time, which is owing to the larger inelastic strain in each cycle, according to the Coffin-Manson relationship [52-54]. Since the result is comparable to those reported by Shankar et al. [82], in the sense that the lifetime with compressive hold is much shorter than that with tensile hold or without hold, the assistant effect of compressive hold time to oxide layer is also an important reason of reduced lifetime with compressive hold. However, the topic of fatigue damage and lifetime is not the focus of the current work. The material responses in these two tests with hold times illustrate the static recovery of kinematic hardening and cyclic softening of P91 at $550{ }^{\circ} \mathrm{C}$, which are important for the modeling approach afterwards. 


\subsection{Results of Stress-controlled Ratcheting Tests}

In the second stage of experiments at $550{ }^{\circ} \mathrm{C}$, a variety of groups of uniaxial stress-controlled tests were performed. Fig. 5.7 illustrates one of the tests at $550^{\circ} \mathrm{C}$ performed with $\sigma_{\text {peak }}=325 \mathrm{MPa}$ and $\sigma_{\text {mean }}=10 \mathrm{MPa}$. The stress rate is $\pm 50 \mathrm{MPa} / \mathrm{s}$, which is the same for that in Fig. 4.6 in the previous chapter. As at RT, the stresses are in form of triangle wave (see Fig. 4.6 a) and strains are induced by stresses (see Fig. $4.6 \mathrm{~b}$ ); the induced $\varepsilon_{\text {mean }}$ increase with number of cycles, which shows ratcheting behavior (see Fig. 4.6e), and strain ranges also increase owing to cyclic softening (see Fig. 4.6 d).

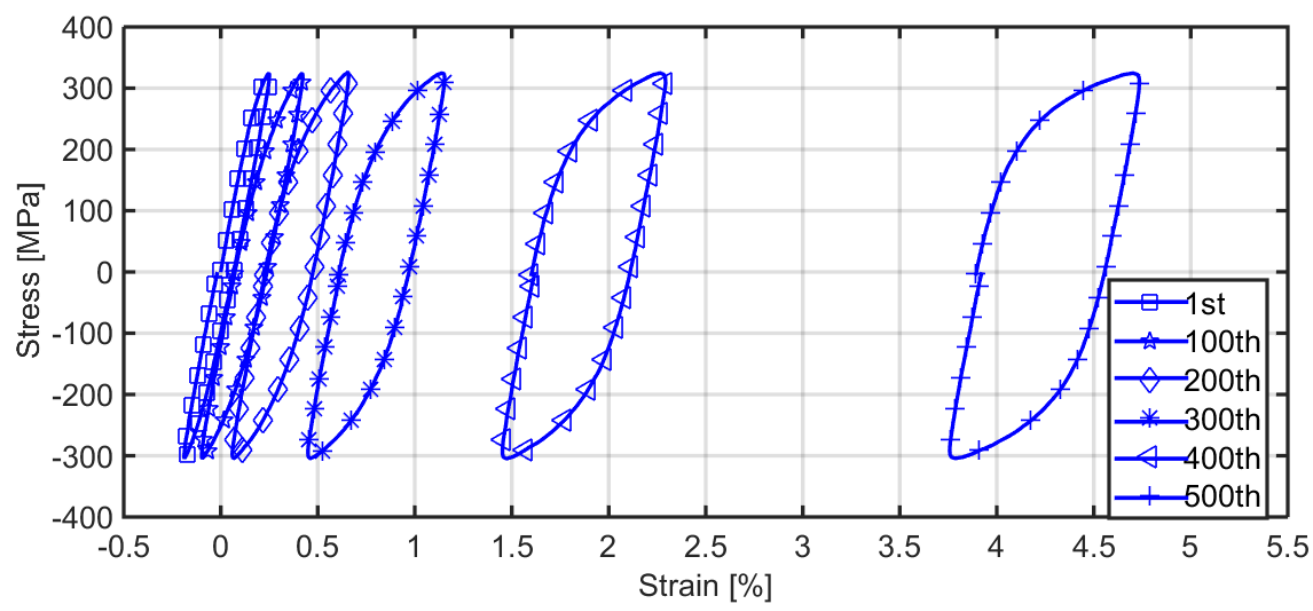

Fig. 5.7 Ratcheting tests at $550^{\circ} \mathrm{C}$ performed with $\sigma_{\text {peak }}=325 \mathrm{MPa}, \sigma_{\text {mean }}=10 \mathrm{MPa}$, stress rate $\pm 50 \mathrm{MPa} / \mathrm{s}$, hysteresis loops of the $1^{\text {st }} 100^{\text {th }} 200^{\text {th }} 300^{\text {th }} 400^{\text {th }} 500^{\text {th }}$ cycles.

In the following Sections 5.2.1 5.2.5, various groups of results are illustrated, corresponding to Table 3.5 and Table 3.6.

\subsubsection{Influence of peak stress}

According to Table 3.5a, six uniaxial ratcheting tests were performed to investigate the influence of peak stress. $\varepsilon_{r}$ versus number of cycles is plotted in Fig. 5.8. Since the $\varepsilon_{r}^{\prime}$ of the test performed with $\sigma_{\text {peak }}=275 \mathrm{MPa}$ was negligible comparing to the other five tests, it is separately plotted in Fig. 5.8b. It is obvious that $\varepsilon_{r}^{\prime}$ is higher with larger $\sigma_{\text {peak }}$. 


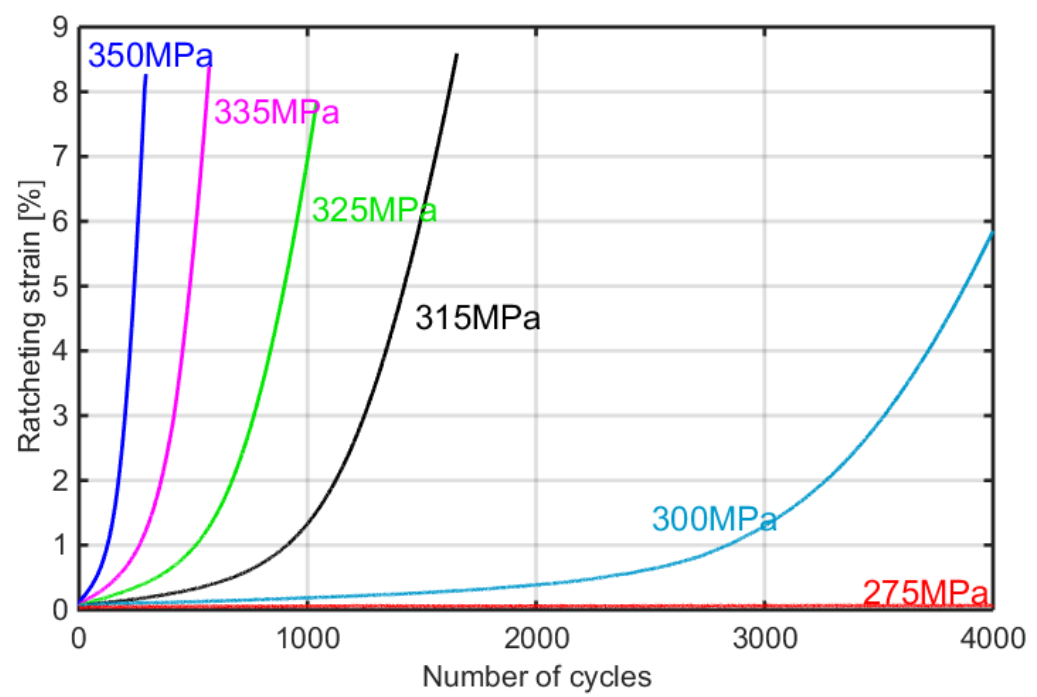

a)

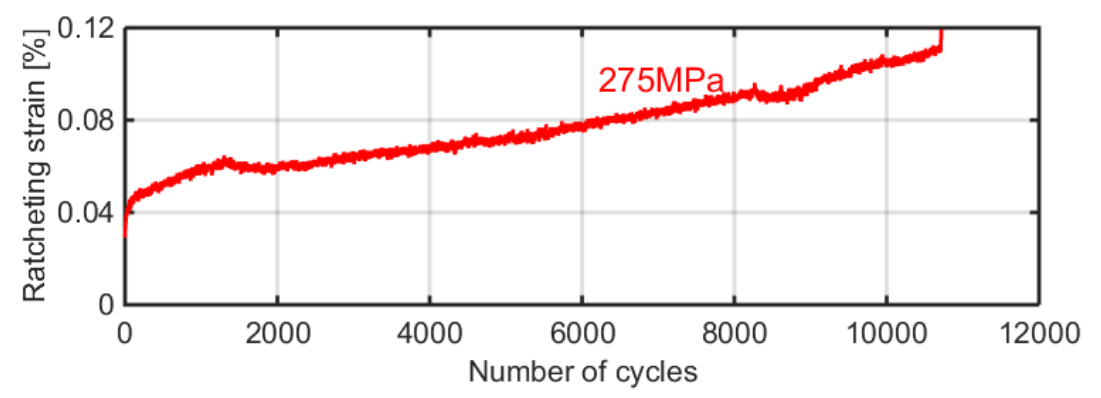

b)

Fig. 5.8 Ratcheting tests at $550^{\circ} \mathrm{C}$ performed with $\sigma_{\text {mean }}=25 \mathrm{MPa}$, stress rate $\pm 50 \mathrm{MPa} / \mathrm{s}$, various $\sigma_{\text {peak }}, \varepsilon_{r} v \mathrm{~s}$. number of cycles.

$\Delta \varepsilon^{i n}$ versus number of cycles of the six ratcheting tests is plotted in Fig. 5.9. The evolution of $\Delta \varepsilon^{i n}$ is similar to that at RT (see Fig. 4.8), with an even and smooth increase of $\Delta \varepsilon^{\text {in }}$ owing to cyclic softening, however without showing two stages as in strain-controlled tests (see Fig. 5.3). Note that none of these six ratcheting tests end with macro cracks.

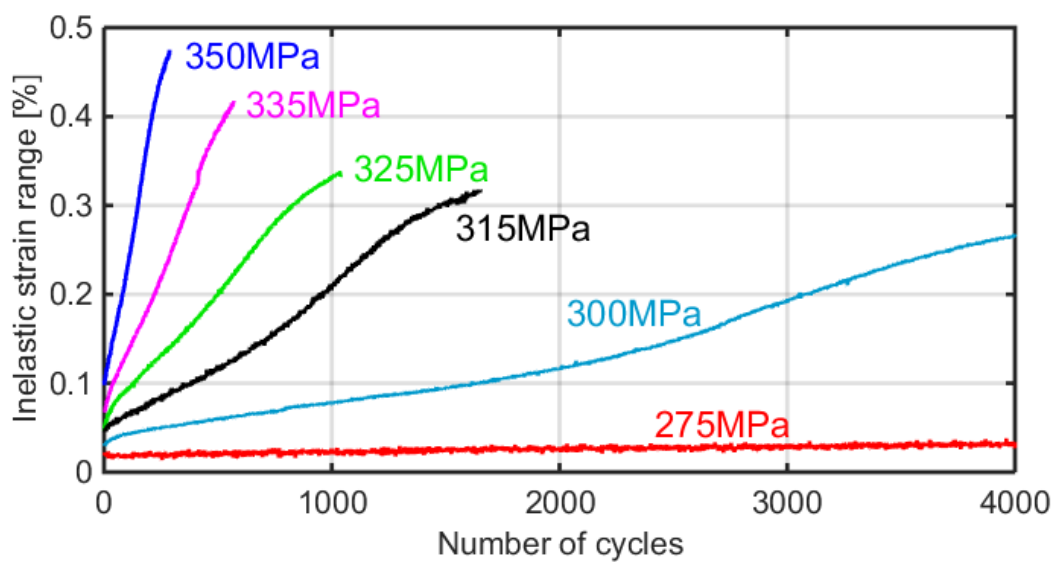

Fig. 5.9 Ratcheting tests at $550{ }^{\circ} \mathrm{C}$ performed with $\sigma_{\text {mean }}=25 \mathrm{MPa}$, stress rate $\pm 50 \mathrm{MPa} / \mathrm{s}$, various $\sigma_{\text {peak }}, \Delta \varepsilon^{\text {in }}$ vs. number of cycles.

When the $\varepsilon_{r}^{\prime}$ are put together with their $\sigma_{\text {peak }}$ in a log-linear plot (see Fig. 5.10), a quasi-linear relationship can be seen, which is similar to the case at RT (see Fig. 4.9). 
$\varepsilon_{r}^{\prime}$ shown in Fig. 5.10 are the average rates until the cycle in which the maximum strain reaches $3 \%$ or cycle number achieves 10000 , which ever comes first.

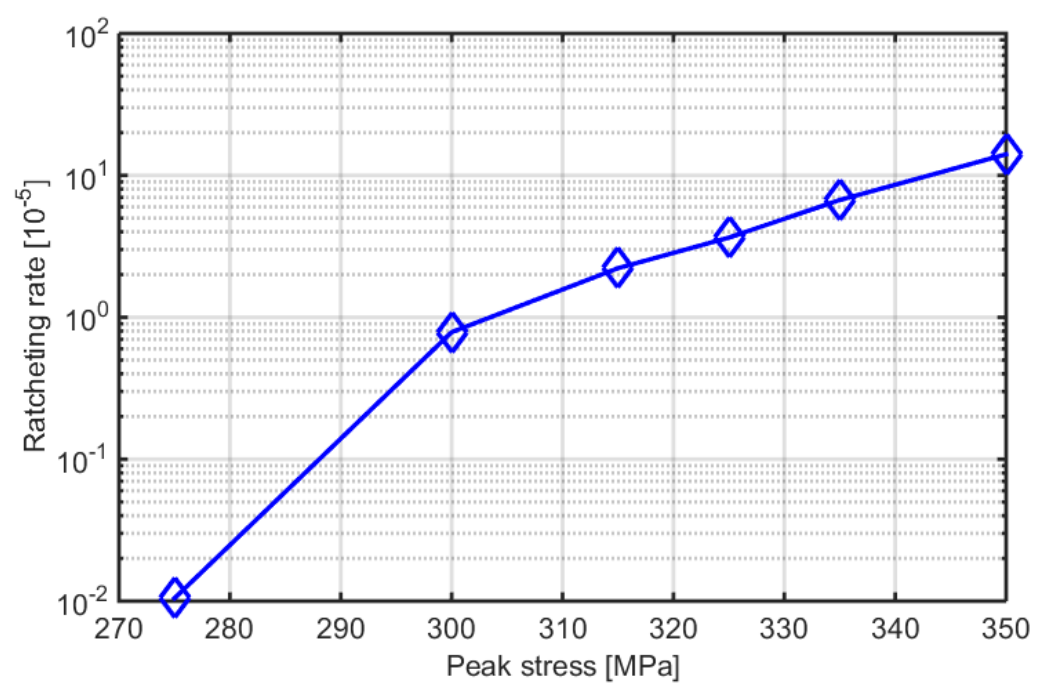

Fig. 5.10 Ratcheting tests at $550^{\circ} \mathrm{C}$ performed with $\sigma_{\text {mean }}=25 \mathrm{MPa}$, stress rate $\pm 50 \mathrm{MPa} / \mathrm{s}$, average ratcheting rates vs. $\sigma_{\text {peak }}$ in log-linear diagram.

Similar to at RT, one more verification test was performed at $550{ }^{\circ} \mathrm{C}$ with $\sigma_{\max }=310 \mathrm{MPa}$ and $\sigma_{\min }=-325 \mathrm{MPa}$. As illustrated in Fig. 5.11, the absolute values of $\varepsilon_{r}$ in the loading cases with stress ranges $325 \sim-310 \mathrm{MPa}$ and 310 -325 MPa agree with each other; in other words, the symmetric mean stress $( \pm 7.5 \mathrm{MPa})$ leads to symmetric $\varepsilon_{r}$. This symmetry can be compared with the asymmetry in the cases at RT reported in Section 4.2.1 (see Fig. 4.10), where the loadings with compressive $\sigma_{\text {mean }}$ at RT lead to a similar but lower magnitude of $\varepsilon_{r}^{\prime}$ than that with tensile $\sigma_{\text {mean }}$, if the absolute values of $\sigma_{\text {mean }}$ are the same.

This symmetry shown in Fig. 5.11 supports the assumption that the material strength of $\mathrm{P} 91$ at $550{ }^{\circ} \mathrm{C}$ under tension and compression is the same.

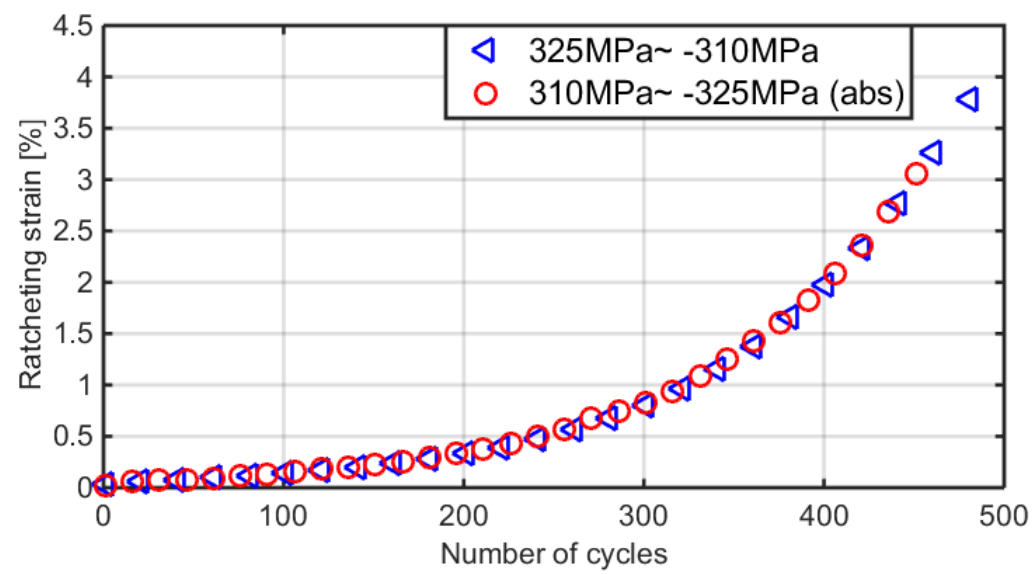

Fig. 5.11 A group of ratcheting tests at $550{ }^{\circ} \mathrm{C}$ performed with symmetric $\sigma_{\text {mean }}$ $( \pm 7.5 \mathrm{MPa}), \varepsilon_{r}$ vs. number of cycles. 


\subsubsection{Influence of Mean stress/Stress Ratio}

According to Table 3.5b, 16 uniaxial ratcheting tests were carried out with the same maximum stress (peak tensile stress) of $325 \mathrm{MPa}$ and various minimum stresses ranging from $-335 \mathrm{MPa}$ to zero. Fig. 5.12 illustrates all these $\varepsilon_{r}$ versus number of cycles. Fig. 5.12b clarifies some cases with relatively lower $\varepsilon_{r}^{\prime}$ in Fig. 5.12a while Fig. 5.12c further enlarges two cases in Fig. 5.12b.

The results are similar to the cases at $\mathrm{RT}$ in the sense that the maximum $\sigma_{\text {mean }}$ $(162.5 \mathrm{MPa})$ does not lead to fastest ratcheting with the same peak tensile stress. Instead, this maximum $\sigma_{\text {mean }}$ leads to one of the two lowest $\varepsilon_{r}$. The case with lowest $\varepsilon_{r}^{\prime}$ is with $\sigma_{\text {mean }}=100 \mathrm{MPa}$, which is even slower than the case with $\sigma_{\text {mean }}=162.5 \mathrm{MPa}$ (Fig. $5.12 \mathrm{c}$ ). It is clear that in the case with $\sigma_{\text {mean }}=162.5 \mathrm{MPa}$, the minimum stress is zero and the specimen is always under tensile loading. The creep strain leads to faster accumulated strain than the case with $\sigma_{\text {mean }}=100 \mathrm{MPa}$. After all, $\varepsilon_{r}^{\prime}$ in these two cases is negligible compared to the rates in the other tests. It can be concluded that shake down happens in these two cases, which is similar to the case with a stress range of 500 0 MPa at RT, as shown in Fig. 4.14 in Section 4.2.2.

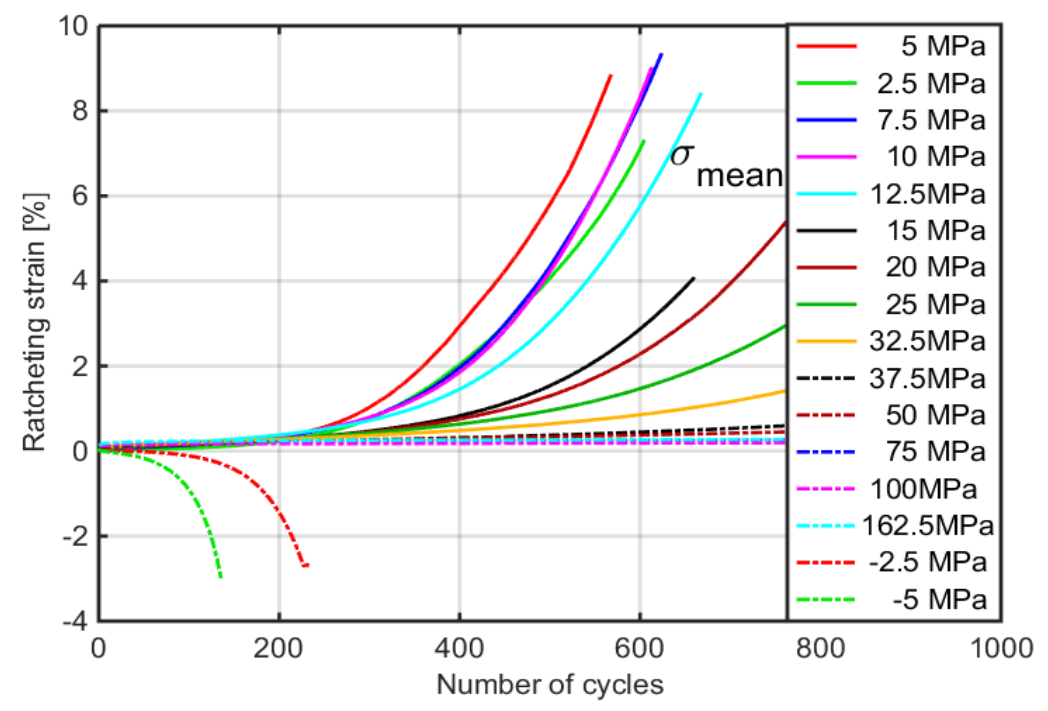

a)

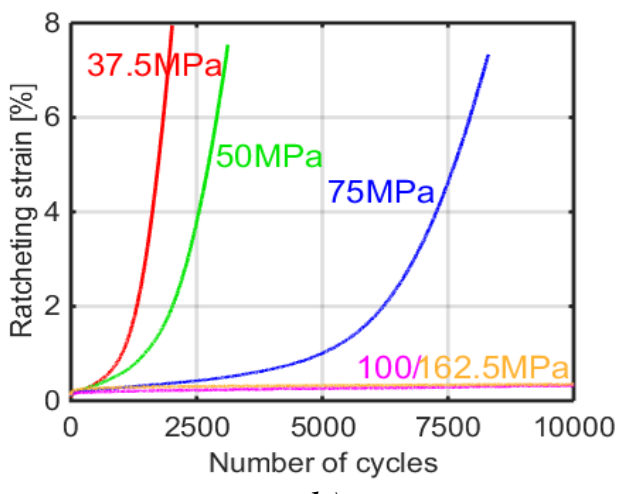

b)

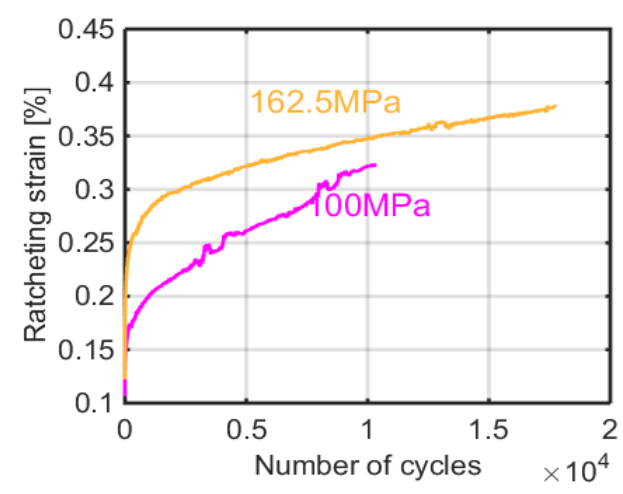

c)

Fig. 5.12 Ratcheting tests at $550^{\circ} \mathrm{C}$ performed with $\sigma_{\text {peak }}=325 \mathrm{MPa}$, stress rate $\pm 50 \mathrm{MPa} / \mathrm{s}$, various $\sigma_{\text {mean }}, \varepsilon_{r}$ vs. number of cycles. 
$\Delta \varepsilon^{i n}$ versus number of cycles of the 16 ratcheting tests are plotted in Fig. 5.13. It is clear that larger stress range leads to a higher increase in the rate of $\Delta \varepsilon^{\text {in }}$, similar to at RT (see Fig. 4.12) and the evolution of $\Delta \varepsilon^{\text {in }}$ owing to cyclic softening is also similar to that at RT. Still, no macro cracks were observed on any specimens of these 16 ratcheting tests.

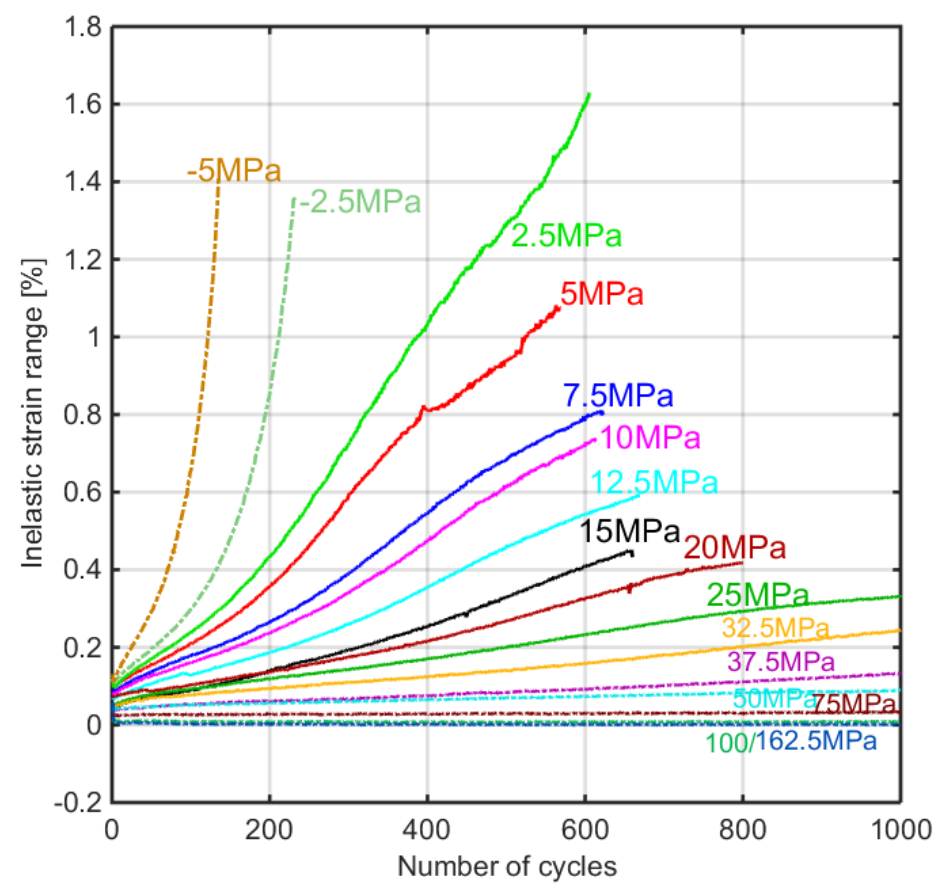

Fig. 5.13 Ratcheting tests at $550^{\circ} \mathrm{C}$ performed with $\sigma_{\text {peak }}=325 \mathrm{MPa}$, stress rate $\pm 50 \mathrm{MPa} / \mathrm{s}$, various $\sigma_{\text {mean }}, \Delta \varepsilon^{\text {in }}$ vs. number of cycles.

Fig. 5.14 shows the relation between $\varepsilon_{r}^{\prime}$ and stress ratios. The average $\varepsilon_{r}^{\prime}$ together with corresponding stress ratios are plotted in this diagram. $\varepsilon_{r}^{\prime}$ is calculated as the average rates until the cycle in which the maximum strain reaches $\pm 3 \%$ or until $10000^{\text {th }}$ cycle, whichever comes first. The maximum $\varepsilon_{r}^{\prime}$ appears around a stress ratio of -0.95 and decreases with increasing stress ratio until 0 . This phenomenon is similar to that at RT and the cause has already been discussed in Section 4.2.2.

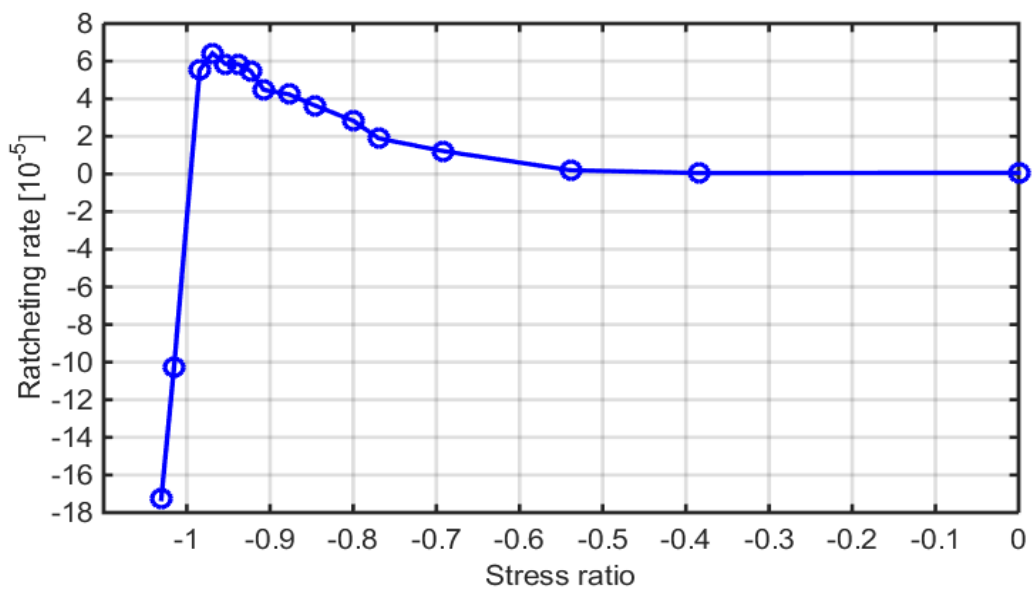

Fig. 5.14 Ratcheting tests at $550{ }^{\circ} \mathrm{C}$ performed with $\sigma_{\text {peak }}=325 \mathrm{MPa}$, stress rate $\pm 50 \mathrm{MPa} / \mathrm{s}$, average ratcheting rates vs. stress ratios. 


\subsubsection{Ratcheting with Zero Mean Stress}

In the uniaxial symmetric strain-controlled LCF tests at $550{ }^{\circ} \mathrm{C}$ reported in Section 5.1, symmetric peak stresses are induced with multiple strain ranges, which indicates that the asymmetry of material strength under tension and compression at RT do not exist at $550{ }^{\circ} \mathrm{C}$. Under stress-controlled loading, tests with zero $\sigma_{\text {mean }}$ were performed to check whether positive ratcheting will happen, similar to that at RT.

As listed in Table $3.5 \mathrm{c}$, four tests with zero $\sigma_{\text {mean }}$ were performed and the results are plotted in Fig. 5.15. The results seem quite different from those at RT, which are reported in Section 4.2.3. At RT, symmetric stress-controlled loadings always lead to positive ratcheting and a larger $\sigma_{a}$ leads to a higher positive $\varepsilon_{r}^{\prime}$.

However, in these four tests at $550{ }^{\circ} \mathrm{C}$, stress amplitude $\sigma_{a}=350 \mathrm{MPa}$ leads to positive ratcheting while the accumulated strains in tests performed with $\sigma_{a}=340$ and 325 and $315 \mathrm{MPa}$ have an uncertain direction. Further, all these four tests ended with fracture. Although the accumulated strains are not exactly zero, they reach no more than $0.5 \%$ until fracture, while in the cases at RT the strain can reach more than $5 \%$ without macro cracks. Therefore, the fracture comes much earlier than the problem of ratcheting at $550{ }^{\circ} \mathrm{C}$. On the other hand, the accumulated strains in these tests are not exactly zero (due to non-ideally symmetric controlled loading) but are still negligible compared to those in the RT cases (see Section 4.2.3).

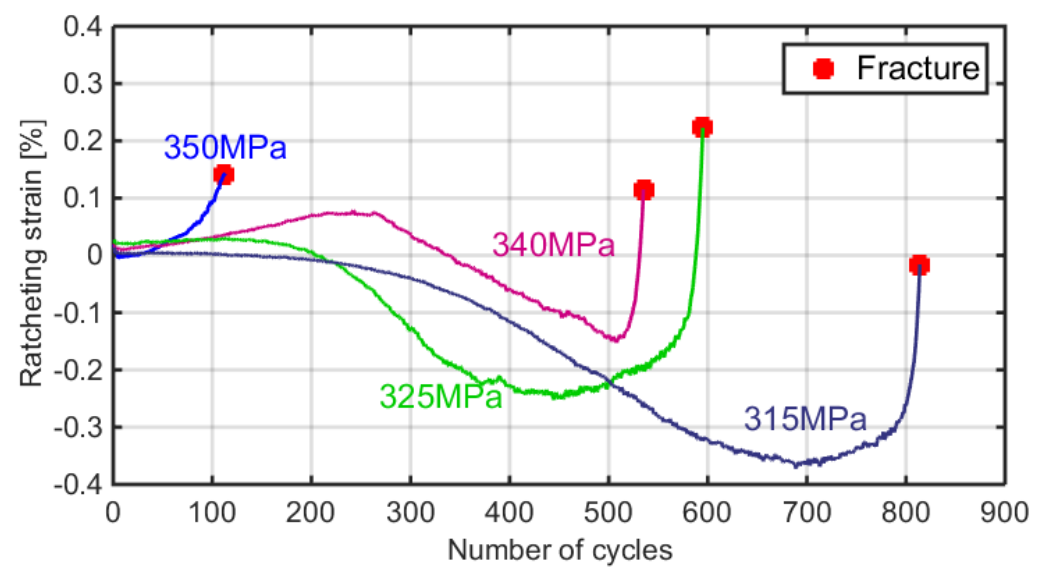

Fig. 5.15 Ratcheting tests at $550^{\circ} \mathrm{C}$ performed with zero $\sigma_{\text {mean }}$, stress rate $\pm 50 \mathrm{MPa} / \mathrm{s}$, various $\sigma_{a}$, $\varepsilon_{r}$ vs. number of cycles.

$\Delta \varepsilon^{i n}$ versus number of cycles is plotted in Fig. 5.17. All four tests ended with fractures, which led to a fast acceleration of increase of $\Delta \varepsilon^{i n}$ at the end of the tests. However, except for the last acceleration, the evolution of $\Delta \varepsilon^{i n}$ before macro cracks appeared is still similar to those in the other ratcheting tests at $550{ }^{\circ} \mathrm{C}$ under asymmetric loadings (see Fig. 5.9 and Fig. 5.13). Note that except for these four tests, all the other ratcheting tests at $550{ }^{\circ} \mathrm{C}$ ended without the appearance of macro cracks. 


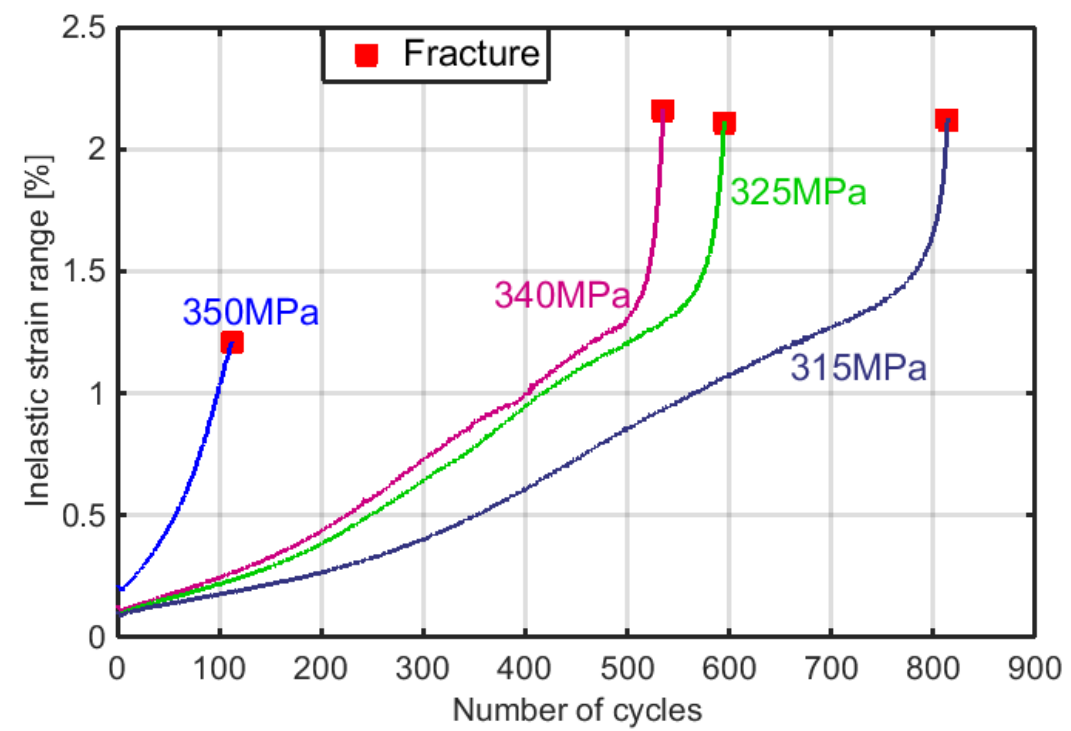

Fig. 5.16 Ratcheting tests at $550^{\circ} \mathrm{C}$ performed with zero $\sigma_{\text {mean }}$, stress rate $\pm 50 \mathrm{MPa} / \mathrm{s}$, various $\sigma_{a}, \Delta \varepsilon^{i n}$ vs. number of cycles.

On the contrary to the corresponding phenomena at RT, the material at $550{ }^{\circ} \mathrm{C}$ shows:

1. Symmetry of peak tensile and compressive stresses in strain-controlled LCF tests (see Fig. 5.5).

2. Identical magnitudes of $\varepsilon_{r}^{\prime}$ with symmetric tensile/compressive $\sigma_{\text {mean }}$ (see Fig. 5.11).

3. Negligible $\varepsilon_{r}^{\prime}$ with zero $\sigma_{\text {mean }}$ (see Fig. 5.15).

These three phenomenon together lead to the conclusion that the asymmetry of material strength under tension and compression at RT does not exist at $550{ }^{\circ} \mathrm{C}$.

\subsubsection{Influence of stress rate}

According to Table $3.5 \mathrm{~d}$, two experiments are carried out were $\dot{\sigma}= \pm 10$ and $\pm 250 \mathrm{MPa} / \mathrm{s}$ to evaluate the visco-plasticity of P91 at $550{ }^{\circ} \mathrm{C}$. Together with the previous test with $\dot{\sigma}= \pm 50 \mathrm{MPa} / \mathrm{s}$, a diagram can be plotted as in Fig. 5.17. Compared to the results obtained at RT (see Section 4.2.4), it is clear that $\dot{\sigma}$ has larger influence on ratcheting behavior.

According to the average $\varepsilon_{r}^{\prime}$ before the peak strain reaches $3 \%$, the test with $\pm 10 \mathrm{MPa} / \mathrm{s}$ has twice higher $\varepsilon_{r}^{\prime}$ than the test with $\pm 50 \mathrm{MPa} / \mathrm{s}$ while in the same case at RT it is only $18.3 \%$ higher. The test with $\pm 250 \mathrm{MPa} / \mathrm{s}$ has $26.5 \%$ lower $\varepsilon_{r}^{\prime}$ than that with $\pm 50 \mathrm{MPa} / \mathrm{s}$ at $550{ }^{\circ} \mathrm{C}$, which is larger than the $22.3 \%$ obtained at RT. Hence, the material has lower viscosity at $550{ }^{\circ} \mathrm{C}$ than that at RT. 


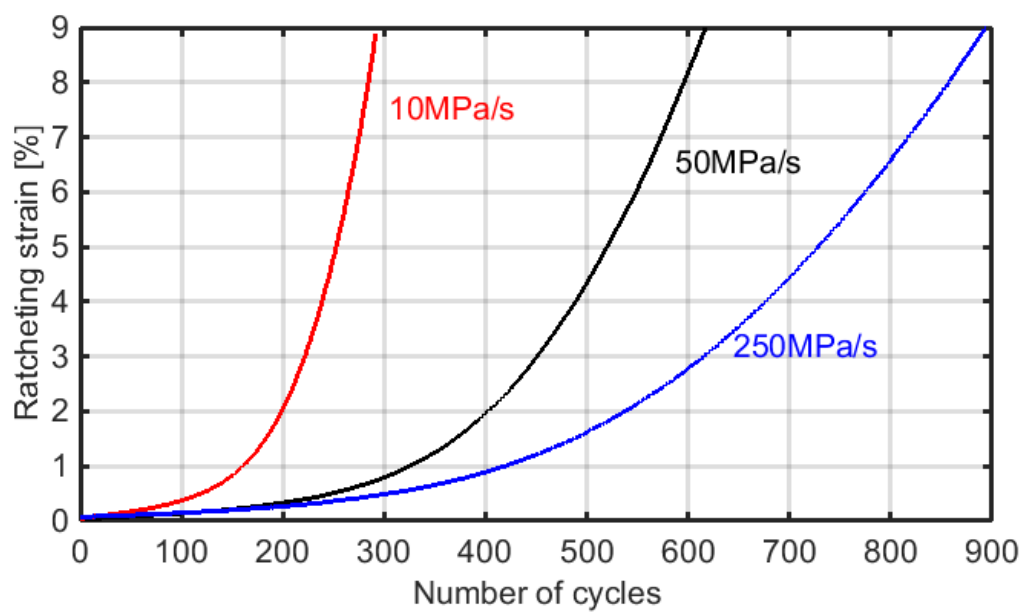

Fig. 5.17 Ratcheting tests at $550^{\circ} \mathrm{C}$ performed with $\sigma_{\text {peak }}=325 \mathrm{MPa}$,

$\sigma_{\text {mean }}=7.5 \mathrm{MPa}$, various stress rates, $\varepsilon_{r} v s$. number of cycles.

$\Delta \varepsilon^{i n}$ versus number of cycles is plotted in Fig. 5.18. $\Delta \varepsilon^{i n}$ in the test performed with stress rate $\pm 10 \mathrm{MPa} / \mathrm{s}$ fluctuates, which was not observed in all other ratcheting tests at both temperatures. This could be owing to fluctuation of the oven temperature. In spite of this fluctuation of $\Delta \varepsilon^{i n}$, the corresponding $\varepsilon_{r}$ shows no influence by such fluctuation (see Fig. 5.17) and the evolutions of $\Delta \varepsilon^{i n}$ in tests performed with $\dot{\sigma}= \pm 50$ and $\pm 250 \mathrm{MPa}$ are similar to the other ratcheting tests at $550{ }^{\circ} \mathrm{C}$ under asymmetric loadings (see Fig. 5.9 and Fig. 5.13).

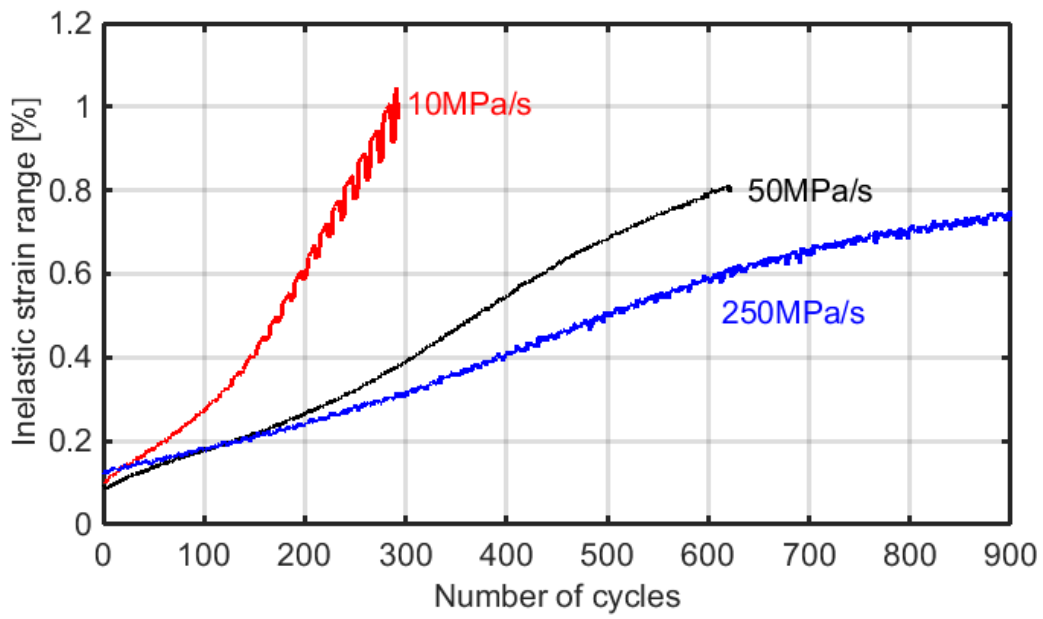

Fig. 5.18 Ratcheting tests at $550^{\circ} \mathrm{C}$ performed with $\sigma_{\text {peak }}=325 \mathrm{MPa}$, $\sigma_{\text {mean }}=7.5 \mathrm{MPa}$, various stress rates, $\Delta \varepsilon^{\text {in }}$ vs. number of cycles.

\subsubsection{Influence of Hold Time}

Similar to at RT, several ratcheting tests were carried out with hold times at $550{ }^{\circ} \mathrm{C}$, as listed in Table 3.5e. In addition, several creep tests were performed in comparison to the ratcheting tests with hold times according to Table 3.6.

Fig. 5.19 illustrates the above-mentioned experiments at $550{ }^{\circ} \mathrm{C}$. The two ratcheting tests with 5 and 0.5 min hold times at tensile peaks are compared with two creep tests; 
one is the engineering-stress-controlled technical creep test, and the other one is the true-stress-controlled physical creep test, as shown in Fig. 5.19a. It is clear that the creep strain in the engineering-stress-controlled creep test is larger than that of the true-stress-controlled creep test. The accumulated strain in the ratcheting test performed with a hold time of $5 \mathrm{~min}$ at tensile peaks $\left(\sigma_{\text {peak }}=325 \mathrm{MPa}\right)$ is mainly composed of accumulated creep strains, and the accumulated strain is larger than the creep strain of $\sigma_{\text {creep }}=325 \mathrm{MPa}$ in both engineering- and true-stress-controlled creep tests. In the test performed with 0.5 min hold times at tensile peaks $\left(\sigma_{\text {peak }}=325\right.$ $\mathrm{MPa}$ ), the accumulated strain is even larger than that obtained with 5 min hold times.

In Fig. 5.19b, the strain-time curves of two experiments are plotted: one is true-stress-controlled creep test with $\sigma_{\text {creep }}=-310 \mathrm{MPa}$, and the other is ratcheting with hold times at compressive peaks $\sigma_{\min }=-310 \mathrm{MPa}$. It can be seen that the magnitude of this creep strain is lower than the magnitude of accumulated strain in the ratcheting performed with hold times at compressive peaks. Together with the comparison shown in Fig. 5.19a, we can come to conclusion that the cyclic loading accelerates the strain accumulation comparing to the corresponding pure creep test. 


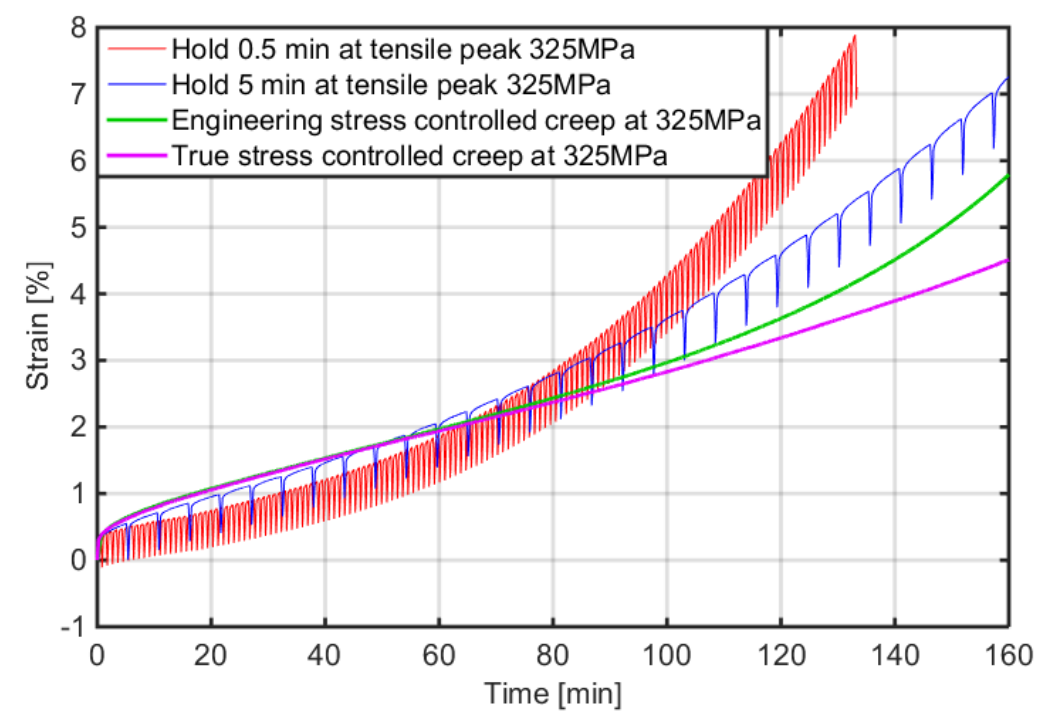

a) Ratcheting tests performed with $\sigma_{\text {peak }}=325 \mathrm{MPa}, \sigma_{\text {mean }}=7.5 \mathrm{MPa}$, stress rate $\pm 50 \mathrm{MPa} / \mathrm{s}$, hold $0.5 \& 5$ min at peak tension, compared with eng.- \& true-stress-controlled creep tests $\sigma_{\text {creep }}=325 \mathrm{MPa}$.

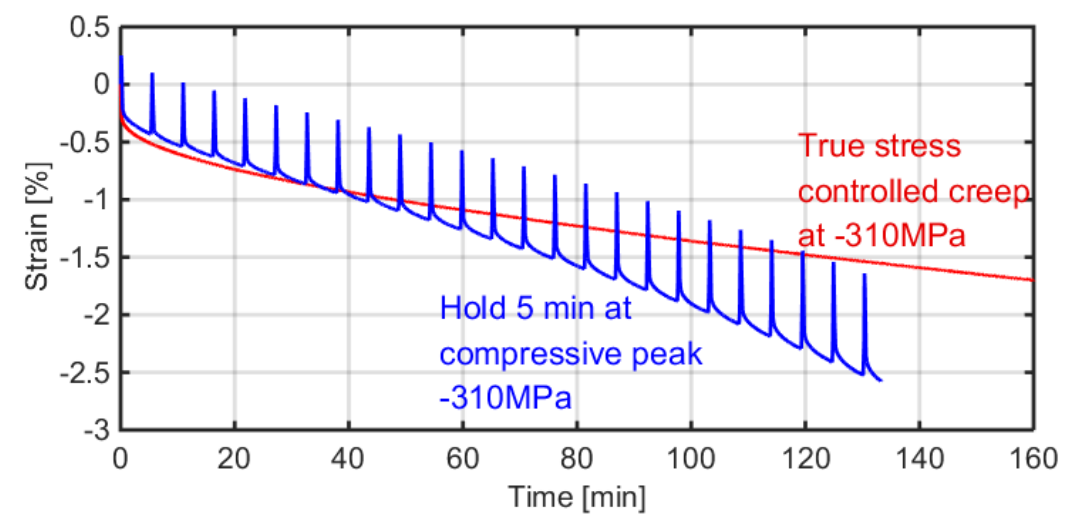

b) Ratcheting tests performed with $\sigma_{\text {peak }}=325 \mathrm{MPa}, \sigma_{\text {mean }}=7.5 \mathrm{MPa}$, stress rate $\pm 50 \mathrm{MPa} / \mathrm{s}$ and hold $5 \mathrm{~min}$ at peak compression, compared with true-stress-controlled creep test at $\sigma_{\text {creep }}=-310 \mathrm{MPa}$.

Fig. 5.19 Comparison between ratcheting tests with hold times and creep tests at $550^{\circ} \mathrm{C}$, strain vs. time.

The accumulated strain in the test performed with 0.5 min hold times at tensile peaks is firstly lower than the corresponding creep strain. However, it accelerates and surpasses the creep strain in the later stage. The reason is, on the one hand, the creep strains during hold times are increasing with increasing cycle number owing to softening, and on the other hand, the creep initially has a faster primary creep and then a slower secondary creep. The creep strain during each 0.5 min hold time in each cycle is plotted versus number of cycles in Fig. 5.20. 


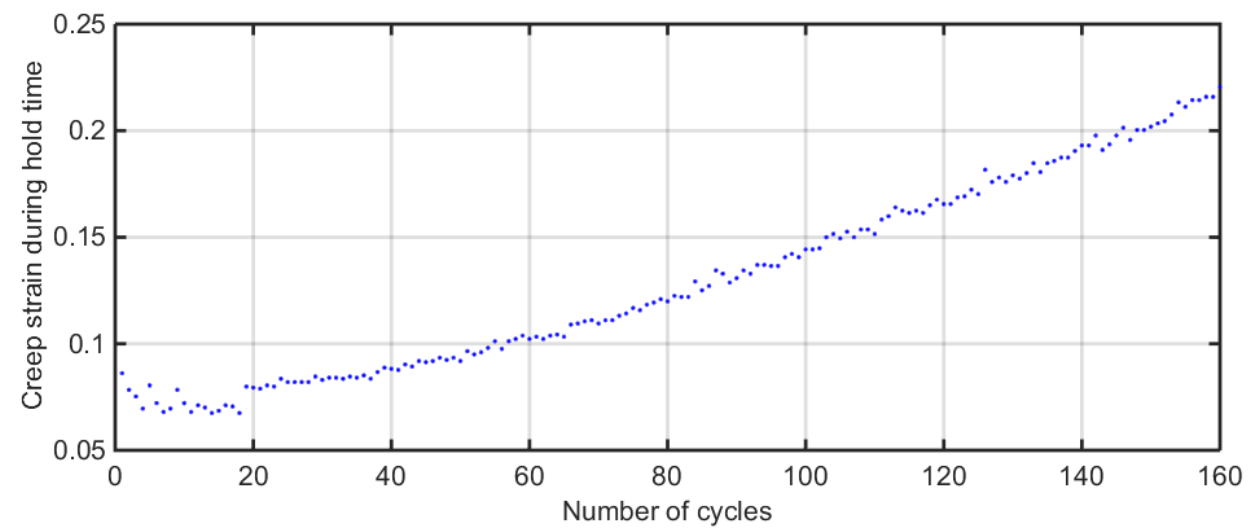

Fig. 5.20 Ratcheting tests at $550^{\circ} \mathrm{C}$ performed with $\sigma_{\text {peak }}=325 \mathrm{MPa}$, $\sigma_{\text {mean }}=7.5 \mathrm{MPa}$, stress rate $\pm 50 \mathrm{MPa}$, hold 0.5 min at peak tension, creep strains during hold times vs. number of cycles.

These results at $550{ }^{\circ} \mathrm{C}$ can be compared with the results at RT with hold times at tensile peaks. As discussed in Section 4.2.4, in the test performed at RT with $\sigma_{\text {peak }}=$ $500 \mathrm{MPa}, \sigma_{\text {mean }}=25 \mathrm{MPa}$ and 10 min hold times at tensile peaks, the accumulated partial inelastic strain formed during the stress-changing process is negative $(-15.63 \%)$, although $\sigma_{\text {mean }}$ is tensile. Similar phenomena occur at $550{ }^{\circ} \mathrm{C}$. For instance, in the case shown in Fig. 5.20, the total accumulated creep strains during hold times is $29.77 \%$ while the total strain is $8.34 \%$, which means the accumulated partial inelastic strain formed during the stress-changing process is $-21.43 \%$, although $\sigma_{\text {mean }}$ is tensile. The reason was discussed in Section 4.2.4, that the material response to cyclic stress-controlled loading has a tendency to close the hysteresis loops.

However, with longer hold times at peak stress (i.e., 5 min), the material responses are more similar to those from the pure creep test. The total strain is mostly composed of accumulated creep strains during hold times. In addition, some more pure creep tests were performed according to Table 3.6. The result for $\sigma=310 \mathrm{MPa}$ is the absolute value in the creep test with $\sigma=-310 \mathrm{MPa}$. The results are plotted in Fig. 5.21, together with data obtained by Kimura et al. [106].

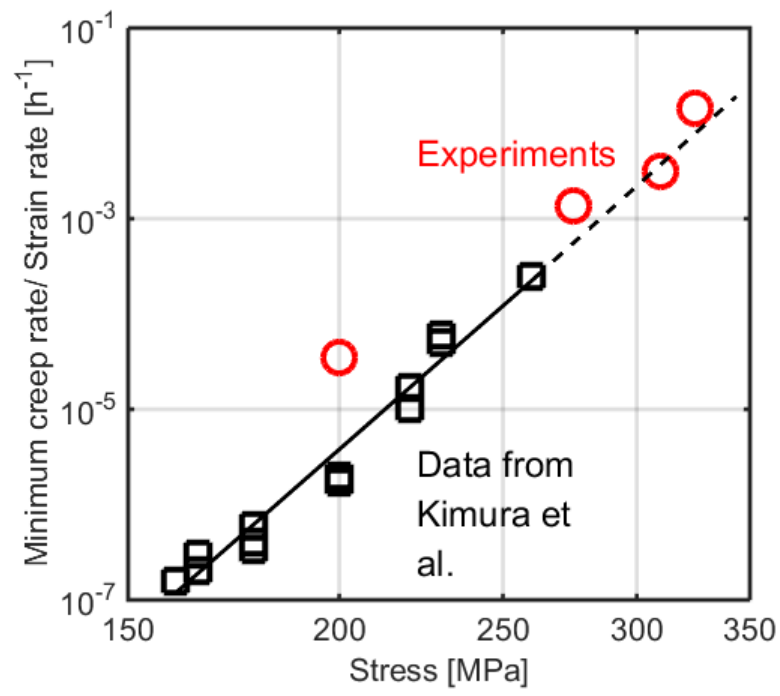

Fig. 5.21 Minimum creep rates vs. $\sigma_{\text {peak }}$ for mod. $9 \mathrm{Cr}-1 \mathrm{Mo}$ steel at $550{ }^{\circ} \mathrm{C}$. 
The SCHENCK hydraulic testing machine in the current work was not specifically designed for, nor necessarily suitable for, creep tests. A special creep machine requires quite stable loading, usually controlled by gravity. However, in spite of the result with $\sigma=200 \mathrm{MPa}$, the minimum creep rates in the other three creep tests (marked as red circles) roughly agree with the extrapolation of the data obtained by Kimura et al. [106]. Hence, the results of the creep tests and ratcheting tests with hold times at $550{ }^{\circ} \mathrm{C}$ are reliable.

\subsubsection{Diameter Check}

After all experiments at $550{ }^{\circ} \mathrm{C}$, the tested specimens were rechecked, because some specimens in $550{ }^{\circ} \mathrm{C}$ ratcheting tests showed obvious necking.

Detailed measurements were carried out to measure the diameters of tested specimens in different axial positions. The results for the high-temperature specimens are illustrated in Fig. 5.22.

As can be seen for various stress ranges, the minimum cross section always appears in the middle of the axial position. The only exception is the one with stress range $275 \sim-225 \mathrm{MPa}$, where the accumulated strain is $0.11 \%$ only. In spite of this exception, the necking occurs and becomes more apparent if the strain is larger than $3 \%$. In Fig. 5.22, the three diameters marked on each specimen include two near the end of the gage length and one in the middle. When the strain is larger than $3 \%$, the difference in the cross section is above $5 \%$, which is not acceptable.

Owing to the structural influence of necking, the measured data shows no longer pure material behavior. Therefore, only data before the total strain reaches $3 \%$ are taken to fit the value of material parameters in the modeling approach. 

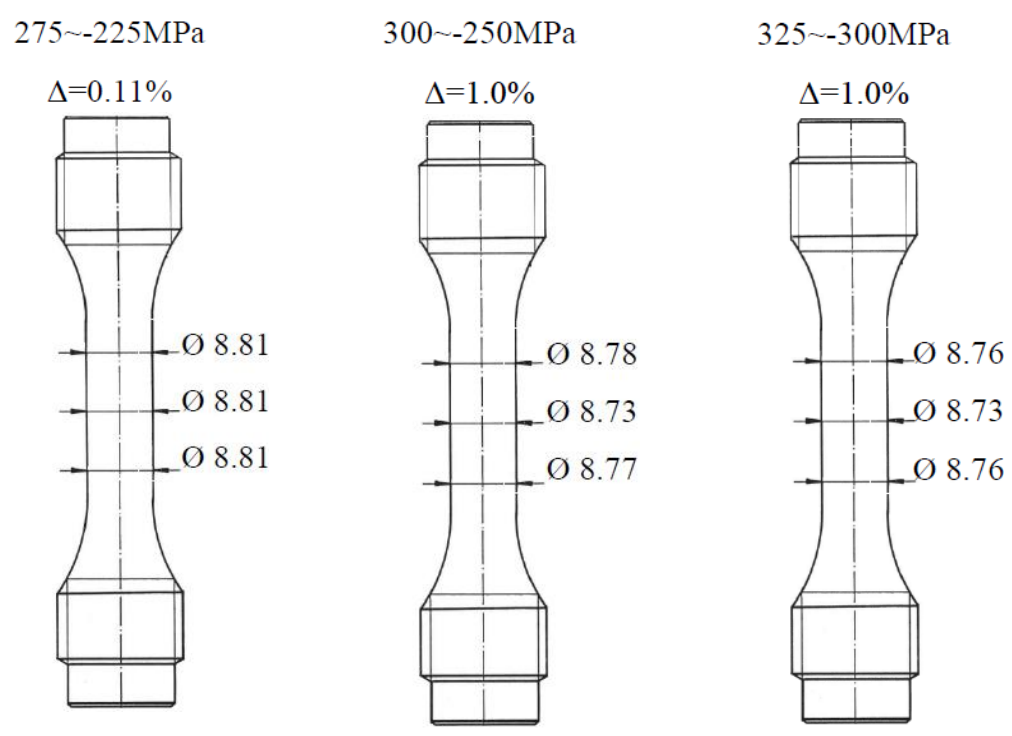

300 -250MPa

$325 \sim-300 \mathrm{MPa}$

$300 \sim-250 \mathrm{MPa}$
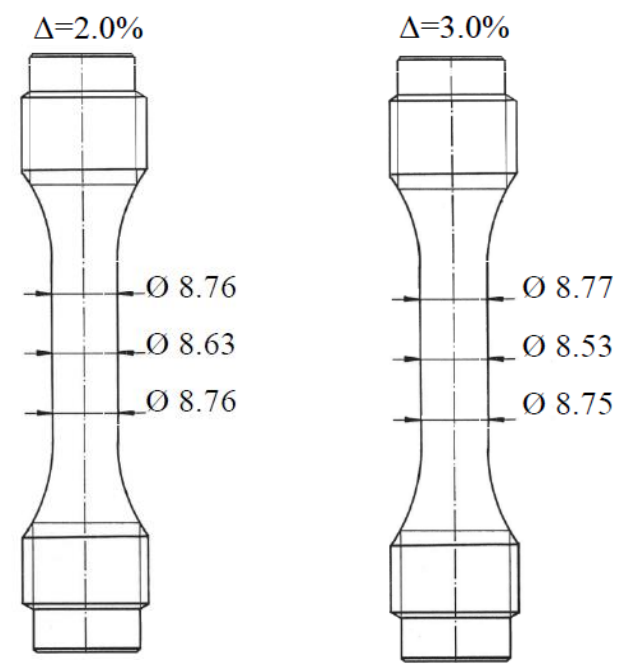

$325 \sim-300 \mathrm{MPa}$

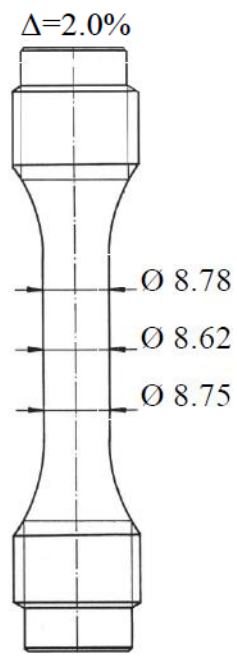

$325 \sim-295 \mathrm{MPa}$

$300 \sim-250 \mathrm{MPa}$

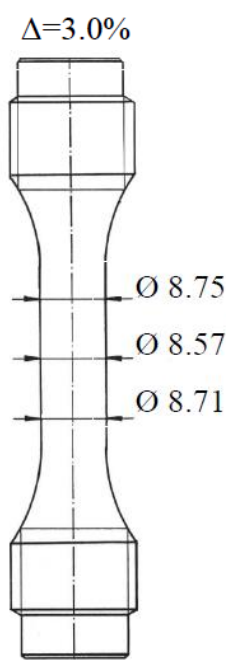

$300 \sim-250 \mathrm{MPa}$
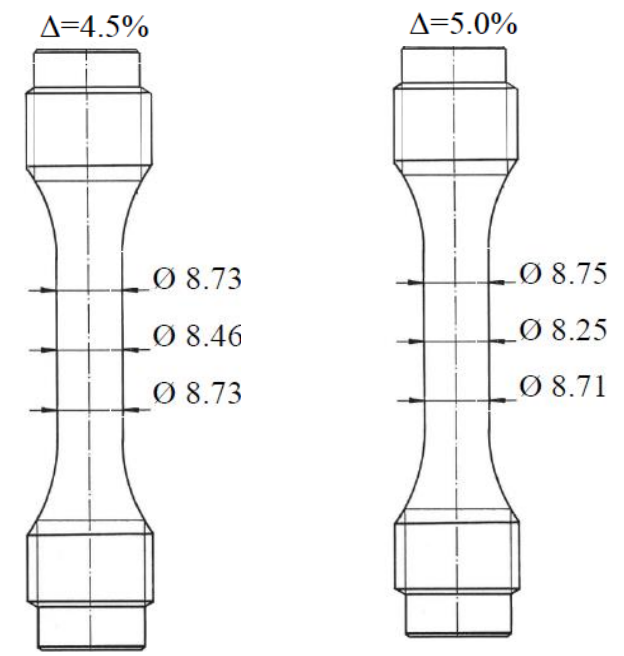

$325 \sim-315 \mathrm{MPa}$

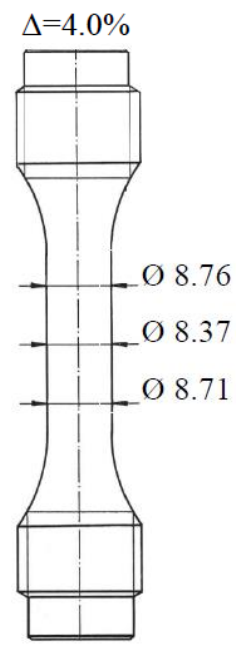

$315 \sim-265 \mathrm{MPa}$
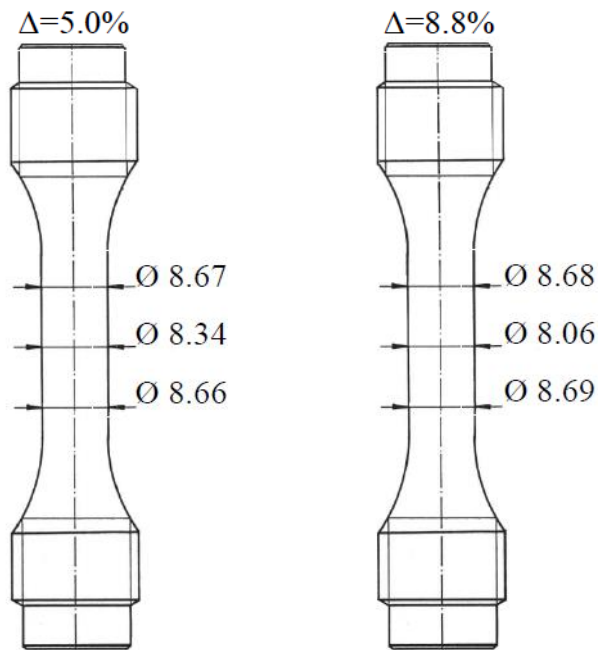

Fig. 5.22 Necking check on specimens in $550{ }^{\circ} \mathrm{C}$ ratcheting tests. 


\section{Simulation and Modeling}

\subsection{Requirements and Programming}

Based on the experimental results reported in Chapters 4 and 5, a database including strain-controlled LCF tests and stress-controlled ratcheting tests for the P91 steel at both room temperature and $550{ }^{\circ} \mathrm{C}$ could be built. To analyze the mechanical behavior and predict material responses under more arbitrary loading conditions, a model was built to simulate the mechanical behavior of P91. The model description should agree with material responses qualitatively and quantitatively. According to experimental results at both temperatures, the simulated results should fulfill the following criteria:

1. Fitting on $\varepsilon_{r}$ under multiple loading conditions.

2. Fitting on shapes of hysteresis loops.

3. Showing cyclic softening in strain-controlled LCF tests.

4. Larger $\sigma_{\text {peak }}$ leads to higher $\varepsilon_{r}$.

5. Highest $\varepsilon_{r}^{\prime}$ with stress ratio of around -0.9 -0.95.

6. Strain range of hysteresis loop increases with increasing cyclic number.

7. Positive ratcheting with zero $\sigma_{\text {mean }}$ at RT.

8. Higher $\dot{\sigma}$ leads to lower $\varepsilon_{r}^{\prime}$ and vise versa.

9. Hold time at tensile and compressive peak leads to higher $\varepsilon_{r}^{\prime}$ at RT.

10. Fitting on accumulation of strain in ratcheting tests at $550{ }^{\circ} \mathrm{C}$ performed with hold times and in creep tests

Owing to the complicated mechanical behavior and the simple geometry of tested specimens, analytical simulation was chosen, where a constitutive model could be built.

According to the review of work by a variety of scientists and engineers in Section 2.2, the constitutive model can originate from some current models and be modified to simulate the mechanical behavior of P91.

In the following discussion, a uniaxial constitutive model is firstly presented because all experiments reported in Chapter 4 and 5 are under uniaxial loading. Hence, the model in uniaxial form is enough to generate simulated results to compare with the performed experiments. Further extension to the multiaxial form is discussed afterwards.

The modeling approach is firstly applied on experiments at RT, and then on those at $550{ }^{\circ} \mathrm{C}$. 
The model under modification is Aktaa-Schmitt model [1]. This model is based on the so-called Chaboche model [5, 58-61]. which considers creep and plasticity as arising from the same dislocation source [62]. The Aktaa-Schmitt model has an additional description of cyclic softening, typically for Reduced Activation Ferritic Martensitic (RAFM) steels. Hence, this model is also known as the RAFM model. The equations of the RAFM model under modification are listed in Table 6.1 [1].

$\dot{\varepsilon}=\dot{\varepsilon}^{i n}+\dot{\varepsilon}^{e l}$
$\dot{\varepsilon}^{e l}=\frac{\dot{\sigma}}{E}$
$\dot{\varepsilon}^{i n}=\left\langle\frac{|2|-k}{Z}\right\rangle^{n} \operatorname{sgn}(\Sigma) \quad$ with $\Sigma=\frac{\sigma}{\psi}-\Omega$
$\Omega=\Omega_{1}+\Omega_{2}$ with $\dot{\Omega}_{i}=H_{i} \dot{\varepsilon}^{i n}-C_{i} \Omega_{i}\left|\dot{\varepsilon}^{i n}\right|-R_{i}\left|\Omega_{i}\right|^{m_{i}-1} \Omega_{i}$
$\psi=\psi_{1}+\psi_{2}$, with $\psi_{1}(t=0)=0$ and $\psi_{2}(t=0)=1$
$\dot{\psi}_{1}=-h\left|\dot{\varepsilon}^{i n}\right|$
$\dot{\psi}_{2}=c\left(\psi_{s}-\psi_{2}\right)\left|\dot{\varepsilon}^{i n}\right|-r_{\psi}\left|\psi_{2}-\psi_{r}\right|^{m_{\psi}-1}\left(\psi_{2}-\psi_{r}\right)$
$\psi_{s}=1-\psi_{s, \infty}\left(1-\exp \left(-c_{s-\infty<\tau<t}\left|\varepsilon^{i n}(\tau)\right|\right)\right)$

Table 6.1 Constitutive equations in RAFM model

A difference between the model listed above and the original one in [1] is that the coupled damage is ignored in the current work because, except for one test at RT $\left(\sigma_{a}=520 \mathrm{MPa}\right)$ and four tests at $550{ }^{\circ} \mathrm{C}\left(\sigma_{a}=350,340,325\right.$, and $\left.315 \mathrm{MPa}\right)$ performed under symmetric loading, all other ratcheting tests reported in Chapter 4 and 5 were stopped before significant damage appeared: no kink on hysteresis loop was observed, such as the one shown in Fig. 4.1c, hence no macro cracks were observed on most specimens in the ratcheting tests. On the other hand, the coupled damage mentioned in [1] was for describing failure by fracture. From an engineering point of view, under asymmetrical stress-controlled cyclic loading, the failure of a structure owing to ratcheting should happen before the failure owing to fracture.

Another difference is in eq. (6-4) in which the back stress (BS) $\Omega$ is a superposition of more than one sub-BS. More sub-BSs lead to better fitting of the material response. In other modeling approaches, for example, the Ohno-Abdel-Karim model [6], the simulated BS is decomposed into eight components to fit the real material behavior. In the Yaguchi-Takahashi model [7], there are also eight sub-BS. However, it is supposed to minimize the number of BS components to simplify the simulation process and still give an acceptable simulation result. This can be seen in the later discussion. Note that the dynamic recovery of BS in eq. (6-4) follows the ArmstrongFrederick rule (see eq. (2-6)). 
The static recovery is supposed to be thermally activated at generally high temperature. Therefore, to simplify the model for RT cases, parameter $R_{i}$ in the term of static recovery of kinematic hardening (see eq. (6-4)) and $r_{\psi}$ in the term of static recovery of isotropic softening (see eq. (6-7)) are set to be zero. $\psi_{s}$ in eq. (6-7) is assumed to be constant

$$
\psi_{s}=1-\psi_{s, \infty}
$$

for simplicity. Hence eqs. (6-4) and (6-7) are reduced into eqs. (6-9) and (6-10)

$$
\begin{aligned}
& \dot{\Omega}_{i}=H_{i} \dot{\varepsilon}^{i n}-C_{i} \Omega_{i}\left|\dot{\varepsilon}^{i n}\right| \\
& \dot{\psi}_{2}=c\left(1-\psi_{s, \infty}-\psi_{2}\right)\left|\dot{\varepsilon}^{i n}\right|
\end{aligned}
$$

Before experiments were carried out on P91, simulation programs had already been written in MATLAB. The programs were written according to the above-mentioned seven equations (eqs. (6-1), (6-2), (6-3), (6-5), (6-6), (6-9), (6-10)). Runge-Kutta fourth order iteration method is applied. Further, programs that can determine parameter values in these equations were written to fit the experimental data. The fitting programs are based on a fortran program MINUIT developed at CERN [107]. The main field of usage of MINUIT is statistical data analysis of experimental data recorded at CERN.

To verify the simulation ability and correctness of the calculation with MATLAB, programs were written according to the original RAFM model in [1] and with the same parameter values in [1] to check the model description compared to the material response of EUROFER97.

Fig. 6.1 illustrates the comparison between model and material responses for straincontrolled LCF tests on EUROFER97 at $550{ }^{\circ} \mathrm{C}$. It is obvious that the simulation result is satisfactory, matching the shape of loops and decrease of peak tensile stresses (owing to cyclic softening). Hence, the calculation with MATLAB is proved to be correct. 

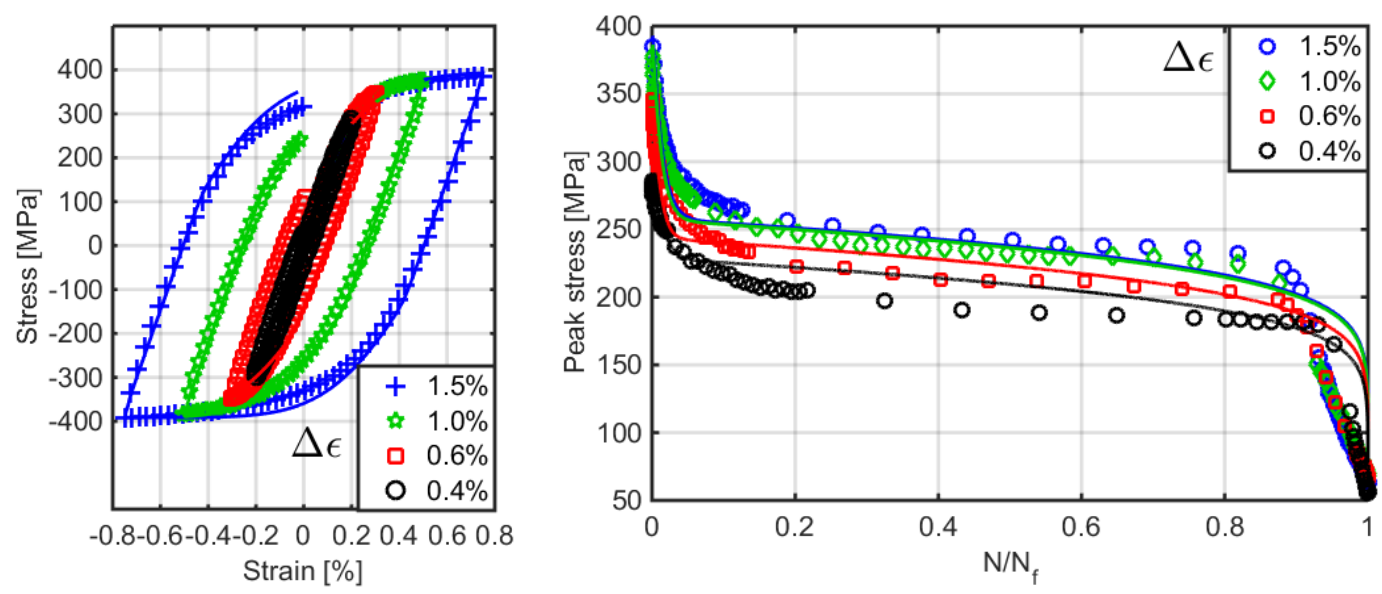

Fig. 6.1 Comparison between material response (markers) and model description (curves): Strain-controlled LCF tests on EUROFER97 at $550{ }^{\circ}$ C. Left: hysteresis loops of the first cycles. Right: peak tensile stresses vs. normalized number of cycles.

In the iteration method, one of the key factors influencing the result is the step size. By calculating $\sigma_{\text {peak }}$ in the cycle at half lifetime in the LCF test of EUROFER97 performed with strain range of 1.0\% (marked in green in Fig. 6.1), different time steps were tested, as listed in Table 6.2. Except for the results with 0.1 and 0.09 seconds as time steps, all the other calculated $\sigma_{\text {peak }}$ at half lifetime are almost equal. Hence, the iteration result converges with decreasing time step.

\begin{tabular}{c|c|c}
\hline Time step [Second] & $\begin{array}{c}\text { Iteration steps per } \\
\text { cycle }\end{array}$ & $\begin{array}{c}\sigma_{\text {peak }} \text { of half lifetime } \\
{[\mathrm{MPa}]}\end{array}$ \\
\hline 0.1 & 67 & 223.6 \\
0.09 & 74 & 225.0 \\
0.08 & 83 & 235.7 \\
0.07 & 95 & 236.3987 \\
0.05 & 133 & 236.4038 \\
0.01 & 667 & 236.3985 \\
0.001 & 6667 & 236.3986 \\
\hline
\end{tabular}

Table 6.2 Test results with various time steps in Runge-Kutta fourth order iteration method.

In the simulation program in MATLAB, an automatic time-stepping algorithms was firstly defined in the following way: the iteration result $x\left(\Delta t_{i}\right)$ was calculated with time step $\Delta t_{i}$ and $x\left(\Delta t_{i+1}\right)$ was calculated with time step $\Delta t_{i+1}=\frac{\Delta t_{i}}{2}$. The initial time step $\Delta t_{0}=0.02 \mathrm{~s}$. The iteration result $x\left(\Delta t_{i}\right)$ is reliable when

$$
\operatorname{abs}\left\{\frac{x\left(\Delta t_{i}\right)-x\left(\Delta t_{i+1}\right)}{x\left(\Delta t_{i}\right)}\right\}<10^{-6}
$$


However, this time-stepping algorithm is time-costing during the simulation. A practical time-stepping algorithm is defined with the time-step chosen according to the increase/decrease rate of inelastic strain and making sure there are at least 500 iteration steps in each cycle:

$$
\Delta t_{i}=\frac{\Delta t_{0}}{1+a b s\left\lceil\Delta \varepsilon_{i-1}^{i n} \Delta t_{0} / \Delta \varepsilon_{0} \Delta t_{i-1}\right\rceil}
$$

in which $\Delta t_{0}=0.02 \mathrm{~s}, \Delta \varepsilon_{0}=6 \times 10^{-6}, \Delta \varepsilon_{i-1}^{i n} / \Delta t_{i-1}$ is the increase/decrease rate of inelastic strain in the previous iteration. Function $\lceil x\rceil$ is the ceiling function, which is the smallest integer not less than $x$. Such a practical time-stepping algorithm leads to much shorter computation time.

The error owing to this practical time-stepping algorithm in this Runge-Kutta fourth order iteration method has been proved to be negligible, such as the difference between the results with time step 0.01 and 0.001 second in Table 6.2.

\subsection{Initial Fitting of Parameter Values}

As discussed in the previous section, simulation programs were written in MATLAB, according to the constitutive model constructed with seven equations (eqs. (6-1), (6-2), (6-3), (6-5), (6-6), (6-9), (6-10)). The next step is to fit parameter values for P91.

After strain-controlled LCF tests are finished at RT, the parameter values are fitted according to the material responses. The fitting process is as follows: $E$ is the Young's modulus, which is calculated according to the slope of stress-strain unloading line in the first cycle. Parameters $k, Z, n, H_{1}, C_{1}, H_{2}$, and $C_{2}$ are fitted to make each simulated stresses agree with every measured data point in the first cycle.

The fitting algorithm mixes the sum of absolute relative errors between experimental results $x_{\text {test }}$ and simulated results $x_{\text {sim }}$ (eq. (6-13)) and the sum of absolute errors (eq. (6-14)). The calculation of these errors has less calculation time in MATLAB than using, for example, the least-square method.

$$
\begin{aligned}
& \Delta_{1}=\sum_{i=1}^{N}\left\{\left|1-\frac{x_{\text {test }, i}}{x_{\text {sim }, i}}\right|+\left|1-\frac{x_{\text {sim }, i}}{x_{\text {test }, i}}\right|\right\} \\
& \Delta_{2}=\sum_{i=1}^{N}\left|x_{\text {test }, i}-x_{\text {sim }, i}\right|
\end{aligned}
$$

The sum of absolute errors is used when the stress-strain hysteresis loops are fitted. The sum of absolute relative errors is used when the peak stresses are fitted. Applying the sum of absolute relative errors has better performance than, for example, the least-square method when the magnitudes of experimental results, for example peak stresses, range from relatively low to very high values. 
As shown in Fig. 6.2a, the simulated hysteresis loops agree with experimental ones in the first cycle for various total strain ranges.

Afterwards parameters $h, c$ and $\psi_{s, \infty}$ are fitted to have the simulated $\sigma_{\text {peak }}$ match the experimental $\sigma_{\text {peak }}$ in each cycle till the end of saturation stage of cyclic softening. As shown in Fig. 6.2c, the $\sigma_{\text {peak }}$ in the simulated results shows a fast decrease in the first stage and a slow decrease in the second stage (saturation stage), which is the same as in material responses. Fig. 6.2b illustrates the hysteresis loops of the cycles at the half $N_{0}$. It is clear that the model description qualitatively and quantitatively agrees with the material responses in the strain-controlled LCF tests on P91 at RT.

$N_{0}$ is a roughly defined cycle number until which the data are considered to be reliable, as discussed in Section 4.1.

The 11 fitted parameter values are listed in Table 6.3.

\begin{tabular}{ll}
\hline$E(M P a)$ & 220086 \\
$k(M P a)$ & 142.8 \\
$Z\left(M P a s^{1 / n}\right)$ & 55.259 \\
$n$ & 151.38 \\
$H_{1}(M P a)$ & 460394 \\
$C_{1}$ & 1979 \\
$H_{2}(M P a)$ & 44984 \\
$C_{2}$ & 256.7 \\
$h$ & $1.333 \times 10^{-3}$ \\
$c$ & 0.51099 \\
$\psi_{s, \infty}$ & 0.1077 \\
\hline
\end{tabular}

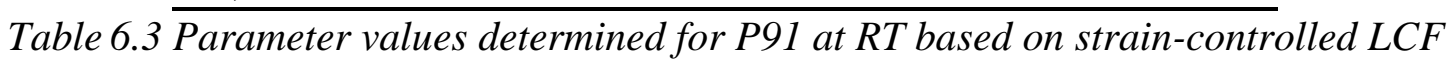
tests. 


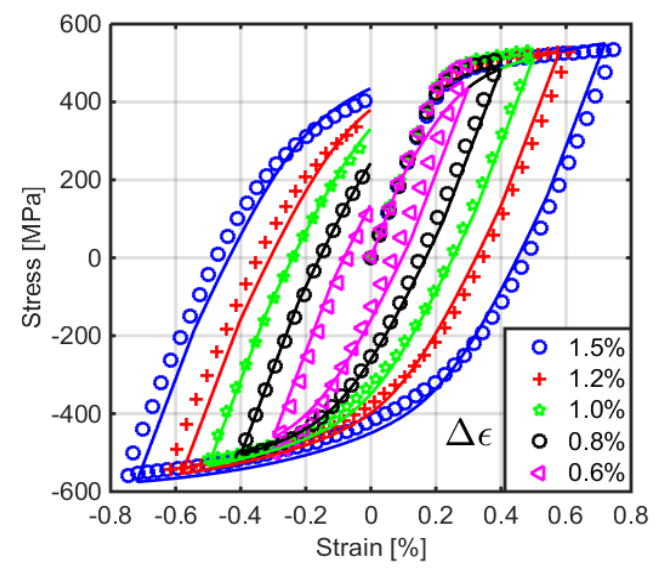

a) Hysteresis loops of the first cycles

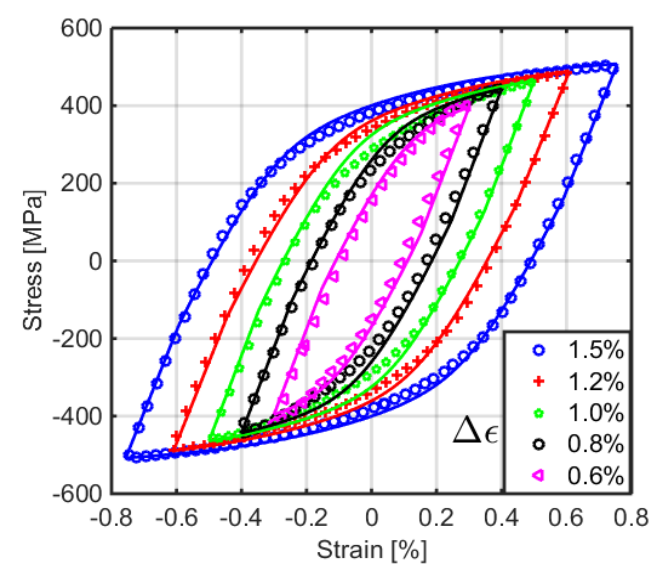

b) Hysteresis loops of the cycles at $N_{0} / 2$

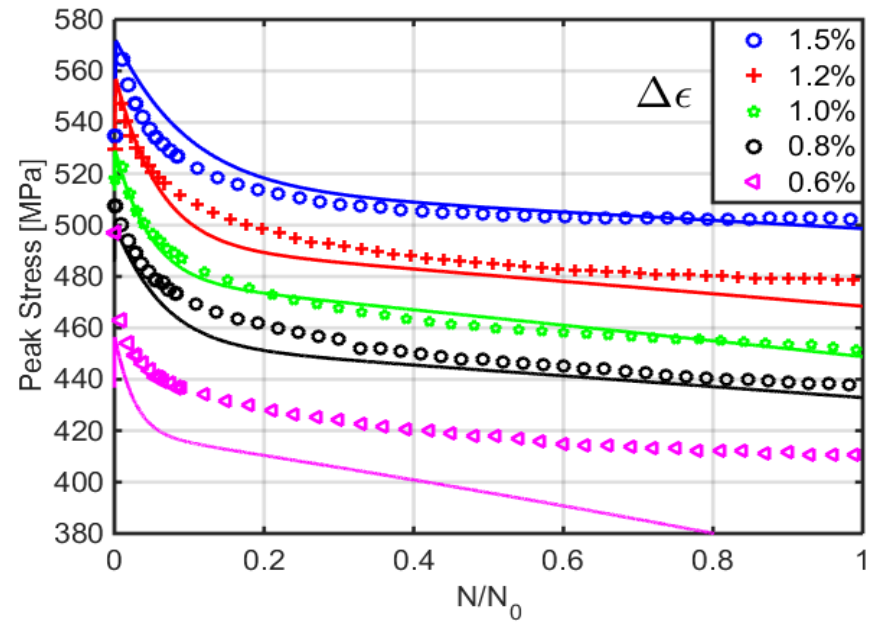

c) Peak tensile stresses vs. normalized number of cycles.

Fig. 6.2 Comparison between material response (markers) and RAFM model description (curves): Strain-controlled LCF tests on P91 at RT performed with various strain ranges.

However, with the same model and the same parameter values, a stress-controlled test performed with $\sigma_{\text {peak }}=500 \mathrm{MPa}$ and $\sigma_{\text {mean }}=25 \mathrm{MPa}$ is simulated. Fig. 6.3 illustrates the comparison between the material response and model description. Apparently, the accumulated strain in the simulation is much larger than that in material response, although the shape of the simulated hysteresis loop in the first cycle is similar to the experimental one. Therefore, the RAFM model with Armstrong-Frederick rule for kinematic hardening dramatically overestimates $\varepsilon_{r}$. 

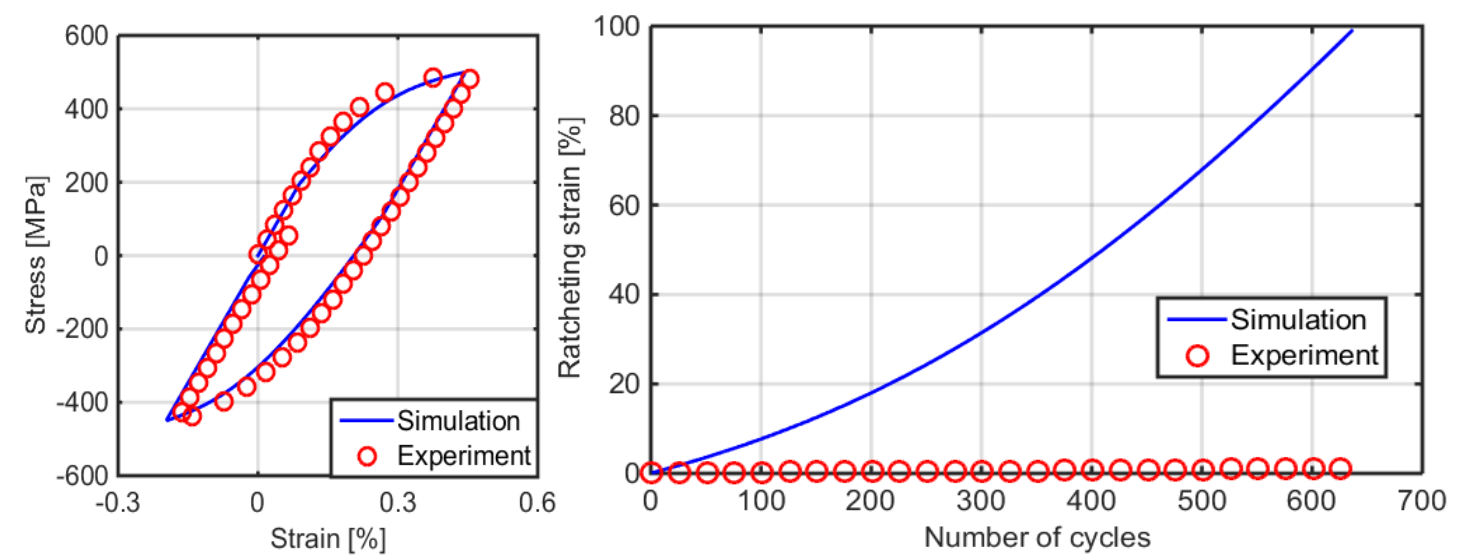

Fig. 6.3 Comparison between material response (markers) and RAFM model description (curves): Stress-controlled test at RT performed with $\sigma_{\text {peak }}=500 \mathrm{MPa}$,

$\sigma_{\text {mean }}=25 \mathrm{MPa}$, stress rate $\pm 50 \mathrm{MPa} / \mathrm{s}$. Left: loop of the first cycle. Right: accumulation of strain vs number of cycles.

In the aim of fitting $\varepsilon_{r}$ under multiple loading conditions, which is the first criterion for modeling listed in Section 6.1, the current RAFM model is modified, as discussed in the following sections.

\subsection{Testing with Existing Models}

\subsubsection{Testing with RAFM Model}

As illustrated in the previous section, the current RAFM model shows good ability to simulate strain-controlled LCF tests, but it obviously overestimates the accumulated strain under stress-controlled cyclic loading.

Different parameter values were tested in the current constitutive model (eqs. (6-1), $(6-2),(6-3),(6-5),(6-6),(6-9),(6-10))$ to simulate ratcheting. It was found that, when the parameters $C_{1}$ or $C_{2}$ are set to be zero, the model can yield no more ratcheting, which means if any one of the BS components has no dynamic recovery, there is no more ratcheting in the simulation.

The simulated results with different values of $C_{1}$ and $C_{2}$ are illustrated in Fig. 6.4. As can be seen in Fig. 6.4a, if the value of $C_{1}$ is kept as the value determined in the initial fitting of parameter values (shown in Table 6.3), the simulated hysteresis loop in the first cycle still approximately agrees with the experimental data. However, $\varepsilon_{r}$ in the simulated result is, comparing to material response, negligible, because $C_{2}=0$. If the value of $C_{1}$ is set to be zero, as shown in Fig. $6.4 \mathrm{~b}$ and c, even the simulated hysteresis loop in the first cycle is far from acceptable, with straight lines and sharp corners. The reason is that the parameters $H_{i}$ and $C_{i}$ of BS component $\Omega_{1}$ are much larger than the parameters of $\Omega_{2}$ (shown in Table 6.3), consequently $\Omega_{1}$ determines the shapes of the hysteresis loops (matching the plastic modulus) near the yield point, while $\Omega_{2}$ can make the simulated loops much closer to the experimental loops at higher strain, but 
is still much smaller than $\Omega_{1}$ and has a much smaller influence on simulated loop shapes.

Beside the influence on loop shapes, as long as one of the dynamic recovery terms is set to be zero, the accumulated strain in model description is negligible compared to material response.
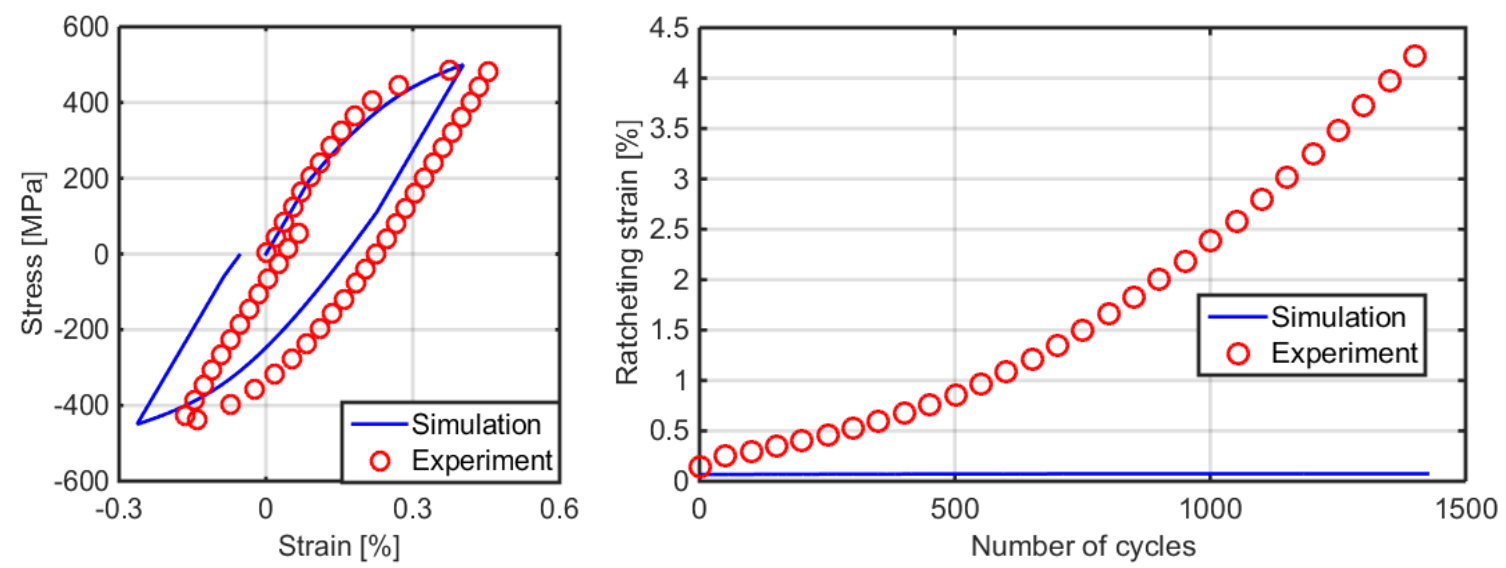

a) $C_{1}=1979, C_{2}=0$
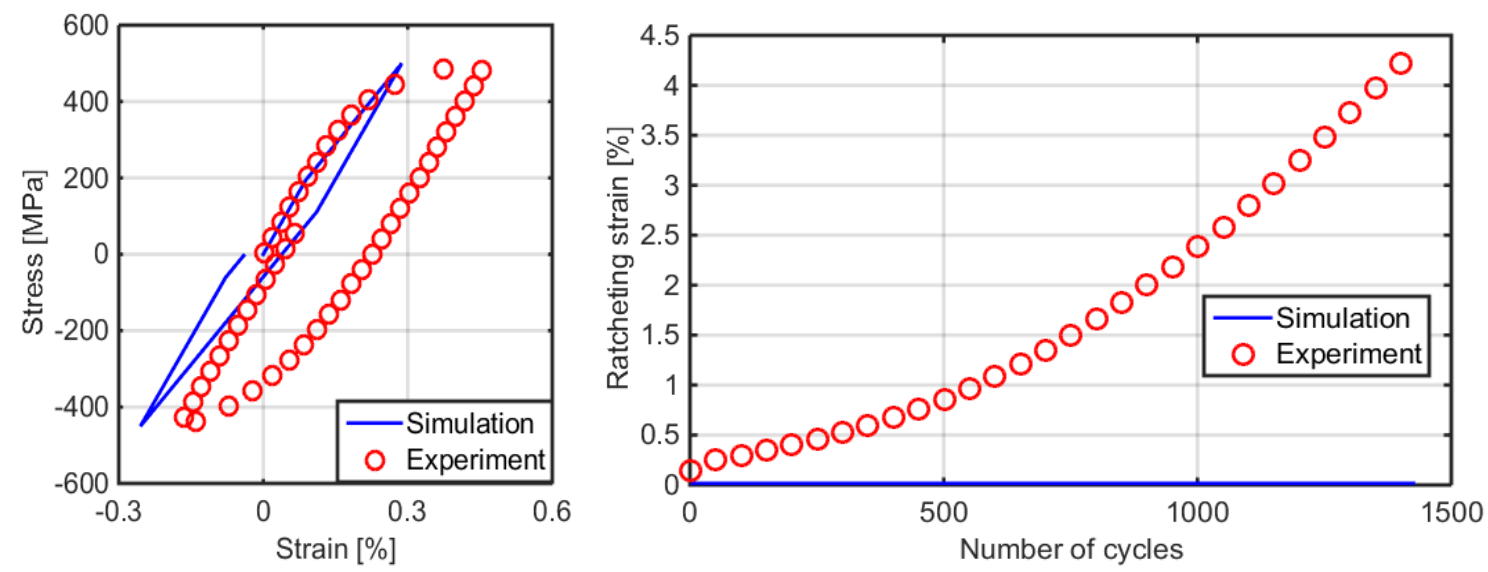

b) $C_{1}=0, C_{2}=0$
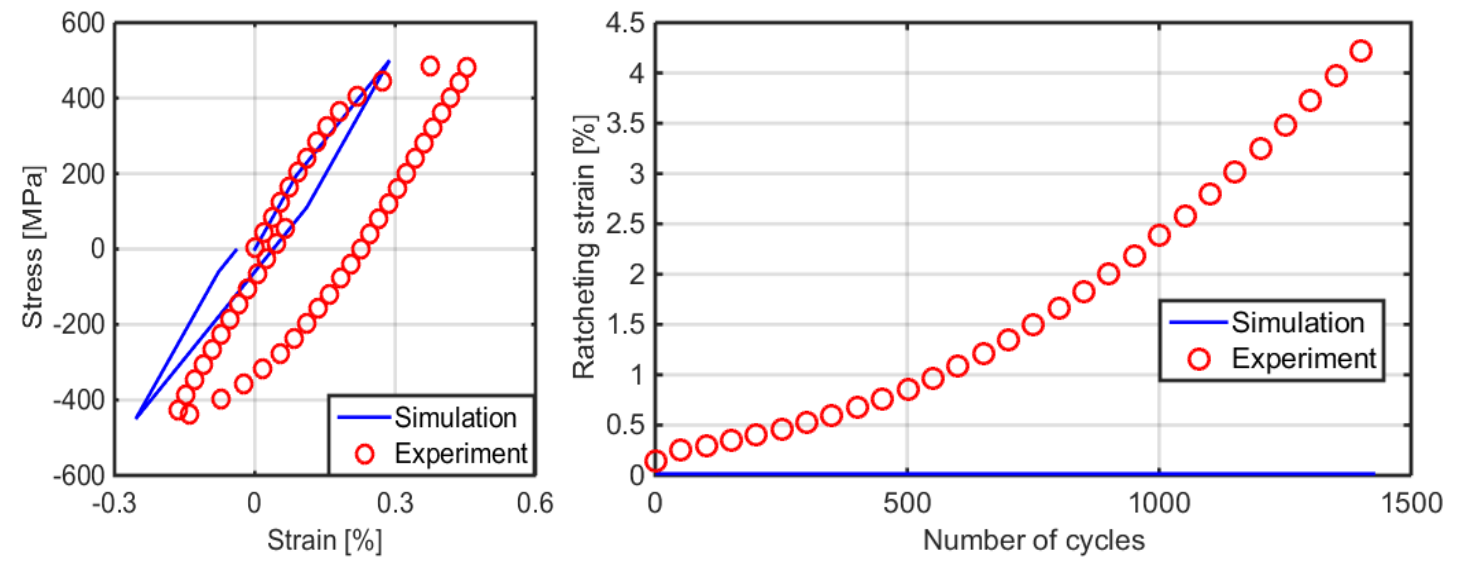

c) $C_{1}=0, C_{2}=256.7$

Fig. 6.4 Comparison between material response (markers) and RAFM model description (curves) with various parameter values for dynamic recovery:

Stress-controlled tests at $R T$ performed with $\sigma_{\text {peak }}=500 \mathrm{MPa}, \sigma_{\text {mean }}=25 \mathrm{MPa}$, stress 
rate $\pm 50 \mathrm{MPa} / \mathrm{s}$. Left: loop of the first cycle. Right: accumulation of strain vs number of cycles.

To fit $\varepsilon_{r}$ in the case with $\sigma_{\text {peak }}=500 \mathrm{MPa}, \sigma_{\text {mean }}=25 \mathrm{MPa}$, and $\dot{\sigma}= \pm 50 \mathrm{MPa} / \mathrm{s}$ at $\mathrm{RT}$, the parameter $C_{2}$ is set to be 5, then both the loop shape and accumulated strain in the simulated results match the experimental data satisfactorily, as shown in Fig. 6.5a.

However, with the same parameter values $\left(C_{1}=1979, C_{2}=5\right)$, the RAFM model description for the case with $\sigma_{\text {peak }}=500 \mathrm{MPa}, \sigma_{\text {mean }}=250 \mathrm{MPa}$, and $\dot{\sigma}=$ $\pm 50 \mathrm{MPa} / \mathrm{s}$ at RT has a great difference from the corresponding material response, as shown in Fig. 6.5b.

Therefore, the value of $C_{2}$ is not constant, but a function of the loading, which indicates that the main task to fit $\varepsilon_{r}$ under multiple loading conditions is to modify the term for dynamic recovery of BS 2 .
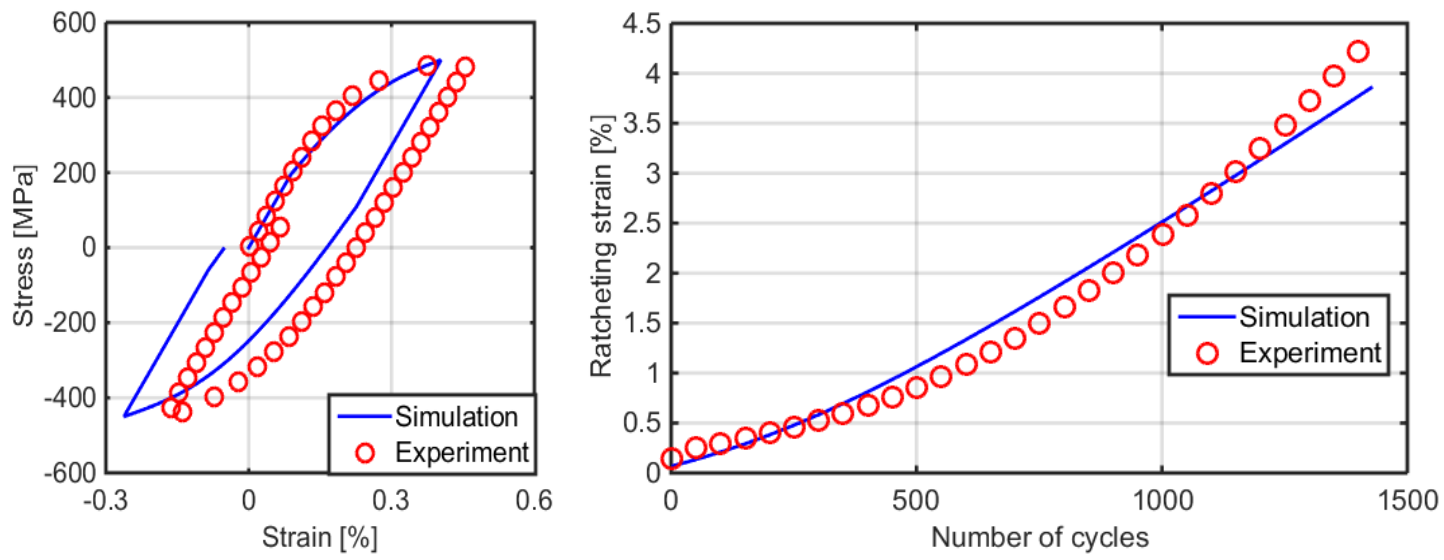

a) $\sigma_{\text {peak }}=500 \mathrm{MPa}, \sigma_{\text {mean }}=25 \mathrm{MPa}$, stress rate $\pm 50 \mathrm{MPa} / \mathrm{s}$ at $\mathrm{RT}$
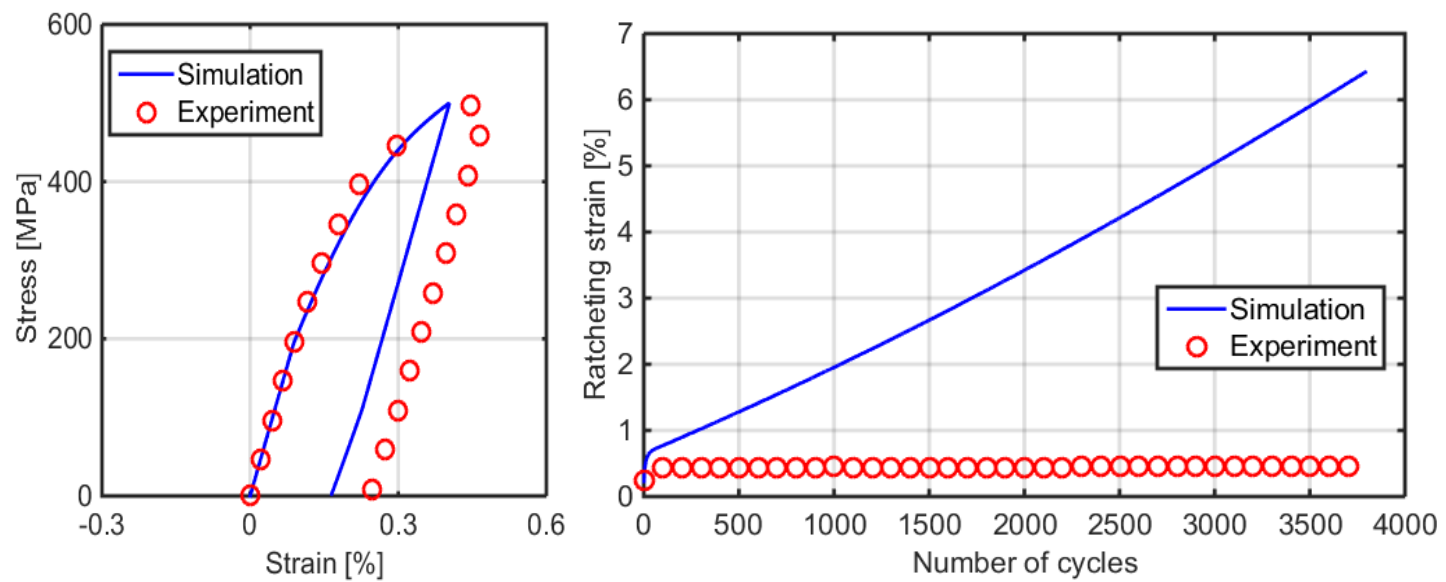

b) $\sigma_{\text {peak }}=500 \mathrm{MPa}, \sigma_{\text {mean }}=250 \mathrm{MPa}$, stress rate $\pm 50 \mathrm{MPa} / \mathrm{s}$ at $R T$

Fig. 6.5 Comparison between material response (markers) and RAFM model description (curves): Stress-controlled tests with $C_{1}=1979$ and $C_{2}=5$. Left: loop of the first cycle. Right: accumulation of strain vs. number of cycles. 


\subsubsection{Testing with Ohno-Wang Model I (OW I)}

In the modeling approaches reported in $[3,4,6,30,51,65,66]$, the main attention was paid to modification of the term of dynamic recovery of the kinematic hardening.

As mentioned in review of Ohno and Wang [3,4] in Section 2.2, a critical value $r_{i}$ for the magnitude of BS component $\Omega_{i}$ was assumed in OW I: If the magnitude of $\Omega_{i}$ reaches the value of $r_{i}$, the magnitude of $\Omega_{i}$ stops increasing, as illustrated in Fig. 2.6.

According to [3], eq. (6-9) is altered into:

$$
\dot{\Omega}_{i}=H_{i} \dot{\varepsilon}^{i n}-H s\left(\Omega_{i}{ }^{2}-\left(\frac{H_{i}}{C_{i}}\right)^{2}\right) C_{i} \Omega_{i}\left\langle\dot{\varepsilon}^{i n} \frac{\Omega_{i}}{\left|\Omega_{i}\right|}\right\rangle
$$

in which the dynamic recovery of kinematic hardening is only activated when the magnitude of $\Omega_{i}$ reaches the critical value of $\frac{H_{i}}{C_{i}}$. Hs denotes the Heaviside step function as mentioned in Section 2.2. On the other hand, the magnitude of $\Omega_{i}$ will stay constant after it reaches the critical value, as reviewed in Section 2.2.

By changing both equations for $\Omega_{1}$ and $\Omega_{2}$ in to eq. (6-15), the results are shown in Fig. 6.6a. If the equation of $\Omega_{1}$ is kept as eq. (6-9) and only the equation of $\Omega_{2}$ is changed to eq. (6-15), the results are shown in Fig. 6.6b.

Comparing the results shown in Fig. $6.6 \mathrm{a}$ and b, it is clear that if both equations of dynamic recovery of $\Omega_{1}$ and $\Omega_{2}$ are altered into the form of OW I (eq. (6-15)), the simulated hysteresis loops are composed of straight lines and sharp corners, while keeping the equation of $\Omega_{1}$ as in Armstrong-Frederick rule (eq. (6-9)), the simulated loop shape of the first cycle is closer to the experimental data. However, both cases in Fig. 6.6 dramatically underestimate $\varepsilon_{r}$. As discussed in [3, 4], OW I yields no ratcheting. 

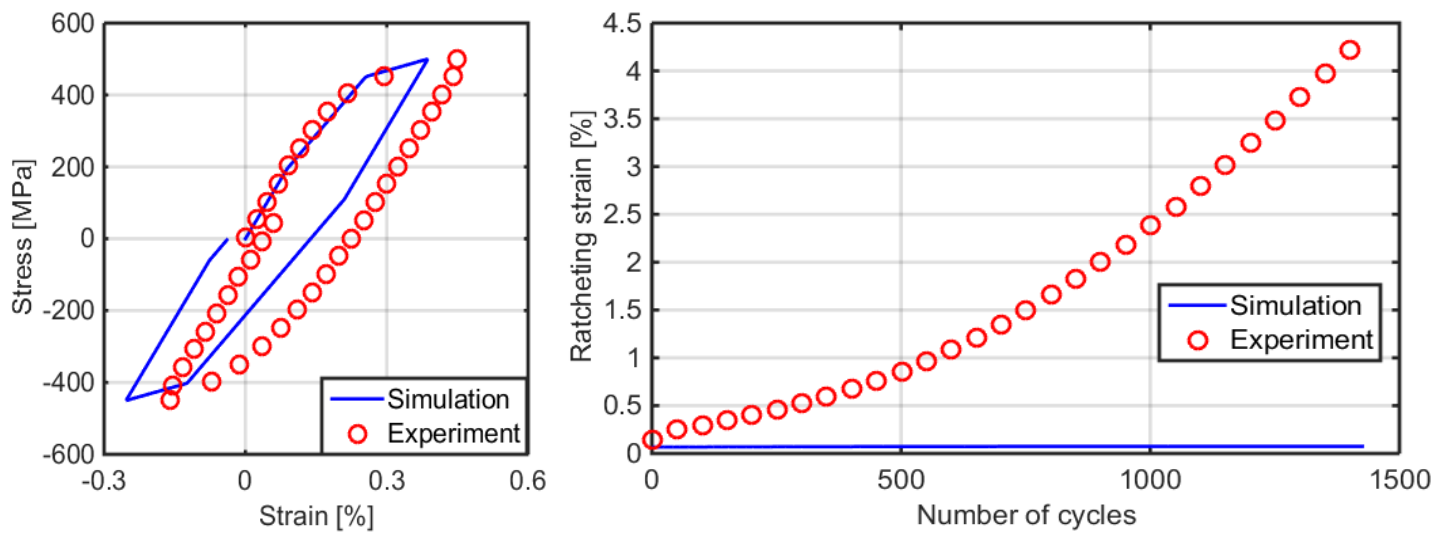

a) Both $\Omega_{1} \& \Omega_{2}$ follows OW I rule.
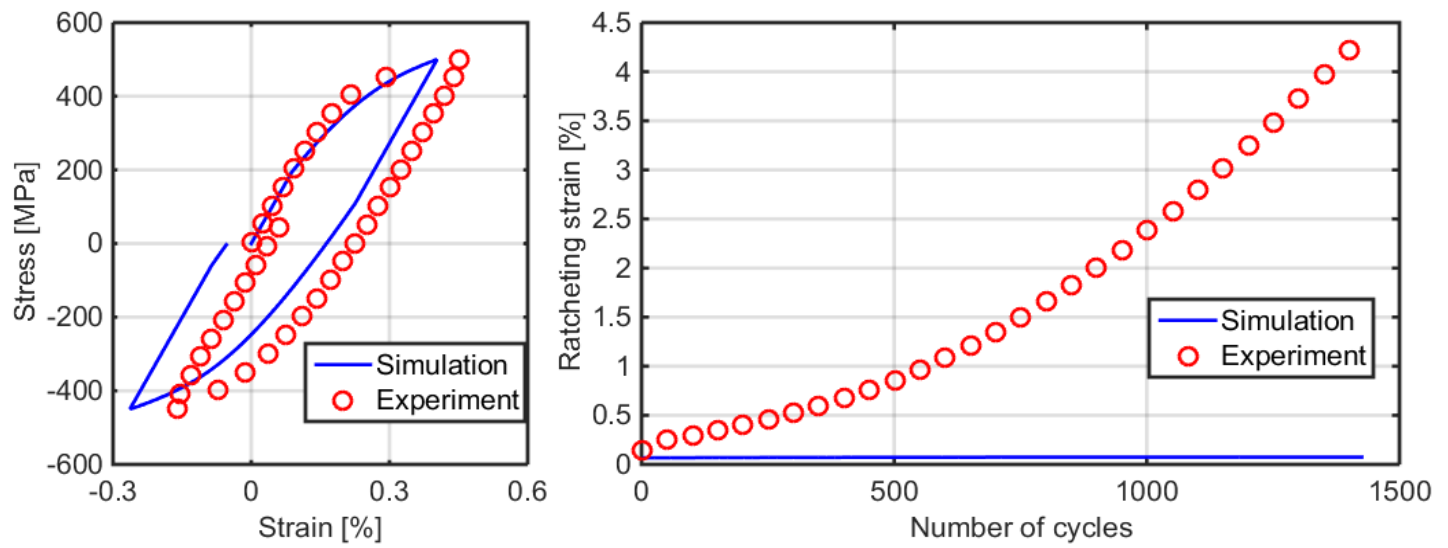

b) $\Omega_{1}$ follows $A F$ rule and $\Omega_{2}$ follows $O W$ I rule.

Fig. 6.6 Comparison between material response (markers) and OW I description

(curves): Stress-controlled tests at RT performed with $\sigma_{\text {peak }}=500 \mathrm{MPa}$, $\sigma_{\text {mean }}=25 \mathrm{MPa}$, stress rate $50 \mathrm{MPa} / \mathrm{s} . \mathrm{C}_{1}=1979, C_{2}=256.7$, Left: loop of the first cycle. Right: accumulation of strain vs. number of cycles.

In [3, 4], eight instead of two components of BS were assumed to make simulated loop shapes closer to those in the experimental results; in other words, shorter and denser straight lines in the simulation to approximate the smooth curves in the material response. Still, the simulated loops were piecewise linear and expressed no uniaxial $\varepsilon_{r}[3,4]$.

\subsubsection{Testing with Ohno-Wang Model II (OW II)}

To avoid the multi-linear behavior in the model description of OW I, OW II was developed in which the Heaviside function $H s\left(\Omega_{i}{ }^{2}-\left(\frac{H_{i}}{C_{i}}\right)^{2}\right)$ was replaced by the term $\left(\frac{\Omega_{i} C_{i}}{H_{i}}\right)^{m_{i}}$. The BS equation is as follows:

$$
\dot{\Omega}_{i}=H_{i} \dot{\varepsilon}^{\text {in }}-\left(\frac{\Omega_{i} C_{i}}{H_{i}}\right)^{m_{i}} C_{i} \Omega_{i}\left\langle\dot{\varepsilon}^{\text {in }} \frac{\Omega_{i}}{\left|\Omega_{i}\right|}\right\rangle
$$


Eq. (6-16) reduces to eq. (6-15) when $m_{i} \rightarrow \infty$.

Fig. 6.7 illustrates the simulated results with application of OW II.
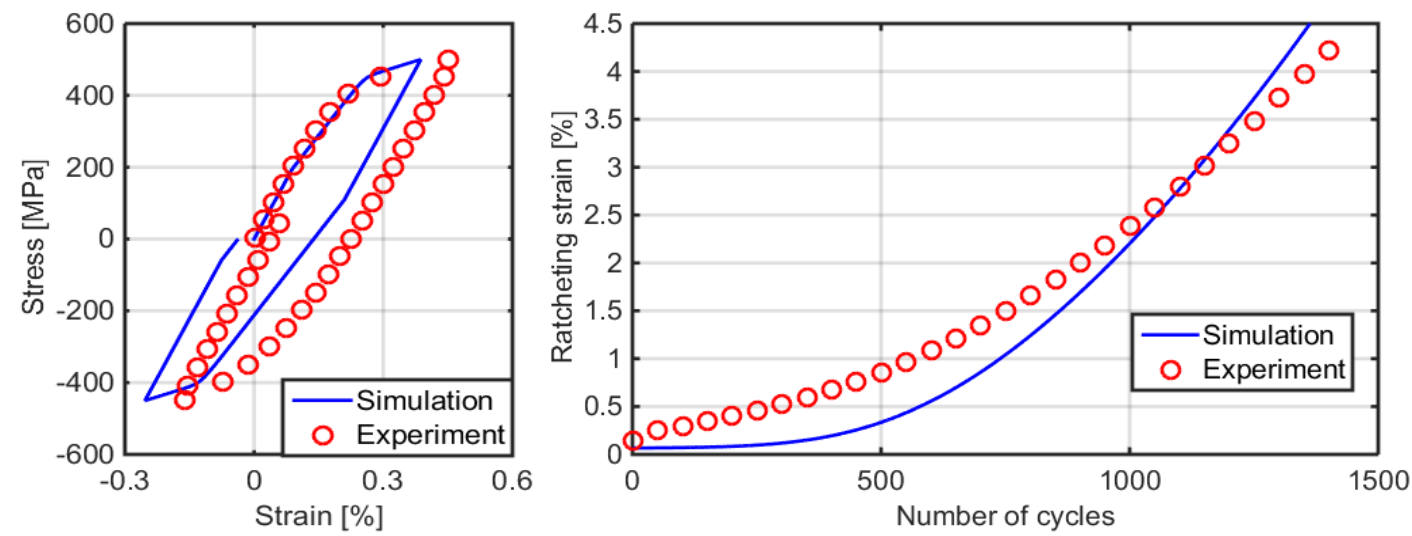

a) Both $\Omega_{1} \& \Omega_{2}$ follows OW II rule.
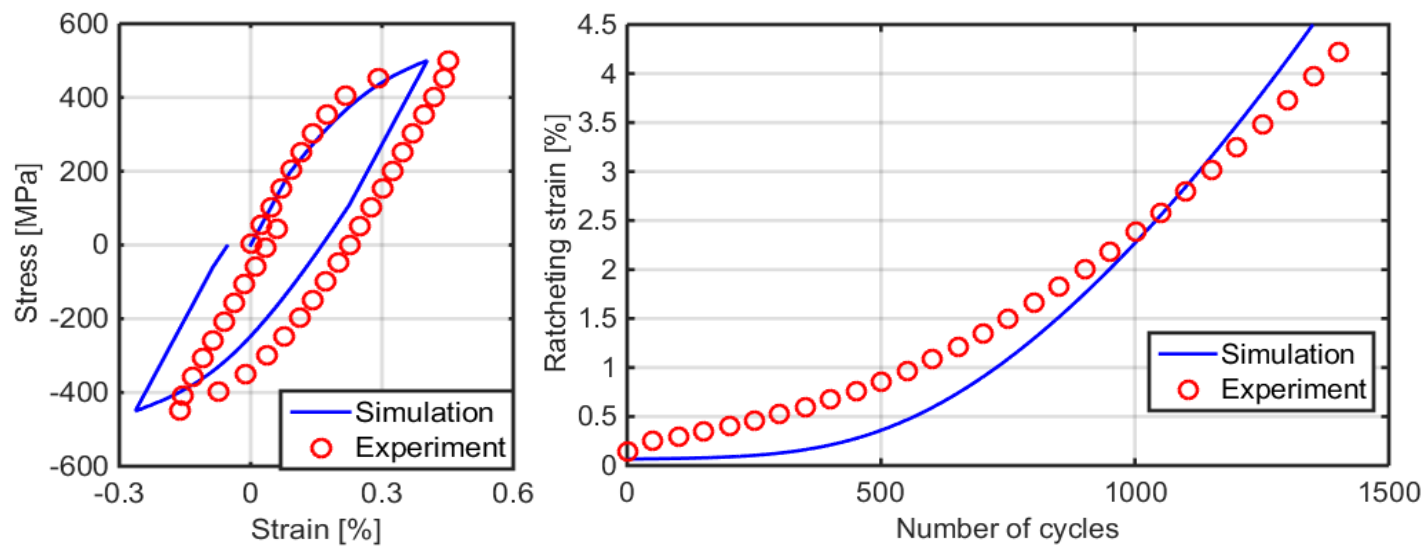

b) $\Omega_{1}$ follows AF rule and $\Omega_{2}$ follows OW II rule.

Fig. 6.7 Comparison between material response (markers) and OW II description (curves): Stress-controlled tests at RT performed with $\sigma_{\text {peak }}=500 \mathrm{MPa}$, $\sigma_{\text {mean }}=25 \mathrm{MPa}$, stress rate $50 \mathrm{MPa} / \mathrm{s} . \mathrm{C}_{1}=1979, C_{2}=256.7$. Left: loop of the first cycle. Right: accumulation of strain vs. number of cycles.

The equations of $\Omega_{1}$ and $\Omega_{2}$ are changed into eq. (6-16), and suitable values of $m_{1}$ and $m_{2}$ are searched for the case with $\sigma_{\text {peak }}=500 \mathrm{MPa}, \sigma_{\text {mean }}=25 \mathrm{MPa}$, and $\dot{\sigma}= \pm 50 \mathrm{MPa} / \mathrm{s}$ at RT. It is found that if $m_{1}>8$ and $m_{2}=7$, the model yields a similar $\varepsilon_{r}$ as the material and the value of $m_{1}$ does not affect the simulated $\varepsilon_{r}$ much as long as $m_{1}>8$. By setting $m_{1}=8$ and $m_{2}=7$, the loop of the first cycle and accumulation of strain in both material response and model description are shown in Fig. 6.7a. The loop is, as in Fig. 6.7 a), piecewise linear. If the equation of $\Omega_{1}$ is kept as eq. (6-9) and we change only the equation of $\Omega_{2}$ into eq. (6-16), the loop can be much smoother, as shown in Fig. 6.7b, and the simulated $\varepsilon_{r}$ is similar to that shown in Fig. 6.7a. 
Further, similar to the case with $\sigma_{\text {mean }}=25 \mathrm{MPa}$, the model and material response in the case with $\sigma_{\text {peak }}=500 \mathrm{MPa}, \sigma_{\text {mean }}=250 \mathrm{MPa}$, and $\dot{\sigma}= \pm 50 \mathrm{MPa} / \mathrm{s}$ is compared, as shown in Fig. 6.8. Parameter values are the same as the cases shown in Fig. 6.7.
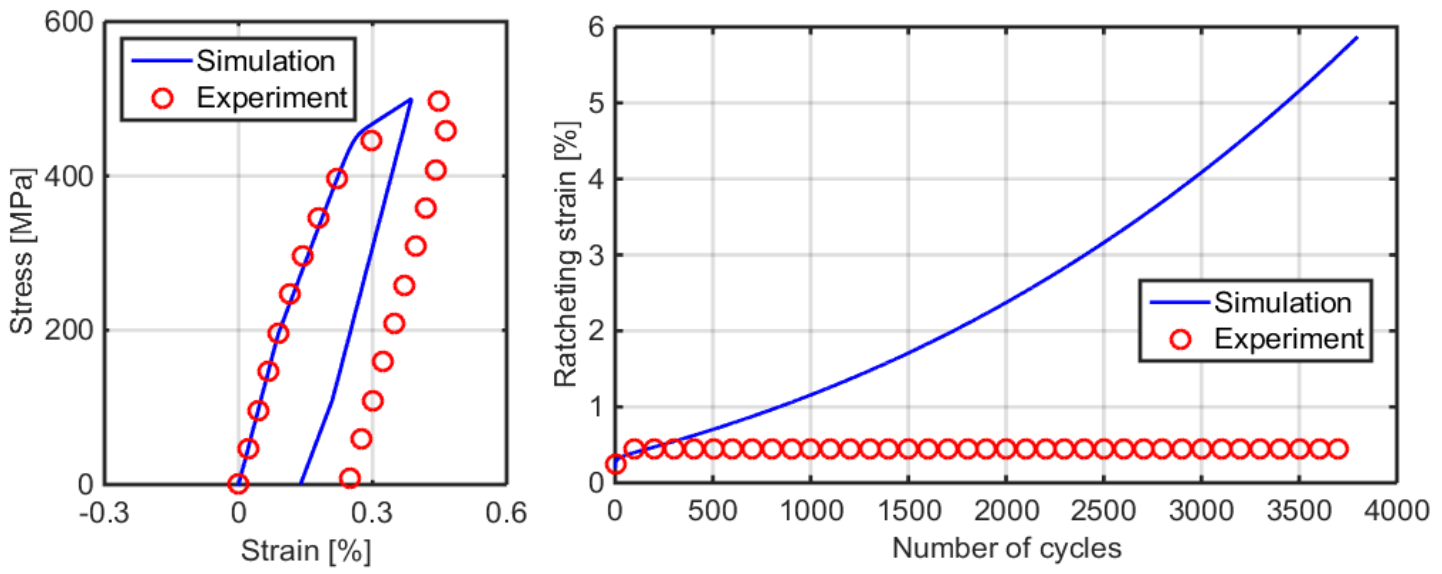

a) Both $\Omega_{1} \& \Omega_{2}$ follows $O W$ II rule.
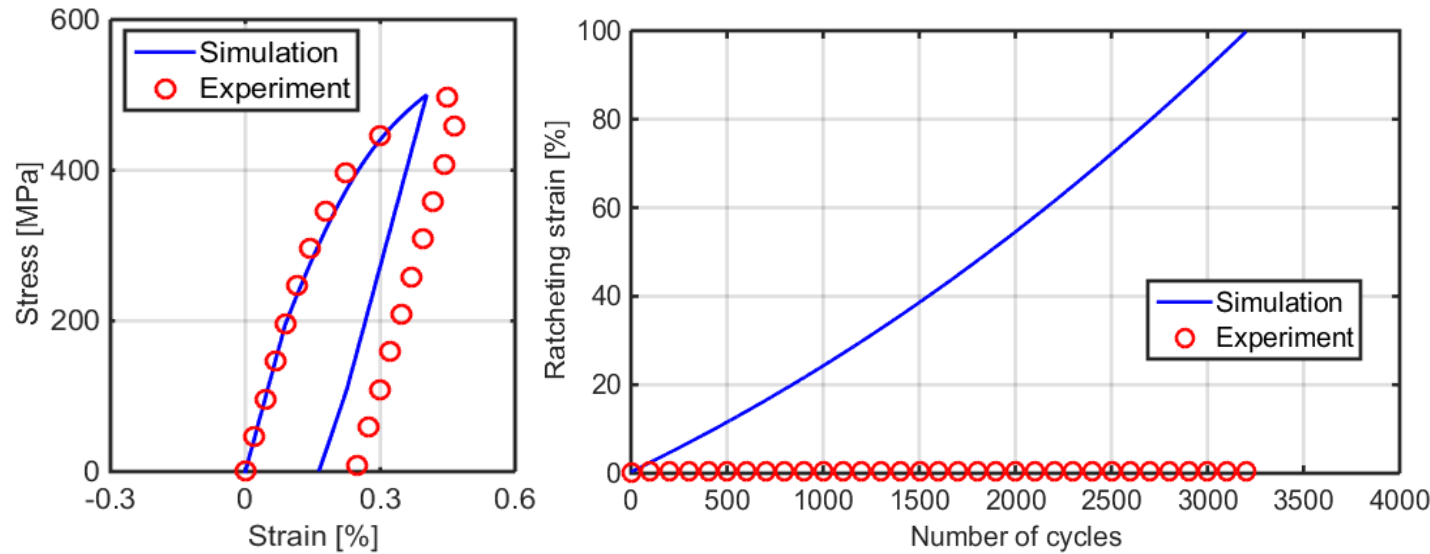

b) $\Omega_{1}$ follows AF rule and $\Omega_{2}$ follows OW II rule.

Fig. 6.8 Comparison between material response (markers) and OW II description (curves): Stress-controlled tests at RT performed with $\sigma_{\text {peak }}=500 \mathrm{MPa}$,

$\sigma_{\text {mean }}=250 \mathrm{MPa}$, stress rate $\pm 50 \mathrm{MPa} / \mathrm{s} . \mathrm{C}_{1}=1979, \mathrm{C}_{2}=256.7, \mathrm{~m}_{1}=8, \mathrm{~m}_{2}=7$, Left: loop of the first cycle. Right: accumulation of strain vs. number of cycles.

Fig. 6.8a shows the comparison with both equations for $\Omega_{1}$ and $\Omega_{2}$ changed to eq. (6-16), while Fig. 6.8b shows the comparison with only the equation for $\Omega_{2}$ changed to eq. (6-16). As can be seen, OW II overestimates the $\varepsilon_{r}$ with larger $\sigma_{\text {mean }}$, such as in this case with $\sigma_{\text {mean }}=250 \mathrm{MPa}$, the model yields too much $\varepsilon_{r}$ compared to the material response.

Further, another case was checked in which hold times at tensile peaks are included. The comparison between model description and material response is illustrated in Fig. 6.9. All parameter values and equations are the same as the cases shown in Fig. 6.7a and Fig. 6.8a. As can be seen, OW II dramatically underestimates the accumulated strain for the case with hold time at peak tensile stress. Note that the 
simulated creep during hold time at tensile peak in the case shown in Fig. 6.9 is too small to be seen in the current view, while the creep in experiment is obvious.
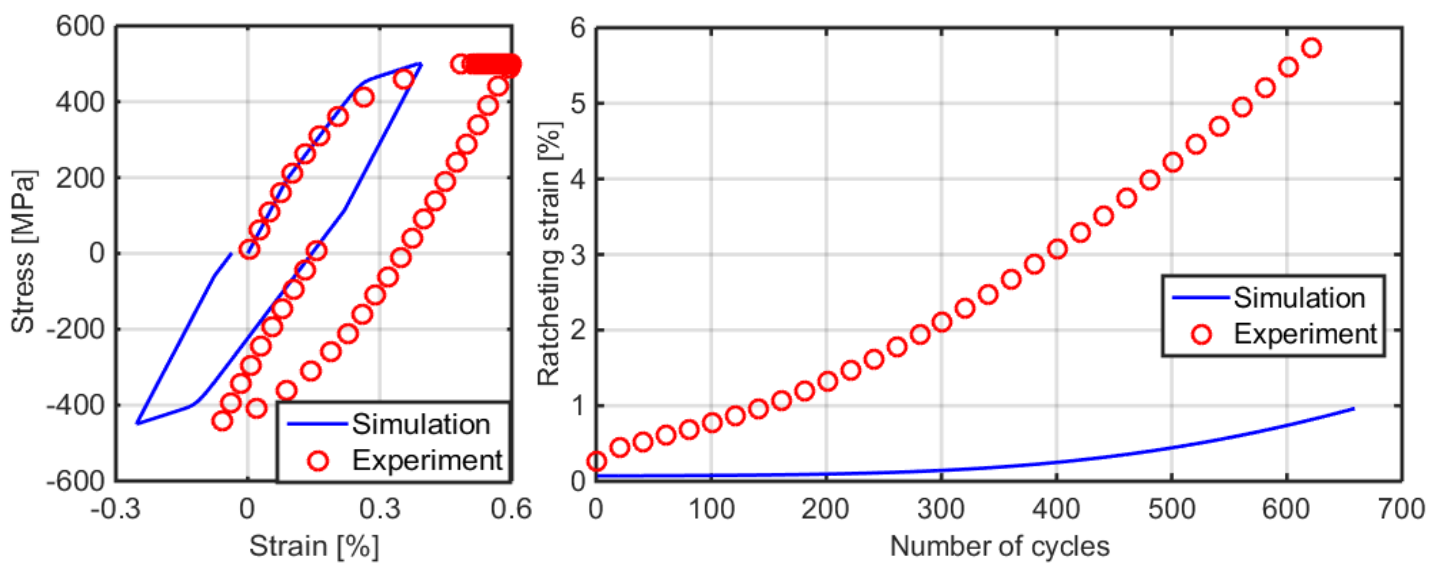

Fig. 6.9 Comparison between material response (markers) and OW II description (curves): Stress-controlled tests at RT performed with $\sigma_{\text {peak }}=500 \mathrm{MPa}$, $\sigma_{\text {mean }}=25 \mathrm{MPa}$, stress rate $\pm 50 \mathrm{MPa} / \mathrm{s}$, and hold 10 min at tensile peak. $C_{1}=1979$, $C_{2}=256.7, m_{1}=8$, and $m_{2}=7$. Left: loop of the first cycle. Right: accumulation of strain vs. number of cycles.

\subsection{Development of New Model for Room Temperature}

Both the Ohno-Abdel-Karim model [6] and the Kang model [30, 51, 65] (reviewed in Section 2.2) are basically slight modifications of the OW I and II models. The main disadvantage of these models is that too many BS components are required to simulate $\varepsilon_{r}$ and loop shapes. For instance, $10 \mathrm{BS}$ components were assumed in [51] by applying the Kang model, which was too complicated from an engineering point of view. On the other hand, it is a great challenge to fit all experiments under multiple loading conditions, especially to fit those cases with the same $\sigma_{\text {peak }}$ and various stress ratios ranging from $<-1$ to 0 , as discussed in Section 4.2.2 for tests at RT and Section 5.2.2 for tests at $550{ }^{\circ} \mathrm{C}$.

A new model is built firstly in this section based on the experimental results at RT. It is subsequently extended to fit experiments at $550{ }^{\circ} \mathrm{C}$ in Section 6.5.

One of the aims in the new modeling process is to reduce complexity: instead of four, eight, or more components of BS, the new model should include no more than four components of BS and still fulfill the 10 criteria listed in the very first place in this chapter. Among the 10 criteria, the first one, fitting on $\varepsilon_{r}$ under multiple loading conditions, is the most important criterion and has the highest privilege, which means it receives the largest weight during parameter fitting.

According to the models reviewed in Section 2.2 and tested in Section 6.3, it was found that one BS component is enough to fit the shapes of stress-strain hysteresis loops. This BS component can be named BS 1, which should have a large value of plastic modulus $\left(H_{1}\right)$ and a large value of modulus of dynamic recovery $\left(C_{1}\right)$. The 
dynamic recovery rule of this $\mathrm{BS} 1$ should follow the AF rule to avoid a piecewise linear shape of the hysteresis loop.

Another BS component, namely BS 2, can be assumed to control the accumulation speed of strain. This BS 2 shall have a smaller value of plastic modulus $\left(H_{2}\right)$ than that of BS 1 to minimize the influence on the shape of the simulated hysteresis loop. The design of the dynamic recovery term of BS 2 is the most important task in the current modeling approach, because this term should be designed to fit $\varepsilon_{r}$ under multiple loading conditions, including those with various $\sigma_{\text {peak }}$, smaller stress ratios $(R<-0.8)$, larger stress ratios $(R>-0.8)$, zero $\sigma_{\text {mean }}$, various $\dot{\sigma}$, and various hold times.

\subsubsection{Formulation for Room Temperature}

As mentioned at the beginning of this chapter, uniaxial form of model is firstly formulated, which is enough to simulate all experiments presented in Chapters 4 and 5 . The equations of the constitutive model for RT tests are listed in Table.

\begin{tabular}{l}
\hline$\dot{\varepsilon}=\dot{\varepsilon}^{i n}+\dot{\varepsilon}^{e l}$ \\
$\dot{\varepsilon}^{e l}=\frac{\sigma}{E}$ \\
$\dot{\varepsilon}^{i n}=\left\langle\frac{|\Sigma|-k}{Z}\right\rangle^{n} \operatorname{sgn}(\Sigma) \quad$ with $\Sigma=\frac{\sigma}{\psi}-\Omega$ \\
$\psi=\psi_{1}+\psi_{2}$, with $\psi_{1}(t=0)=0$ and $\psi_{2}(t=0)$ \\
$\quad=1$ \\
$\dot{\psi}_{1}=-h\left|\dot{\varepsilon}^{i n}\right|$ \\
$\dot{\psi}_{2}=c\left(1-\psi_{s, \infty}-\psi_{2}\right)\left|\dot{\varepsilon}^{i n}\right|$ \\
$\Omega_{1}=\Omega_{1}+\Omega_{2}$ \\
$\dot{\Omega}_{1}=H_{1} \dot{\varepsilon}^{i n}-C_{1} \Omega_{1}\left|\dot{\varepsilon}^{i n}\right|$ \\
$\dot{\Omega}_{2}=H_{2} \dot{\varepsilon}^{i n}-\Omega_{2}\left\langle\dot{\varepsilon}^{i n} \frac{\Omega_{2}}{r_{2}}+\left|\dot{\varepsilon}^{i n}\right| \mu_{2} \operatorname{sgn}(\sigma)\right\rangle$ \\
\hline
\end{tabular}

Table 6.4 Constitutive equations of new developed model for P91 at RT.

$E, k, Z, n, h, c, \psi_{s, \infty}, H_{1}, C_{1}, H_{2}, r_{2}$, and $\mu_{2}$ are material- and temperaturedependent parameters.

The kinematic hardening (back stress) is composed of two components $\Omega_{1}$ and $\Omega_{2}$, as discussed at the beginning of Section 6.4. $\Omega_{1}$ follows the dynamic recovery rule of Armstrong-Frederick (eq. (6-18)) and $\Omega_{2}$ has a new designed dynamic recovery rule 
(eq. (6-19)). Instead of the parameter $C_{2}$ in eqs. (2-11), (2-14), (2-15), (2-19), (6-15), (6-16), and (6-18), the parameter $r_{2}$ is included to control the magnitude of dynamic recovery of BS 2 . The parameters $H_{2}, r_{2}$ and $\mu_{2}$ are independent from each other, in which $\mathrm{H}_{2}$ is the plastic modulus of BS 2 , and $\mu_{2}$ controls the magnitude of asymmetry under tension and compression at RT.

Note that the BS 2 expresses the tendency to close the hysteresis loop, as discussed in Section 4.2.4. In Fig. 6.10, the developments of the two BS components are illustrated. It was found that the BS 2 develops around a middle stress of approximately $25 \mathrm{MPa}$, which is the mean stress of the applied stress-controlled loading. This behavior of BS 2 compensates most effects of the asymmetric loading, leaving only a tiny increment of inelastic strain in each cycle, which is the ratcheting.

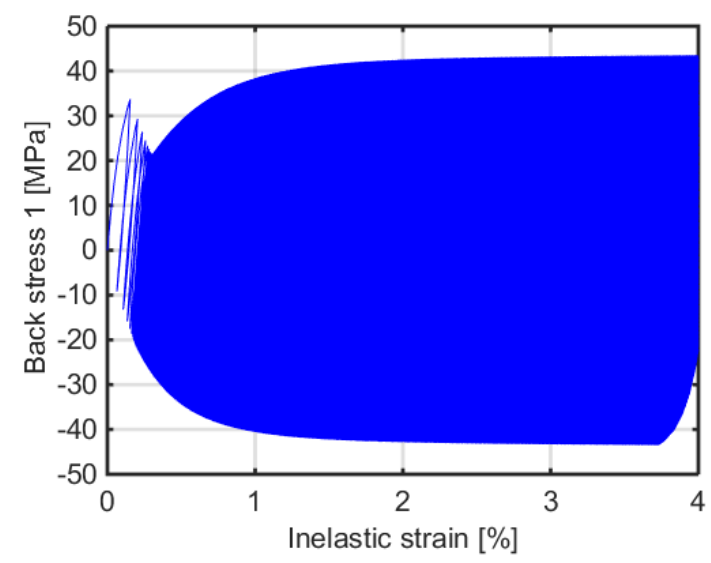

a) BS 1 vs. inelastic strain

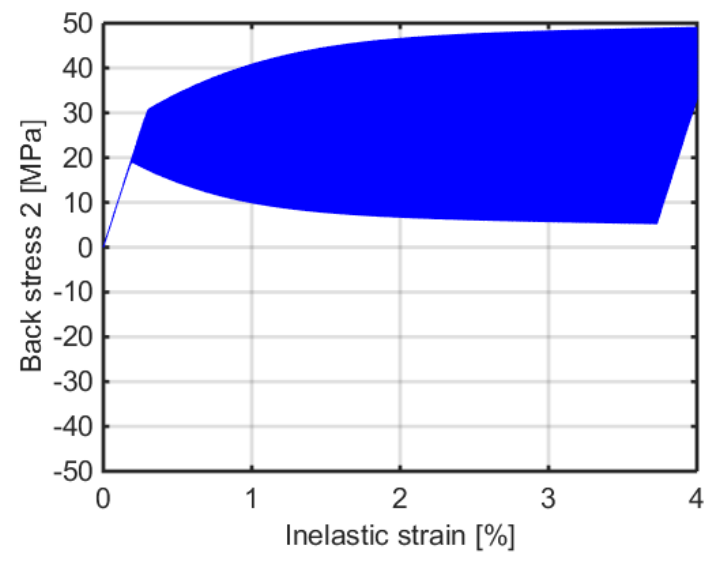

b) BS 2 vs. inelastic strain.

Fig. 6.10 Back stress components in the new developed model for the test simulated at $R T$ with $\sigma_{\text {peak }}=500 \mathrm{MPa}, \sigma_{\text {mean }}=25 \mathrm{MPa}$, stress rate $\pm 50 \mathrm{MPa} / \mathrm{s}$.

As in the Abdel-Karim model [66], various candidates for the new design of dynamic recovery rule are tested, as listed in Table 6.5.

\begin{tabular}{l|}
\hline$\Omega_{2}\left\langle\dot{\varepsilon}^{i n}\right\rangle\left\langle\frac{\Omega_{2}}{r_{2}}+\mu_{2}\right\rangle$ \\
$\Omega_{2}\left|\dot{\varepsilon}^{i n}\right|\left\langle\frac{\Omega_{2}}{r_{2}}+\mu_{2}\right\rangle$ \\
$\left|\Omega_{2} \dot{\varepsilon}^{i n}\right|\left\langle\frac{\Omega_{2}}{r_{2}}+\mu_{2}\right\rangle$ \\
$\left\langle\Omega_{2} \dot{\varepsilon}^{\text {in }}\right\rangle\left\langle\frac{\Omega_{2}}{r_{2}}+\mu_{2}\right\rangle$ \\
$\Omega_{2}\left|\dot{\varepsilon}^{\text {in }} \frac{\Omega_{2}}{r_{2}}+\right| \dot{\varepsilon}^{\text {in }}\left|\mu_{2} \operatorname{sgn}(\sigma)\right|$
\end{tabular}

Table 6.5 Candidates of equations for dynamic recovery of back stress 2 in new developed model for P91 at RT.

Using eqs. (6-20)-(6-23) for BS 2, none of them could yield negative ratcheting for cases with $\sigma_{\max }=500 \mathrm{MPa}, \sigma_{\min }=-550 \mathrm{MPa}$, and $\dot{\sigma}= \pm 50 \mathrm{MPa} / \mathrm{s}$ at RT or $\sigma_{\max }=450 \mathrm{MPa}, \sigma_{\min }=-500 \mathrm{MPa}$, and $\dot{\sigma}= \pm 50 \mathrm{MPa} / \mathrm{s}$ at RT. Fig. 6.11 illustrates 
the simulation result using eq. (6-23) for BS 2. The simulated $\varepsilon_{r}$ is in the opposite direction to that in the experiment. Applying eqs. (6-20)-(6-22) gives a similar model description as shown in Fig. 6.11.

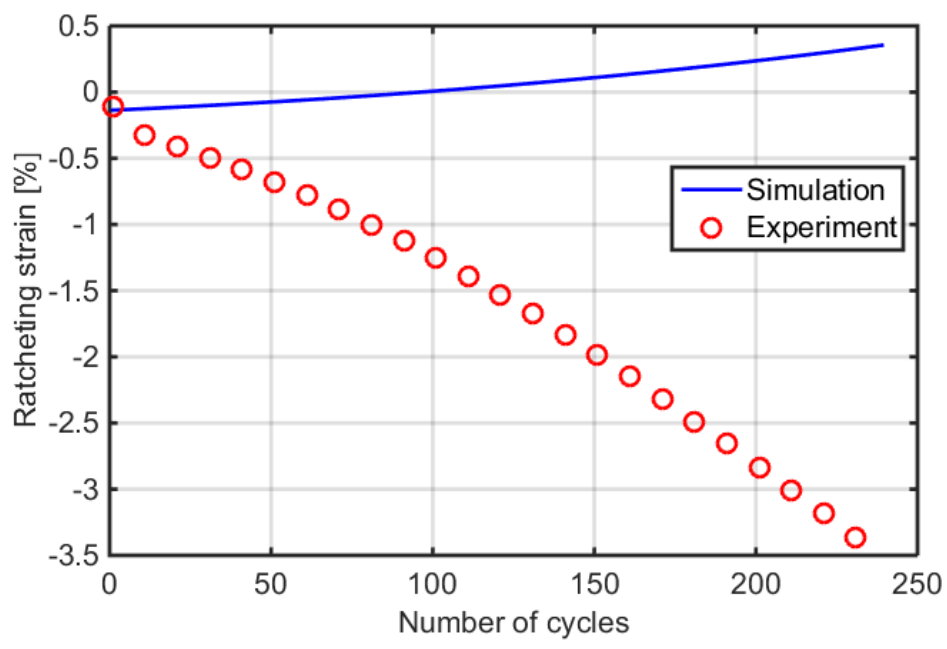

Fig. 6.11 Comparison between material response(markers) and model description(curves): Stress-controlled tests at $R T$ with $\sigma_{\max }=500 \mathrm{MPa}$, $\sigma_{\min }=-550 \mathrm{MPa}$, stress rate $\pm 50 \mathrm{MPa} / \mathrm{s}$.

However, with the same parameter values, no vast difference in simulated $\varepsilon_{r}$ was found between the simulation result using eq. (6-24) and the result using eq. (6-19). The difference in the model is between the Macaulay bracket $\langle x\rangle$ and the absolute value $|x|$. These two candidates were tested with difference cases, including loading with smaller stress ratios $\left(\sigma_{\text {peak }}=500 \mathrm{MPa}, \sigma_{\text {mean }}=10\right.$ and $25 \mathrm{MPa}$, and $\dot{\sigma}= \pm 50$ $\mathrm{MPa} / \mathrm{s})$, loading with larger stress ratios $\left(\sigma_{\text {peak }}=500 \mathrm{MPa}\right.$, $\sigma_{\text {mean }}=100$ and $250 \mathrm{MPa}$, and $\left.\dot{\sigma}= \pm 50 \mathrm{MPa} / \mathrm{s}\right)$, loading with zero $\sigma_{\text {mean }}$ $\left(\sigma_{\text {peak }}=500 \mathrm{MPa}, \sigma_{\text {mean }}=0 \mathrm{MPa}, \dot{\sigma}= \pm 50 \mathrm{MPa} / \mathrm{s}\right)$, loading with various $\dot{\sigma}$ $\left(\sigma_{\text {peak }}=500 \mathrm{MPa}, \sigma_{\text {mean }}=25 \mathrm{MPa}\right.$, and $\dot{\sigma}= \pm 10,50$, and $\left.250 \mathrm{MPa} / \mathrm{s}\right)$, and loading with various hold times $\left(\sigma_{\text {peak }}=500 \mathrm{MPa}, \sigma_{\text {mean }}=25 \mathrm{MPa}, \dot{\sigma}= \pm 50 \mathrm{MPa} / \mathrm{s}\right.$, one with $10 \mathrm{~min}$ hold time at tensile peak and another with 10 min hold time at compressive peak). Eq. (6-19) was chosen as the best among these candidates because it has better fitting to the diagram of $\varepsilon_{r}^{\prime}$ vs. various stress ratios, as shown in Fig. 4.13. From the mechanical point of view, application of the Macaulay bracket is more reasonable because the dynamic recovery is supposed to occur when BS and inelastic strain rate have the same direction.

The new design of dynamic recovery rule (eq. (6-19)) is similar to that in the OhnoAbdel-Karim model [6], as shown in eqs. (2-15) and (2-16) in Chapter 2. However, the parameter $\mu_{2}$ is now a controller of asymmetry under tension and compression, instead of a combination tool between the AF and OW models in [6]. With $\mu_{2}>0$, the model in cases with zero $\sigma_{\text {mean }}$ yields a positive $\varepsilon_{r}$, and the model description in strain-controlled LCF tests shows higher magnitudes of compressive peak stresses than the corresponding peak tensile stresses, as already discussed in Section 4.1 and illustrated in Fig. 4.5a. 
The effect of parameter $\mu_{2}$ is illustrated in Fig. 6.12: In the case with $\sigma_{a}=550 \mathrm{MPa}$ and zero $\sigma_{\text {mean }}$, the best simulation can be yielded with $\mu_{2}=2.4$, as shown with the blue curve in Fig. 6.12. If $\mu_{2}=0$, then the model yields no $\varepsilon_{r}$ (green line in Fig. 6.12). When $\mu_{2}=-2.4$, the model yields negative and symmetric $\varepsilon_{r}$ (black curve in Fig. 6.12) to the simulated $\varepsilon_{r}$ with $\mu_{2}=2.4$.

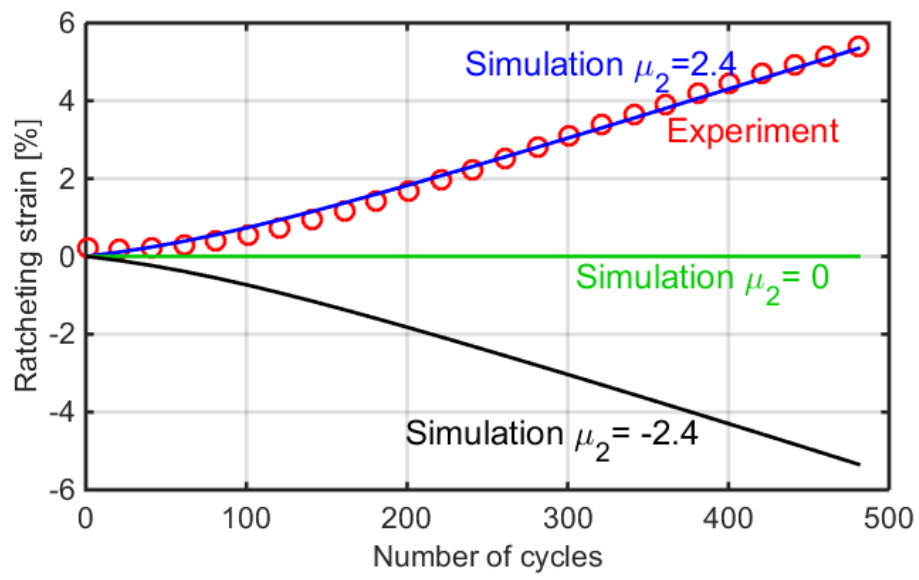

Fig. 6.12 Comparison between material response (markers) and model description (curves): Stress-controlled tests at $R T$ performed with $\sigma_{\text {peak }}=500 \mathrm{MPa}$, $\sigma_{\text {mean }}=0 \mathrm{MPa}$, stress rate $\pm 50 \mathrm{MPa} / \mathrm{s}$, with various values of $\mu_{2}$.

The Yaguchi-Takahashi model $[7,26]$ expresses the asymmetry of material strength by introducing a term for hydrostatic pressure:

$$
J_{m}(\boldsymbol{\sigma})=\eta|\operatorname{tr}(\boldsymbol{\sigma})|^{l} \operatorname{sgn}(\operatorname{trace}(\boldsymbol{\sigma}))
$$

to show smaller true elastic limit under tension than that under compression. A similar fitting approach is also performed by taking $J_{m}(\boldsymbol{\sigma})$ into eq. (6-3), as has been done in the Yaguchi-Takahashi model (see eq. (2-22)). However, no better model description can be simulated than the application of a parameter $\mu_{2}$ in the dynamic recovery term.

Hence, the positive value of $\mu_{2}$ indicates that the reason for larger material strength under compression is the relatively smaller dynamic recovery. A further explanation is that the compressive hydrostatic pressure inhibits the dislocation migration and annihilation at RT, owing to second phase particles. At high temperature, for example $550{ }^{\circ} \mathrm{C}$, dislocation migration is more thermally activated than at RT and is relatively less influenced by hydrostatic pressure, hence in the high-temperature tests reported in Chapter 5, no asymmetry was observed. However, since the asymmetry of material strength was still observed at $550{ }^{\circ} \mathrm{C}$ for mod. $9 \mathrm{Cr}-1 \mathrm{Mo}$ steel, as reported in [26], the suggestion above should be further verified.

The parameter values are fitted in a similar way to those in the RAFM model mentioned in Section 6.2: Young's modulus $E$ controls the slope of the unloading line of the first cycle. The parameters $k, Z, n, H_{1}$, and $C_{1}$ control the shape of the inelastic region of the loops in strain- and stress-controlled tests. Parameter $k$ is theoretical yield strength, parameter $H_{1}$ is inelastic modulus of BS $1, \frac{H_{1}}{C_{1}}$ is the largest possible value of BS 1. Parameter $c$ controls the decreasing rates of peak tensile and 
compressive stresses in the first stage of cyclic softening in strain-controlled tests. Parameter $\psi_{s, \infty}$ controls the magnitude of peak tensile and compressive stress at the end of the first stage of cyclic softening. Parameter $h$ controls the slope of decrease of $\sigma_{\text {peak }}$ in the saturation stage (second stage) of cyclic softening. The values of the above-mentioned parameters are fitted accordingly. The parameters $H_{2}, r_{2}$, and $\mu_{2}$ are fitted according to $\varepsilon_{r}^{\prime}$ under multiple cyclic loadings in stress-controlled tests presented in Section 4.2.

The trick in the parameter fitting process is to simulate $\varepsilon_{r}$ under multiple loading conditions where the values of parameters $k, Z, n, H_{1}$, and $C_{1}$ still play roles. For instance, if one set of parameter values had satisfactory simulating performance for tests with high $\varepsilon_{r}^{\prime}$, it can dramatically over- or under-estimate $\varepsilon_{r}$ for tests with relatively low $\varepsilon_{r}^{\prime}$. Different groups of values of $k, Z, n, H_{1}$, and $C_{1}$ can yield similar shaped hysteresis loops; however, these values have different performances in simulating $\varepsilon_{r}$ under various stress-controlled cyclic loadings.

The same problem also exists for the parameters of softening $\left(h, c\right.$, and $\left.\psi_{s, \infty}\right)$, which also affect the simulated $\varepsilon_{r}$, since cyclic softening accelerates ratcheting and this is why strain-controlled LCF tests should be performed. As illustrated in Fig. 6.13a, the simulation without softening underestimates $\varepsilon_{r}$. Further, as shown in Fig. 6.13b, the simulation result without softening shows no increase of strain range of hysteresis loop cycle by cycle, as the material does. Note that fitting on increase of strain range is also one of the criteria listed at the beginning of this chapter. 


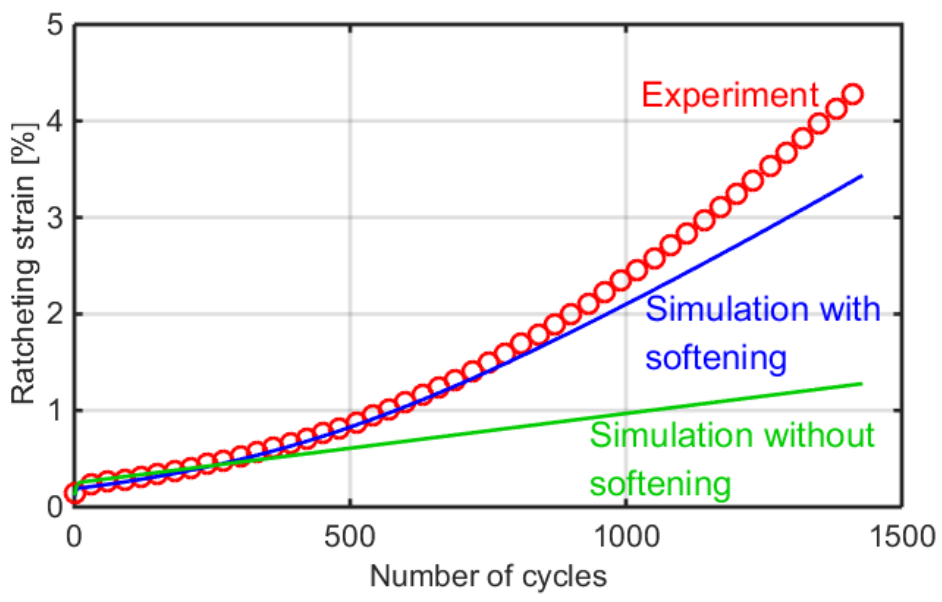

a) $\varepsilon_{r} v s$. number of cycles.

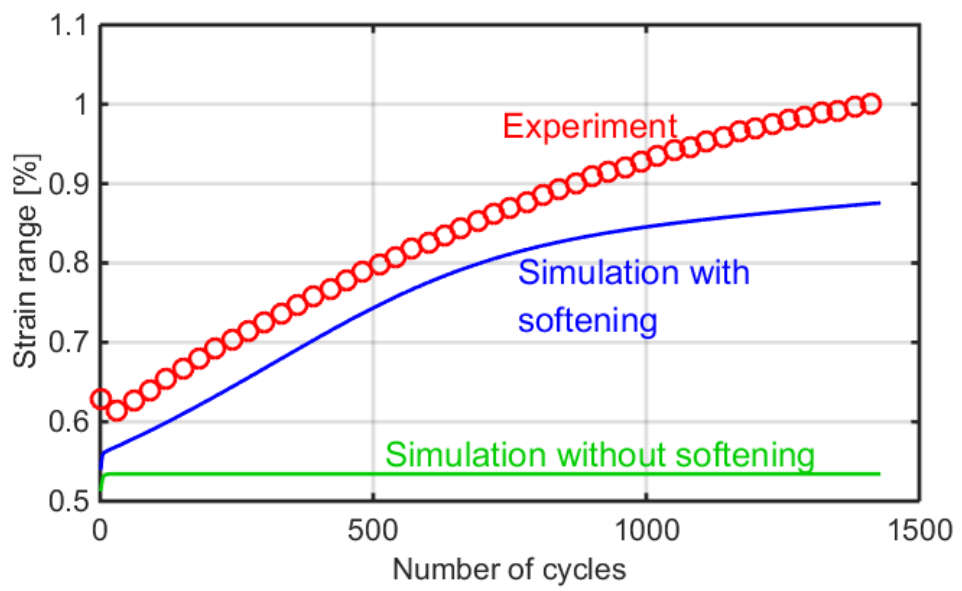

b) Strain ranges vs. number of cycles.

Fig. 6.13 Comparison between material response (markers) and model description (curves): Stress-controlled tests at $R T$ performed with $\sigma_{\text {peak }}=500 \mathrm{MPa}$, $\sigma_{\text {mean }}=25 \mathrm{MPa}$, stress rate $\pm 50 \mathrm{MPa} / \mathrm{s}$, with or without term of softening in simulation.

As mentioned above, the physical meaning of parameter $k$ is the theoretical yielding strength, or the so-called true elastic limit, over which the loading can activate dislocation movement and plastic straining. However, it is impossible to measure the exact value of the true elastic limit with the current precision of the experiment equipment. The only parameter value that can be physically measured is the Young's modulus $E$.

Therefore, except for the parameter $E$, all values shall be changed to fit $\varepsilon_{r}$ in stresscontrolled tests. The shape of loops can be compromised, if necessary, to make $\varepsilon_{r}$ in the model description agree with those in material responses.

The fitted values of the 12 material parameters for P91 at RT are listed in Table 6.6. The simulation results for RT are presented in the following section. 


\begin{tabular}{ll}
\hline$E(M P a)$ & 220086 \\
$k(M P a)$ & 239.094 \\
$Z\left(M P a s^{1 / n}\right)$ & 249.399 \\
$n$ & 32.8131 \\
$H_{1}(M P a)$ & 41551.1 \\
$C_{1}$ & 787.543 \\
$H_{2}(M P a)$ & 13905.9 \\
$r_{2}$ & 15.3982 \\
$\mu_{2}$ & 0.94295 \\
$h$ & $1.0169 \times 10^{-3}$ \\
$c$ & 0.63815 \\
$\psi_{s, \infty}$ & 0.08748 \\
\hline Table 6.6 Parameters of the new developed model determined for P91 at $R T$.
\end{tabular}

\subsubsection{Simulation Results for Room Temperature}

In this section, simulation results are presented for tests at RT. In each diagram, the markers indicate experimental results and the curves indicate the corresponding simulated results with the corresponding colors.

Fig. 6.14 shows the results of the strain-controlled LCF tests. The simulated shapes of the hysteresis loops approximately coincide with the experimental data points, in spite of corners near the onset points for yield (see Fig. 6.14a and b. As mentioned above, the loop shape can be compromised to fitting on $\varepsilon_{r}$ in stress-controlled tests. However, the loop shapes from the simulation are still acceptable.

Fig. 6.14c shows that the cyclic softening of P91 with various strain ranges is well simulated with the new developed model.

Hence, the new model satisfactorily simulates the strain-controlled tests at RT. 

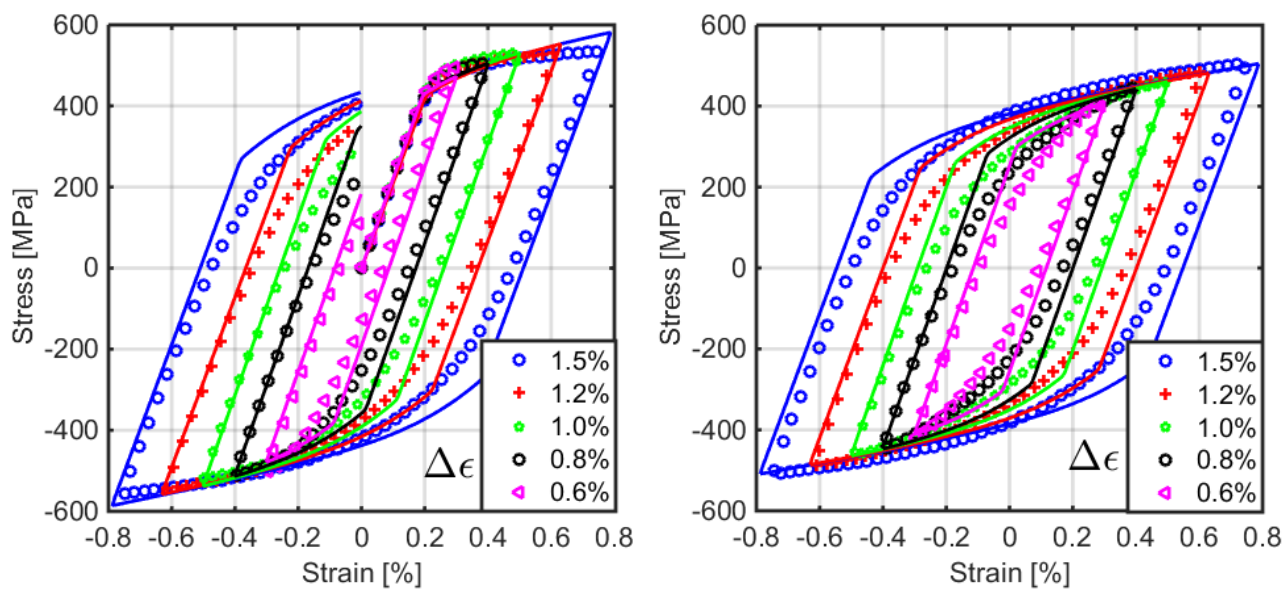

a) Hysteresis loops of the first cycle.

b) Hysteresis loops of the cycle at $N_{0} / 2$.

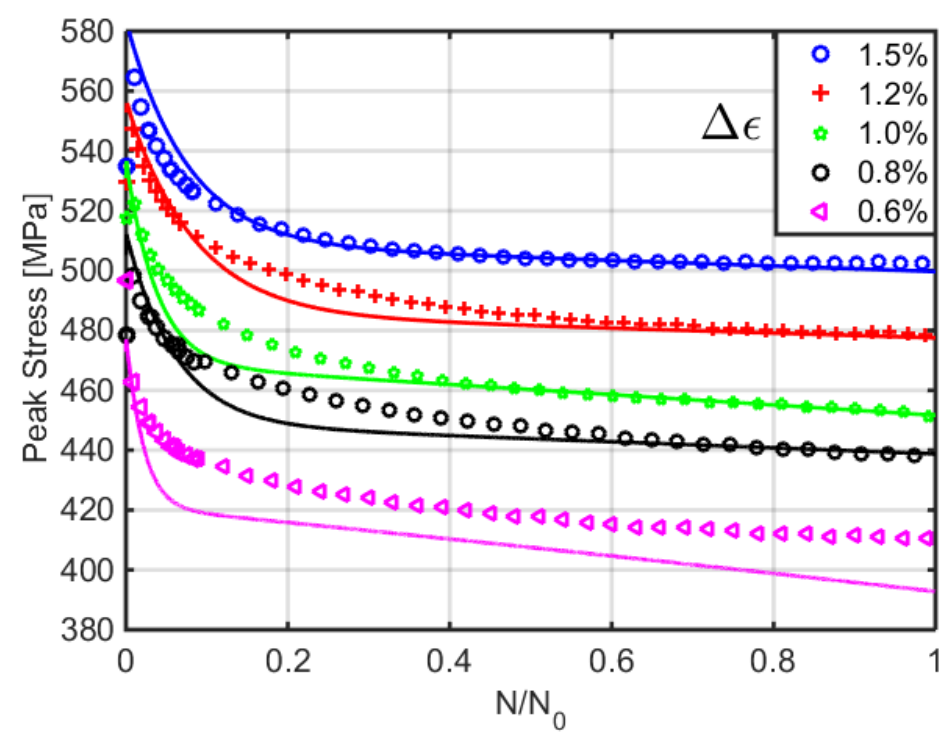

c) Peak tensile stresses vs. normalized number of cycles

Fig. 6.14 Comparison between material response (markers) and model description (curves): Strain-controlled LCF tests performed with various strain ranges on P91 at $R T$.

Fig. 6.15 and Fig. 6.16 illustrate the simulation results for ratcheting tests performed with the same $\sigma_{\text {mean }}$ and various $\sigma_{\text {peak }}$. Fig. 6.15 shows plots of $\varepsilon_{r}$ vs. number of cycles for several tests. Fig. 6.16 shows the relation between $\varepsilon_{r}^{\prime}$ and $\sigma_{\text {peak }}$. The ratcheting rates $\varepsilon_{r}^{\prime}$ shown in Fig. 6.16, both of material responses and model description, are the average rates until the cycle in which the maximum strain reaches $4 \%$ or the cycle number achieves 2500 , whichever comes first. The results show that the model is able to predict $\varepsilon_{r}^{\prime}$ with a very large range of multiple loadings, yielding very high $\left(>10^{-4}\right)$ to relatively negligible $\left(<10^{-6}\right) \varepsilon_{r}^{\prime}$ at RT. 


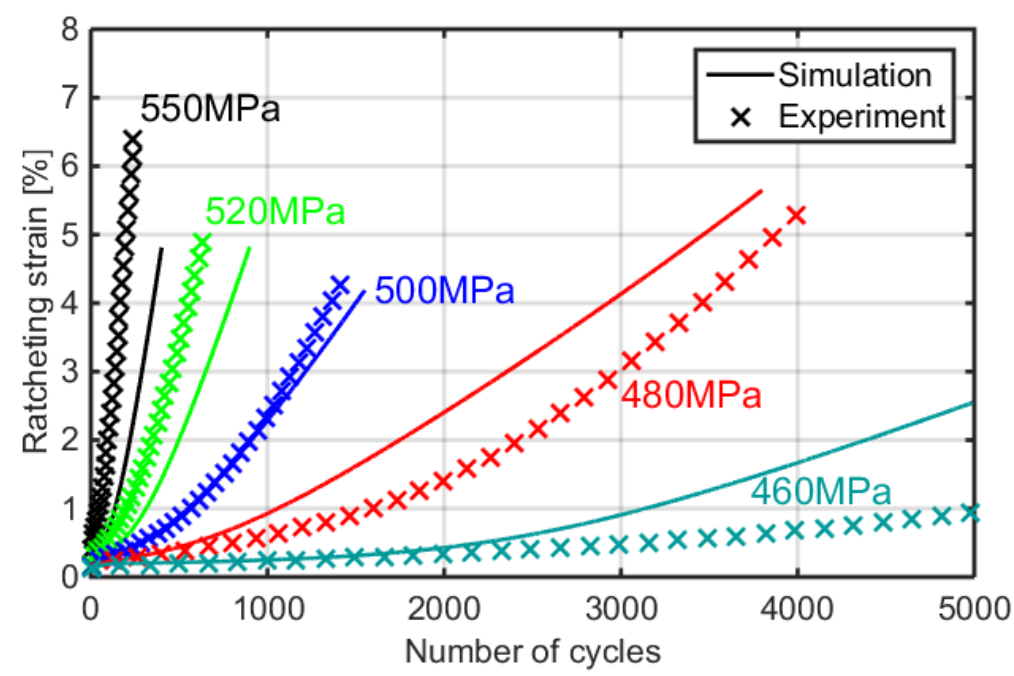

a)

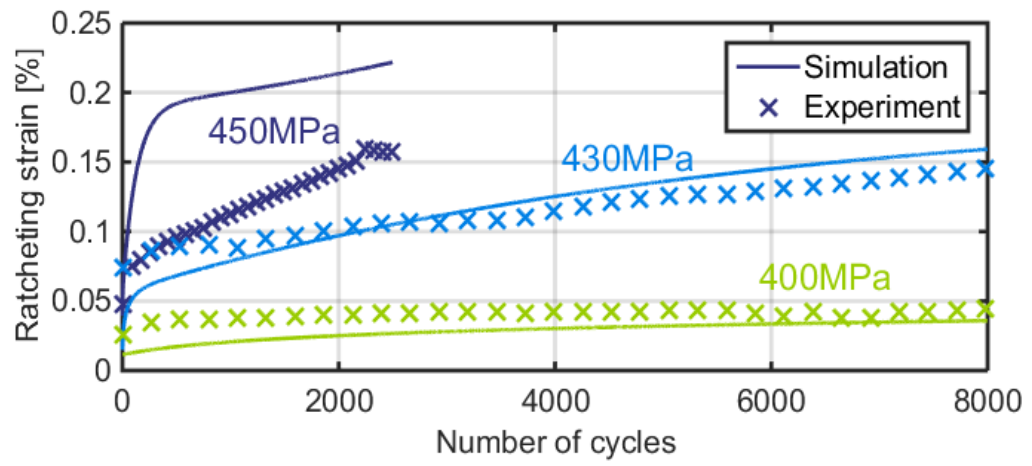

b)

Fig. 6.15 Comparison between material response (markers) and model description (curves): Ratcheting tests at $R T$ performed with $\sigma_{\text {mean }}=25 \mathrm{MPa}$, stress rate $\pm 50 \mathrm{MPa} / \mathrm{s}$, various $\sigma_{\text {peak }}, \varepsilon_{r} v \mathrm{~s}$. number of cycles.

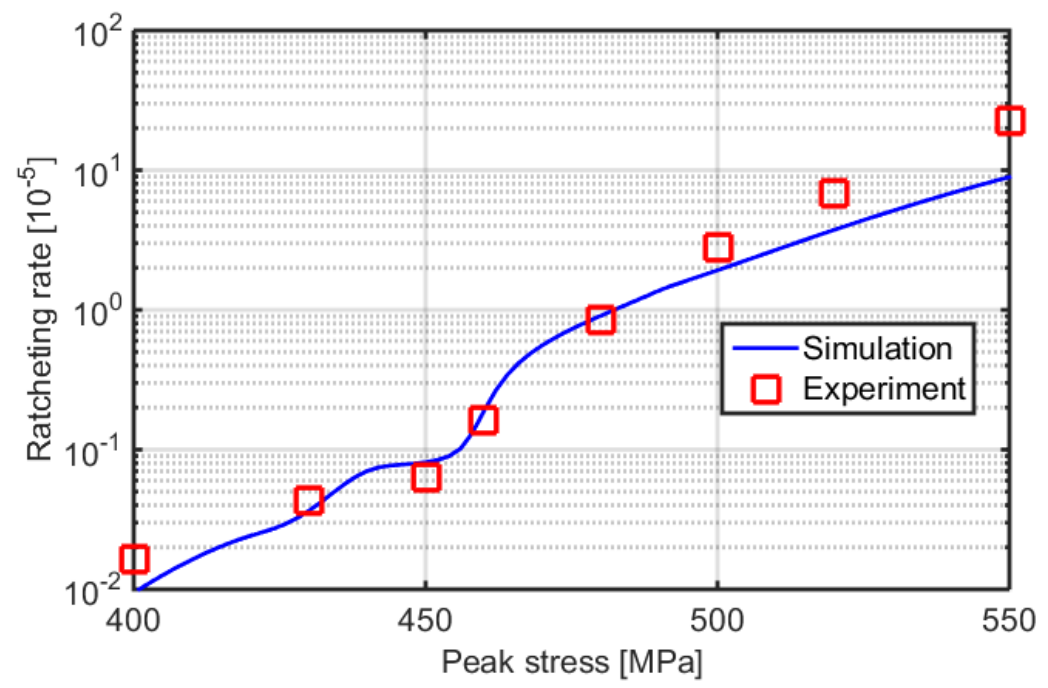

Fig. 6.16 Comparison between material response (markers) and model description (curves): Ratcheting tests at $R T$ performed with $\sigma_{\text {mean }}=25 \mathrm{MPa}$, stress rate $\pm 50 \mathrm{MPa} / \mathrm{s}$, various $\sigma_{\text {peak }}$, average ratcheting rates $v \mathrm{~s} . \sigma_{\text {peak }}$. 
Fig. 6.17 shows the simulation results for ratcheting tests performed with the same $\sigma_{\text {peak }}$ but different stress ratios. The ratcheting rates $\varepsilon_{r}$ are the average rates before the $1250^{\text {th }}$ cycle. As can be seen, the simulation also shows a maximum $\varepsilon_{r}$ near the stress ratio of -0.9 and they show very small $\varepsilon_{r}$ with stress ratios $R$ larger than -0.6 $(-0.6<\mathrm{R}<0)$, similar to the material responses.

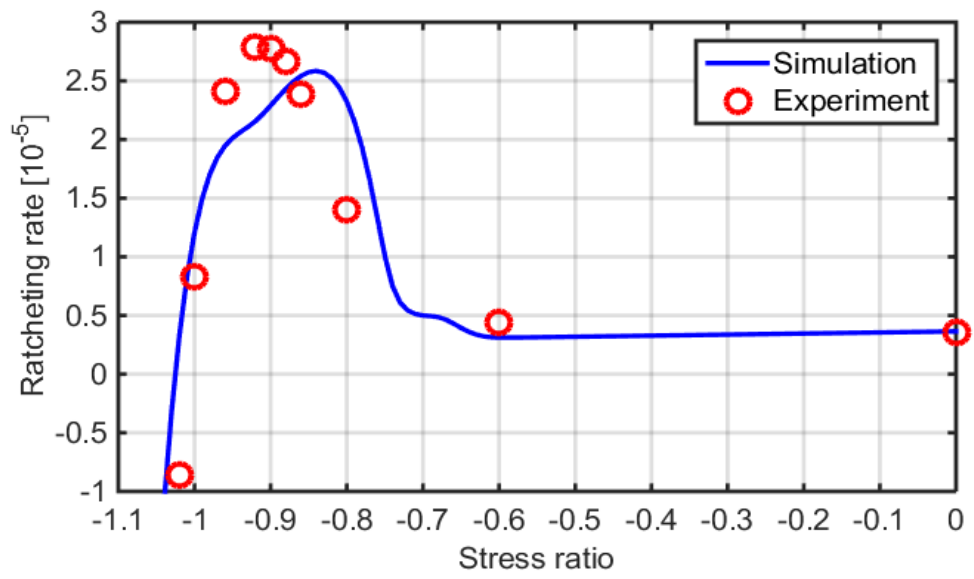

Fig. 6.17 Comparison between material response (markers) and model description

(curves): Ratcheting tests at RT performed with $\sigma_{\text {peak }}=500 \mathrm{MPa}$, stress rate $\pm 50 \mathrm{MPa} / \mathrm{s}$, various stress ratios, and average ratcheting rates vs. stress ratios.

Fig. 6.18 and Fig. 6.19 show the tests performed under symmetric stress-controlled loadings. Fig. 6.18 shows plots of $\varepsilon_{r}$ vs. number of cycles with various $\sigma_{a}$. Fig. 6.19 shows the relation between $\varepsilon_{r}^{\prime}$ and $\sigma_{a}$. The ratcheting rates $\varepsilon_{r}^{\prime}$ are the average rates until the cycle in which the maximum strain reaches $2 \%$ or the cycle number reaches 1500 , whichever comes first. The asymmetry of material strength in the model is controlled by the parameter $\mu_{2}$, as discussed in Section 6.4.1. The value of $\mu_{2}$ is 0.942949 (other from $\mu_{2}=2.4$ in Fig. 6.12) to compromise between material response under different loadings. Replacing $\mu_{2}$ with a function of hydrostatic pressure was also tested

$$
\mu_{2}=\rho|\sigma|^{n}
$$

with $\rho$ and $n$ as parameters. However, no better simulation result was acquired. Therefore $\mu_{2}$ was kept constant for simplicity. As shown in Fig. 6.18 and Fig. 6.19, the agreement between model description and material response is satisfactory. 


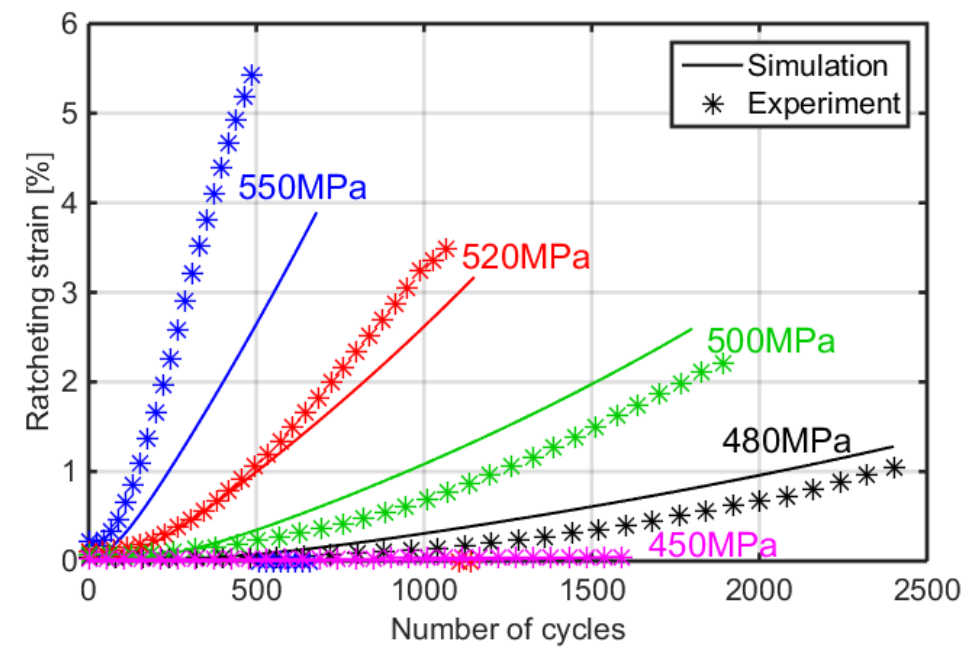

Fig. 6.18 Comparison between material response (markers) and model description (curves): Ratcheting tests at RT performed with zero $\sigma_{\text {mean, }}$ stress rate $\pm 50 \mathrm{MPa} / \mathrm{s}$, various $\sigma_{a}$, and $\varepsilon_{r} v s$. number of cycles.

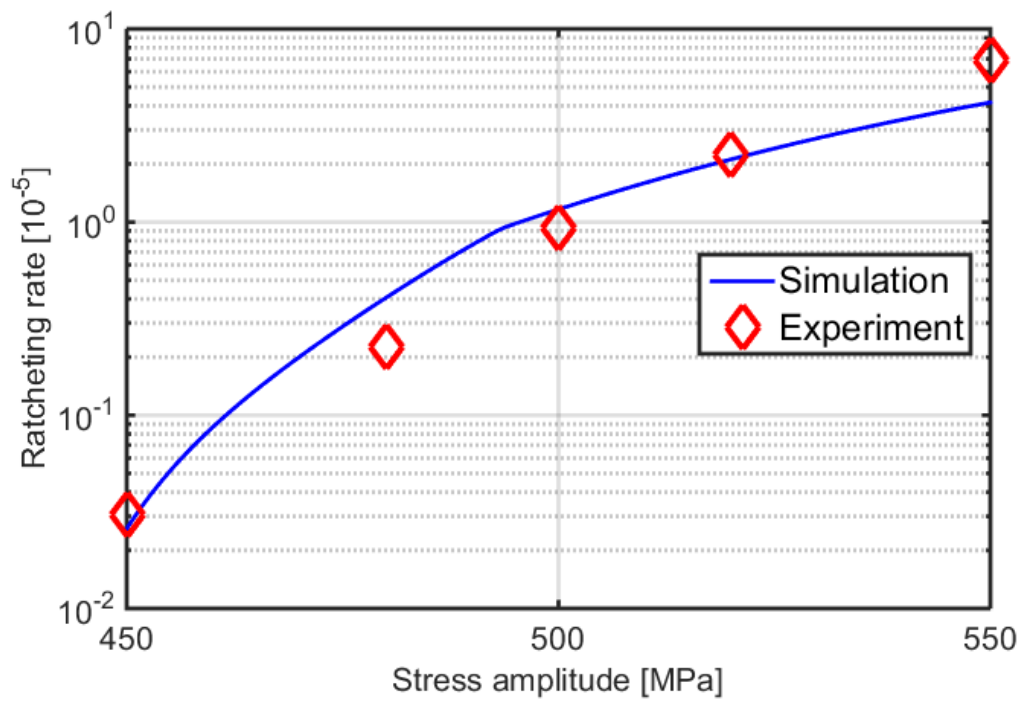

Fig. 6.19 Comparison between material response (markers) and model description (curves): Ratcheting tests at RT performed with zero $\sigma_{\text {mean, }}$ stress rate $\pm 50 \mathrm{MPa} / \mathrm{s}$, various $\sigma_{a}$, and average ratcheting rates vs. $\sigma_{a}$.

Fig. 6.20 illustrates the results of ratcheting tests with various $\dot{\sigma}$. The model description also shows the influence of visco-plasticity as seen in the material response. The matching between model and material responses in Fig. 6.20 is satisfactory. 


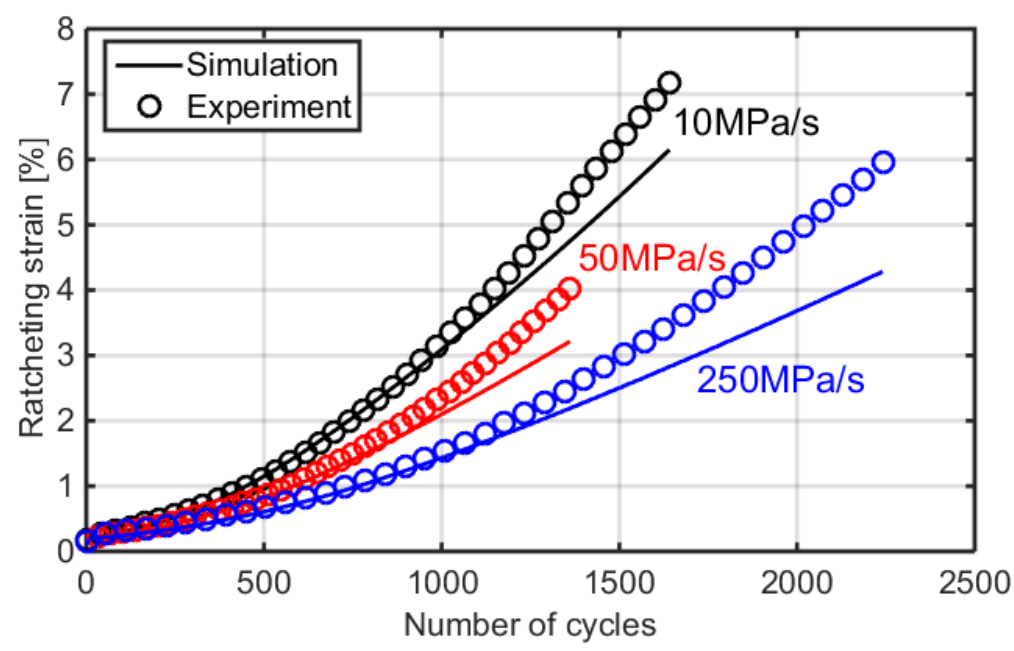

Fig. 6.20 Comparison between material response (markers) and model description (curves): Ratcheting tests at RT performed with $\sigma_{\text {peak }}=500 \mathrm{MPa}, \sigma_{\text {mean }}=25 \mathrm{MPa}$, various stress rates, and $\varepsilon_{r}$ vs. number of cycles.

Fig. 6.21 shows those tests with 10 min hold times at peak stresses. The model perfectly simulates $\varepsilon_{r}$ in the case with 10 min hold times at tensile peaks but underestimates $\varepsilon_{r}$ in the case with 10 min hold times at compressive peaks. The matching, however, is still acceptable.

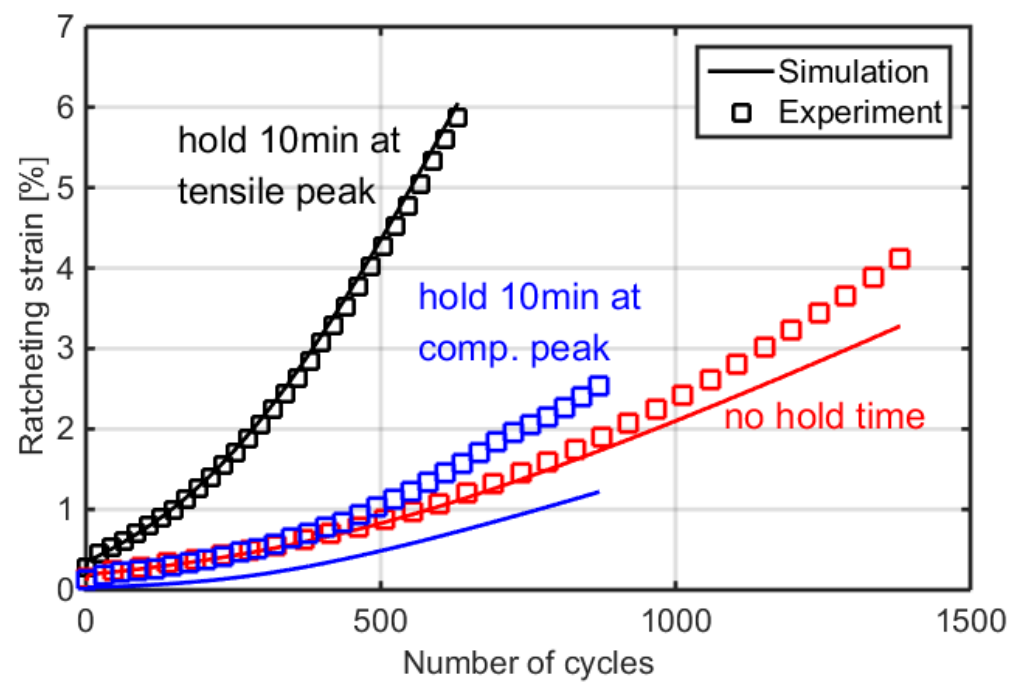

Fig. 6.21 Comparison between material response (markers) and model description (curves): Ratcheting tests at RT performed with $\sigma_{\text {peak }}=500 \mathrm{MPa}, \sigma_{\text {mean }}=25 \mathrm{MPa}$, various hold time types, and $\varepsilon_{r}$ vs. number of cycles.

After comparing the model description and corresponding material responses in all diagrams in this section, the good simulation ability of the new developed model for P91 at RT is verified. 


\subsection{Development of New Model for $550{ }^{\circ} \mathrm{C}$}

In the previous sections in this chapter, a new model was developed for P91 at RT. The simulation ability of this new developed model was proved by its model description under multiple loading conditions, as illustrated in section 6.4.2.

Further, a model was built for P91 at $550{ }^{\circ} \mathrm{C}$, which is based on the model for RT. The main difference for the material at RT and $550{ }^{\circ} \mathrm{C}$ is that the static recovery of kinematic hardening and isotropic softening is supposed to be thermally activated at high temperature. Hence, the corresponding terms in the constitutive equations should not be eliminated as at RT.

The modeling of BS at high temperature is basically the same as at RT, which is to keep the number of BS sub-components as two, the first one controlling the shape of simulated hysteresis loops and the second one controlling the simulated $\varepsilon_{r}$. The parameter $\mu_{2}$, which expresses the asymmetry of material strength at RT, should now be zero for the high-temperature cases because, according to the experiments reported in Chapter 5, no asymmetry is observed at $550{ }^{\circ} \mathrm{C}$. The term for dynamic recovery of the second $\mathrm{BS}$ component is further modified.

\subsubsection{Formulation for $550{ }^{\circ} \mathrm{C}$}

The constitutive equations for $\mathrm{P} 91$ at $550{ }^{\circ} \mathrm{C}$ are listed in Table 6.7. Comparing to the equations for cases at RT in Table 6.4, several equations are different for the hightemperature case: in eq. (6-26), the cyclic softening controller $\psi_{2}$ includes the term expressing the static recovery of softening:

$$
r_{\psi}\left|\psi_{2}-\psi_{r}\right|^{m_{\psi}-1}\left(\psi_{2}-\psi_{r}\right)
$$

BS 1 takes the form as in [1] (eq. (6-4)) including static recovery of kinematic hardening:

$$
R_{1}\left|\Omega_{1}\right|^{m_{1}-1} \Omega_{1}
$$

BS 2 (eq. (6-27)) includes the term for static recovery and the term for dynamic recovery includes the power function of the BS 2 owing to the difficulty in simulating $\varepsilon_{r}$ under multiple loading conditions. 


$$
\begin{aligned}
& \dot{\varepsilon}=\dot{\varepsilon}^{i n}+\dot{\varepsilon}^{e l} \\
& \dot{\varepsilon}^{e l}=\frac{\sigma}{E} \\
& \dot{\varepsilon}^{i n}=\left\langle\frac{|\Sigma|-k}{Z}\right\rangle^{n} \operatorname{sgn}(\Sigma) \text { with } \Sigma=\frac{\sigma}{\psi}-\Omega \\
& \psi=\psi_{1}+\psi_{2}, \text { with } \psi_{1}(t=0)=0 \text { and } \psi_{2}(t=0)=1 \\
& \dot{\psi}_{1}=-h\left|\dot{\varepsilon}^{i n}\right| \\
& \dot{\psi}_{2}=c\left(1-\psi_{s, \infty}-\psi_{2}\right)\left|\dot{\varepsilon}^{\text {in }}\right|-r_{\psi}\left|\psi_{2}-\psi_{r}\right|^{m_{\psi^{-1}}}\left(\psi_{2}-\psi_{r}\right) \\
& \Omega_{2}=\Omega_{1}+\Omega_{2} \\
& \dot{\Omega}_{1}=H_{1} \dot{\varepsilon}^{\text {in }}-C_{1} \Omega_{1}\left|\dot{\varepsilon}^{\text {in }}\right|-R_{1}\left|\Omega_{1}\right|^{m_{1}-1} \Omega_{1} \\
& \dot{\Omega}_{2}=H_{2} \dot{\varepsilon}^{\text {in }}-\left|\Omega_{2}\right|^{n_{2}-1} \Omega_{2}\left\langle\dot{\varepsilon}^{i n} \frac{\Omega_{2}}{r_{2}}\right\rangle-R_{2}\left|\Omega_{2}\right|^{m_{2}-1} \Omega_{2}
\end{aligned}
$$

Table 6.7 Constitutive equations of new developed model for $P 91$ at $550{ }^{\circ} \mathrm{C}$

$E, k, Z, n, h, c, r_{\psi}, \psi_{r}, m_{\psi}, \psi_{s, \infty}, H_{1}, C_{1}, R_{1}, m_{1}, H_{2}, r_{2}, R_{2}, m_{2}$, and $n_{2}$ are materialand temperature-dependent parameters. Comparing the parameters for RT, there are additional ones for static recovery of cyclic softening $\left(r_{\psi}, \psi_{r}\right.$, and $\left.m_{\psi}\right)$ and kinematic hardening $\left(R_{1}, m_{1}, R_{2}\right.$, and $\left.m_{2}\right)$. The parameters $r_{\psi}, \psi_{r}$, and $m_{\psi}$ are fitted with experimental data from strain-controlled LCF tests with hold times, as reported in Section 5.1. The parameters $R_{1}, m_{1}, R_{2}$, and $m_{2}$ are fitted with data from straincontrolled LCF tests with hold times, creep tests, and stress-controlled ratcheting tests with hold times.

Comparing the model for $550{ }^{\circ} \mathrm{C}$ and that for RT, it is obvious that the model for RT is a simplification of the model for high temperature because the static recovery of kinematic hardening and cyclic softening is eliminated for the RT case, in spite of the small difference in the term for dynamic recovery of the BS 2 .

Similar to the RT case, various candidates for new design of dynamic recovery rule were tested for the $550{ }^{\circ} \mathrm{C}$ case, as listed in Table 6.8. 


$$
\begin{aligned}
& \left|\Omega_{2}\right|^{n_{2}-1} \Omega_{2}\left|\dot{\varepsilon}^{i n}\right| \frac{\Omega_{2}}{r_{2}} \\
& \left|\Omega_{2}\right|^{n_{2}-1} \Omega_{2}\left\langle\dot{\varepsilon}^{i n}\right\rangle \frac{\Omega_{2}}{r_{2}} \\
& \left|\Omega_{2}\right|^{n_{2}-1} \Omega_{2}\left|\dot{\varepsilon}^{i n} \frac{\Omega_{2}}{r_{2}}\right|
\end{aligned}
$$

Table 6.8 Candidates of equations for dynamic recovery of back stress 2 in new developed model for $P 91$ at $550{ }^{\circ} \mathrm{C}$

It was found that, by using eqs. (6-28) and (6-29), no negative ratcheting was simulated for the cases with compressive $\sigma_{\text {mean }}$. As shown in Fig. 6.22, the model description with eq. (6-28) yields positive and symmetric $\varepsilon_{r}$ to the material response. The model description with eq. (6-29) is also similar.

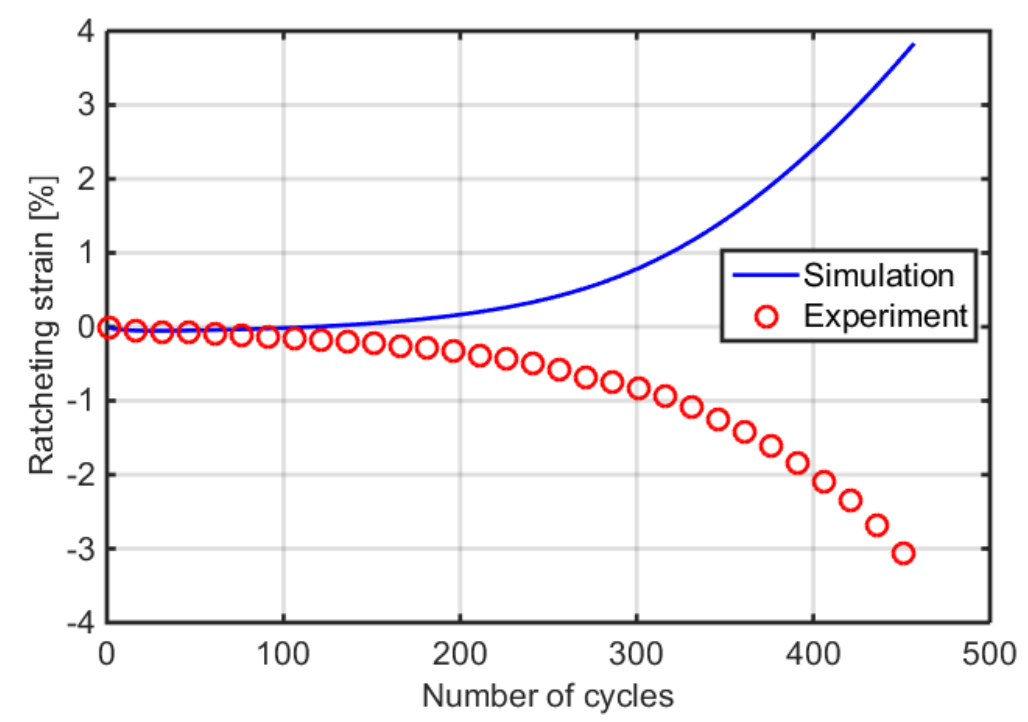

Fig. 6.22 Comparison between material response (markers) and model description (curves): Stress-controlled tests at $550^{\circ} \mathrm{C}$ performed with $\sigma_{\max }=310 \mathrm{MPa}, \sigma_{\min }=-$ $325 \mathrm{MPa}$, and stress rate $\pm 50 \mathrm{MPa} / \mathrm{s}$.

However, no significant difference was found between the simulated results with eqs. (6-30) and (6-27). A similar situation can be recalled for the RT, in which both candidates for dynamic recovery of BS 2 (eqs. (6-19) and (6-24)) yield similar and satisfying model descriptions under multiple loading conditions, as discussed in Section 6.4.1. The difference in the models is between the Macaulay bracket $\langle x\rangle$ and the absolute value $|x|$.

Therefore, as for the RT case, the parameter values are fitted with the two candidates of equations for dynamic recovery by applying the fitting program MINUIT. Eq.

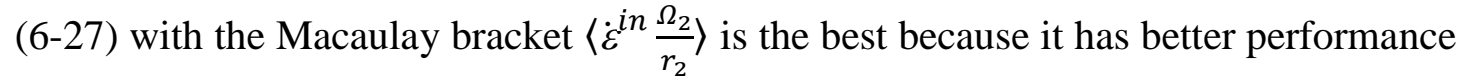
in fitting the diagram of $\varepsilon_{r}^{\prime}$ vs. various stress ratios, as shown in Fig. 5.14 in Chapter 5. It is also reasonable from the mechanical point of view, as discussed in Section 6.4.1 for RT. 
The fitted values of the 19 material parameters for $\mathrm{P} 91$ at $550{ }^{\circ} \mathrm{C}$ are listed in Table 6.9. The simulation results for $550{ }^{\circ} \mathrm{C}$ are presented in the following section.

\begin{tabular}{ll}
\hline$E(M P a)$ & $173130 ;$ \\
$k(M P a)$ & 65.2917 \\
$Z\left(M P a s^{1 / n}\right)$ & 295.332 \\
$n$ & 47.911 \\
$H_{1}(M P a)$ & 55479.1 \\
$C_{1}$ & 638.752 \\
$R_{1}$ & $3.32178 \times 10^{-3}$ \\
$m_{1}$ & 2.08665 \\
$H_{2}(M P a)$ & 13853.8 \\
$r_{2}$ & 0.21402 \\
$R_{2}$ & $3.68420 \times 10^{-6}$ \\
$m_{2}$ & 0.017228 \\
$n_{2}$ & 0.707266 \\
$h$ & $1.98945 \times 10^{-2}$ \\
$c$ & 3.85381 \\
$r_{\psi}$ & $8.86652 \times 10^{-5}$ \\
$\psi_{r}$ & 0.850816 \\
$m_{\psi}$ & 1.47506 \\
$\psi_{s, \infty}$ & 0.206453 \\
\hline Table Parameters of the new developed model determined for P91 at $550{ }^{\circ} \mathrm{C}$
\end{tabular}

\subsubsection{Simulation Results for $550{ }^{\circ} \mathrm{C}$}

In this section, simulation results are presented for tests at $550{ }^{\circ} \mathrm{C}$. In each diagram, the markers indicate experimental results and the curves indicate the corresponding model description.

Fig. 6.23 shows the results in strain-controlled LCF tests at $550{ }^{\circ} \mathrm{C}$. The simulated shapes of hysteresis loops approximately coincide with the experimental data points, in spite of not-too-sharp corners near the onset points for yield. As in the RT cases, the loop shape can be compromised to fitting on $\varepsilon_{r}$ in stress-controlled tests. However, the loop shapes in the model description are still acceptable.

Fig. 6.23c shows that the cyclic softening of P91 at high temperature with various strain ranges is well simulated with the new developed model.

Hence, the new model satisfactorily simulates the strain-controlled tests at $550{ }^{\circ} \mathrm{C}$. 

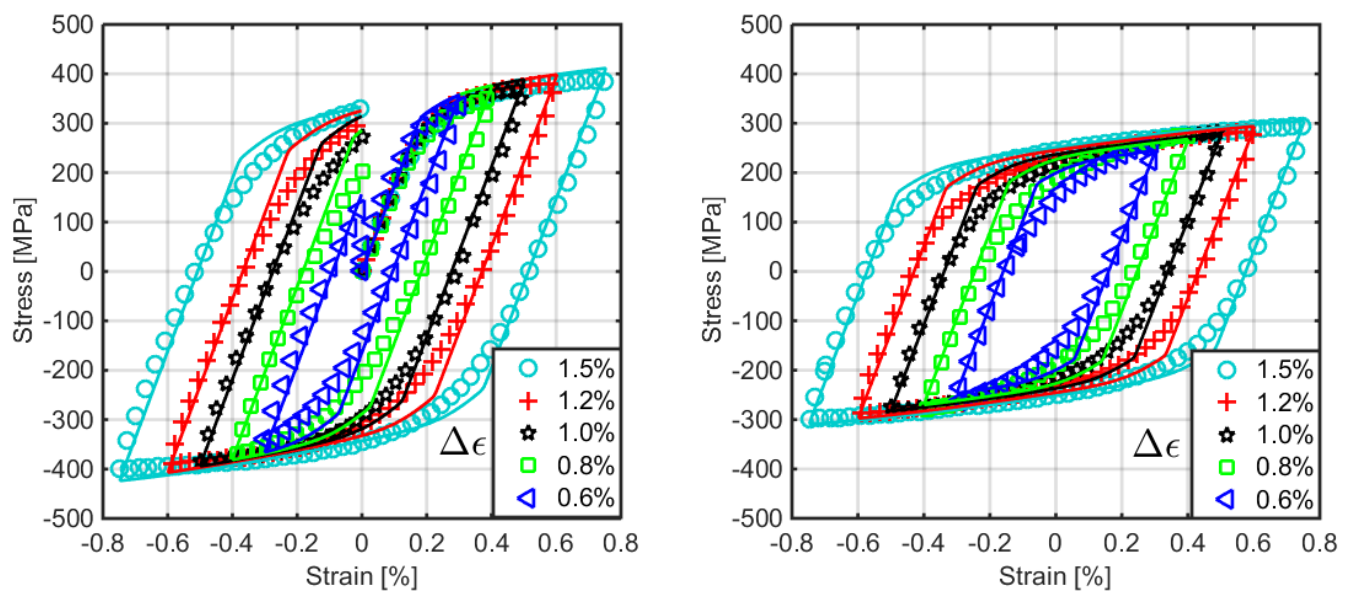

a) Hysteresis loops of the first cycle.

b) Hysteresis loops of the cycle at $N_{f} / 2$.

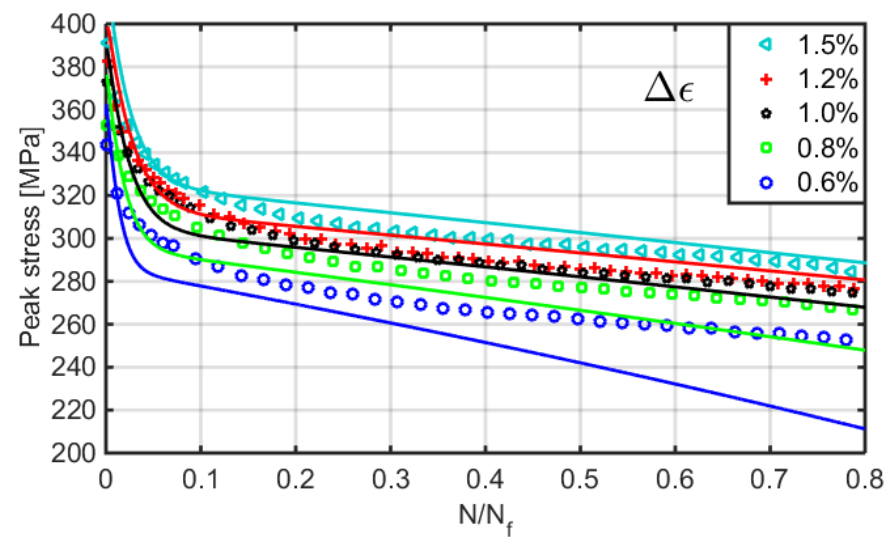

c) Peak tensile stresses vs. normalized number of cycles

Fig. 6.23 Comparison between material response (markers) and model description (curves): Strain-controlled LCF tests performed with various strain ranges on P91 at $550{ }^{\circ} \mathrm{C}$.

Fig. 6.24 and Fig. 6.25 illustrate the results for ratcheting tests at $550{ }^{\circ} \mathrm{C}$ with the same $\sigma_{\text {mean }}$ and different $\sigma_{\text {peak }}$. Fig. 6.24 shows plots of $\varepsilon_{r}$ vs. number of cycles. Fig. 6.25 shows the relation between $\varepsilon_{r}^{\prime}$ and $\sigma_{\text {peak }}$. The ratcheting rates $\varepsilon_{r}^{\prime}$, both of material responses and model description, are the average rates until the cycle in which the maximum strain reaches $3 \%$, except the marker of experiment with $\sigma_{\text {peak }}=275 \mathrm{MPa}$, which indicates the average $\varepsilon_{r}$ when the cycle number reaches 10000 , since the test was stopped at the $10000^{\text {th }}$ cycle and reaches $\varepsilon_{r}=0.1 \%$ only. As can be seen, the agreement between model and material responses is quite good. Hence, the model is able to predict $\varepsilon_{r}^{\prime}$ under loadings in a very large range, yielding very high to relatively negligible $\varepsilon_{r}^{\prime}$ at $550{ }^{\circ} \mathrm{C}$. 


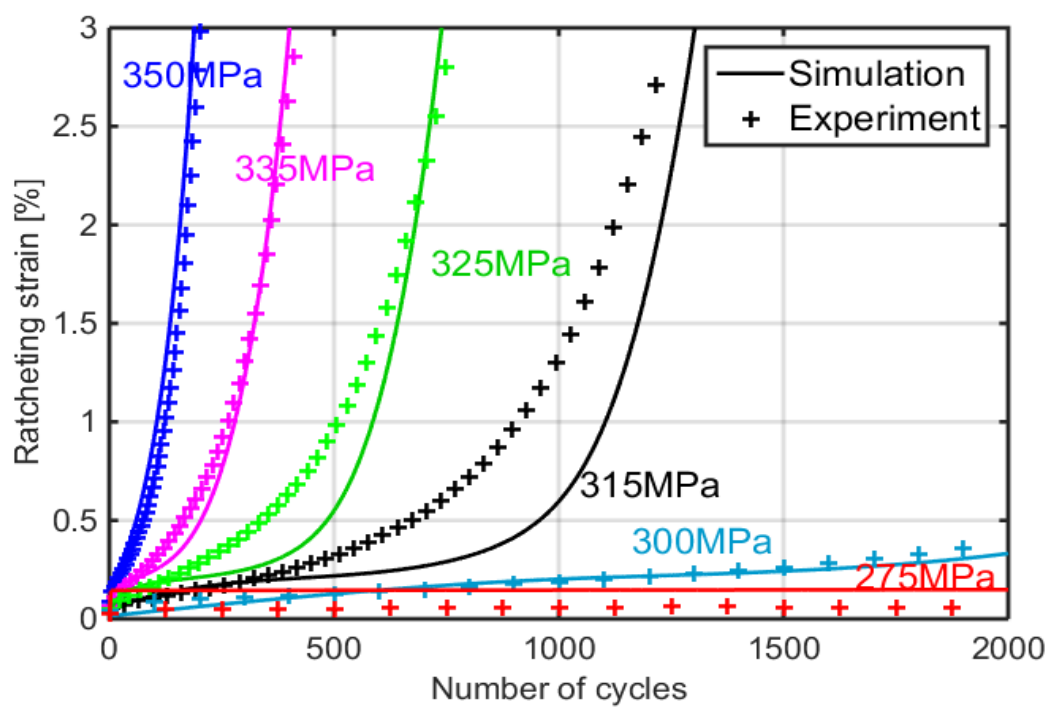

a)

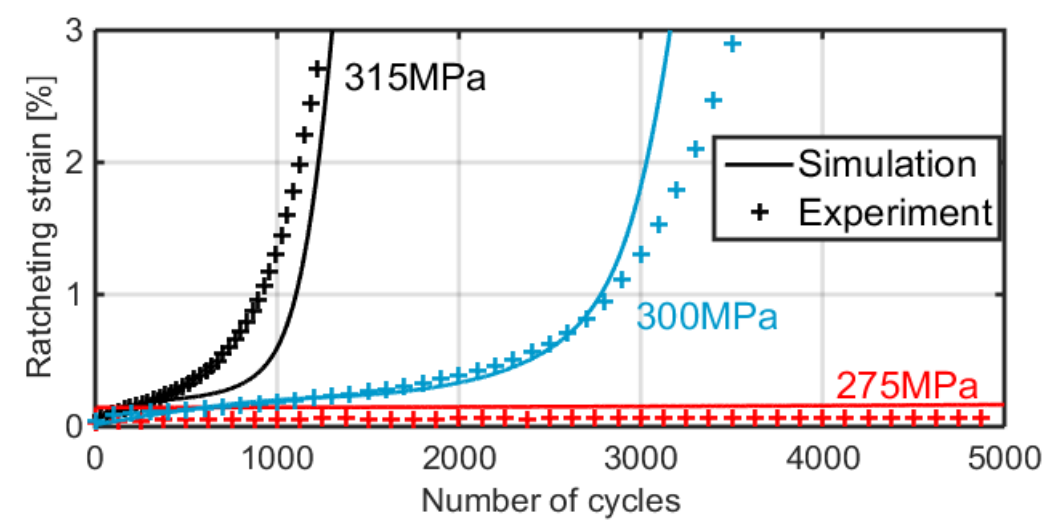

b)

Fig. 6.24 Comparison between material response (markers) and model description (curves): Ratcheting tests at $550{ }^{\circ} \mathrm{C}$ performed with $\sigma_{\text {mean }}=25 \mathrm{MPa}$, stress rate $\pm 50 \mathrm{MPa} / \mathrm{s}$, various $\sigma_{\text {peak }}$, and $\varepsilon_{r}$ vs. number of cycles.

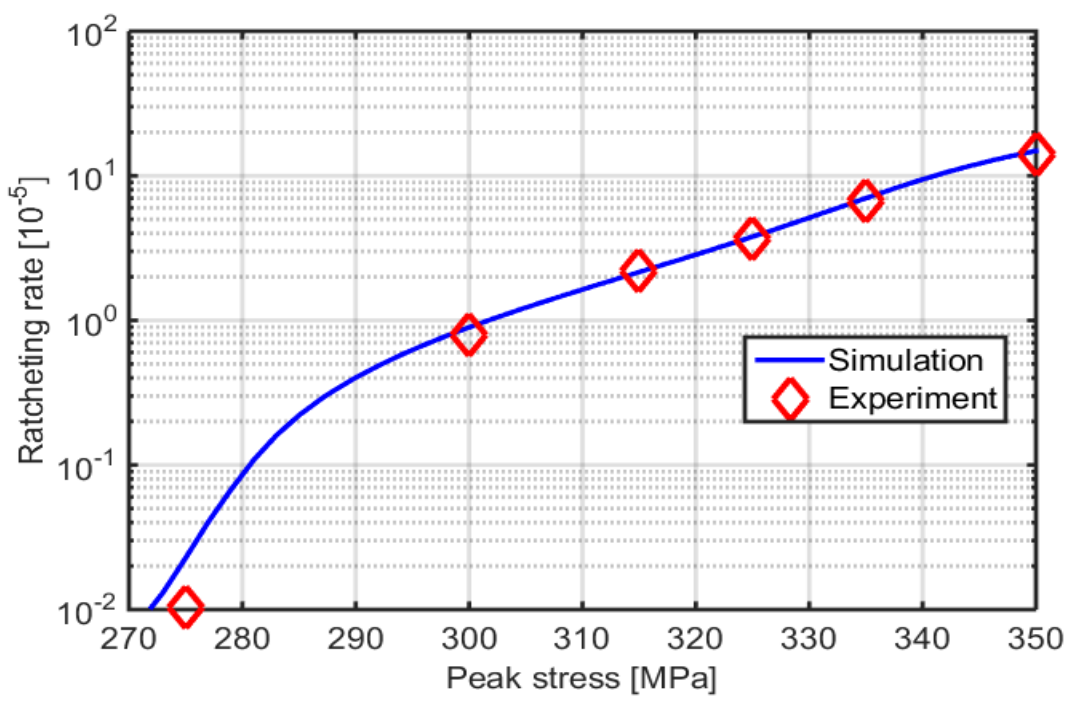

Fig. 6.25 Comparison between material response (markers) and model description (curves): Ratcheting tests at $550^{\circ} \mathrm{C}$ performed with $\sigma_{\text {mean }}=25 \mathrm{MPa}$, stress rate $\pm 50 \mathrm{MPa} / \mathrm{s}$, various $\sigma_{\text {peak }}$, average ratcheting rates $v$ s. $\sigma_{\text {peak }}$. 
Fig. 6.26 shows the results of the ratcheting tests at $550{ }^{\circ} \mathrm{C}$ with the same $\sigma_{\text {peak }}$ but different stress ratios. The ratcheting rates $\varepsilon_{r}^{\prime}$ are the average rates until the cycle in which the maximum strain reaches $\pm 3 \%$ or until the $10000^{\text {th }}$ cycle, whichever comes first. As can be seen, the simulation also shows maximum $\varepsilon_{r}$ near a stress ratio of -0.95 and very low $\varepsilon_{r}^{\prime}$ with stress ratios larger than -0.6 , similar to the material responses. The matching between the model and material responses is satisfactory.

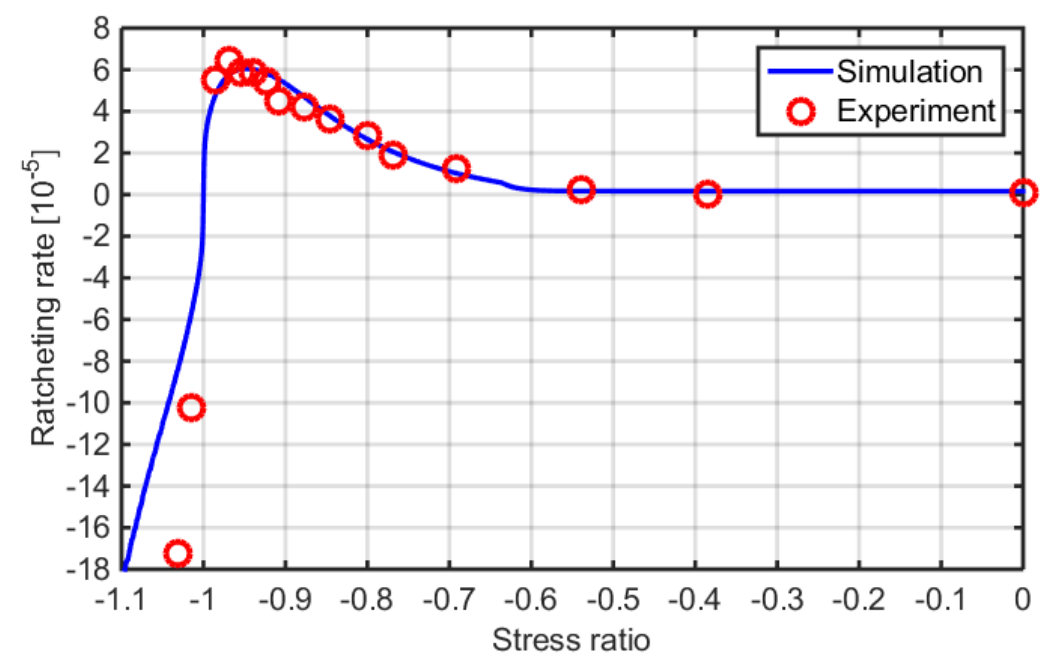

Fig. 6.26 Comparison between material response (markers) and model description (curves): Ratcheting tests at $550^{\circ} \mathrm{C}$ performed with $\sigma_{\text {peak }}=325 \mathrm{MPa}$, stress rate $\pm 50 \mathrm{MPa} / \mathrm{s}$, various stress ratios, and average ratcheting rates vs. stress ratios.

Fig. 6.27 illustrates the results of ratchetings at $550{ }^{\circ} \mathrm{C}$ with various $\dot{\sigma}$. The model description also shows the influence of visco-plasticity as in the material response and simulates the material responses for the cases with stress ratios of \pm 10 and $50 \mathrm{MPa}$ very well. However, the model underestimates $\varepsilon_{r}$ with a stress ratio of $\pm 250 \mathrm{MPa}$.

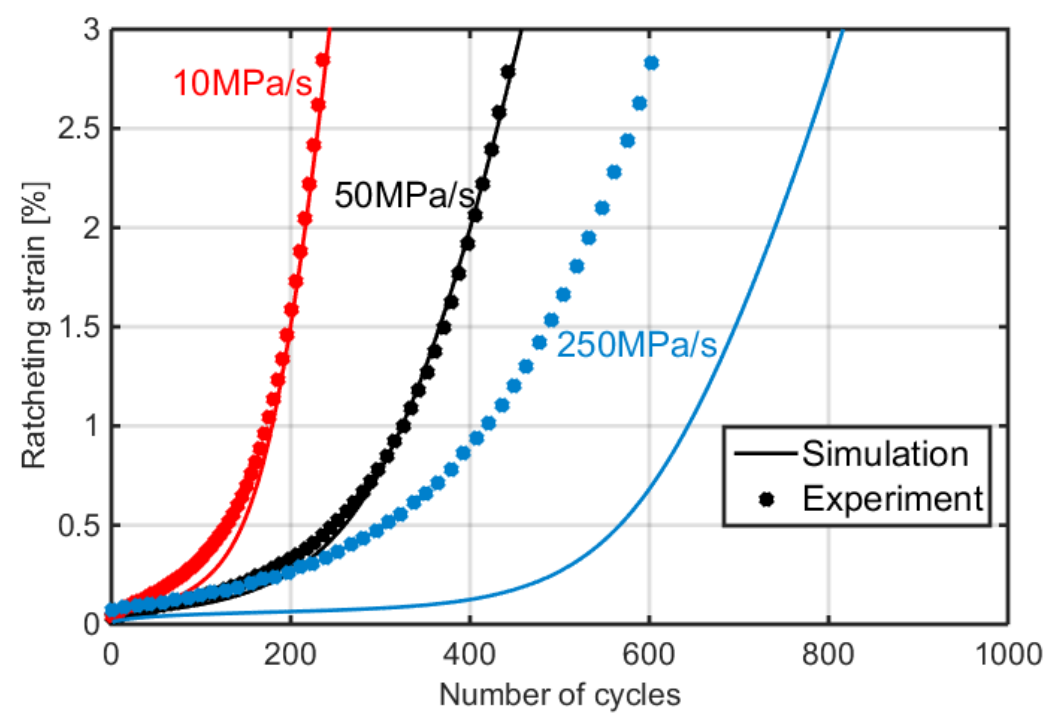

Fig. 6.27 Comparison between material response (markers) and model description (curves): Ratcheting test at $550^{\circ} \mathrm{C}$ performed with $\sigma_{\text {peak }}=325 \mathrm{MPa}, \sigma_{\text {mean }}=7.5 \mathrm{MPa}$, various stress rates, and $\varepsilon_{r} v s$. number of cycles. 
The simulated result for the case with $0.5 \mathrm{~min}$ hold time at $550{ }^{\circ} \mathrm{C}$ matches the material response quite well, as shown in Fig. 6.28. However, the model underestimates the accumulated strain in the case with 5 min hold time, as shown in Fig. 6.29. However, the simulated strain shown in Fig. 6.29 still increases and is only around 3-4 times slower than the experimental result. Thus, the simulation is still qualitatively correct.

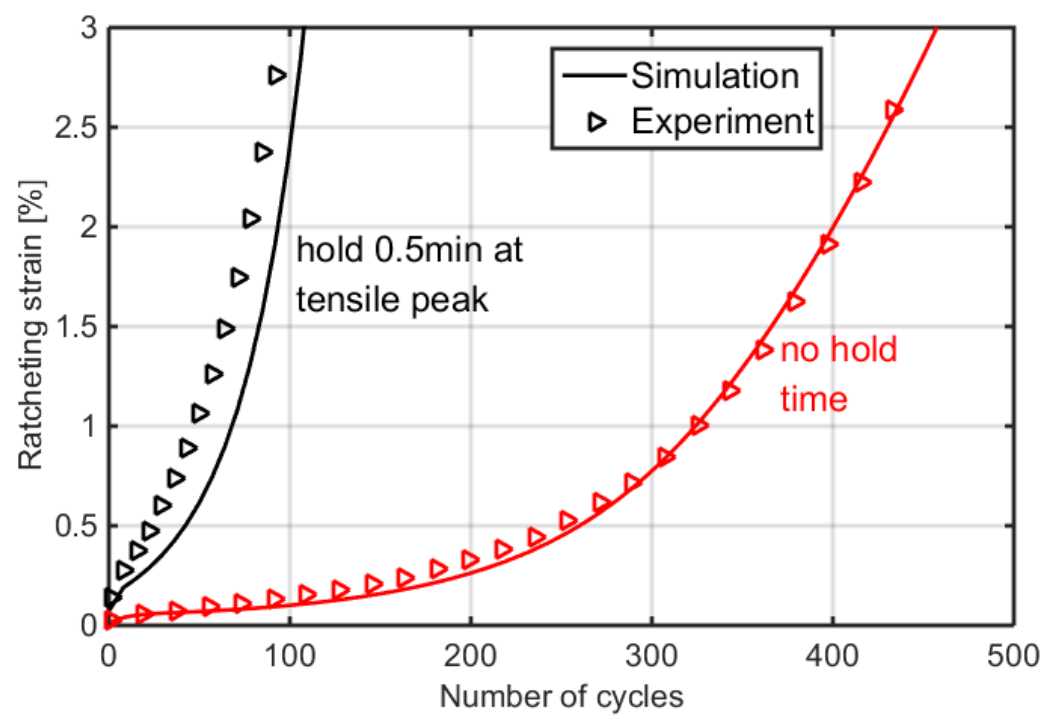

Fig. 6.28 Comparison between material response (markers) and model description (curves): Ratcheting test at $550^{\circ} \mathrm{C}$ performed with $\sigma_{\text {peak }}=325 \mathrm{MPa}, \sigma_{\text {mean }}=7.5 \mathrm{MPa}$, stress rate $\pm 50 \mathrm{MPa} / \mathrm{s}$, hold $0.5 \mathrm{~min}$ at tensile peak and without hold time, and $\varepsilon_{r} v s$. number of cycles.

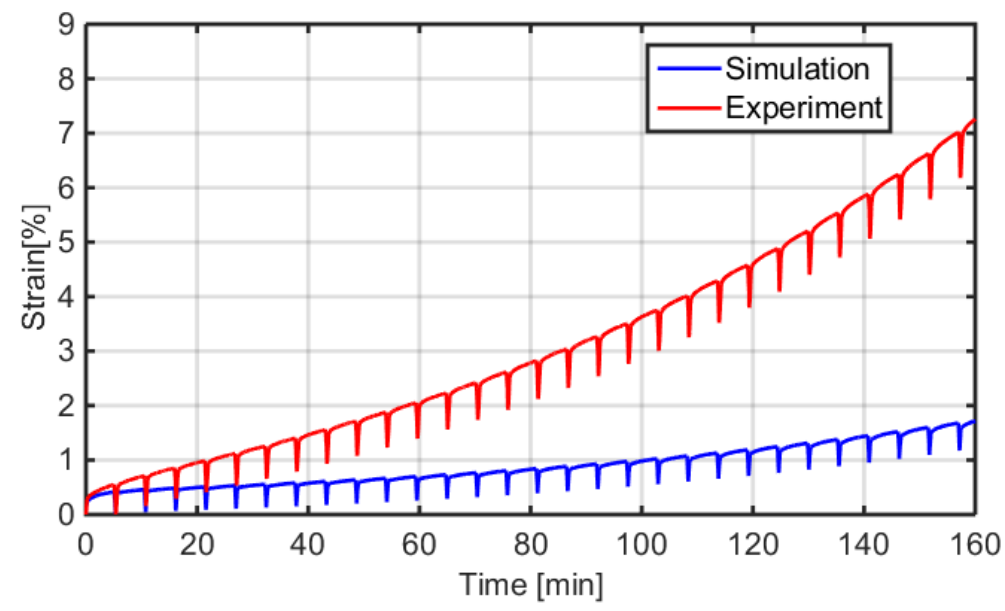

Fig. 6.29 Comparison between material response (markers) and model description (curves): Ratcheting test at $550^{\circ} \mathrm{C}$ performed with $\sigma_{\text {peak }}=325 \mathrm{MPa}, \sigma_{\text {mean }}=7.5 \mathrm{MPa}$, stress rate $\pm 50 \mathrm{MPa} / \mathrm{s}$, hold $5 \mathrm{~min}$ at tensile peak, and strain vs. time.

After comparing the model description and corresponding material responses in all diagrams in this section, the good simulation ability of the new developed model for P91 at $550{ }^{\circ} \mathrm{C}$ is verified. 


\subsection{Multiaxial Formulation of the New Developed Model}

As mentioned at the beginning of this chapter, a constitutive model in uniaxial form is enough to simulate all the experiments performed in the current work, since all experiments are uniaxial.

However, in more general situations, loadings are multiaxial and the corresponding model should also be multiaxial. Although multiaxial verification experiments are unable to be carried out with the current experimental equipment, it is still worth to extend the uniaxial model to multiaxial form for the future research.

As discussed in Section 6.5.1, the constitutive model for RT is merely a simplification of the model for $550{ }^{\circ} \mathrm{C}$. For this reason, the extension to multiaxial form can be based on the uniaxial form for $550{ }^{\circ} \mathrm{C}$ in Section 6.5.1.

The equations for the multiaxial model are listed in the Table 6.10. 


$$
\begin{aligned}
& \varepsilon=\varepsilon^{e l}+\varepsilon^{i n} \\
& \boldsymbol{\varepsilon}^{e l}=\frac{(1+v)}{E} \boldsymbol{\sigma}-\frac{v}{E}(\operatorname{trace}(\boldsymbol{\sigma})) \mathbf{1} \\
& \dot{\boldsymbol{\varepsilon}}^{i n}=\frac{3}{2}\left\langle\frac{\Sigma_{e q}-K}{Z}\right)^{n} \frac{\boldsymbol{\Sigma}}{\Sigma_{e q}} \\
& \text { with } \boldsymbol{\Sigma}=\frac{\boldsymbol{s}}{\psi}-\boldsymbol{\Omega}, \boldsymbol{s}=\boldsymbol{\sigma}-\frac{1}{3} \operatorname{trace}(\boldsymbol{\sigma}) \mathbf{1} \text { and } \Sigma_{e q}=\sqrt{\frac{3}{2} \Sigma: \Sigma} \\
& \dot{p}=\sqrt{\frac{2}{3} \dot{\varepsilon}^{i n}: \dot{\varepsilon}^{i n}} \\
& \psi=\psi_{1}+\psi_{2} \text {, with } \psi_{1}(t=0)=0 \text { and } \psi_{2}(t=0)=1 \\
& \dot{\psi}_{1}=-h \dot{p} \\
& \dot{\psi}_{2}=c\left(1-\psi_{s, \infty}-\psi_{2}\right) \dot{p}-r_{\psi}\left|\psi_{2}-\psi_{r}\right|^{m_{\psi^{-1}}}\left(\psi_{2}-\psi_{r}\right) \\
& \dot{\boldsymbol{\Omega}}_{\mathbf{1}}=\frac{2}{3} H_{1} \dot{\boldsymbol{\varepsilon}}^{i n}-C_{1} \boldsymbol{\Omega}_{1} \dot{p}-R_{1} J\left(\boldsymbol{\Omega}_{1}\right)^{m_{1}-1} \boldsymbol{\Omega}_{1} \\
& \text { with } J\left(\boldsymbol{\Omega}_{1}\right)=\sqrt{\frac{3}{2} \Omega_{1}: \Omega_{1}} \\
& \dot{\boldsymbol{\Omega}}_{\mathbf{2}}=\frac{2}{3} H_{2} \dot{\boldsymbol{\varepsilon}}^{i n}-J\left(\boldsymbol{\Omega}_{2}\right)^{n_{2}-1} \boldsymbol{\Omega}_{2}\left\langle\dot{\boldsymbol{\varepsilon}}^{i n}: \frac{\boldsymbol{\Omega}_{2}}{r_{2}}+\dot{p} f\right\rangle-R_{2} J\left(\boldsymbol{\Omega}_{2}\right)^{m_{2}-1} \boldsymbol{\Omega}_{2} \\
& \text { with } f=f(\boldsymbol{\sigma})
\end{aligned}
$$

Table 6.10 Constitutive equations of new developed model for P91 in its multiaxial formulation.

As listed in Table 6.10, since the factor indicating cyclic softening $\psi$ is scalar, the equations for the cyclic softening (eqs. (6-5), (6-6), and (6-26)) are the same as in the uniaxial form (Table 6.7). All material parameters are the same as in the uniaxial form.

In eq. (6-36), $f$ is a function of external loading $\boldsymbol{\sigma}$ which expresses the influence of hydrostatic pressure on the rate of dynamic recovery. One of the possible equations of $f$ is suggested to be 


$$
f=\rho|\operatorname{trace}(\boldsymbol{\sigma})|^{n} \operatorname{sgn}(\operatorname{trace}(\boldsymbol{\sigma}))
$$

In simplification, $\rho|\operatorname{trace}(\boldsymbol{\sigma})|^{n}$ can be replaced by a constant $\mu_{2}$. Hence, by transforming eq. (6-36) into uniaxial form, $\dot{p} f$ is equivalent to $\left|\dot{\varepsilon}^{i n}\right| \mu_{2} \operatorname{sgn}(\sigma)$ as in eq. (6-19). The exact form of $f$ should be determined with more multiaxial tests.

Equations listed in Table 6.10 are proved to be equivalent to the uniaxial form (Table 6.4 and Table 6.7) under the uniaxial loading, according to the following calculations (eqs. (6-38) (6-46)):

$$
\begin{aligned}
& \boldsymbol{\sigma}=\sigma_{0}\left(\begin{array}{ccc}
1 & & \\
& 0 & \\
& & 0
\end{array}\right) \\
& \boldsymbol{s}=\sigma_{0}\left(\begin{array}{rrr}
\frac{2}{3} & & \\
& -\frac{1}{3} & \\
& & -\frac{1}{3}
\end{array}\right) \\
& \Omega=\Omega_{0}\left(\begin{array}{lll}
\frac{2}{3} & & \\
& -\frac{1}{3} & \\
& & -\frac{1}{3}
\end{array}\right) \\
& \boldsymbol{\Sigma}=\left(\frac{\sigma_{0}}{\psi}-\Omega_{0}\right)\left(\begin{array}{lll}
\frac{2}{3} & & \\
& -\frac{1}{3} & \\
& & -\frac{1}{3}
\end{array}\right) \\
& \Sigma_{e q}=\sqrt{\frac{3}{2} \Sigma: \Sigma}=\left|\frac{\sigma_{0}}{\psi}-\Omega_{0}\right|
\end{aligned}
$$


$\dot{\boldsymbol{\varepsilon}}^{i n}=\dot{\varepsilon}_{0}^{i n}\left(\begin{array}{rrr}1 & & \\ & -\frac{1}{2} & \\ & & -\frac{1}{2}\end{array}\right)$

with $\dot{\varepsilon}_{0}^{\text {in }}=\left\langle\frac{\left|\frac{\sigma_{0}}{\psi}-\Omega_{0}\right|-K}{Z}\right\rangle^{n} \operatorname{sgn}\left(\left|\frac{\sigma_{0}}{\psi}-\Omega_{0}\right|\right)$

$\dot{p}=\sqrt{\frac{2}{3} \dot{\varepsilon}^{i n: \dot{\varepsilon}^{i n}}}=\left|\dot{\varepsilon}_{0}^{i n}\right|$

$\dot{\Omega}_{1}=\dot{\Omega}_{1,0}\left(\begin{array}{lrr}\frac{2}{3} & & \\ & -\frac{1}{3} & \\ & & -\frac{1}{3}\end{array}\right)$

with

$\dot{\Omega}_{1,0}=\left(H_{1} \dot{\varepsilon}_{0}^{i n}-C_{1} \Omega_{1,0}\left|\dot{\varepsilon}_{0}^{i n}\right|-R_{1}\left|\Omega_{1,0}\right|^{m_{1}-1} \Omega_{1,0}\right)$

$\dot{\boldsymbol{\Omega}}_{2}=\dot{\Omega}_{2,0}\left(\begin{array}{lrr}\frac{2}{3} & & \\ & -\frac{1}{3} & \\ & & -\frac{1}{3}\end{array}\right)$

with

$\dot{\Omega}_{2,0}=H_{2} \dot{\varepsilon}_{0}^{i n}-\left|\Omega_{2,0}\right|^{n_{2}-1} \Omega_{2,0}\left\langle\dot{\varepsilon}_{0}^{i n} \frac{\Omega_{2,0}}{r_{2}}+\left|\dot{\varepsilon}_{0}^{i n}\right| f\right\rangle-R_{2}\left|\Omega_{2,0}\right|^{m_{2}-1} \Omega_{2,0}$ 


\section{Discussion}

In the uniaxial strain-controlled and stress-controlled tests performed at RT and $550{ }^{\circ} \mathrm{C}$, a database was built for future application of mod. $9 \mathrm{Cr}-1 \mathrm{Mo}$ FM steel. Under stress-controlled cyclic loading, ratcheting behavior was found on P91 steel at both temperatures. A unified visco-plastic deformation model taking into account the complex non-saturating cyclic softening of RAFM steels was further modified to adapt the ratcheting behavior of P91. The simulation ability of a new developed constitutive model was proved to be satisfactory.

However, several issues arose during this research, which should be discussed further.

One of the issues is the asymmetry of material strength under tension and compression, or namely strength-differential phenomenon. This asymmetry is observed at RT but not at $550{ }^{\circ} \mathrm{C}$ in the current work. However, [26] still reported the asymmetry of material strength at $550{ }^{\circ} \mathrm{C}$ for mod. $9 \mathrm{Cr}-1 \mathrm{Mo}$ steel. As mentioned in Section 2.1, several ratcheting tests reported in [26] were performed with $\sigma_{\text {peak }}=400$ $\mathrm{MPa}$, which contradicts the ultimate tensile strength of $374 \mathrm{MPa}$ of T91 reported by SCK $\cdot$ CEN [55], although both materials mentioned in [26] and [55] are mod. 9Cr1 Mo FM steels. According to the tensile test at $550{ }^{\circ} \mathrm{C}$ in the current work, the ultimate tensile strength of $\mathrm{P} 91$ at $550{ }^{\circ} \mathrm{C}$ is $386.1 \mathrm{MPa}$, which is comparable to the $374 \mathrm{MPa}$ for T91 reported in [55]. Hence, the tests reported in [26] should be performed with a different mod. 9Cr-1Mo FM steel than those in SCK •CEN [55] and in the current work.

An explanation for this asymmetry at RT and its disappearance at $550{ }^{\circ} \mathrm{C}$ is that the rate of dynamic recovery under compression is lower than that under tension at RT. The compressive hydrostatic pressure inhibits the dislocation migration and annihilation at RT owing to second phase particles. Hence, the hydrostatic pressure inhibits the dynamic recovery under compression. At high temperature, i.e., $550{ }^{\circ} \mathrm{C}$, dislocation migration is more thermally activated than at RT and is relatively less influenced by hydrostatic pressure, and consequently no asymmetry is observed at high temperature. This explanation is expressed in the modeling approach with a parameter $\mu_{2}$ in the term of dynamic recovery of BS 2 .

Casey and Sullivan [104] and Drucker [105] suggested that the hydrostatic pressure affects the theoretical yield strength and leads to the asymmetry of material strength under tension and compression. In the modelling approaches in [104], as well as in the Yaguchi-Takahashi model [7], the hydrostatic pressure was taken to calculate the theoretical yield strength. However, the theoretical yield strength is unable to be measured without very high-precision experimental equipment. Hence, the effect of hydrostatic pressure on the theoretical yield strength has not been experimentally verified. The effect of hydrostatic pressure on the dynamic recovery can also explain the asymmetry of material strength. Accordingly, a simple introduction of a parameter $\mu_{2}$ leads to satisfactory agreement between model description and material responses, 
as shown in Fig. 6.18 and Fig. 6.19. A similar fitting approach to the YaguchiTakahashi model (see eq. (2-22)) was also performed. However, the simulation results were no better than the application of parameter $\mu_{2}$ in the dynamic recovery term.

On the contrary to the suggestions in [104] and [105], Jung [103] is against the suggestion that hydrostatic pressure affects dislocation movement. Jung believes that the pressure-induced increase of crystal lattice friction impeding dislocation movement completely compensates the increase of interaction between dislocations. Owing to this debate on the effect of hydrostatic pressure, further investigation on this topic is required.

According to [104] and [105], the hydrostatic pressure should lead to volumetric plastic strain of the specimens, which contradicts the prerequisite to apply the so called "true-stress-controlled ratcheting test". The true-stress controlling is based on the von Mises criterion with no volumetric plastic strain. However, after measuring the diameters of the specimens after experiments, as mentioned in Section 4.2.6, it was found that the shrinkage of the cross section area corresponds to the axial deformation, which means the volumetric plastic strain is negligible. Hence, the prerequisite to apply the "true-stress-controlled ratcheting test" was verified at RT. On the other hand, this prerequisite was only roughly satisfied at $550{ }^{\circ} \mathrm{C}$ before the total strain reaches $3 \%$ owing to necking.

The explanation for the necking at $550{ }^{\circ} \mathrm{C}$ is as follows. According to the exact measurement of the diameters along the received specimens, the diameter varies between $8.79 \mathrm{~mm}$ and $8.81 \mathrm{~mm}$ owing to deviations in production. The maximum diameter can lie anywhere within the specimen section with quasi-homogenous diameter. However, the necking always occurs exactly at the middle of the specimens, as shown in Fig. 5.22, which indicates that the middle of the specimen is always softer than the other sections. According to temperature measurement along the specimen, when the middle section is $550{ }^{\circ} \mathrm{C}$, the two ends of the quasi-homogenous section are around $545{ }^{\circ} \mathrm{C}$, which is caused by the temperature distribution in the whole oven. Hence, the temperature difference can explain why the necking always occurs at exactly the middle of the specimen. Further, the data acquired in the experiments at high temperature should be an average value within the gage length of the extensometer.

The definition of lifetime of specimens should be reconsidered. The lifetime of a structural component is literally a period of usage or number of usage after which the component is no longer safe for further application and must be replaced. However, the criteria to define such period or number of usage are not universal. In the strain-controlled LCF tests at $550{ }^{\circ} \mathrm{C}$, the definition of lifetime follows the way reported in [101], which is the cycle during which $\sigma_{\text {peak }}$ has decreased by $10 \%$ from that predicted by extrapolation of the saturation curve (stage 2), in which an obvious macro crack propagation occurs.

However, in spite of measurement error, as long as $\sigma_{\text {peak }}$ clearly deviates from the extrapolation of the saturation curve, that is, decreases by only $1 \%$ from the extrapolation line, it is clear that unstable macro crack propagation has already begun. Hence it is supposed the $10 \%$ decrease from the extrapolation line reported in [101] is 
only to eliminate the measurement error to be certain that the macro cracking has already started. In the strain-controlled LCF tests of the current work, the curves in $\sigma_{\text {peak }}-N$ diagrams (as shown in Fig. 4.3 and Fig. 5.4) are generally smoother than those reported in [101] (as shown in Fig. 2.12.). Hence, in the current work, it is also possible to define the lifetime $N_{f}$ in the LCF tests at $550{ }^{\circ} \mathrm{C}$ by the cycle with, for example, $5 \%$ deviation from the extrapolation line.

In the LCF tests at RT, a clear definition of lifetime is not possible since the macro crack does not always appear within the gage length of the extensometer. For this reason, data are considered to be reliable until a roughly defined cycle $N_{0}$, which lies within the stage where the peak stress is linearly decreasing (saturation stage of cyclic softening) and near the cycle where the deviation of peak stress from the linear decrease appears owing to the macro crack. Further, the lifetime $N_{f}$ is roughly determined as the cycle number $N_{0}$. Although it is roughly defined, there is no vast difference between this cycle number $N_{0}$ to a clearly defined $N_{f}$ with, for example, a $10 \%$ decrease from the extrapolation line.

In the stress-controlled tests, on the other hand, the failure of the specimen is generally not owing to macro cracking, but rather unacceptable deformation of, for example, 5\% owing to ratcheting, as in most of the ratcheting tests reported in Chapters 4 and 5. The criterion for an "unacceptable deformation" can only be clearly determined in practical application. However, in several stress-controlled tests in the current work, for example, the test performed with $\sigma_{a}=520 \mathrm{MPa}$ at RT and the four tests at $550{ }^{\circ} \mathrm{C}\left(\sigma_{a}=350,340,325\right.$, and $\left.315 \mathrm{MPa}\right)$ under symmetric stress-controlled loading, the macro crack still appears before 5\% deformation owing to ratcheting.

Further, owing to the fact that necking occurs on most specimens tested at $550{ }^{\circ} \mathrm{C}$, as shown in Fig. 5.22, the failure of the specimens is that they are no longer safe after obvious shrinkage from the cross section as received, for example, 5\%. As mentioned above, the reason for the necking is suggested to be distribution of temperature along the specimen. Hence, the definition of lifetime in these cases is even more complicated because necking will lead to either unacceptable deformation or fracture very fast.

It is recalled that in the tests with hold times at RT, as reported in Section 4.2.5, there is inelastic deformation during hold times. In the test performed with static stress $\sigma=500 \mathrm{MPa}$, there is an inelastic strain increment of $0.24 \%$ in the first 5 hours after the stress stops at $500 \mathrm{MPa}$ and only $0.02 \%$ inelastic strain increment during the following 19 hours. The inelastic strain with static stress at RT is similar to creep, although creep is generally understood to obviously occur when the temperature is higher than approximately 0.3 of the melting temperature. However, there is no exactly defined temperature above which creep will happen. In the test with static stress $\sigma=500 \mathrm{MPa}$, it is believed that it is a creep behavior with only a primary stage and no secondary stage.

One more phenomenon in the experiment is worth discussing: Comparing the tests reported in Section 4.2.4 and 5.2.4, it was found that the ratcheting test performed with stress rate $\pm 10 \mathrm{MPa}$ has an $18.3 \%$ higher $\varepsilon_{r}^{\prime}$ than that with stress rate $\pm 50 \mathrm{MPa}$ at $\mathrm{RT}$, but is twice as high at $550{ }^{\circ} \mathrm{C}$, which indicates lower viscosity at high 
temperature. However, the test performed with $\pm 250 \mathrm{MPa} / \mathrm{s}$ has a $22.3 \%$ lower $\varepsilon_{r}^{\prime}$ than the test performed with $\pm 50 \mathrm{MPa} / \mathrm{s}$ at RT while it is only $26.5 \%$ lower at $550{ }^{\circ} \mathrm{C}$. It was found the percentage changes of $22.3 \%$ and $26.5 \%$ were comparable. This phenomenon implies that, at high loading rate, the viscosity is relatively less sensitive to the change of temperature.

There are also several issues in question in the modeling approach of the current work. The current modeling approach is similar to that in Koo and Lee [24], which was also for mod. $9 \mathrm{Cr}-1 \mathrm{Mo}$ steel. The number of BS components was reduced to three in their report [24]. It was found that the term of dynamic recovery of the third BS component could control the rate of ratcheting. However, the ratcheting tests reported in [24] were too few to cover a large range of loading conditions and all ratcheting tests were stopped before the $100^{\text {th }}$ cycle. Further, it is questionable that, in the ratcheting tests reported in [24], $\varepsilon_{r}^{\prime}$ went progressively slower after the so-called "progressive deformation instability", as shown in Fig. 2.3 and Fig. 2.4, which indicates this "instability" happened only once and disappeared afterwards. Such "instability" was only intuitively suggested to be the consequence of cyclic softening, however without explicit explanation or any approach to simulate this "instability" with the proposed model. In the tests at $550{ }^{\circ} \mathrm{C}$, which were reported in Chapter 5, such "instability" was never observed. The simulation results of ratcheting were not illustrated in [24] with their proposed model. Besides, since the asymmetry of material strength at $600{ }^{\circ} \mathrm{C}$ was not observed, the proposed model in [24] did not include a term to express such asymmetry. For these reasons, it was necessary to develop a new constitutive model, as has been reported in Chapter 6, in which a model was developed with only two BS components, one controlling the shapes of hysteresis loops and the other controlling the ratcheting rates.

When comparing the fitted parameter values listed in Table 6.3 and those in Table 6.6, it can be seen that the values of parameters $k, Z, n, H_{1}, C_{1}, h, c$, and $\psi_{s, \infty}$ are different in the two tables. As mentioned in Section 6.4.1, different groups of these parameter values can yield similar shaped hysteresis loops in simulation of either strain- or stress-controlled tests. However, these groups of parameter values have different performances in simulating $\varepsilon_{r}$ under multiple stress-controlled cyclic loadings. Hence, although parameters have their own physical meaning, as mentioned in Section 6.4.1, it is only possible to fit the parameters until an acceptable simulation is acquired, which means that a direct determination of these parameter values, except for Young's modulus, is still not possible.

In the choice of a better constitutive equation of BS 2 for both RT and $550{ }^{\circ} \mathrm{C}$ cases, it comes to the choice between the Macaulay bracket (eqs. (6-19) and (6-27)) and the absolute value (eqs. (6-24) and (6-30)). As mentioned in Section 6.4.1, the Macaulay bracket is more reasonable based on the hypothesis that the dynamic recovery is supposed to occur only when BS and inelastic strain rate having the same direction. This hypothesis follows the modeling approach of the OW I model, as shown in eqs. (2-11), (2-12), and (2-13). However, according to the AF model, dynamic recovery would also occur when BS and inelastic strain rate have opposite directions, as shown in eq. (2-6) and eq. (2-7). The physical background was not discussed in Ohno and Wang's report [3, 4], or in Armstrong and Frederick's report [62]. 
Ohno and Abdel-Karim [6] simply combined both ideas into eq. (2-15) without further discussion from the physical point of view.

The section in which the BS and inelastic strain rate having opposite signs is illustrated in red in the stress-strain hysteresis loop shown in Fig. 7.1. In spite of the difference from the physical point of view, the simulated results are similar when using the Macaulay bracket and the absolute value. Fig. 7.2 illustrates the comparison of increasing rate of BS 2 between application of the Macaulay bracket (blue curve) and the absolute value (red curve). As can be seen, the blue and red curves coincide with each other, except for two short sections, and the deviation is relative small. Hence, the simulated results are similar.

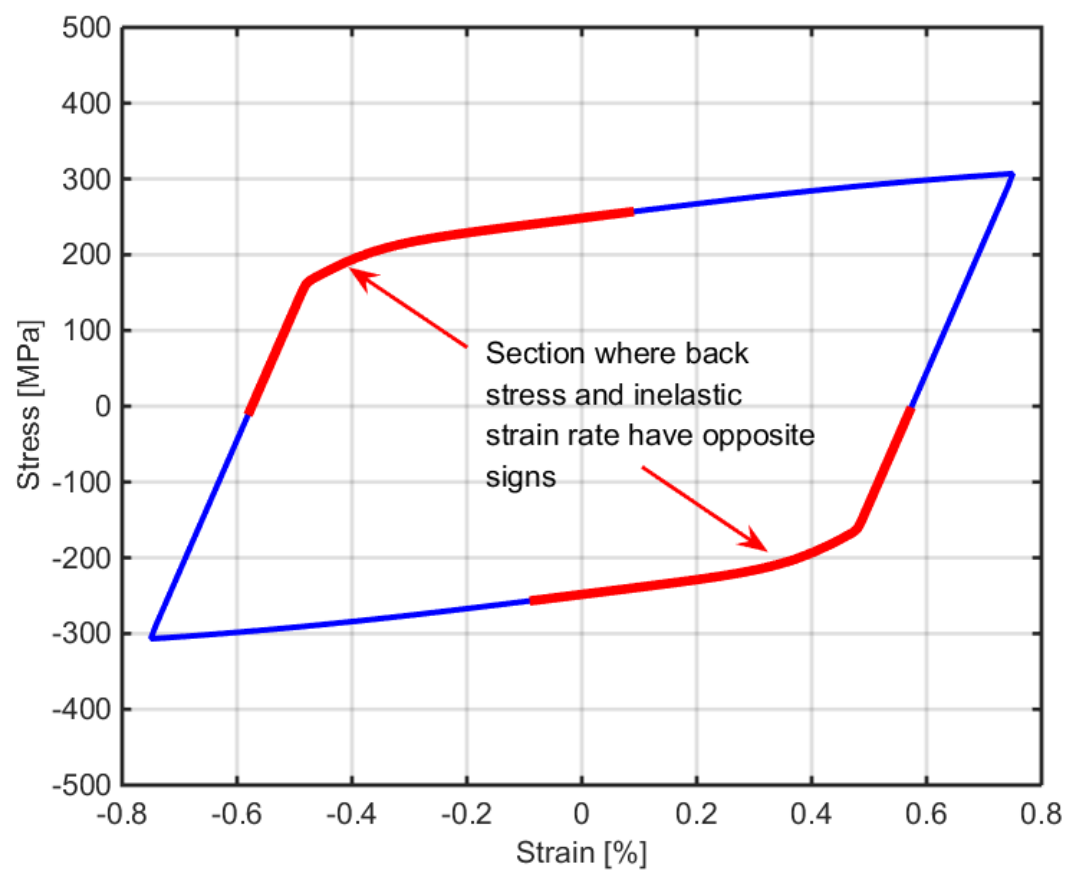

Fig. 7.1 Simulated stress-strain hysteresis loop of $200^{\text {th }}$ cycle in the strain-controlled $L C F$ test performed with $\Delta \varepsilon=1.5 \%$ at $550{ }^{\circ} \mathrm{C}$ 


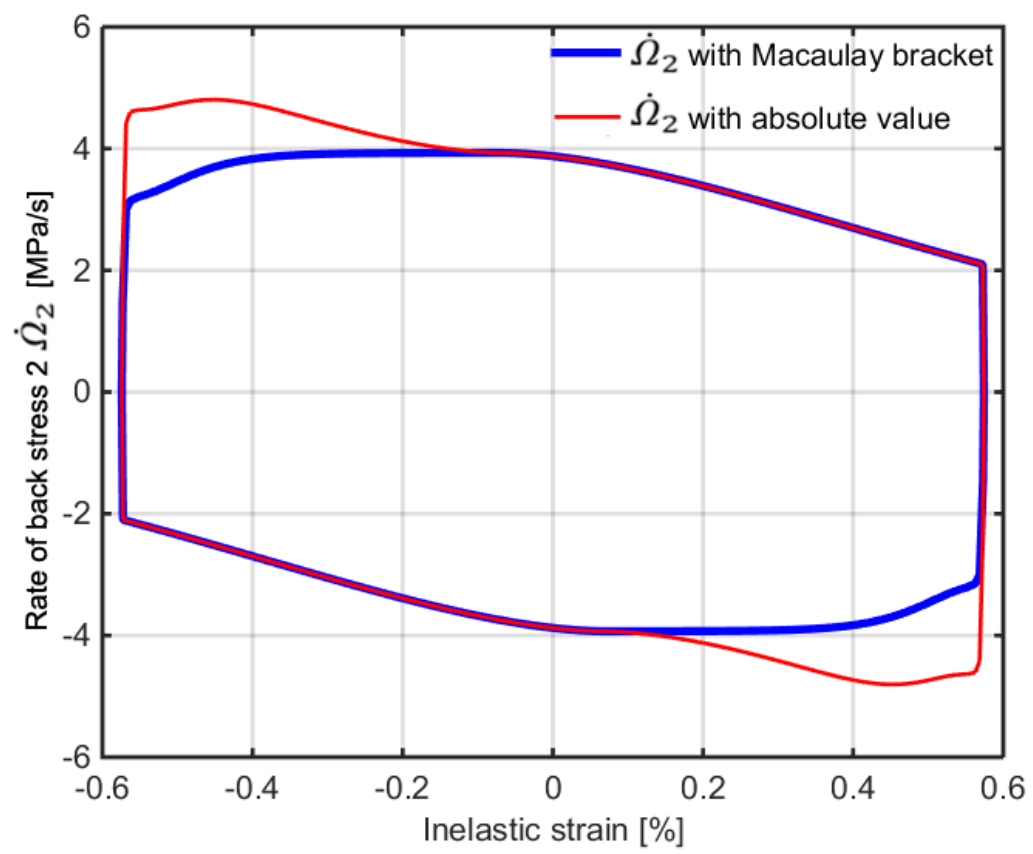

Fig. 7.2 Comparison between using Macaulay bracket and absolute value, simulated result: $200^{\text {th }}$ cycle of the strain-controlled LCF test performed with $\Delta \varepsilon=1.5 \%$ at $550^{\circ} \mathrm{C}$, increasing rate of $B S 2$ vs. inelastic strain.

The last, but not least, issue is that the new proposed model in the current work does not have satisfactory performance for simulating the strain increment in the ratcheting test at $550{ }^{\circ} \mathrm{C}$ with long hold times (i.e., $5 \mathrm{~min}$ ) at peak stress. The reason is that in parameter fitting, the criterion "fitting on ratcheting strains in all experiments" has the largest weight while most experiments at $550{ }^{\circ} \mathrm{C}$ are performed without or with a short hold time $(0.5 \mathrm{~min})$. However, in the experiment illustrated in Fig. 6.29, the total strain is mostly composed of accumulated creep strains during hold times, which is a different mechanism of accumulation of inelastic strain, as discussed in Section 5.2.5. Hence, the criterion "fitting on accumulation of strain in creep test" compromises for the "fitting on ratcheting strain". Further research is required to investigate the inelastic strain increment of P91 during creep or hold time at $550{ }^{\circ} \mathrm{C}$. 


\section{Summary and Outlook}

In the uniaxial strain-controlled and stress-controlled tests performed at RT and $550{ }^{\circ} \mathrm{C}$, a database was built for future application of $9 \mathrm{Cr}-1 \mathrm{Mo} \mathrm{FM}$ steel at RT and $550{ }^{\circ} \mathrm{C}$. The material under research shows obvious cyclic softening in straincontrolled LCF tests at both temperatures. (see Fig. 4.2c and Fig. 5.3c).

At RT, the material shows asymmetry of material strength under tension and compression, which is supported by three facts:

a) Larger magnitude of peak compressive stress than corresponding peak tensile stress in strain-controlled LCF tests (see Fig. 4.4b);

b) Lower magnitude of ratcheting rate with compressive mean stress in stress-controlled ratcheting tests (see Fig. 4.10c);

c) Positive ratcheting under symmetric stress-controlled loadings (see Fig. 4.15).

At $550{ }^{\circ} \mathrm{C}$, the material shows symmetry of material strength under tension and compression, which is supported by three facts:

a) Identical magnitude of peak compressive and tensile stress in strain-controlled LCF tests (see Fig. 5.5);

b) Identical magnitudes of ratcheting rates with symmetric compressive and tensile mean stress (see Fig. 5.11);

c) Negligible ratcheting under symmetric stress-controlled loadings (see Fig. 5.15).

In spite of the difference in the symmetry of material strength at RT and $550{ }^{\circ} \mathrm{C}$, the effects of various influencing factors to $\varepsilon_{r}^{\prime}$ are similar:

1. With the same $\sigma_{\text {mean }}$, larger $\sigma_{\text {peak }}$ leads to higher $\varepsilon_{r}^{\prime}$ (see Fig. 4.7 and Fig. 5.8).

2. With the same $\sigma_{\text {peak }}$, highest $\varepsilon_{r}^{\prime}$ is reached with stress ratio of around -0.9-0.95 (see Fig. 4.13 and Fig. 5.14).

3. Strain range of hysteresis loop increases with cyclic number (see Fig. 4.8 and Fig. 5.9).

4. Higher $\dot{\sigma}$ leads to lower $\varepsilon_{r}^{\prime}$ and vice versa (see Fig. 4.18 and Fig. 5.17).

A constitutive model has been proposed. The model is originated from the Chaboche Model and adopts isotropic softening factor from the RAFM model. To simulate the ratcheting behavior of the material, the kinematic hardening/back stress (BS) is divided into two sub-components, one controls the shapes of simulated stress-strain hysteresis loops, and the other controls the ratcheting rate. The asymmetry of material strength at RT is expressed with a parameter $\mu_{2}$. This model has been proved to have good simulation ability for material response under both strain- and stress-controlled loading conditions. The simulated results agree with the corresponding material response within a large range of multiple loading. 
Since all tests in the current work were performed only under uniaxial loading, the proposed model is in uniaxial form, which is enough to generate simulated results to compare with performed experiments. Owing to the fact that the multiaxial loadings are more general in the real working condition of the structural components, further extension to multiaxial form of the proposed uniaxial model was also proposed. In the further research on P91 steel, multiaxial tests shall be performed to verify the model in multiaxial form.

In the current work, only isothermal mechanical behavior at two temperatures (RT and $550{ }^{\circ} \mathrm{C}$ ) was investigated. Tests shall be performed at more temperatures in future research to check whether the asymmetry of material strength under tension and compression at RT still exists. Microstructural investigation is required to discover the cause of such asymmetry at RT. Further, research on thermal mechanical behavior shall be carried out at conditions closer to the real working conditions of the structural components

Since the failure mode of the specimens in the ratcheting test is supposed to be unacceptable ratcheting strain, no damage factor is included in the proposed constitutive model. In future improvement of the model, more tests should be performed that end with fracture to investigate the damage of the material. 


\section{Reference}

[1] J. Aktaa and R. Schmitt, "High temperature deformation and damage behavior of RAFM steels under low cycle fatigue loading: Experiments and modeling", Fusion Engineering and Design, vol. 81, pp. 2221-2231, 2006.

[2] H. Hübel, "Basic conditions for material and structural ratcheting", Nuclear Engineering and Design, vol. 162, pp. 55-65, 1996.

[3] N. Ohno and J. D. Wang, "Kinematic Hardening Rules with Critical State of Dynamic Recovery, Part I: Formulation and basic features for ratchetting behavior", International Journal of Plasticity, vol. 9, pp. 375-390, 1993.

[4] N. Ohno and J. D. Wang, "Kinematic Hardening Rules with Critical State of Dynamic Recovery, Part II: Application to experiments of ratcheting behavior", International Journal of Plasticity, vol. 9, pp. 391-403, 1993.

[5] J. L. Chaboche and G. Cailletaud, "On the calculation of structures in cyclic plasticity or viscoplasticity", Computers \& Structures, vol. 23, pp. 23-31, 1986.

[6] M. Abdel-Karim and N. Ohno, "Kinematic hardening model suitable for ratchetting with steady-state", International Journal of Plasticity, vol. 16, pp. 225-240, 2000.

[7] M. Yaguchi and Y. Takahashi, "Ratchetting of viscoplastic material with cyclic softening, part 2: application of constitutive models", International Journal of Plasticity, vol. 21, pp. 835-860, 2005.

[8] L. F. Coffin, "The Influence of Mean Stress on the Mechanical Hysteresis Loop Shift of 1100 Aluminum", Journal of Fluids Engineering, vol. 86(4), pp. 673-680, 1964.

[9] G. Facheris and K. G. F. Janssens, "An internal variable dependent constitutive cyclic plastic material description including ratcheting calibrated for AISI 316L", Computational Materials Science, vol. 87, pp. 160-171, 2014.

[10] G. Facheris and K. G. F. Janssens, "Cyclic mechanical behavior of 316L: Uniaxial LCF and strain-controlled ratcheting tests", Nuclear Engineering and Design, vol. 257, pp. 100-108, 2013.

[11] Y. Dong, G. Kang, Y. Liu, H. Wang, and X. Cheng, "Dislocation evolution in 316L stainless steel during multiaxial ratchetting deformation", Materials Characterization, vol. 65, pp. 62-72, 2012.

[12] A. Sarkar, A. Nagesha, P. Parameswaran, R. Sandhya, and M. D. Mathew, "Influence of dynamic strain aging on the deformation behavior during ratcheting of a 316LN stainless steel", Materials Science and Engineering: A, vol. 564, pp. 359-368, 2013.

[13] S. Krishna, T. Hassan, I. Ben Naceur, K. Saï, and G. Cailletaud, "Macro versus micro-scale constitutive models in simulating proportional and nonproportional cyclic and ratcheting responses of stainless steel 304", International Journal of Plasticity, vol. 25, pp. 1910-1949, 2009.

[14] G. Kang, Q. Gao, and X. Yang, "Uniaxial and non-proportionally multiaxial ratcheting of SS304 stainless steel at room temperature: experiments and 
simulations", International Journal of Non-Linear Mechanics, vol. 39, pp. 843-857, 2004.

[15] G. Kang, Q. Gao, L. Cai, and Y. Sun, "Experimental study on uniaxial and nonproportionally multiaxial ratcheting of SS304 stainless steel at room and high temperatures", Nuclear Engineering and Design, vol. 216, pp. 13-26, 2002.

[16] Q. Gao, G. Z. Kang, and X. J. Yang, "Uniaxial ratcheting of SS304 stainless steel at high temperatures: visco-plastic constitutive model", Theoretical and Applied Fracture Mechanics, vol. 40, pp. 105-111, 2003.

[17] G. Kang, Y. Li, and Q. Gao, "Non-proportionally multiaxial ratcheting of cyclic hardening materials at elevated temperatures: Experiments and simulations", Mechanics of Materials, vol. 37, pp. 1101-1118, 2005.

[18] Y. Liu, G. Kang, and Q. Gao, "Stress-based fatigue failure models for uniaxial ratchetting-fatigue interaction", International Journal of Fatigue, vol. 30, pp. 1065-1073, 2008.

[19] G. Kang, Q. Gao, and X. Yang, "A visco-plastic constitutive model incorporated with cyclic hardening for uniaxial/multiaxial ratcheting of SS304 stainless steel at room temperature", Mechanics of Materials, vol. 34, pp. 521531, 2002.

[20] G. Kang and Q. Kan, "Constitutive modeling for uniaxial time-dependent ratcheting of SS304 stainless steel", Mechanics of Materials, vol. 39, pp. 488499, 2007.

[21] M. Shariati and H. Hatami, "Experimental study of SS304L cylindrical shell with/without cutout under cyclic axial loading", Theoretical and Applied Fracture Mechanics, vol. 58, pp. 35-43, 2012.

[22] C. K. Mukhopadhyay, T. Jayakumar, T. K. Haneef, S. Suresh Kumar, B. P. C. Rao, S. Goyal, et al., "Use of acoustic emission and ultrasonic techniques for monitoring crack initiation/growth during ratcheting studies on 304LN stainless steel straight pipe", International Journal of Pressure Vessels and Piping, vol. 116, pp. 27-36, 2014.

[23] 304, 304L, 304H, 304N, 304HN, 304LN 18-8 Austenitic Stainless Steel. Available: http://amsresources.com/304-austenitic-stainless-steel/

[24] G.-H. Koo and J.-H. Lee, "Investigation of ratcheting characteristics of modified 9Cr-1Mo steel by using the Chaboche constitutive model", International Journal of Pressure Vessels and Piping, vol. 84, pp. 284-292, 2007.

[25] X.-T. Zheng, F.-Z. Xuan, and P. Zhao, "Ratcheting-creep interaction of advanced 9-12\% chromium ferrite steel with anelastic effect", International Journal of Fatigue, vol. 33, pp. 1286-1291, 2011.

[26] M. Yaguchi, "Ratchetting of viscoplastic material with cyclic softening, part 1: experiments on modified 9Cr-1Mo steel", International Journal of Plasticity, vol. 21, pp. 43-65, 2005.

[27] P. Zhao and F.-Z. Xuan, "Ratchetting behavior of advanced 9-12\% chromium ferrite steel under creep-fatigue loadings", Mechanics of Materials, vol. 43, pp. 299-312, 2011.

[28] M. Ando, N. Isobe, K. Kikuchi, and Y. Enuma, "Effect of ratchet strain on fatigue and creep-fatigue strength of Mod.9Cr-1Mo steel", Nuclear Engineering and Design, vol. 247, pp. 66-75, 2012. 
[29] Y. Li, X. Pan, and G. Wang, "Low cycle fatigue and ratcheting properties of steel 40Cr under stress controlled tests", International Journal of Fatigue, vol. 55, pp. 74-80, 2013.

[30] G. Kang, Y. Liu, J. Ding, and Q. Gao, "Uniaxial ratcheting and fatigue failure of tempered 42CrMo steel: Damage evolution and damage-coupled viscoplastic constitutive model", International Journal of Plasticity, vol. 25, pp. 838-860, 2009.

[31] G. Kang, Y. Liu, and J. Ding, "Multiaxial ratchetting-fatigue interactions of annealed and tempered 42CrMo steels: Experimental observations", International Journal of Fatigue, vol. 30, pp. 2104-2118, 2008.

[32] C. Li, G. Chen, X. Chen, and W. Zhang, "Ratcheting strain and simulation of $16 \mathrm{MnR}$ steel under uniaxial cyclic loading", Computational Materials Science, vol. 57, pp. 43-47, 2012.

[33] M. Zeinoddini and M. Peykanu, "Strain ratcheting of steel tubulars with a rectangular defect under axial cycling: A numerical modeling", Journal of Constructional Steel Research, vol. 67, pp. 1872-1883, 2011.

[34] G. Kang, Y. Dong, Y. Liu, H. Wang, and X. Cheng, "Uniaxial ratchetting of 20 carbon steel: Macroscopic and microscopic experimental observations", Materials Science and Engineering: A, vol. 528, pp. 5610-5620, 2011.

[35] Y. Dong, G. Kang, Y. Liu, and H. Jiang, "Multiaxial ratcheting of 20 carbon steel: Macroscopic experiments and microscopic observations", Materials Characterization, vol. 83, pp. 1-12, 2013.

[36] X. Yang, "Low cycle fatigue and cyclic stress ratcheting failure behavior of carbon steel 45 under uniaxial cyclic loading", International Journal of Fatigue, vol. 27, pp. 1124-1132, 2005.

[37] N. Khutia, P. P. Dey, S. K. Paul, and S. Tarafder, "Development of non Masing characteristic model for LCF and ratcheting fatigue simulation of SA333 C-Mn steel", Mechanics of Materials, vol. 65, pp. 88-102, 2013.

[38] S. K. Paul, "Effect of anisotropy on ratcheting: An experimental investigation on IFHS steel sheet", Materials Science and Engineering: A, vol. 538, pp. 349-355, 2012.

[39] M. Wen, H. Li, D. Yu, G. Chen, and X. Chen, "Uniaxial ratcheting behavior of Zircaloy-4 tubes at room temperature", Materials \& Design, vol. 46, pp. 426-434, 2013.

[40] J. Peng, C.-Y. Zhou, Q. Dai, X.-H. He, and X. Yu, "Fatigue and ratcheting behaviors of CP-Ti at room temperature", Materials Science and Engineering: A, vol. 590, pp. 329-337, 2014.

[41] L.-x. Cai, Q.-y. Niu, S.-y. Qiu, and Y.-j. Liu, "Ratcheting Behavior of T225NG Titanium Alloy under Uniaxial Cyclic Stressing: Experiments and Modeling", Chinese Journal of Aeronautics, vol. 18, pp. 31-39, 2005.

[42] Q. Kan and G. Kang, "Constitutive model for uniaxial transformation ratchetting of super-elastic NiTi shape memory alloy at room temperature", International Journal of Plasticity, vol. 26, pp. 441-465, 2010.

[43] G. Kang, "Advances in transformation ratcheting and ratcheting-fatigue interaction of NiTi shape memory alloy", Acta Mechanica Solida Sinica, vol. 26, pp. 221-236, 2013.

[44] M. Kotoul, "Constitutive modeling of ratcheting of metal particulatereinforced ceramic matrix composites", materials Science and Engineering: A, vol. 319-321, pp. 657-661, 2001. 
[45] Z. Zhang and X. Chen, "Multiaxial ratcheting behavior of PTFE at room temperature", Polymer Testing, vol. 28, pp. 288-295, 2009.

[46] A. D. Drozdov and J. d. Christiansen, "Cyclic viscoelastoplasticity of polypropylene/nanoclay hybrids", Computational Materials Science, vol. 53, pp. 396-408, 2012.

[47] M. Shariati, H. Hatami, H. Yarahmadi, and H. R. Eipakchi, "An experimental study on the ratcheting and fatigue behavior of polyacetal under uniaxial cyclic loading", Materials \& Design, vol. 34, pp. 302-312, 2012.

[48] G. Tao and Z. Xia, "Ratcheting behavior of an epoxy polymer and its effect on fatigue life", Polymer Testing, vol. 26, pp. 451-460, 2007.

[49] X. Chen and R. Jiao, "Modified kinematic hardening rule for multiaxial ratcheting prediction", International Journal of Plasticity, vol. 20, pp. 871898, 2004.

[50] T. Hassan, L. Taleb, and S. Krishna, "Influence of non-proportional loading on ratcheting responses and simulations by two recent cyclic plasticity models", International Journal of Plasticity, vol. 24, pp. 1863-1889, 2008.

[51] G. Kang, "A visco-plastic constitutive model for ratcheting of cyclically stable materials and its finite element implementation", Mechanics of Materials, vol. 36, pp. 299-312, 2004.

[52] S. S. Manson, "Behavior of Materials under Conditions of Thermal Stress," Lewis Flight Propulsion Laboratory1952.

[53] R. W. Smith, M. H. Hirschberg, and S. S. Manson, "Fatigue behavior of materials under strain cycling in low and intermediate life range," NASA1978.

[54] J. L.F. Coffin, "The Deformation and Fracture of a Ductile Metal Under Superimposed Cyclic and Monotonic Strain," in Achievement of High Fatigue Resistance in Metals and Alloys, ed: American Society for Testing and Materials, 1970, pp. 53-76.

[55] R. Chaouadi, "Flow and Fracture Behavior of 9\%Cr-Ferritic/Martensitic Steels," SCK CEN2005.

[56] G. Chen, Z.-S. Zhang, Y.-H. Mei, X. Li, D.-J. Yu, L. Wang, et al., "Applying viscoplastic constitutive models to predict ratcheting behavior of sintered nanosilver lap-shear joint", Mechanics of Materials, vol. 72, pp. 61-71, 2014.

[57] G. Kang and Q. Gao, "Uniaxial and non-proportionally multiaxial ratcheting of U71Mn rail steel: experiments and simulations", Mechanics of Materials, vol. 34, pp. 809-820, 2002.

[58] J. L. Chaboche, "On some modifications of kinematic hardening to improve the description of ratchetting effects", International Journal of Plasticity, vol. 7, pp. 661-678, 1991.

[59] J. Lemaitre and J.-L. Chaboche, Mechanics of solid materials: Press Syndicate of the University of Cambridge, 1990.

[60] J.-L. Chaboche, "Stress calculations for lifetime prediction in turbine blades", International Journal of Solids and Structures, vol. 10, pp. 473-481, 1974.

[61] J.-L. Chaboche, "Continuous damage mechanics - A tool to describe phenomena before crack initiation", Nuclear Engineering and Design, vol. 64, pp. 233-247, 1981.

[62] C. O. Frederick and P. J. Armstrong, "A mathematical representation of the multiaxial Bauschinger effect", Materials at High Temperatures, vol. 24, pp. 1-26, 2007. 
[63] K. P. Walker, "Research and development program for nonlinear structural modelling with advanced time-temperature dependent constitutive relationships," United Technologies Research Center, NASA1981.

[64] P. O. Kettunen and V.-T. Kuokkala, Plastic Deformation and Strain Hardening, 2002.

[65] S. Guo, G. Kang, and J. Zhang, "A cyclic visco-plastic constitutive model for time-dependent ratchetting of particle-reinforced metal matrix composites", International Journal of Plasticity, vol. 40, pp. 101-125, 2013.

[66] M. Abdel-Karim, "Modified kinematic hardening rules for simulations of ratchetting", International Journal of Plasticity, vol. 25, pp. 1560-1587, 2009.

[67] R. L. Klueh and A. T. Nelson, "Ferritic/martensitic steels for next-generation reactors", Journal of Nuclear Materials, vol. 371, pp. 37-52, 2007.

[68] K. Laha, S. Saroja, A. Moitra, R. Sandhya, M. D. Mathew, T. Jayakumar, et $a l .$, "Development of India-specific RAFM steel through optimization of tungsten and tantalum contents for better combination of impact, tensile, low cycle fatigue and creep properties", Journal of Nuclear Materials, vol. 439, pp. 41-50, 2013.

[69] Q. Huang, C. Li, Y. Li, M. Chen, M. Zhang, L. Peng, et al., "Progress in development of China Low Activation Martensitic steel for fusion application", Journal of Nuclear Materials, vol. 367-370, pp. 142-146, 2007.

[70] B. Fusion Engineering and DesignRaj and T. Jayakumar, "Development of Reduced Activation Ferritic-Martensitic Steels and fabrication technologies for Indian test blanket module", Journal of Nuclear Materials, vol. 417, pp. 72-76, 2011.

[71] R. L. Klueh, "Reduced-activation bainitic and martensitic steels for nuclear fusion applications", Current Opinion in Solid State and Materials Science, vol. 8, pp. 239-250, 2004.

[72] E. E. Bloom, "The challenge of developing structural materials for fusion power systems", Journal of Nuclear Materials, vol. 258-263, pp. 7-17, 1998.

[73] D. W. Kim and W.-S. Ryu, "Evaluation of Factors Affecting Cyclic Softening Behaviors of Mod. 9Cr-1Mo Steel", Procedia Engineering, vol. 10, pp. 376382, 2011.

[74] J. F. Henry, "Growing experience with P91 T91 forcing essential code", Combined Cycle Journal, vol. First Quarter, 2005.

[75] "Welding "Grade 91" alloy steel", V\&M Tubes Corporation (Vallourec \& Mannesmann), vol. Inc. May, pp. 1-5, 2007.

[76] "Low Alloy Steel: P91 - Modified 9CrMo", Metrode Products Data sheet.

[77] W. B. Jones, C. R. Hills, and D. H. Polonis, "Microstructural Evolution of Modified 9Cr-1Mo Steel", Metallurgical Transactions A, vol. 22A, pp. 10491058, 1991.

[78] "Effect of Thickness on the Transformation Behavior of Grade 91 Steel," ASME Standards Technology, LLC2013.

[79] V. Karthik, K. Laha, P. Parameswaran, K. S. Chandravathi, K. V. Kasiviswanathan, T. Jayakumar, et al., "Tensile properties of modified 9Cr1 Mo steel by shear punch testing and correlation with microstructures", International Journal of Pressure Vessels and Piping, vol. 88, pp. 375-383, 2011.

[80] V. Thomas Paul, S. Saroja, and M. Vijayalakshmi, "Microstructural stability of modified 9Cr-1Mo steel during long term exposures at elevated temperatures", Journal of Nuclear Materials, vol. 378, pp. 273-281, 2008. 
[81] C. A. Hippsley and N. P. Haworth, "Hydrogen and temper embrittlement in 9Cr-1Mo steel", Materials Science and Technology, vol. 4, pp. 791-802, September 1988.

[82] V. Shankar, M. Valsan, K. B. S. Rao, R. Kannan, S. L. Mannan, and S. D. Pathak, "Low cycle fatigue behavior and microstructural evolution of modified 9Cr-1Mo ferritic steel", Materials Science and Engineering: A, vol. 437, pp. 413-422, 2006.

[83] V. Shankar, R. Sandhya, and M. D. Mathew, "Creep-fatigue-oxidation interaction in Grade 91 steel weld joints for high temperature applications", Materials Science and Engineering: A, vol. 528, pp. 8428-8437, 2011.

[84] B. Fournier, M. Sauzay, C. Caes, M. Noblecourt, M. Mottot, A. Bougault, et al., "Creep-fatigue-oxidation interactions in a $9 \mathrm{Cr}-1 \mathrm{Mo}$ martensitic steel. Part I: Effect of tensile holding period on fatigue lifetime", International Journal of Fatigue, vol. 30, pp. 649-662, 2008.

[85] P. Zhao and F. Xuan, "Microstructural stability and its effect on ratchetting effect of advanced 9-12\% Cr ferrite steel at high temperature", Procedia Engineering, vol. 27, pp. 1588-1595, 2012.

[86] A. Kumar, K. Laha, T. Jayakumar, K. B. S. Rao, and B. Raj, "Comprehensive microstructural characterization in modified 9Cr-1Mo ferritic steel by ultrasonic measurements", Metallurgical and Materials Transactions A, vol. 33A, pp. 1617-1626, 2002.

[87] A. Kumar, B. K. Choudhary, K. Laha, T. Jayakumar, K. B. S. Rao, and B. Raj, "Characterisation of microstructure in $9 \% \mathrm{Cr}$ ferritic steel using ultrasonic measurements", vol. 56, pp. 483-497, 2003.

[88] C. G. Panait, W. Bendick, A. Fuchsmann, A. F. Gourgues-Lorenzon, and J. Besson, "Study of the microstructure of the Grade 91 steel after more than $100,000 \mathrm{~h}$ of creep exposure at $600{ }^{\circ} \mathrm{C}$ ", International Journal of Pressure Vessels and Piping, vol. 87, pp. 326-335, 2010.

[89] G. Golański and S. Mroziński, "Low cycle fatigue and cyclic softening behaviour of martensitic cast steel", Engineering Failure Analysis, vol. 35, pp. 692-702, 2013.

[90] V. Shankar, K. Mariappan, R. Sandhya, and M. D. Mathew, "Evaluation of Low Cycle Fatigue Damage in Grade 91 Steel Weld Joints for High Temperature Applications", Procedia Engineering, vol. 55, pp. 128-135, 2013.

[91] M. Sauzay, H. Brillet, I. Monnet, M. Mottot, F. Barcelo, B. Fournier, et al., "Cyclically induced softening due to low-angle boundary annihilation in a martensitic steel", Materials Science And Engineering a-Structural Materials Properties Microstructure And Processing, vol. 400, pp. 241-244, Jul 25 2005.

[92] S. Kim and J. R. Weertman, "Investigation of microstructural changes in a ferritic steel caused by high temperature fatigue", Metallurgical Transactions A, vol. 19A April, pp. 999-1007, 1988.

[93] R. Kannan, V. Sankar, R. Sandhya, and M. D. Mathew, "Comparative Evaluation of the Low Cycle Fatigue Behaviours of P91 and P92 Steels", Procedia Engineering, vol. 55, pp. 149-153, 2013.

[94] B. Fournier, M. Sauzay, F. Barcelo, E. Rauch, A. Renault, T. Cozzika, et al., "Creep-Fatigue Interactions in a 9 Pct Cr-1 Pct Mo Martensitic Steel: Part II. Microstructural Evolutions", Metallurgical and Materials Transactions A, vol. 40, pp. 330-341, 2009. 
[95] B. Fournier, M. Sauzay, C. Caës, M. Noblecourt, M. Mottot, L. Allais, et al., "Creep-Fatigue Interactions in a 9 Pct Cr-1 Pct Mo Martensitic Steel: Part I. Mechanical Test Results", Metallurgical and Materials Transactions A, vol. 40, pp. 321-329, 2009.

[96] M. F. Giordana, P. F. Giroux, I. Alvarez-Armas, M. Sauzay, and A. Armas, "Micromechanical modeling of the cyclic softening of EUROFER 97 steel", Procedia Engineering, vol. 10, pp. 1268-1273, 2011.

[97] J. F. Stubbins and D. S. Gelles, "Fatigue performance and cyclic softening of F82H, a ferritic-martensitic steel", Journal of Nuclear Materials, vol. 233-237, pp. 331-335, 1996.

[98] A. F. Armas, I. Alvarez-Armas, C. Petersen, M. Avalos, and R. Schmitt, "Internal and effective stress analysis during cyclic softening of F82H mod. Martensitic stainless steel", European Structural Integrity Society, vol. 29, pp. 45-51, 2002.

[99] H. J. Chang and J. J. Kai, "Effects of temperature on the low cycle fatigue and microstructures of HT-9 ferritic steel", Journal of Nuclear Materials, vol. 191194, pp. 836-840, 1992.

[100] A. F. Armas, M. Avalos, I. Alvarez-Armas, C. Petersen, and R. Schmitt, "Dynamic strain ageing evidences during low cycle fatigue deformation in ferrtic-martensitic stainless steels", Journal of Nuclear Materials, vol. 258263, pp. 1204-1208, 1998.

[101] A. A. Saad, W. Sun, T. H. Hyde, and D. W. J. Tanner, "Cyclic softening behaviour of a P91 steel under low cycle fatigue at high temperature", Procedia Engineering, vol. 10, pp. 1103-1108, 2011.

[102] B. Fournier, M. Sauzay, and A. Pineau, "Micromechanical model of the high temperature cyclic behavior of 9-12\% Cr martensitic steels", International Journal of Plasticity, vol. 27, pp. 1803-1816, 2011.

[103] J. Jung, "A note on the influence of hydrostatic pressure on dislocations", Philosophical Magazine A, vol. 43, pp. 1057-1061, 1981.

[104] J. Casey and T. D. Sullivan, "Pressure dependency, strength-differential effect, and plastic volume expansion in metals", International Journal of Plasticity, vol. 1, pp. 39-61, 1985.

[105] D. C. Drucker, "Plasticity Theory, Strength-Differential (SD)Phenomenon, and Volume Expansion in Metals and Plastics", Metallurgical Transactions, vol. 4, pp. 667-673, March 1973.

[106] K. Kimura, H. Kushima, and K. Sawada, "Long-term creep deformation property of modified 9Cr-1Mo steel", Materials Science And Engineering aStructural Materials Properties Microstructure And Processing, vol. 510-511, pp. 58-63, 2009.

[107] J. Fred, "MINUIT Tutorial-Function Minimization," CERN2004. 